\title{
TREATMENT OF ACUTE GRAFT-VERSUS-HOST DISEASE USING INORGANIC-ORGANIC HYBRID NANOPARTICLES
}

\author{
Dissertation \\ in fulfillment of the requirements for the degree \\ "Doctor rerum naturalium (Dr. rer. nat.)" \\ of the Georg-August-University Göttingen
}

within the GGNB (Göttingen Graduate School for Neurosciences, Biophysics, and Molecular Biosciences) Molecular Biology of Cells study program at the Georg-August-University School of Science (Göttingen)

submitted by

Tina Katarina Kaiser, née Baake

born in

Langenhagen, Germany

Göttingen, September 2019 


\section{THESIS COMMITTEE}

Prof. Dr. Holger Reichardt

$\left(1^{\text {st }}\right.$ Referee)

Institute for Cellular and Molecular Immunology

University Medical Center, Göttingen

Prof. Dr. Lutz Walter

( $2^{\text {nd }}$ Referee)

Department of Primate Genetics

German Primate Center, Göttingen

Prof. Dr. Matthias Dobbelstein

Institute of Molecular Oncology

University Medical Center, Göttingen

\section{ADDITIONAL MEMBERS OF THE EXAMINATION BOARD}

Prof. Dr. Hubertus Jerry

Department of Clinical and Experimental Endocrinology

University Medical Center, Göttingen

\section{Prof. Dr. Michael Schön}

Department of Dermatology, Venereology and Allergology University Medical Center, Göttingen

\section{Prof. Dr. Frauke Alves}

Department of Translational Molecular Imaging Max Planck Institute of Experimental Medicine, Göttingen

Date of thesis submission: $30^{\text {th }}$ September, 2019

Date of the oral examination: $27^{\text {th }}$ November, 2019 


\section{DeCLARATION}

I hereby declare that I have written this $\mathrm{PhD}$ thesis entitled "Treatment of acute Graft-versus-Host Disease using inorganic-organic hybrid nanoparticles" independently and with no other sources and aids than quoted. This thesis has not been submitted elsewhere for any academic degree.

Tina Katarina Kaiser

$30^{\text {th }}$ of September, 2019

Göttingen, Germany 
Part of this work have been published or submitted in the following articles:

BAAKE, T., JORSS, K., SUENNEMANN, J., ROSSMANN, L.,

BOHNENBERGER, H., TUCKERMANN, J. P., REICHARDT, H. M., FISCHER, H. J. \& REICHARDT, S. D. 2018. The glucocorticoid receptor in recipient cells keeps cytokine secretion in acute graft-versus-host-disease at bay. Oncotarget, 9, 15437-15450.

KAISER, T. K., KHORENKO, M., MOUSSAVI, A., ENGELKE, M., BORETIUS, S., FELDMANN, C. \& REICHARDT, H. M. submitted. Highly selective organ distribution and cellular uptake of inorganic-organic hybrid nanoparticles customized for the targeted delivery of glucocorticoids. Journal of Controlled Release. 


\section{TABLE OF CONTENTS}

ABSTRACT

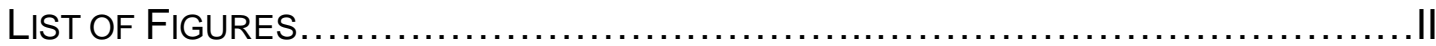

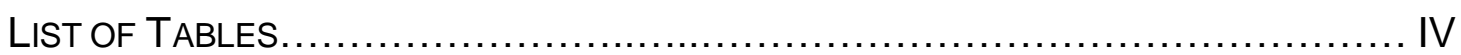

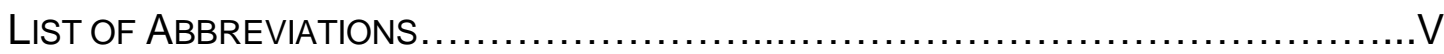

$1 \quad$ INTRODCUTION........................................................................... 1

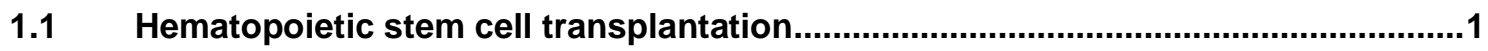

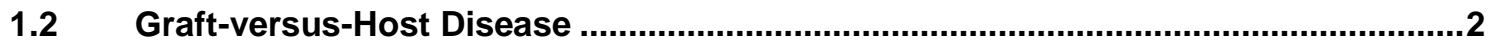

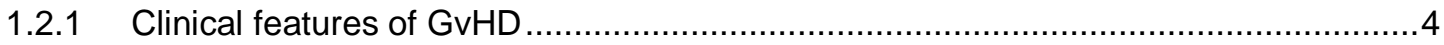

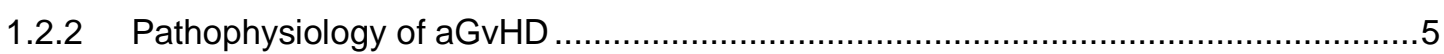

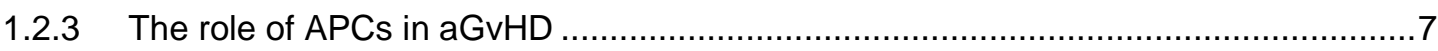

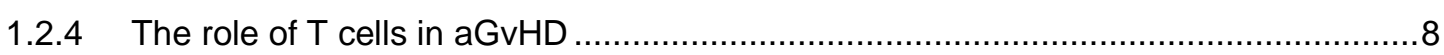

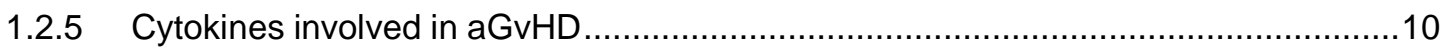

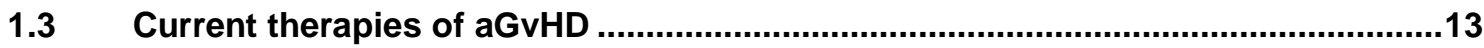

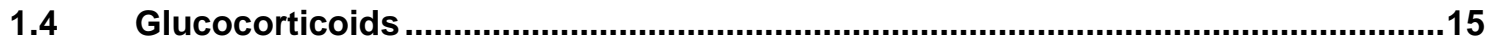

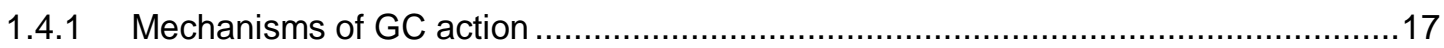

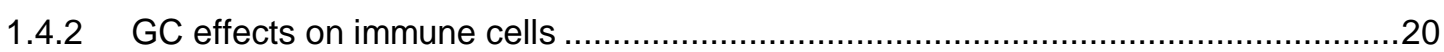

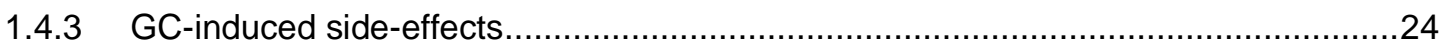

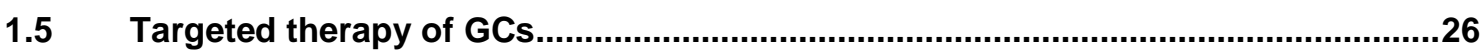

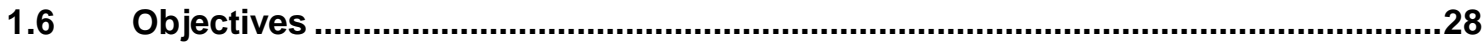

2 MATERIAL \& METHOdS ............................................................ 30

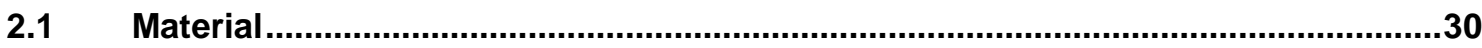

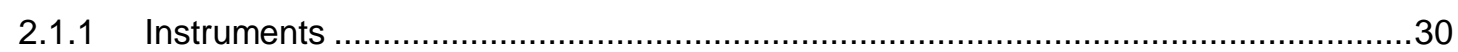

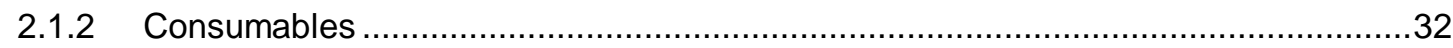

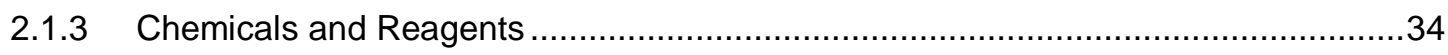

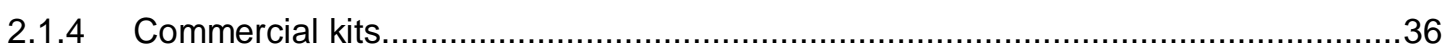

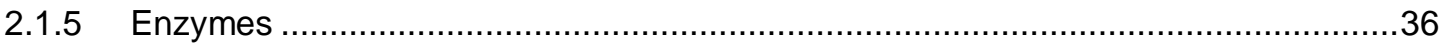

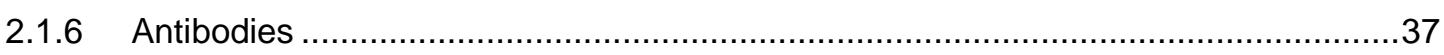

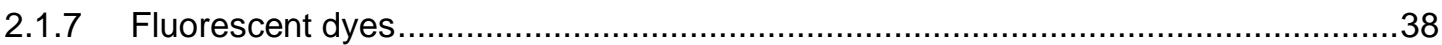




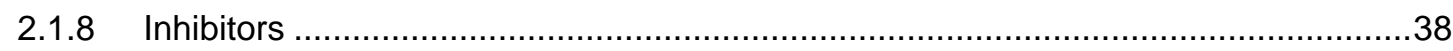

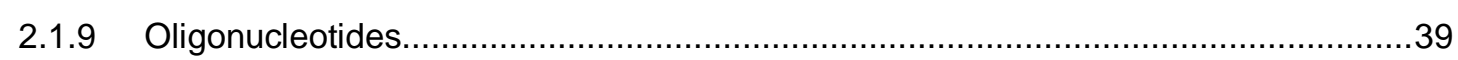

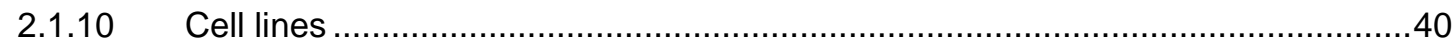

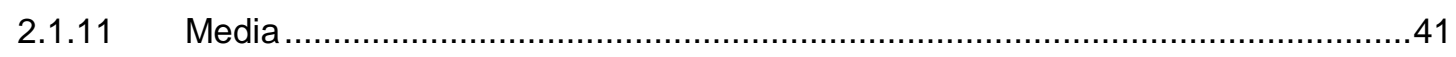

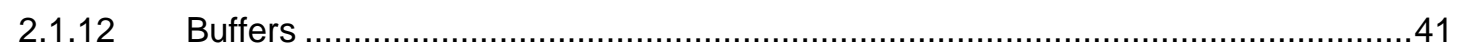

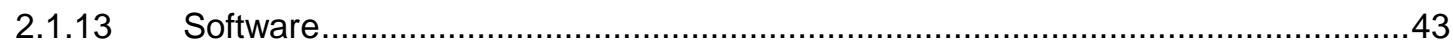

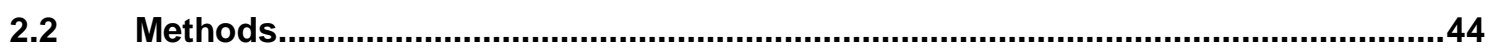

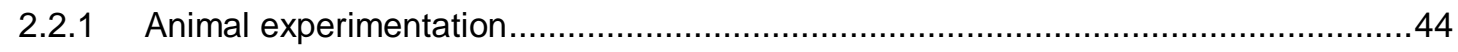

2.2.2 Acute GvHD mouse model: disease induction ....................................................44

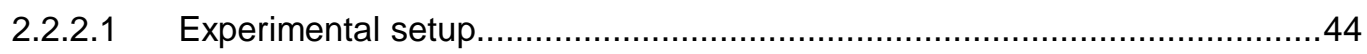

2.2.2.2 Preparation of $\mathrm{T}$ cell depleted bone marrow cells ...................................45

2.2.2.3 Preparation of splenic T cells ..........................................................46

2.2.2.4 Purity control of cell preparation .................................................46

2.2.3 Acute GvHD mouse model: disease progression ................................................47

2.2.3.1 Monitoring of clinical symptoms ......................................................... 47

2.2.3.2 Long-term and short-term acute GvHD experiments .............................48

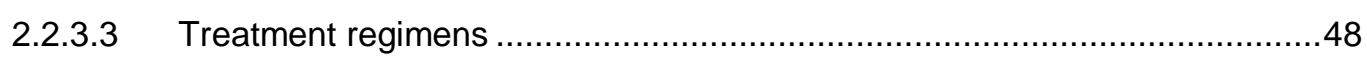

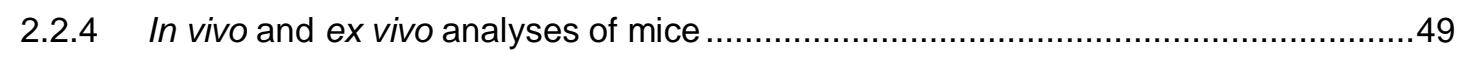

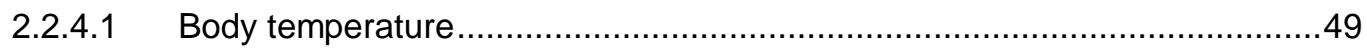

2.2.4.2 Blood glucose level ............................................................................. 49

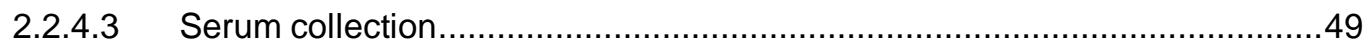

2.2.4.4 Tissue culture of jejunum biopsies for the analysis of cytokine ...................... secretion by infiltrated immune cells ....................................................49

2.2.4.5 Flow cytometric characterization of the cellular composition of ....................... immune cells in the lamina propria ............................................... 50

2.2.4.6 Inductively Coupled Plasma-Mass Spectrometry ..................................52

2.2.5 Experimental setup for the analysis of glucocorticoid associated..............................

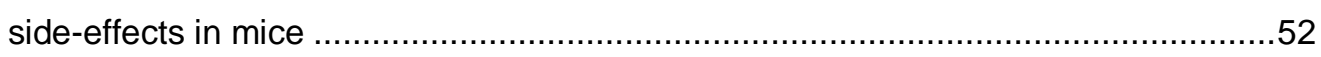

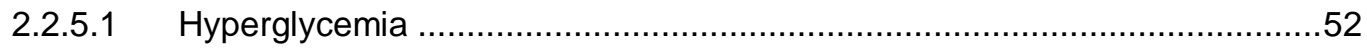

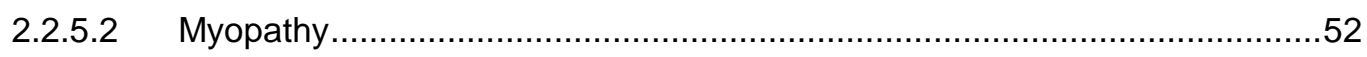

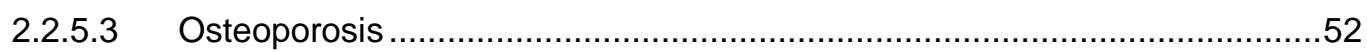

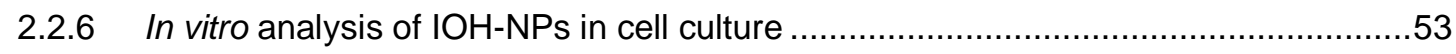

2.2.6.1 Cellular uptake of $1 \mathrm{OH}-\mathrm{NPs}$ into primary immune cells..............................53

2.2.6.2 Cellular uptake of $\mathrm{IOH}-\mathrm{NPs}$ into different cell lines.................................53

2.2.6.3 Viability test of cell lines ............................................................... 54

2.2.6.4 Characterization of BMP-NP uptake into MH-S cells................................54

2.2.6.5 Bone marrow derived macrophages................................................55

2.2.6.6 Flow cytometric analysis of BMDMs ..............................................55

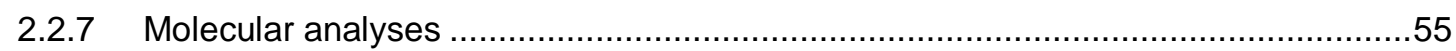




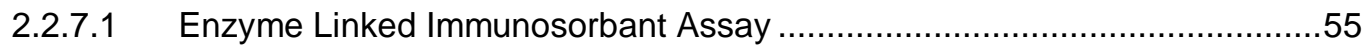

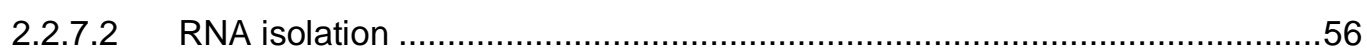

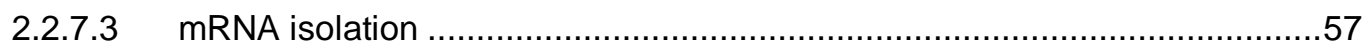

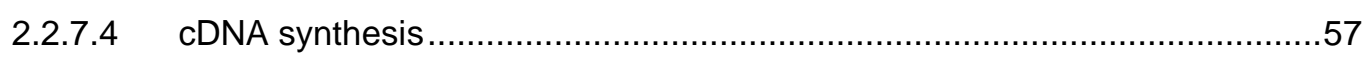

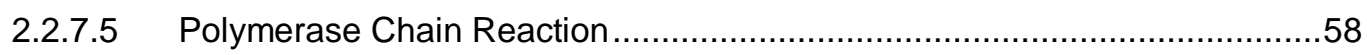

2.2.7.6 Quantitative Reverse Transcription-PCR .............................................59

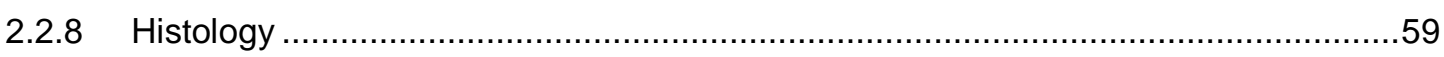

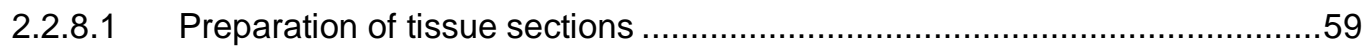

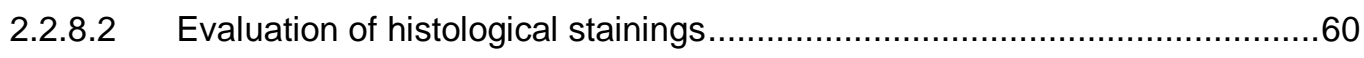

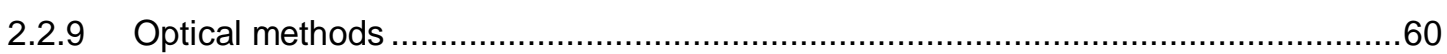

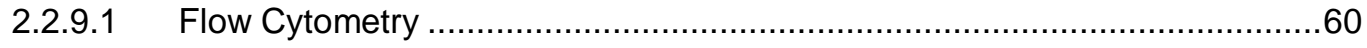

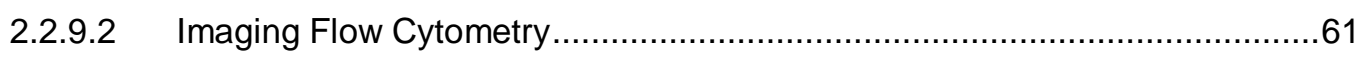

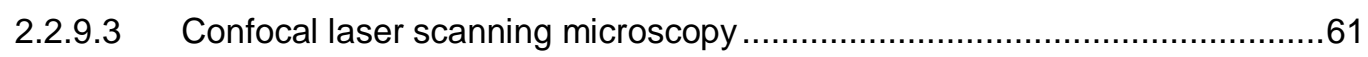

2.2.9.4 Magnetic Resonance Imaging .............................................................62

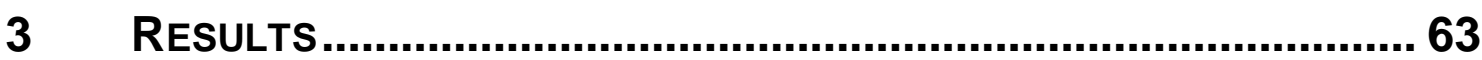

3.1 Role of the GR in myeloid cells in aGvHD

3.1.1 Deletion of the GR in recipient myeloid cells exacerbated aGvHD..........................63

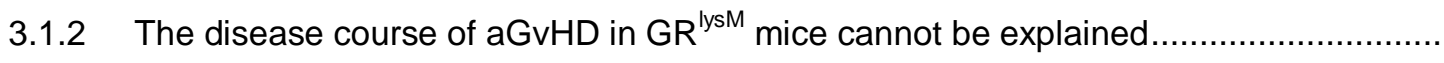

by target tissue damage in the jejunum...........................................................66

3.1.3 The disease course of aGvHD in GR $^{\text {lysM }}$ mice cannot be explained

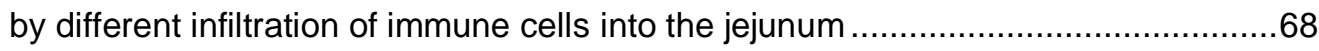

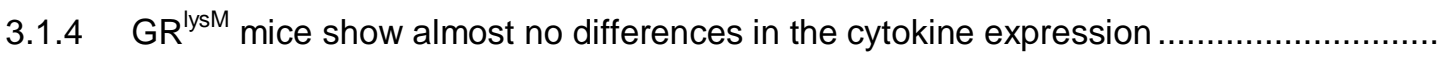
in the target organ jejunum in comparison to $\mathrm{GR}^{\text {flox }}$ mice .....................................70

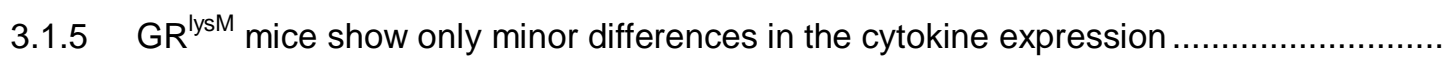
in the target organ liver in comparison to $\mathrm{GR}^{\text {flox }}$ mice.............................................72

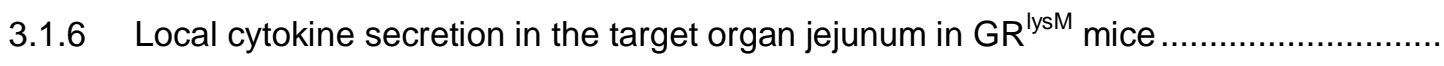
shows only minor differences compared to $\mathrm{GR}^{\text {flox }}$ mice........................................74

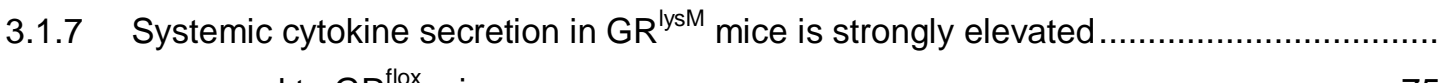

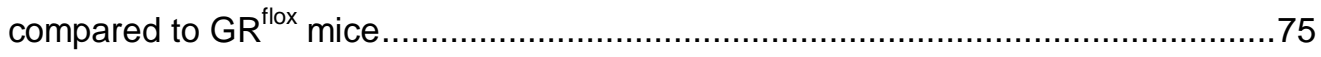

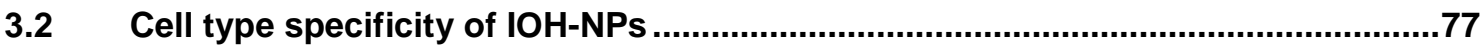

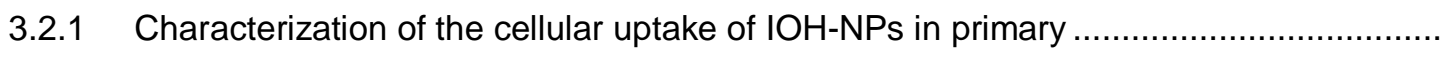
immune cells and the macrophage cell line MH-S ...............................................78

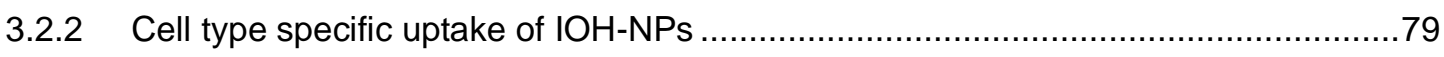

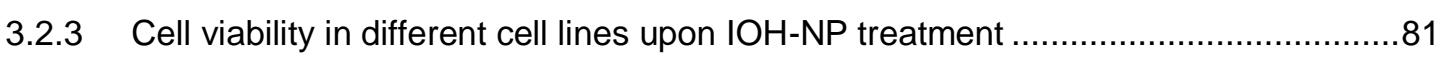

3.2.4 Characterization of the endocytic $\mathrm{IOH}-\mathrm{NP}$ uptake pathway in $\mathrm{MH}-\mathrm{S}$ cells .................82

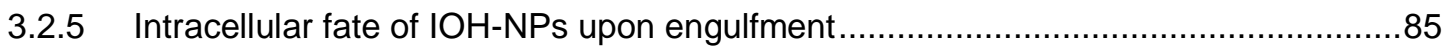

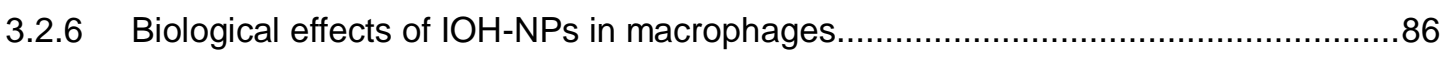


3.3 Organ distribution of $\mathrm{IOH}-\mathrm{NPs}$ in vivo after intraperitoneal injection into mice ....87

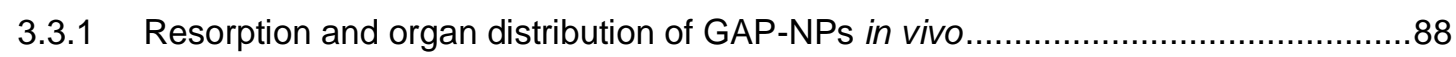

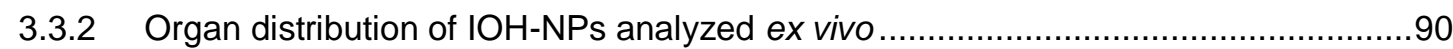

3.4 Application of BMP-NPs as a targeted therapy for aGvHD in mice...........................

3.4.1 BMP-NP and BMX treatment prolongs the survival in a mouse model of aGvHD mice with similar efficiency.......................................................

3.4.2 BMP-NP and BMX treatment ameliorates clinical features in the early phase of aGvHD to a similar extent

3.4.3 BMP-NP and BMX treatment ameliorates target tissue destruction in the jejunum in the early phase of aGvHD with similar efficiency

3.4.4 BMX, but not BMP-NP treatment reduces infiltration of $\mathrm{CD} 8^{+}$and $\mathrm{CD}^{+}$into the jejunum in the early phase of aGvHD

3.4.5 GR expression in myeloid cells is required for therapeutic efficacy. of BMP-NP treatment in the early phase of aGvHD

3.4.6 BMP-NP and BMX treatment does not reduce systemic cytokine. secretion in the early phase of aGvHD

3.4.7 BMP-NP and BMX treatment reduces the cytokine gene expression in the early phase of aGvHD in the jejunum to a similar extent 106

3.5 Assessing the side-effect profile of a targeted GC therapy using IOH-NPs.........109

3.5.1 BMP-NP treatment upregulates metabolic liver enzymes similar to BMX 109

3.5.2 BMP-NP treatment induces myopathy to a similar extent as free BMX treatment ..111

3.5.3 BMP-NP treatment reduces the bone turnover similar to BMX application 113

4 Discussion

4.1 Role of the GR in myeloid cells in the context of aGvHD mice 115

4.2 Interactions of $\mathrm{IOH}-\mathrm{NPs}$ with selected cell types in vitro. 119

4.3 Organ distribution of $\mathrm{IOH}-\mathrm{NPs}$ in mice in vivo .123

4.4 IOH-NPs as a new therapeutic approach for GC therapy of aGvHD 126

4.5 GC-induced side-effects after BMP-NP treatment .131

4.6 Conclusions and future directions .135

5 References 


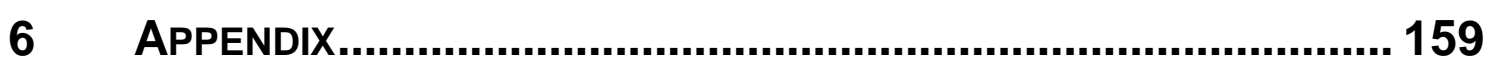

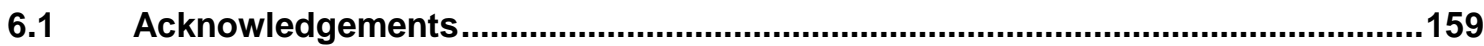

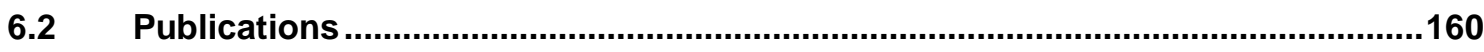




\section{ABSTRACT}

Acute Graft-versus-Host Disease (aGvHD) is a severe complication of allogeneic hematopoietic stem cell transplantation, which is induced by donor $\mathrm{T}$ cells that become stimulated after recognizing recipient proteins as foreign. Glucocorticoids (GCs) are the standard first-line therapy of aGvHD due to their strong immunosuppressive effects mediated via the ubiquitously expressed glucocorticoid receptor (GR). While GC therapy is believed to mainly target $T$ cells, our results show that radioresistant recipient myeloid cells are also crucial. This was demonstrated by using genetically engineered mice lacking the GR in myeloid cells and thus being refractory to GCs. These $\mathrm{GR}^{\mathrm{lysM}}$ mice were unable to limit systemic cytokine secretion during aGvHD leading to a premature death of the mice. Considering the importance of myeloid cells, we tested the potential of a targeted delivery of GCs to this cell type by using inorganic-organic hybrid nanoparticles (IOH-NPs). Our results demonstrate that IOH-NPs were preferentially taken up by macrophages, internalized via macropinocytosis, and localized to the lysosomal compartment. Magnetic resonance imaging and analysis by Inductive Coupled Plasma-Mass Spectrometry further revealed that $\mathrm{IOH}-\mathrm{NPs}$ were rapidly cleared from the peritoneal cavity after intraperitoneal injection in mice and thereafter accumulated in abdominal organs. When we induced aGvHD in mice and treated them with $\mathrm{IOH}-\mathrm{NPs}$ containing the GC betamethasone (BMP-NPs), the disease was ameliorated to a similar extent as by the free drug by limiting tissue destruction in the jejunum. The therapeutic effects were abrogated when GR $^{\mathrm{lysM}}$ mice were treated with BMP-NPs, confirming that this nanoformulation mainly acted via macrophages in vivo. Nevertheless, BMP-NPs employed partially different mechanisms and reduced the local production of pro-inflammatory cytokines in the first place. Further in vivo analyses revealed that despite their cell type specificity, typical metabolic side-effects of GCs in muscle, liver and bone could not be circumvent by the use of IOH-NPs. Collectively, this work reveals an important role of myeloid cells as targets of GC therapy of aGvHD and suggest that specifically targeting these cells might improve certain aspects of this therapeutic regimen. 


\section{LIST OF FIGURES}

Figure 1: Pathophysiology of aGvHD..

Figure 2: Glucocorticoid (GC) secretion is controlled via the hypothalamic-pituitaryadrenal (HPA) axis.

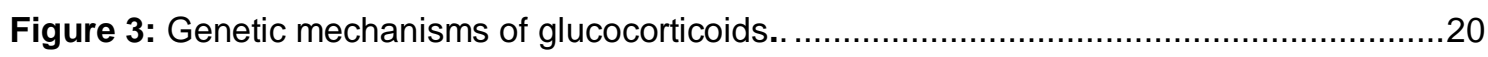

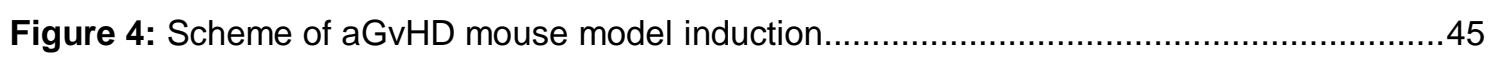

Figure 5: Gating strategy of flow cytometric analyses of $\mathrm{T}$ cell depleted bone marrow......

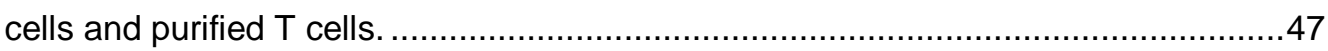

Figure 6: Scheme of GC treatment of aGvHD long-term and short-term experiments. .............48

Figure 7: Gating strategy of flow cytometric analyses for the characterization of..................

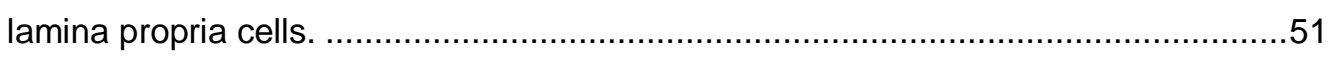

Figure 8: Clinical features of aGvHD in the GR ${ }^{l y s M}$ mouse model..........................................65

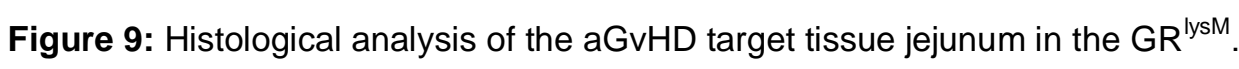
mouse model

Figure 10: Immunohistochemical analysis of the jejunum in aGvHD in the $\mathrm{GR}^{\mathrm{lysM}}$.....

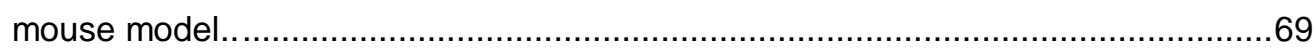

Figure 11: Cytokine expression in the jejunum of aGvHD in the $\mathrm{GR}^{\mathrm{lysM}}$ mouse model..............71

Figure 12: Cytokine expression in the liver of aGvHD in the $\mathrm{GR}^{\mathrm{IysM}}$ mouse model....................73

Figure 13: Local cytokine secretion in the jejunum of aGvHD in the $\mathrm{GR}^{\mathrm{lysM}}$ mouse

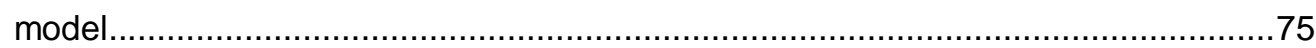

Figure 14: Systemic cytokine levels in aGvHD in the $\mathrm{GR}^{\mathrm{lysM}}$ mouse model.............................76

Figure 15: Characterization of $\mathrm{IOH}-\mathrm{NPs}$ in cultures and $\mathrm{MH}-\mathrm{S}$ cells......................................

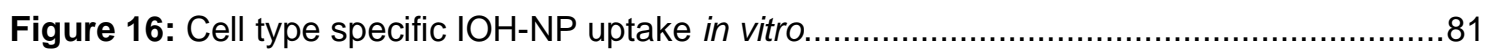

Figure 17: Cell viability upon $\mathrm{IOH}-\mathrm{NP}$ treatment in different cell lines in vitro............................82

Figure 18: Endocytotic IOH-NP internalization pathway in MH-S cells in vitro. .........................84

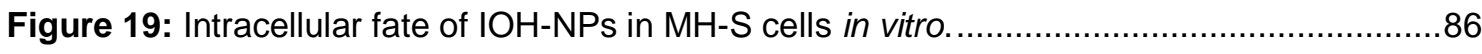

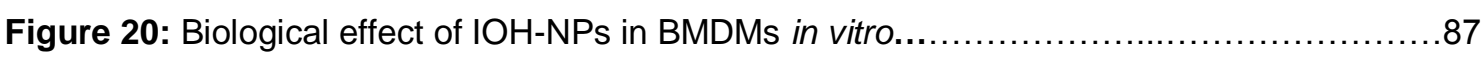

Figure 21: Resorption and organ distribution of GAP-NPs via MRI in vivo.............................89

Figure 22: Organic distribution of IOH-NPs analyzed via ICP-MS ex vivo...............................90

Figure 23: Survival of aGvHD wt mice upon treatment with GCs. .......................................

Figure 24: Clinical features of aGvHD in GC-treated wt mice in the early phase... ...................94

Figure 25: Histological analysis of the jejunum in the early phase of aGvHD in.... GC-treated wt mice.

Figure 26: Immunohistochemical analysis of the jejunum in the early phase of aGvHD in GC-treated wt mice.

Figure 27: Characterization of the cellular composition of the inflammatory infiltrate in the lamina propria in the jejunum in GC-treated wt mice in the early. phase of aGvHD. 
Figure 28: Clinical features in the early phase of aGvHD in the $\mathrm{GR}^{\mathrm{lysM}}$ model treated with.

BMP-NPs.

Figure 29: Histological and immunochemical analyses of the jejunum in the early phase of....... aGvHD in the $G^{l y s M}$ model treated with BMP-NPs.

Figure 30: Systemic cytokine levels in the early phase of aGvHD in wt mice treated with GCs

Figure 31: Cytokine expression in the jejunum in the early phase of aGvHD in wt mice treated with GCs

Figure 32: Blood glucose level and metabolic enzyme expression in the liver after GC treatment in wt mice.

Figure 33: Body weight, muscle weight and gene expression in the M. gastrocnemius after

$\mathrm{GC}$ treatment in wt mice.

Figure 34: Systemic levels of bone resorption and formation marker in GC-treated wt mice.. 114 


\section{LIST OF TABLES}

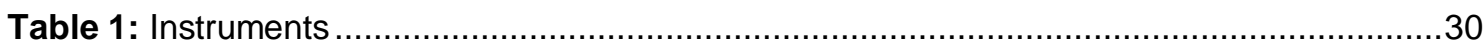

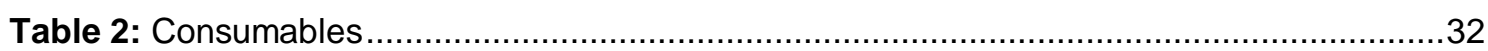

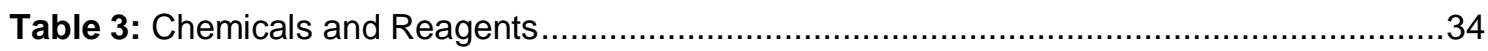

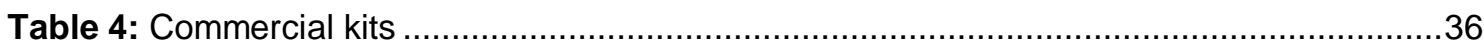

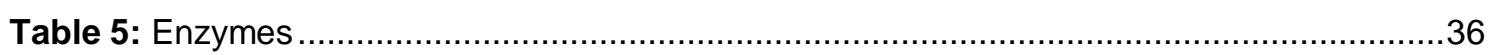

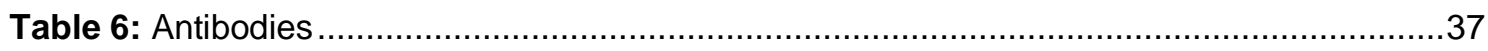

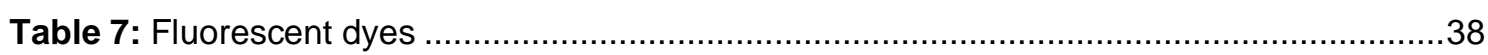

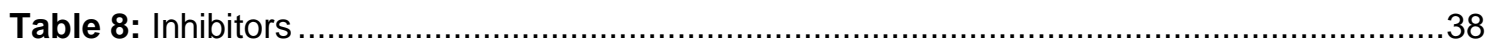

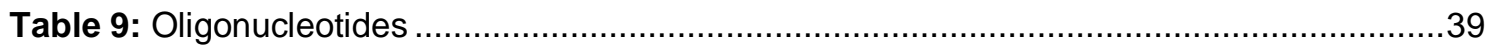

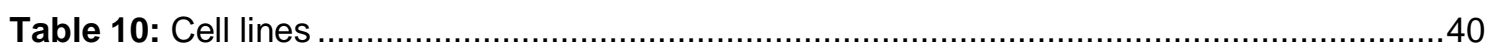

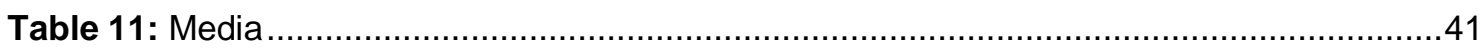

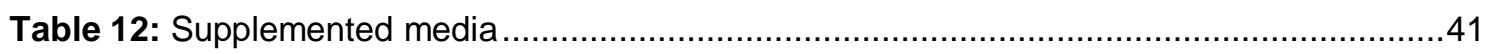

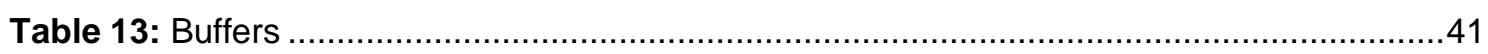

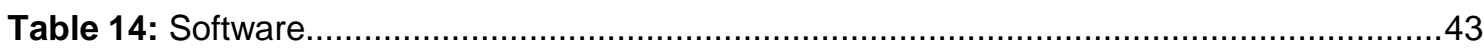

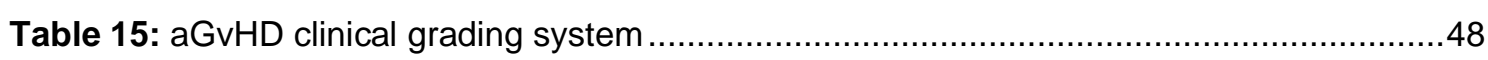

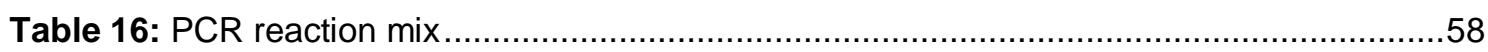

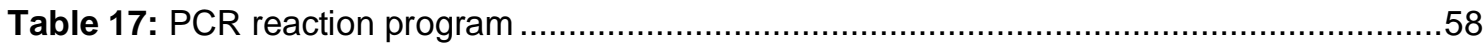




\section{LIST OF ABBREVIATIONS}

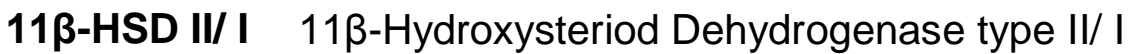

AAI

ACTH

AF-1

aGvHD

Amiloride

AP-1

APC

Assoc.

ATCC

ATG

Bcl-2

BDS

BM

BMDMs

BMP

BMP-NPs

BMT

BMX

BSA

CB

CBG

CCL-2

CCR2

CD

cDNA

cGvHD

CNS

Col1A1

CRF

CTL

CytoD

DAMPs

DBD

DC

$\mathrm{ddH}_{2} \mathrm{O}$

DMEM

DMSO

DNA

dNTPs

DP

DPZ

DR
Allergic Airway Inflammation

Adreno-Corticotrophin-Releasing Hormone

Activation Function Domain

Acute Graft-versus-Host Disease

Amiloride hydrochloride hydrate

Activator Protein 1

Antigen Presenting Cells

Associate

American Type Cell Collection

Anti-Thymocyte Globulin

B cell lymphoma-2

Bright Detail Similarity

Bone Marrow

Bone Marrow Derived Macrophages

Betamethasone Phosphate

Betamethasone Phosphate-Nanoparticles

Bone Marrow Transplantation

Betamethasondihydrogenphosphat-Dinatrium (Celestan)

Bovine Serum Albumin

Cord Blood

Corticosteroid-Binding Globulin

Chemokine $\mathrm{C}-\mathrm{C}$ motif Ligand-2

CC chemokine Receptor

Cluster of Differentiation

Complementary DNA

Chronic Graft-versus-Host Disease

Central Nervous System

Collagen, type I, Alpha 1

Corticotrophin-Releasing Factor

Cytotoxic T-lymphocytes

Cytochalasin D

Danger-Associated-Molecular-Patterns

DNA Binding Domain

Dentritic Cells

Deionized Distilled Water

Dulbecco's Modified Eagle's Medium

Dimethylsulfoxid

Deoxyribonucleic Acid

Deoxynucleotide Triphosphates

Dexamethasone Palmitate

German Primate Center

Deep Red 


\begin{tabular}{|c|c|}
\hline DSP & Dexamethasone Sodium Phosphate \\
\hline DTT & Dithiothreitol \\
\hline EAE & Experimental Autoimmune Encephalitis \\
\hline EBMT & European Group for Blood and Marrow Transplantation \\
\hline EDTA & Ethylendiaminetetraacedic Acid \\
\hline ELISA & Enzyme Linked Immunosorbant Assay \\
\hline Em & Emission \\
\hline EP-NP & Empty Nanoparticles \\
\hline EtOH & Ethanol \\
\hline Exc & Excitation \\
\hline FACS & Fluorescent Activating Cell Sorting \\
\hline FBS & Fetal Bovine Serum \\
\hline FCS & Fetal Calf Serum \\
\hline FDA & Food and Drug Administration \\
\hline FKBP51 & FK506-Binding Protein 51 \\
\hline FMN & Flavinmononucleotide \\
\hline Fox01 & Forkhead box 01 \\
\hline FSC & Forward Scatter \\
\hline FSC-A & Forward Scatter Area \\
\hline FSC-H & Forward Scatter Height \\
\hline Fwd & Forward \\
\hline GAP-NP & $\mathrm{Gd}^{3+} 2[\mathrm{AMP}]^{2-3} \mathrm{IOH}-\mathrm{NPs}$ \\
\hline GCs & Glucocorticoids \\
\hline G-CSF & Granulocyte-Colony Stimulating Factor \\
\hline Gd & Gadolinium \\
\hline GI & Gastrointestinal tract \\
\hline GIO & GC-induced Osteoporosis \\
\hline GR & Glucocorticoid Receptor \\
\hline GREs & Glucocorticoid Responsive Elements \\
\hline GvL & Graft-versus-Leukemia \\
\hline H\&E & Haematoxylin and Eosin \\
\hline $\mathrm{H}_{2} \mathrm{O}_{2}$ & Hydrogen Peroxide \\
\hline $\mathrm{H}_{2} \mathrm{SO}_{4}$ & Sulfuric Acid \\
\hline HLA & Human Leucocyte Antigen \\
\hline HP1 & Heterochromatin Protein 1 \\
\hline HPA & Hypothalamic-Pituitary-Adrenal \\
\hline HRP & Horse Radish Peroxidase \\
\hline Hrs & Hours \\
\hline HSCT & Hematopoietic Stem Cell Transplantation \\
\hline Hsp & Heatshock proteins \\
\hline i.m. & Intramuscularly \\
\hline i.p. & Intraperitoneally \\
\hline i.v. & Intravenously \\
\hline ICP-MS & Inductively Coupled Plasma-Mass Spectrometry \\
\hline IFN & Interferon \\
\hline
\end{tabular}




\begin{tabular}{|c|c|}
\hline IL & Interleukin \\
\hline iNOS & Inducible Nitric Oxide Synthase \\
\hline IOH-NPs & Inorganic-Organic Hybrid-Nanoparticles \\
\hline IVC & Individually Ventilated Cages \\
\hline $\mathrm{KCl}$ & Potassium Chloride \\
\hline $\mathrm{KH}_{2} \mathrm{PO}_{4}$ & Potassium Dihydrogen Phosphate \\
\hline LBD & Ligand Binding Domain \\
\hline LCCM & L929 Cell Conditioned Medium \\
\hline $\mathbf{L N}$ & Lymph Nodes \\
\hline LP & Liposomes \\
\hline LPS & Lipopolysaccharides \\
\hline M. & Musculus \\
\hline mAbs & Monoclonal Antibodies \\
\hline MAPK & Mitogen-Activated Protein Kinase \\
\hline MCP-1 & Monocyte Chemoattractant Protein-1 \\
\hline M-CSF & Macrophage Colony-Stimulating Factor \\
\hline MDC & Monodansyl-Cadaverine \\
\hline $\mathrm{MgCl}_{2}$ & Magnesiumchlorid \\
\hline MHC & Major Histocompatibility Complex \\
\hline miHAs & Minor Histocompatibility Antigens \\
\hline ml & Milliliter \\
\hline MMF & Mycophenolate Mofetil \\
\hline MRI & Magnetic Resonance Imaging \\
\hline mRNA & Messenger ribonucleic acid \\
\hline MT2 & Metallothionein 2 \\
\hline MTx & Methotrexate \\
\hline $\mathrm{Na}_{2} \mathrm{CO}_{3}$ & Sodium Carbonate \\
\hline $\mathrm{Na}_{2} \mathrm{HPO}_{4}$ & Disodium Hydrogen- Phosphate \\
\hline $\mathrm{NaCl}$ & Sodium Chloride \\
\hline NADPH & Nicotinamide Adenine Dinucleotide Phosphate \\
\hline $\mathrm{NaHCO}_{3}$ & Sodium Hydrogen Carbonate \\
\hline NF-kB & Nuclear Factor kappa B \\
\hline nGREs & Negative Glucocorticoid Responsive Elements \\
\hline $\mathrm{NH}_{4} \mathrm{Cl}$ & Ammonium Chloride \\
\hline NK & Natural Killer \\
\hline NL & Nuclear Localization \\
\hline NO & Nitric Oxide \\
\hline NPs & Nanoparticles \\
\hline NTD & N-terminal Transactivation Domain \\
\hline $\mathrm{O} / \mathrm{N}$ & Overnight \\
\hline PAMPs & Pathogen-Associated-Molecular-Pattern \\
\hline PAS & Periodic Acid Schiff \\
\hline PBMCs & Peripheral Blood Stem Cells \\
\hline PBS & Phosphate Saline Buffer \\
\hline PEG & Polyethylene \\
\hline
\end{tabular}




\begin{tabular}{|c|c|}
\hline PEPCK & Phosphoenolpyruvate Carboxylase \\
\hline PFA & Paraformaldehyde \\
\hline PLGA & Poly(Lactic-Co-Glycolic Acid) \\
\hline qRT-PCR & Quantitative Reverse Transcription PCR \\
\hline RE & Responsive Elements \\
\hline Rev & Reverse \\
\hline RNS & Reactive Nitrogen Species \\
\hline ROS & Reactive Oxygen Species \\
\hline RPMI & Roswell Park Memorial Institute \\
\hline RT & Room Temperature \\
\hline SEM & Standard Error of the Mean \\
\hline SPF & Specific-Pathogen-Free \\
\hline SR-aGvHD & Steroid-Refractory aGvHD \\
\hline SSC & Side Scatter \\
\hline TAT & Tyrosine Aminotransferase \\
\hline TBI & Total Body Irradiation \\
\hline Teffs & T effector cells \\
\hline TF & Transcription Factor \\
\hline Th1/ Th2 & T helper \\
\hline TLR & Toll-Like Receptor \\
\hline TM & Transcriptional Machinery \\
\hline TMB & $3,3^{\prime}, 5,5^{\prime}-$ Tetramethylbenzidin \\
\hline TNF & Tumor Necrosis Factor \\
\hline Tregs & $\mathrm{T}$ regulatory cells \\
\hline UMG & University Medical Center \\
\hline Wt & Wild type \\
\hline $\mathrm{Zr}$ & Zirconium \\
\hline $\mathrm{ZrO}^{2+}$ & Zirconium oxide \\
\hline
\end{tabular}




\section{INTRODCUTION}

\subsection{Hematopoietic stem cell transplantation}

Bone marrow transplantation (BMT), or more precisely, hematopoietic stem cell transplantation (HSCT) is most often the only promising therapeutic option for patients suffering from malignant or non-malignant hematological diseases (Blazar and Murphy, 2005). The first global survey on first HSCTs was conducted over a three-year period from 2006 to 2008 by the European Group for Blood and Marrow Transplantation (EBMT) Transplant Activity Survey Office. About 50.000 patients were transplanted annually and the main indications were $53 \%$ lymphoproliferative disorders (lymphoma, plasma cell disorders), $36 \%$ leukemia (acute, chronic and myelodysplastic syndrome/ myeloproliferative syndrome), $5 \%$ solid tumors and $6 \%$ non-malignant diseases such as sickle cell anemia (Gratwohl et al., 2013). HSCTs are subdivided by the origin of the stem cell transplant. Within the survey about $55 \%$ of the patients received their own stem cells (autologous conditions) whereas about $45 \%$ of the patients received stem cells from a family member or an unrelated donor (allogeneic condition). Both forms have unique advantages. The allogeneic form is for example indicated when the patient suffers from a genetically based disease such as Fanconi anemia, affecting the red blood cells. The disadvantage is that patients need long-term immunosuppressive drugs, whereas in the autologous form such complications are avoided. In both HSCT forms, before receiving stem cells, patients are treated with chemotherapy and/ or radiation (conditioning regime). This is inevitable to destroy or at least minimize unwanted cancer cells, prevent bone marrow transplantation failure and, in allogeneic transplantation, induce immunosuppression that permits engraftment (Copelan, 2006, Nelson et al., 2008). In 1968, the first successful allogeneic stem cell transplantation was carried out with BM cells as the source for hematopoietic stem cells. Over the next decades two further sources have been added. First, stem cells are stimulated by granulocyte colony stimulating factor (G-CSF) and are mobilized in the peripheral blood, referred to as peripheral blood stem cells (PBMCs). Second, in 1978 cord blood (CB) has been added as a source and later used 
for allogeneic HSCT whereas it is no source for the autologous transplantation form. However, transplant physicians have three optional sources to choose from for allogeneic transplantations and have to consider the risks and benefits associated with each stem cell source. For example, PBMCs and CB contain fewer red blood cells compared to BM. It is therefore favored by a mismatch in blood groups between donor and recipient preventing hemolysis. Also a factor to consider is the number of mature $T$ cells. Most mature $T$ cells are found in PBMCs, with lower numbers in BM and CB. Higher numbers of T cells increase the risk of developing Graft-versus-Host Disease (GvHD), which is considered as the main source of transplant-related morbidity and mortality. Contrariwise, lower numbers of $T$ cells increase the risk of a relapse in cases of malignant diseases (Cheuk, 2013). Further factors such as overall health status of the patient, its age and the planned conditioning regime also influence the success of transplantation. This shows that despite intensive research over decades, the medical decision-making process for the transplant procedure remains complex and problematic (Okamoto, 2017).

\subsection{Graft-versus-Host Disease}

Since the 1940s, experiments were performed that contribute to our current understanding of the complex pathophysiology of GvHD (Boieri et al., 2016). In 1957, Simonson performed allogeneic transplantations in chickens by injecting adult splenocytes and blood cells into embryos. The recipients suffered from hemolytic anemia and splenomegaly. Simonson concluded that this result was ascribable to the adult immunologically competent cells of the donor as the recipient embryo has no sufficiently mature immune system as of yet to explain the results (Simonsen, 1957). In 1958, Billingham and Brent injected allogeneic adult lymphoid mouse tissue into newborn mice resulting in similar symptoms as ones observed in the chickens embryos before, namely an early death and growth retardation. They also concluded that it was a result of a GvH reaction (Billingham, 1958). Further BMT experiments of other researchers at the time confirmed the reaction of donor immune cells against the recipient and finally the cause of GvHD was revealed, even though not in its complexity (Egdahl et al., 1958, Nakic and Silobrcic, 1958, Finerty, 1952). 
In 1966, Billingham outlined the key requirements of GvHD in his historic Harvey Lecture and this hypothesis is still valid. First, the graft must contain a sufficient amount of immunocompetent cells, by now known as donor $\mathrm{T}$ cells. Second, the host needs to express antigens, mostly unmatched major histocompatibility complex (MHC) class I and II molecules and polymorphic proteins, which are recognized as foreign by the donor cells, which hereby become stimulated. Third, the recipient is incapable to generate a sufficiently strong immune response to eliminate the transplanted cells (Billingham, 1966). Upon identification and typing of the human leucocyte antigen (HLA), which encodes the highly polymorphic $\mathrm{MHC}$ to which donor $\mathrm{T}$ cells mostly respond, allogeneic transplantation became feasible in the early 1960s (Copelan, 2006). The HLA is located on the short arm of chromosome 6 (p21) and inherited as haplotypes (Ball et al., 2008). HLA matching between donor and recipient is the most important factor in preventing GvHD (Kanda, 2013). The HLA loci A, B, C encode for $\mathrm{MHC}$ I proteins expressed on virtually all cell types, whereas the HLA loci, DR, DQ and DP encode for MHC II proteins expressed primarily on antigen presenting cells (APCs) (Teshima et al., 2002). Matches in HLA-A, B, C and HLA-DRB1 alleles are most preferable (Kanda, 2013), but besides focusing only on the HLA alleles themselves, disparities in their linked HLA region also correlates with the occurrence of GvHD (Morishima et al., 2016). Furthermore, genetic differences outside of the HLA loci, concerning the "minor" histocompatibility antigens (miHAs), increase the risk of GvHD as well. miHAs are polymorphic peptides, encoded by a wide range of genes. They derive from intracellular proteins, which are presented by $\mathrm{MHC}$ molecules to donor $\mathrm{T}$ cells, mostly MHC I (Ferrara et al., 2009). About 50 miHAs have been identified so far. HA-1 and HA-2 were the first ones to be described and mismatches between donor and recipient in these genes increases the risk of GvHD (Ghimire et al., 2017). Unlike MHC I and II, miHAs can differ in their tissue expression pattern among individuals (Shlomchik, 2007). Further risk factors for developing GvHD are gender disparities during transplantation, an increased age of both donor and recipient, an ineffective GvHD prophylaxis, the intensity of the conditioning regime (Nassereddine et al., 2017) and a low variety of the gut microbiota (Blazar et al., 2012, Holler et al., 2014, Goker et al., 2001). 


\subsubsection{Clinical features of GvHD}

Clinically, GvHD occurs in two forms, the acute and the chronic form. Historically, both forms were defined by the time point of their onset. According to this definition, acute GvHD (aGvHD) occurs within the first 100 days post BMT and chronic GvHD (cGvHD) occurs only thereafter. Nowadays, it is acknowledged that this definition is inadequate, as both forms have their own pathophysiological entities, involved target organs and therapeutic management (Anderson et al., 2005, Blazar and Murphy, 2005). There are overlapping forms and the most important risk factor of $c G v H D$ is aGvHD, as well as its treatment. In both forms, donor T cells play a central role in the immunologic attack of the host tissues. However, cGvHD has more diverse manifestations as aGvHD and shares characteristics with autoimmune diseases. It is dominated by Th2 cells and results, in most patients, in the generation of autoreactive $\mathrm{T}$ cells and a dysregulation of B cells followed by autoantibody production. It affects the skin, soft tissue, oral mucosa and sometimes the liver (Ratanatharathorn et al., 2001, Szyska and $\mathrm{Na}, 2016)$. In contrast, aGvHD is dominated by Th1 cells and affects the skin, the gastrointestinal (Gl) tract and the liver, although other sites might be affected, too. Skin is the organ, which most often shows the first symptoms. Maculopapular rash usually starts at palms and soles but can spread throughout the whole body, in severe cases blisters can occur. Clinical manifestations in the Gl tract are diarrhea, in severe cases it becomes bloody and is accompanied by cramping, vomiting, abdominal pain and failure to thrive. Jaundice, a consequence of hyperbilirubinemia, is characteristic for liver involvement (Jacobsohn and Vogelsang, 2007, Zeiser and Blazar, 2017, Salomao et al., 2016). aGvHD can be graded into four stages (I - IV, I mild, IV severe) based on the number, stage and degree of involvement of the three organs according to a staging system from 1994. This system subdivides patients into risk categories for complications and mortality (Przepiorka et al., 1995). Patients with aGvHD of grade III - IV have a high mortality rate, with $25 \%$ of grade III and $5 \%$ of grade IV long-term survival (Ferrara et al., 2009). In general, aGvHD affects about 10 - $80 \%$ of the patients, depending on a number of patient- and transplant-related variables, compromising considerably 
the overall success of allogeneic HSCT after relapse (Garnett et al., 2013, Nassereddine et al., 2017).

\subsubsection{Pathophysiology of aGvHD}

The pathophysiology of aGvHD is much better understood in comparison to cGvHD. It is a complex multistep process that can be divided into three phases (Figure 1).

1) Priming of host tissue cells (APCs)

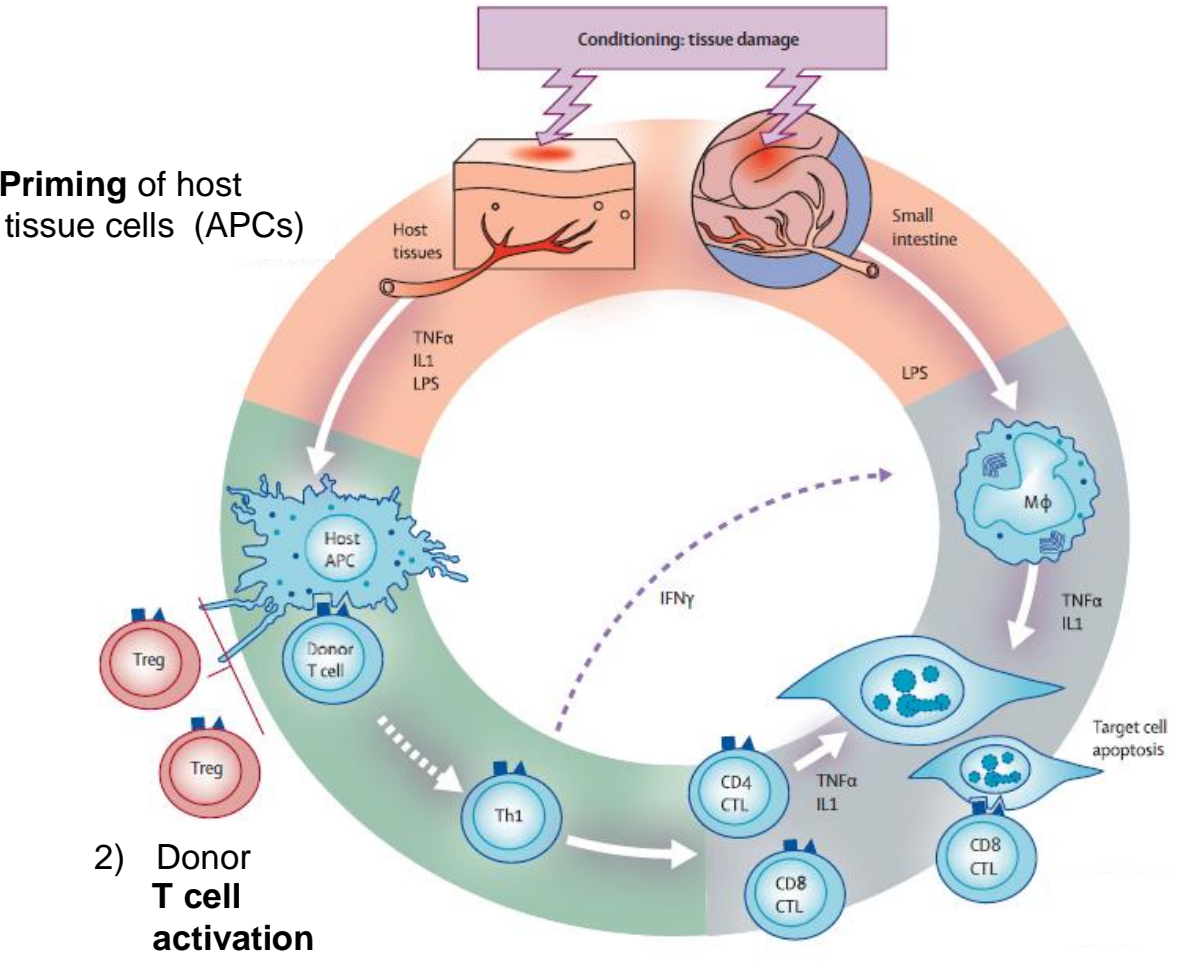

3) T cell trafficking and effector damage

Figure 1: Pathophysiology of aGvHD. Modified from (Ferrara et al., 2009). The establishment of aGvHD occurs in three phases. 1) Activation of host tissues, including antigen presenting cells, by the conditioning regime. 2) Activation, proliferation, differentiation of donor T cells by (host) APCs. 3) T cells migrate to target tissues and induce tissue damage by their effector functions.

The first phase, the so-called "priming phase" occurs even before donor cells are infused into the host. The underlying disease, treatment, infections and the conditioning regimen induce local inflammation due to their toxic effects causing damage to the host tissues (Jaksch and Mattsson, 2005). Subsequently, host tissue cells release danger-associated-molecular-patterns (DAMPs) (Blazar et al., 2012), which includes the secretion of pro-inflammatory cytokines such as 
tumor necrosis factor (TNF) a, Interleukin 6 (IL-6) and IL-1 and biological mediators such as nitric oxide (NO). Consequently, APCs are activated and excessively contribute to the "cytokine storm" (Ghimire et al., 2017). Of particular importance in this process is the injury to the intestinal mucosa and epithelium since bacterial endotoxins such as lipopolysaccharides (LPS) are consequently translocated from the lumen into the circulation. The release of pathogen-associated-molecular-patterns (PAMPs) greatly amplify the activation of APCs, which in turn upregulate the expression of MHC (Socie and Blazar, 2009) and co-stimulatory molecules such as CD80 and CD86 forming an immunological synapse with the T cell receptor and CD28 on T cells leading to their activation. GvHD is entirely dependent on these crucial co-stimulatory molecules (Anderson et al., 2005). Since the conditioning regime boosts host APC activation, a reduced or even non-myeloablative regime as well as a delayed transfer of the graft contributes to the development of a less severe aGvHD (Johnson and Truitt, 1995, Perez-Simon et al., 2005).

The second phase "donor T cell activation and expansion" is the core event of aGvHD. The danger signals, secreted in the first phase, lead to an increased expression of co-stimulatory molecules, such as CD28 by donor T cells making them susceptible for their activation (Ferrara, 1993). CD4 ${ }^{+} \mathrm{T}$ cells respond to disparities in $\mathrm{MHC}$ II molecules, whereas $\mathrm{CD} 8^{+} \mathrm{T}$ cells respond to differences in $\mathrm{MHC}$ I molecules between donor and recipient. Both $\mathrm{T}$ cell subsets can respond to miHAs differences (Sprent et al., 1988). Donor and recipient APCs trigger the activation, proliferation and differentiation of donor-derived $\mathrm{T}$ cells, which provoke the secretion of a Th1 dominated pro-inflammatory cytokine profile including IL-2, interferon (IFN)Y and TNFa (Ball et al., 2008). T cells are also crucial for the graft versus leukemia (GvL) effect. If malignant stem cells in the recipient survive the conditioning regime the patient might experience a relapse, unless such cells are eliminated by the activated donor T cells (Copelan, 2006).

The third phase is the "T cell trafficking and effector phase". The alloreactive effector $\mathrm{T}$ cells migrate to target tissues in response to chemokines and their receptors. Effector cells, such as cytotoxic T-lymphocytes $(C T L)$ and natural 
killer (NK) cells induce further tissue destruction by lysing cells via the Fas/FasL and perforin/granzyme pathways. LPS intensively leaks through the intestinal epithelium stimulating further cytokine secretion (Ghimire et al., 2017). The complex cascade of multiple cellular and inflammatory effectors leads to an escalation and the clinical end-organ-pathology manifestation (Nassereddine et al., 2017). Recent advances in research have further improved our understanding of the contributions of other innate and adaptive immune cells to the pathogenesis of aGvHD (Blazar et al., 2012).

\subsubsection{The role of APCs in aGvHD}

Hematopoietic cells, such as professional APCs, as well as non-hematopoietic cells, such as endothelial cells, are capable of participating or even initiating aGvHD by antigen presentation, although not with the same efficiency. Professional APCs predominantly comprise B cells, dendritic cells (DCs) and macrophages. They are highly efficient in loading peptides on MHC molecules and presenting them, together with crucial co-stimulatory molecules, to $T$ cells. Naïve B cells circulate between the blood stream and secondary lymphoid organs, but their role in aGvHD is still unclear. In mouse models, they have been shown to reduce aGvHD due to the secretion of the anti-inflammatory IL-10 induced by the conditioning regime (Rowe et al., 2006). Circulating monocytes have a half-life of three days and can differentiate into DCs and macrophages. They are actively recruited to the side of inflammations, where they replenish the pool of tissue resident macrophages and DCs (Yang et al., 2014). In contrast to macrophages, DCs present antigens in secondary lymphoid organs that have been taken up in peripheral tissues. Donor $\mathrm{T}$ cells can recognize and react to alloantigens either via direct antigen presentation on host APCs or via indirect presentation, so called cross-presentation, on donor APCs (Ghimire et al., 2017). In general, studies in BMT experimental mouse models have shown, that donor APCs intensify the disease at later stages (Matte et al., 2004). Host APCs though are essential to prime donor T cells and thus are involved in initiating aGvHD and the recruitment as well as priming of CTL during the effector phase in the target tissue including their GvL activity (Duffner et al., 2004, Mapara et al., 2002, Teshima et al., 2002). In contrast, 
non-hematopoietic cells are insufficient in doing so (Shlomchik et al., 1999). In agreement with this notion, the local depletion of host DCs and macrophages, by the application of liposomal clodronate to mice, ameliorated aGvHD and prolonged the survival of the animals (Zhang et al., 2002b). The majority of host APCs and precursor populations are lost due to the conditioning regime within a few days. The loss is compensated by differentiated and progenitor stem cells derived from the graft. Nevertheless, resident macrophages of the recipient and skin DCs (dermal DCs and epithelial Langerhans cells) survive this regime, creating a chimeric APC repertoire. They persist in patients for many months after BMT and contribute to the long conserving risk of developing aGvHD (Haniffa et al., 2009). A small fraction of host CD11+ DCs survive too, but only for a few days. However, this is already enough to contribute to the priming of donor $T$ cells (Zhang et al., 2002a). Resident macrophages stay, among many other locations, in secondary lymphoid tissues of the recipients. Here, they encounter the freshly transferred naïve $T$ cells. Consequently, $T$ cells intensively proliferate in lymph nodes, spleen and Peyer's patches, and 3 to 4 days later they enter the blood stream and migrate to the target tissues (Chakraverty and Sykes, 2007). For many years, the dogma persisted that host macrophages and DCs harm the patient in terms of aGvHD due to their pro-inflammatory immune reaction in this setting (Hill et al., 1997). While this is true for host DCs, increased numbers of surviving host macrophages, induced by pre-transplant CSF-1 therapy, reduce the donor T cell pool and thereby positively influence the development of aGvHD (Duffner et al., 2004, Hashimoto et al., 2011).

\subsubsection{The role of $T$ cells in aGvHD}

T cells are the major inducer of aGvHD and the beneficial GvL effect. Both processes are caused by similar mechanisms and are therefore hardly separated. Initially, the role of $T$ cells became evident when mice received BM cells, in which donor $\mathrm{T}$ cells were specifically reduced or even removed, revealing that the amount of $T$ cells correlated with aGvHD severity (Korngold and Sprent, 1978) and mortality, due to infections and relapse (Horowitz et al., 1990, Wagner et al., 2005). However, the specific role of each T cell subset in aGvHD is still under investigation as a large heterogeneity of $T$ cell subsets 
exists in human and mice. Their activation and subsequent differentiation, as well as their fate, depends on various factors, such as the cytokine microenvironment and the priming by APCs, which is dependent on the type and degree of $\mathrm{MHC}$ or miHA compatibility. In MHC mismatch mouse models, $\mathrm{CD}^{+}$and $\mathrm{CD}^{+} \mathrm{T}$ cells can cause aGvHD (Korngold and Sprent, 1987). In miHA-mismatch models, CD4 ${ }^{+}$cells alone are sufficient for aGvHD and can boost alloreactive $\mathrm{CD}^{+}$cells (van Dijk et al., 1999).

Different $\mathrm{CD}^{+}$subsets have been shown to be specifically involved in the pathogenesis of the affected organs. For example, Th1 cells dominate in the GI tract, whereas Th17 cells are found in the skin (Burman et al., 2007, Iclozan et al., 2010). Preventing the differentiation of naïve Th cells into these subsets thus ameliorated aGvHD in an MHC mismatch mouse model (Yu et al., 2011). In line with this study, transferring IL-17 deficient $\mathrm{CD}^{+} \mathrm{T}$ cells in an allogeneic mouse BMT model delayed, but did not improve aGvHD mortality and reduced the number of Th1 cells in the early phase of the disease. Additionally, pro-inflammatory cytokine production, such as IFNy, was reduced (Kappel et al., 2009). Another study showed that adoptive transfer of in vitro differentiated Th17 cells leads to lethal aGvHD (Carlson et al., 2009). In contrast, the absence of Th17 cells in the graft was associated with an increased Th1 differentiation and infiltration (Yi et al., 2008). Although Th17 cells have been associated with aGvHD, they appear more important for cGvHD (Carlson et al., 2009). Th1 cells, with their characteristic pro-inflammatory cytokine profile, are believed to be the main trigger of aGvHD and are associated with an earlier onset and a more severe disease course (Hill et al., 1997, Hill and Ferrara, 2000). Nevertheless, Th2 cells play also a role in the pathology, as well as in the prevention, of aGvHD (Nikolic et al., 2000, Fowler et al., 1994).

Cytotoxic $\mathrm{CD}^{+} \mathrm{T}$ cells are also well-known to contribute to the tissue destruction in aGvHD by inducing apoptosis via the perforin/granzyme or Fas/FasL pathway. Braun et al. transferred $T$ cells deficient for both lytic mediator pathways in an MHC mismatch mouse model and recipient mice survived in the absence of any aGvHD symptoms. Mortality was still reduced 
when $\mathrm{T}$ cells, deficient for one lytic mediator, were transferred for disease induction, while protection from lethal aGvHD was mainly perforin dependent (Braun et al., 1996). Graubert et al. showed that the perforin/granzyme dependent mechanism was important in an MHC I restricted acute murine aGvHD model while the Fas/FasL dependent mechanism was rather crucial in an MHC II restricted acute murine aGvHD model (Graubert et al., 1997). In contrast, Maeda et al. found that $\mathrm{CD}^{+}$cells deficient for both pathways still induced aGvHD in a MHC I mismatch mouse model (Maeda et al., 2005). In line with the importance of $T$ cells in aGvHD, blocking of co-stimulatory signals diminished their expansion and reduced aGvHD. Namely, application of anti-CD80 and anti-CD86 monoclonal antibodies prevented aGvHD lethality (Blazar et al., 1996). Regulatory T cells (Tregs) play a critical role in establishing tolerance against self-antigens, a feature which is beneficial in aGvHD, demonstrated in experimental mouse models. When Tregs, naturally present in the graft, were removed, the disease was accelerated. Conversely, the enrichment of the graft with freshly isolated Tregs, delayed aGvHD (Cohen et al., 2002). Moreover, infusion of clinical-grade-enriched Tregs from human PBMCs stem cells into mice (xenogeneic GvHD) resulted in delayed death. Mice which were given only Tregs experienced no clinical signs of GvHD (Hannon et al., 2014). In conclusion, the interaction between the various subsets of $T$ cells and the individual microenvironment in patients determines the pathology of aGvHD.

\subsubsection{Cytokines involved in aGvHD}

An important factor determining the course and severity of aGvHD are cytokines secreted by immune cells and other cell types during the disease. They determine the phenotype of naïve $T$ cells and macrophages, two crucial cell types in the context of aGvHD. The pro-inflammatory milieu, triggered by the conditioning-induced tissue damages, activates immune cells and thereby leads to cytokine secretion, which has a pivotal negative impact on aGvHD (Mapara et al., 2006). Key cytokines of Th1 cells are IL-2, IFNy and TNFa, and their differentiation is initiated by IL-12, which is secreted by APCs (Hill and Ferrara, 2000). Neutralization of IL-12 during initiation period of aGvHD in mismatched 
mouse models prevented acute as well as chronic GvHD. While the application of anti-IL-12 antibodies prevented Th1-mediated aGvHD by down regulation of IFNy, it shifted the alloresponse towards a Th2 phenotype characterized by a cytokine profile, dominated by IL-4, IL-5 and IL-10 with mild cGvHD symptoms (Williamson et al., 1997).

The role of the Th1 associated IFNy cytokine is poorly understood and paradoxical, because it has multiple functions, either amplifying or reducing aGvHD (Jaksch and Mattsson, 2005). It activates macrophages, NK cells and cytotoxic $\mathrm{CD} 8^{+} \mathrm{T}$ cells, and promotes Th1 differentiation, thereby contributing to aGvHD (Wang et al., 2009, Hill and Ferrara, 2000). Furthermore, it causes a direct damage to the epithelium within the Gl tract (Burman et al., 2007). Contrariwise, it protects against IL-12 and IL-18, both of which stimulate Th1 differentiation (Yang et al., 1998, Lu and Waller, 2009). In addition, IFNy inhibits proliferation and induces cell death of activated alloreactive donor $\mathrm{T}$ cells, thereby being beneficial in aGvHD (Asavaroengchai et al., 2007). A similar complex effect, as seen for IFNy, has been noted for IL-2. It is currently a clinical target in aGvHD as it supports Th cell and CTL expansion, although it is also necessary to generate Tregs that are beneficial in aGvHD (Ball et al., 2008, Shin et al., 2011, Via and Finkelman, 1993). Höfer et al. suggested that IL-2 acts in a dose-dependent manner, which can be explained by a competition for this cytokine by Tregs and T effector cells (Hofer et al., 2012). This is prevented when low-dose IL-2 is applied together with rapamycin, which selectively targets $T$ effector cells by blocking the mTOR signaling pathway and thereby prevents their expansion. Since Tregs use other signaling pathways, they are able to consume IL-2 for their expansion (Shin et al., 2011).

High levels of TNFa have been shown to correlate with the occurrence and a poor outcome of aGvHD (Holler et al., 1990). Specifically, TNFa have been shown to be toxic to the $\mathrm{Gl}$ tract. Intensification of the conditioning regime increased gut damage, allowing for an increased translocation of LPS into the systemic circulation (Hill et al., 1997). LPS as well as IFNY are potent stimulators of macrophages and monocytes to produce TNFa and IL-1 (Nestel 
et al., 1992). TNFa triggers the expression of adhesion molecules on the vascular epithelium. This enables $T$ cells and other leucocytes to enter target organs and directly contributes to the tissue damage by inducing apoptosis as well as necrosis (Pober, 1987). Since TNFa is involved in all three steps of the pathogenesis of aGvHD, it is an important target for the prevention and treatment of this disease (Korngold et al., 2003).

Elevated IL-6 serum levels in patients have been associated with aGvHD (Symington et al., 1992). Furthermore, IL-6 polymorphisms in recipients of HLA-matched sibling transplants has been linked to altered in vitro and in vivo IL-6 production and consequently to acute and cGvHD (Cavet et al., 2001). IL-6 has pleiotropic biological functions and is produced by various cell types including monocytes, macrophages, T cells, B cells and endothelial cells (Nishimoto and Kishimoto, 2006). Infusion of IL-6 aggravated the disease, while antibody-mediated blockade of the IL-6 receptor improved experimental aGvHD and prevented the GvL effect (Givon et al., 1994, Tawara et al., 2011). This was partially due to the increased numbers of Treg cells and the concomitantly reduced numbers of Th1 and Th17 cells in aGvHD target organs (Chen et al., 2009).

Besides cytokines, multiple chemokines are produced as a consequence to the stimuli from the conditioning regime and host/ donor cell activation orchestrating the trafficking of crucial cells during aGvHD to secondary lymphoid organs as well as target organs (Castor et al., 2012). CCL-2, also known as monocyte chemoattractant protein-1 (MCP-1), is important for monocyte, T cell and NK cell attraction. It is produced by a variety of cells, including endothelial cells and epithelial cells but the main producers of the inflammatory chemokine CCL-2 are monocytes and macrophages (Deshmane et al., 2009), which produce CCL-2 in response to inflammatory stimuli such as TNFa and IL-1 (Hildebrandt et al., 2004). The CC chemokine receptor 2 (CCR2), expressed on many hematopoietic cell types, binds to it ligand CCL-2. In murine bone BMT models, transfer of CCR2 deficient donor $\mathrm{CD}^{+} \mathrm{T}$ cells into recipients reduced gut and 
liver damage and improved the overall survival due to migratory defects into these target organs (Terwey et al., 2005).

As a response, to cope with the strong inflammation during aGvHD, endogenous antagonistic molecules including cytokines, such as IL-10 are released. It is produced by monocytes, macrophages, activated $T$ lymphocytes and $B$ cells, and its action includes the inhibition of antigen-specific proliferative responses of $T$ cells and the suppression of various pro-inflammatory cytokines, for instance IL-1 $\beta$, IL-6 and TNFa (Holler et al., 2000, Min et al., 2001). In line, higher levels of IL-10 at the pre-transplant stage has a protective effect on patients undergoing allogeneic HSCT for transplant-related complications (Baker et al., 1999). IL-10, released by donor T cells, also accounted for a diminished aGvHD mortality in murine studies and administration of exogenous low doses of IL-10 protected mice from lethal aGvHD (Blazar et al., 1998).

\subsection{Current therapies of aGvHD}

The complex mechanisms leading to GvHD and GvL can hardly be separated. The challenge of GvHD prophylaxis and treatment is to successfully prevent the disease, while retaining the GvL effect and avoiding infectious complications and a relapse. Given that aGvHD is a multifaceted disease, standardized therapies are missing and protocols vary between clinical centers (Garnett et al., 2013). In the pre-transplant phase, the choice of the intensity of the conditioning regime dictates the therapy for the patient (Chao and Chen, 2006). Especially in cases with partial MHC-mismatch or non-myeloablative therapy, immunosuppressive drugs are already crucial in the pre-transplant phase to reduce the risk of GvHD (Boieri et al., 2016). Since T cells are contained in the stem-cell graft and assumed to be the main player in aGvHD, therapeutic strategies mainly focus on this cell type (Ho and Cutler, 2008). For example, calcineurin inhibitors, such as tacrolimus or cyclosporine target $T$ cell activation and survival through the IL-2 pathway via NFAT (Chao and Chen, 2006, Zeiser et al., 2016). Usually calcineurin inhibitors are given in combination with methotrexate (MTx) as it is more effective than given alone (Storb et al., 1986). MTx inhibits the production of nucleic acids and proteins by targeting folic acid 
metabolism (Boieri et al., 2016). Calcineurin inhibitors and MTx are also given early after transplantation. They are gradually tapered after 100 days post transplantation and stopped 6 to 12 months post transplantation if the patient did not develop any GvHD symptoms in the meantime. Besides that, polyclonal antibodies, such as anti-thymocyte globulin (ATG) are commonly given in order to deplete T cells already in the pre-transplant phase (Chao and Chen, 2006). Further commonly used immunosuppressive prophylaxis are mycophenolate mofetil (MMF) combined with rapamycin (sirolimus). Both drugs are useful in the $T$ cell-activation phase while they inhibit $T$ cell proliferation via blocking the production of purines and the mTOR pathway (Svennilson, 2005, Zeiser and Blazar, 2017).

Despite prophylaxis, aGvHD still develops in many patients and is then initially treated with glucocorticoids (GCs). Due to their potent anti-inflammatory effects, they are the golden first-line therapy form. Topical GCs are given when patients suffer from grade I aGvHD. Higher grades (II - IV) need administration of high-dose systemic application of GCs. Most centers start with a dose of $1-2 \mathrm{mg} / \mathrm{kg} /$ day prednisolone or methylprednisolone, depending on the severity, and increase the dose if necessary (Garnett et al., 2013, Svennilson, 2005). In a retrospective analysis, it turned out that only $55 \%$ of the patients responded to the therapy of which $35 \%$ showed complete remission and $20 \%$ only a partial improvement of the symptoms (MacMillan et al., 2002). This analysis is representative as the percentage of steroid-refractory (SR-aGvHD) aGvHD patients varies between 50 and $70 \%$ (Deeg, 2007, Garnett et al., 2013). SR-aGvHD is a serious problem and the likelihood to respond decreases with an increasing severity of GvHD in which mortality rates are high. For this reason, SR-aGvHD patients require a second-line therapy (Antin et al., 2004, Deeg, 2007). The most commonly applied agents are ATGs. Furthermore, monoclonal antibodies (mAbs) against TNFa, IL-2, or CD25 are applied. However, the outcome often remains unsatisfactory. Hence, GCs remain mandatory in the management of aGvHD even though responses rates are poor and unwanted side-effects occur (Antin et al., 2004, Klein, 2015, Zeiser and Blazar, 2016, Zhang et al., 2018). 


\subsection{Glucocorticoids}

GCs, such as cortisol in humans and corticosterone in rodents, are steroid hormones (Reichardt and Schutz, 1998). Cortisone was discovered in the 1930s by Edward Kendall. In 1948, adequate amounts had been synthesized by Louis Sarett and could be tested for the first time in the clinics. Philip Hench applied daily doses for three days intramuscularly (i.m.) to a patient, suffering from chronic polyarthritis, which led to a significant amelioration of her pain (Hillier, 2007). In the 1950s, a race started to improve the 'wonder drug' cortisone with synthetic derivatives such as prednisolone, methylprednisolone, dexamethasone or betamethasone (Strehl and Buttgereit, 2013). They have now been used for more than 60 years as very efficient drugs to treat chronic inflammatory diseases, such as inflammatory bowel disease, autoimmune diseases including systemic lupus, allergic diseases including asthma or for immunosuppression of conditions, such as aGvHD (Klein, 2015).

In contrast to these synthetic GCs, endogenous GCs are produced by the adrenal glands. Their release is tightly controlled via the hypothalamic-pituitaryadrenal (HPA) axis, which coordinates physiological reactions to external stimuli (Figure 2). It functions as a neuroendocrine cascade with a negative feedback loop. In brief, higher brain areas stimulate the hypothalamus to secrete the corticotropin-releasing factor (CRF), which in turn stimulates the secretion of adreno-corticotropin-releasing hormone (ACTH) by the anterior pituitary. Consequently, the adrenal cortex is triggered to release cortisol. Cortisol prevents its own overproduction by blocking CRF and ACTH secretion (Reichardt and Schutz, 1998, Rhen and Cidlowski, 2005). Furthermore, local biosynthesis of active GCs has been reported to occur to a minor extent in selected organs such as the thymus, intestine, skin and the brain (Talaber et al., 2013). About $90 \%$ of the endogenously released cortisol in the blood is biologically inactive, because it is bound to the high affinity corticosteroid-binding globulin (CBG) (Rhen and Cidlowski, 2005). This protein plays a crucial role for the distribution of cortisol via the blood circulation to tissue-specific sites, for example neutrophils are capable of cleaving CBG hence providing biologically active GC at inflammatory sites (Pemberton et al., 
1988). Within cells, free cortisol can be converted into the biologically inactive form cortisone by the enzyme 11ß-hydroxysteriod dehydrogenase type II

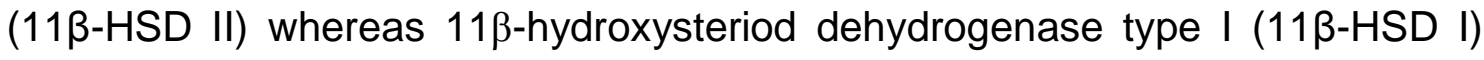
converts cortisone into cortisol (Rhen and Cidlowski, 2005, Cain and Cidlowski, 2017). In comparison to natural GCs, most synthetic derivatives have, beside a longer plasma half-life, a lower affinity towards CBG. Additionally, they are not a substrate for $11 \beta-H S D$ II. Together, these characteristics result in an improved potency and a reduced metabolic clearance (Schacke et al., 2002, Kadmiel and Cidlowski, 2013).

The natural cortisol release is controlled by the circadian rhythm, for which reason the highest blood concentration in humans is usually found in the morning (Strehl and Buttgereit, 2013). Furthermore, GC secretion is triggered by acute and chronic stress, including elevated levels of pro-inflammatory cytokines, such as IL-1, TNFa or IL-6 (Watson et al., 2012, Kadmiel and Cidlowski, 2013, Dunn, 2000). GCs regulate up to $20 \%$ of the genome, including several crucial physiological processes, such as energy metabolism (Strehl and Buttgereit, 2013, Cain and Cidlowski, 2017). Namely, it increases the blood glucose level via three mechanisms: it acts as an antagonist of insulin, triggers gluconeogenesis and the release of glucose from the liver (Strehl and Buttgereit, 2013). Finally, GCs also regulate development, reproduction, cardiovascular homeostasis and play a role in depression (Marques et al., 2009, Vandewalle et al., 2018). 


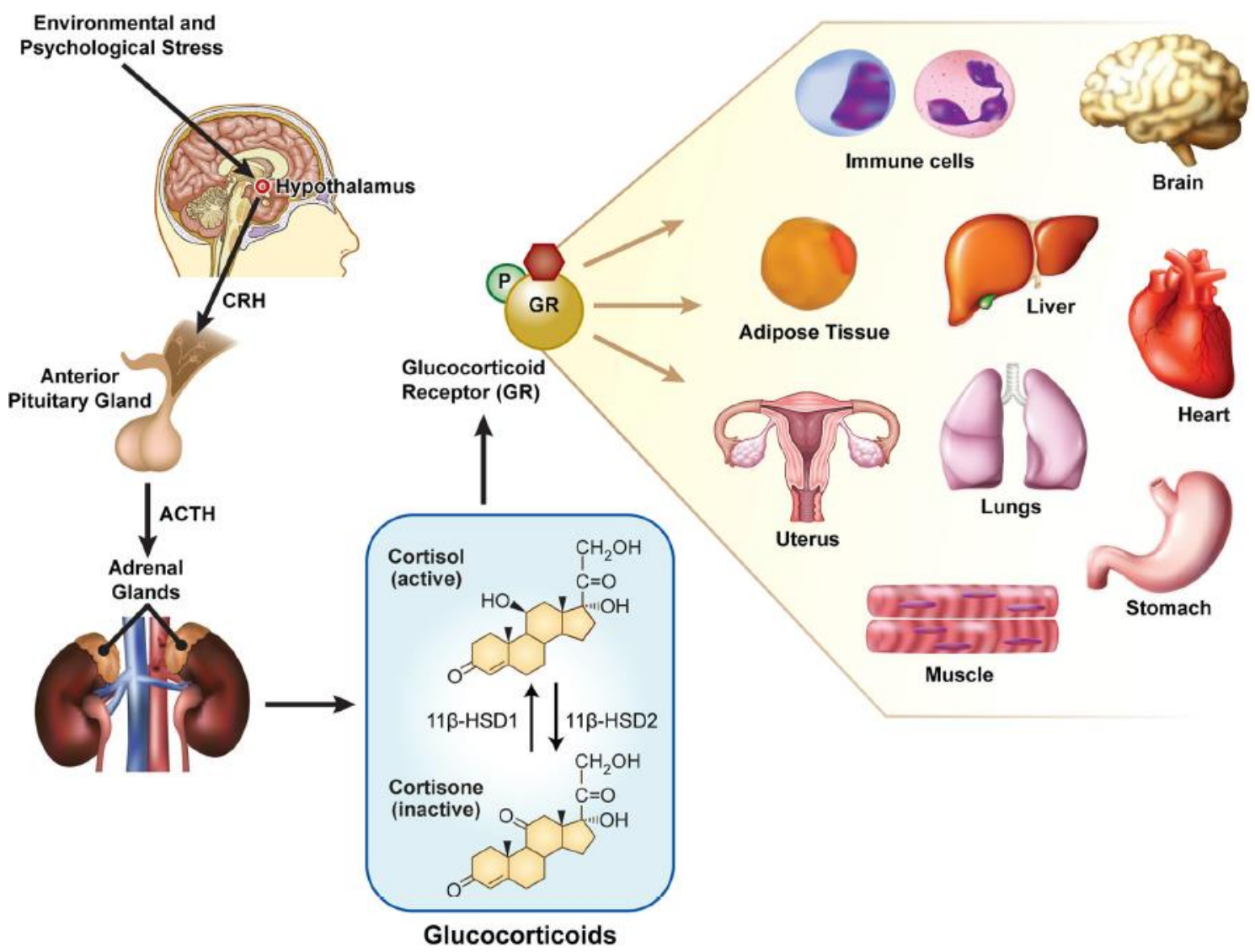

Figure 2: Glucocorticoid (GC) secretion is controlled via the hypothalamic-pituitaryadrenal (HPA) axis. Upon stress the hypothalamus secretes the corticotrophin-releasing hormone $(\mathrm{CRH})$. In turn the anterior pituitary gland releases the adreno-corticotropin-releasing hormone (ACTH) and subsequently the adrenal gland releases the biological active hormone cortisol into the blood stream. Here, $11 \beta$-HSD2 can convert cortisol into the biological inactive form cortisone and $11 \beta$-HSD1 can revert the process. GCs fulfill their function by binding to the ubiquitously expressed glucocorticoid receptor (GR) (Cruz-Topete and Cidlowski, 2015).

\subsubsection{Mechanisms of GC action}

GC effects are mediated mostly by genomic, but also non-genomic mechanisms. The former mechanisms are mediated by the binding of GCs to the cytosolic glucocorticoid receptor (GR), which regulates the expression of target genes (Strehl and Buttgereit, 2013). The GR is encoded by the NR3C1 gene located on chromosome 5q31-32 in humans. GRa and GR $\beta$ isoforms are generated by alternative splicing, but GCs only bind to GR $\alpha$ while the GR $\beta$ isoform acts as dominant inhibitor of GRa. GRa is expressed in nearly all nucleated cells mediating the classical effects of GC signaling (Stahn and Buttgereit, 2008, Kadmiel and Cidlowski, 2013). The GR belongs to the nuclear receptor superfamily, which are mostly ligand-inducible transcription factors 
(Baschant and Tuckermann, 2010, Stahn and Buttgereit, 2008, Rhen and Cidlowski, 2005). It is structured in three domains: an N-terminal transactivation domain (NTD), a central DNA binding domain (DBD) and a C-terminal ligand binding domain (LBD). A flexible hinge region is located between the DBD and LBD. The NTD contains an activation function domain (AF-1), which facilitates the recruitment and direct cooperation of other transcription factors or co-factors (Strehl and Buttgereit, 2013). The LBD, with its $12 \alpha$-helices and $4 \beta$-strands, can form a hydrophobic-ligand binding pocket for GCs and additionally contains a second AF (AF-2). The LBD undergoes conformational changes upon ligand-binding, enabling the interaction of co-activator or co-repressor with the AF-2 domain. Two nuclear localization signals (NL) are located within the LBD. The DBD is a highly conserved region containing two zinc-finger domains allowing a homodimerization of the GR and the interaction with target DNA sequences, so called glucocorticoid responsive elements (GREs) (Oakley and Cidlowski, 2013, Stahn and Buttgereit, 2008, Strehl and Buttgereit, 2013). In the absence of a ligand, the GR stays in the cytoplasm forming a multiprotein complex with heatshock proteins (hsp), such as hsp 90 , hsp 70, hsp 56 or hsp 40 , immunophilins, such as FKBP51 or FKBP52, co-chaperons such as p23 or Srk, or various kinases of the mitogen-activated protein kinase (MAPK) pathway preventing its degradation. GCs can bind with high affinity to the fully disposable ligand-binding site after having passed the cell membrane owing to their hydrophobic structure. Upon ligand-binding, the GR undergoes a conformational change and the multiprotein complex dissociates, leading to the exposure of the NL and consequently to the translocation into the nucleus (Stahn and Buttgereit, 2008, Strehl and Buttgereit, 2013).

Transcription of target genes can either be activated or repressed via three mechanisms (Figure 3). First, direct DNA binding to GREs; second, indirect binding mediated via tethered transcription factors; third, direct DNA-binding, while interacting with nearby DNA-bound "composite" transcription factors (Cruz-Topete and Cidlowski, 2015). The first mechanism involves GR homodimers usually activating gene transcription by the recruitment and interaction of co-activators mediating chromatin remodeling and RNA II 
polymerase activity (Barnes, 2011). As a consequence, anti-inflammatory proteins, for instance IL-10, or proteins involved in metabolic processes, for example in gluconeogenesis, such as phosphoenolpyruvate carboxylase (PEPCK) and tyrosine aminotransferase (TAT), are expressed (Reichardt and Schutz, 1998, Strehl and Buttgereit, 2013). GR homodimers can also bind to negative GREs (nGRE) repressing transcription of target genes by the recruitment of cis-acting co-repressors (Vandevyver et al., 2013, Surjit et al., 2011). The other two mechanisms involve GC monomers. Tethering of the GR with transcription factors, such as nuclear factor $\mathrm{KB}(\mathrm{NF}-\mathrm{kB})$ or activator protein 1 (AP-1), leads to transcriptional repression of pro-inflammatory genes (Barnes, 2011, Cruz-Topete and Cidlowski, 2015). This is due to alterations in the DNA-binding capacity of the partnering transcription factors or an interference with the recruitment of co-regulators and/ or the transcriptional machinery. In general, GC monomers can control transcriptional activation and repression (Cruz-Topete and Cidlowski, 2015, Cain and Cidlowski, 2017). Beside genomic mechanisms, GC effects can also be achieved within seconds to minutes by non-genomic mechanisms (Kadmiel and Cidlowski, 2013). They can occur due to the binding to a postulated membrane-bound GR, the classical cytosolic GR or via GR-independent mechanisms, such as by binding to cellular membranes. The former two mechanisms are thought to be controlled by the interaction with kinases acting in signal transduction pathways, such as the ERK pathway (Cruz-Topete and Cidlowski, 2015). In contrast, interaction with cellular membranes is thought to influence the cellular metabolism by interfering with cation transport through plasma membranes (Buttgereit and Scheffold, 2002). The non-genomic mechanisms are less well studied, but may still participate in pharmacological and physiological GCs effects (Ayroldi et al., 2012). The expression of different GR isoforms, posttranscriptional GR modifications, including phosphorylation, sumoylation, ubiquitination, acetylation or methylation and differences in chromatin accessibility or expression of different GR cofactors impact the transcriptional activity of GCs as well. Consequently, these factors influence GC sensitivity and specificity, which differs between cell types and contributes to the complexity in GC signaling (Duma et al., 2006, Franco et al., 2019). 


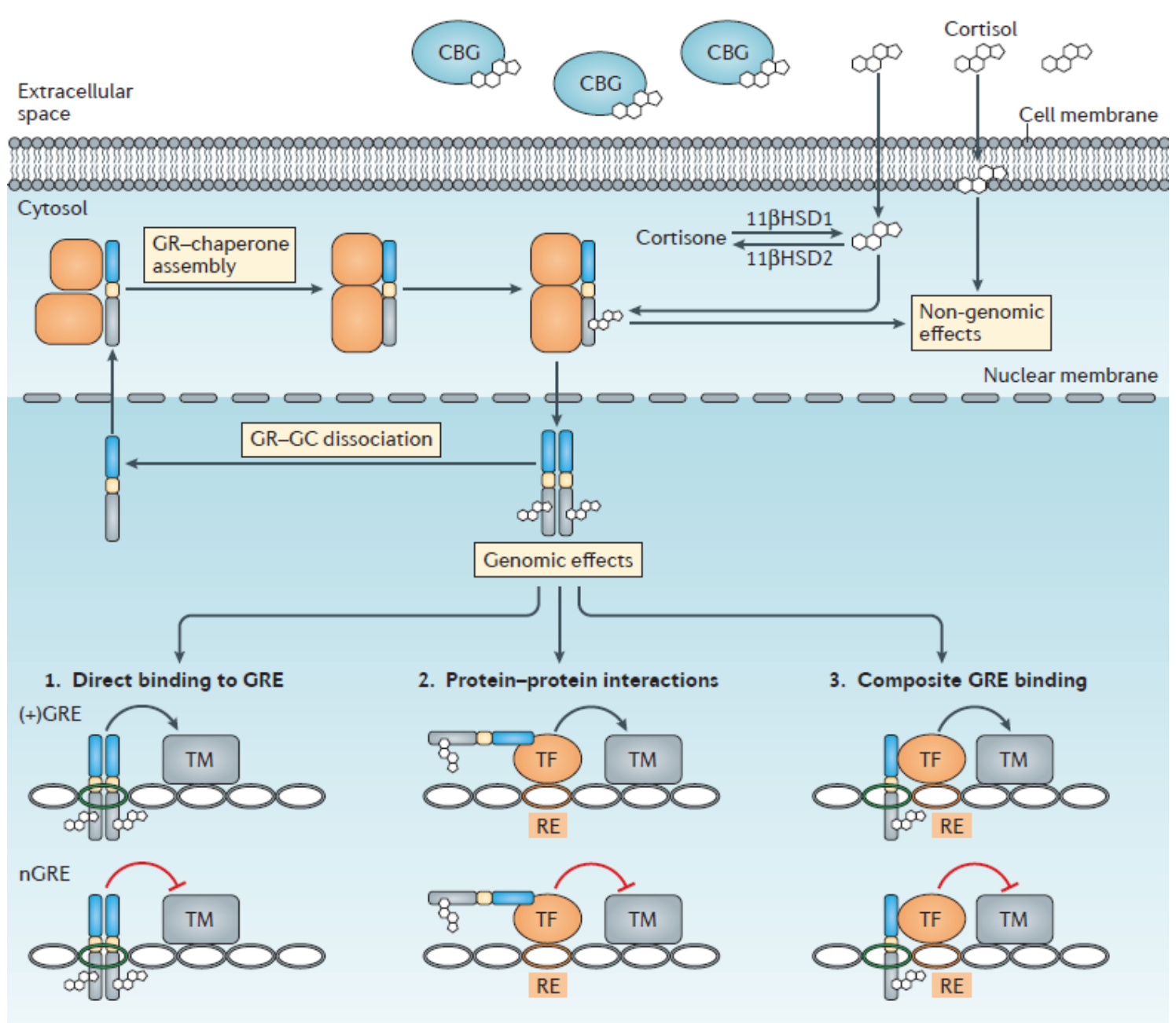

Figure 3: Genetic mechanisms of glucocorticoids. In the extracellular space, corticosteroidbinding globulin (CBG) binds to glucocorticoids, thereby keeping it in an inactive state. Free cortisol can diffuse through the cell membrane, here it can be converted by $11 \beta-\mathrm{HSD} 1$ into cortisone and vice versa by $11 \beta-\mathrm{HSD} 2$, and in addition cortisol can exert non-genomic functions. Moreover, cortisol can bind to the glucocorticoid receptor (GR)-chaperon assembly which leads to the disassembly of the multiproteins from the GR, allowing its translocation into the nucleus. Here it controls positive and negative gene regulation via three distinct mechanisms. First: via direct binding to glucocorticoid responsive elements $((+) G R E)$ or negative-GRE (nGRE). Second: via protein-protein interactions with transcription factors (TF) thereby controlling their transcriptional activity. Third: via composite binding to DNA and TF. All mechanisms regulate in the end the transcriptional machinery (TM); responsive elements (RE) (Cain and Cidlowski, 2017).

\subsubsection{GC effects on immune cells}

GC therapy is a common medication to treat inflammatory diseases, including aGvHD (Garnett et al., 2013). For a long time, the immunosuppressive effects of GCs have been predominantly attributed to the diminished $T$ cell activation and T cell depletion (Almawi et al., 1996). However, nowadays it is well known that GCs manipulate many other cells types within the immune system network, 
too (Franchimont, 2004). In the following, GC actions will be summarized in selected cell types that play a major role in the initiation and establishment of aGvHD.

GCs have an impact on DCs at various stages. DCs first need to process antigens upon uptake and then to receive co-stimulatory signals to mature. GCs promote antigen uptake by increasing the endocytic activity, but DCs are also kept in a more immature state, thus preventing their activation and consequently inhibiting their capacity to stimulate T cells (Piemonti et al., 1999b, Piemonti et al., 1999a). This can be explained by a reduced expression of MHC II, co-stimulatory molecules such as CD86 or CD80 and pro-inflammatory cytokines such as TNFa or IL-12, as well as an increased production of the anti-inflammatory cytokine IL-10 (Matyszak et al., 2000, Kitajima et al., 1996, Moser et al., 1995, Li et al., 2015, Rozkova et al., 2006). Phenotypical changes associated with this skewed development have also been described in DCs treated with GCs during the maturation process and in mature DCs after GC treatment (Rozkova et al., 2006, Butts et al., 2007, Rea et al., 2000). As IL-12 is critical in the development of Th1 cells and IL-10 for the development of Th2 cells during the antigen presentation process, GCs promote humoral immunity (Elenkov, 2004). Furthermore, GCs arrest DCs in an undifferentiated state, which thereby acquire tolerogenic properties. Hence, they induce a state of anergy in naïve $T$ cells and contribute to the maintenance of naturally occurring Tregs (Emmer et al., 2006, Unger et al., 2009). In addition, the number of mature DCs, but not immature DCs is reduced by high-dose GCs, as they are susceptible to GC-induced apoptosis (Cao et al., 2013). Finally, the tissue distribution of DCs is altered by GCs due to a reduced migration towards the lymph nodes via downregulation of the chemokine CCL7 (Vizzardelli et al., 2006).

Monocytes have the basic capacity to differentiate into highly specialized macrophage populations within the target tissue dependent on environmental stimuli (Murray et al., 2014, Laskin, 2009). Initially, they have been grouped into two categories. The first one are "classically activated" M1 macrophages. They 
are activated by pro-inflammatory stimuli such as DAMPs, PAMPs, TNF $\alpha$, IL-1 $\beta$ or IL-6 and display a cytotoxic inflammatory phenotype. M1 macrophages are crucial in the early phase of inflammation, as they are highly effective in destroying pathogens and recruiting immune cells to the site of infection. However, excessive activation of this phenotype can lead to pathological tissue destruction supported by their release of inflammatory mediators. The second category are anti-inflammatory, so called "alternative activated" M2 macrophages. They suppress inflammatory responses and participate in the resolution of inflammation, wound healing and angiogenesis (Martinez et al., 2008, Laskin, 2009, Roszer, 2015). GCs inhibit apoptosis in monocytes and polarize them towards an M2 state (Pemmari et al., 2019, Barczyk et al., 2010). GC-initiated gene programs increase the capacity of macrophages for phagocytosis, promote the clearance of apoptotic cells and debris, which in turn prevents the release of cytotoxic granule contents and pro-inflammatory cytokine production (Giles et al., 2001, Ehrchen et al., 2007, Liu et al., 1999). Examples, and at the same time hallmarks of M2 macrophages, are the enhanced expression of scavenger receptors and mannose receptors such as CD163 and CD206, respectively (Ehrchen et al., 2007, Hogger et al., 1998, Heideveld et al., 2018). Furthermore, GCs trigger the secretion of the anti-inflammatory cytokine IL-10 and TGF $\beta$ (Mozo et al., 2004, Ehrchen et al., 2007). In turn, the release of pro-inflammatory cytokines, such as IL-1 $\beta$, TNFa, IL-6 or IL-12, hallmarks for M1 macrophages, are repressed (Tuckermann et al., 2005). Moreover, the synthesis of inducible nitric oxide synthase (iNOS) and its product nitric oxide (NO) are diminished. GCs suppress nicotinamide adenine dinucleotide phosphate (NADPH) oxidase, thus the synthesis of free oxygen radicals is reduced. The synthesis of eicosanoids, lipid mediators acting as vasodilator and permeably vessels, secreted by macrophages located in inflamed tissues, is inhibited, for example by preventing the expression of cyclooxygenase 2 or phospholipase 2 (Tuckermann et al., 2005, Franchimont, 2004, Cain and Cidlowski, 2017). Also the migration of inflammatory monocytes is repressed due to a GC-mediated decrease in the expression of the chemokine receptor CXCR31 and decreased production of the chemokine CCL-2 (Pachot et al., 2008, Kim et al., 2001). In contrast, it was demonstrated 
that GCs lead to an increased migration of anti-inflammatory monocytes to inflammatory sites (Ehrchen et al., 2007).

T cells are affected by GCs in many ways. Their phenotype is shifted from a Th1 towards a Th2 state, mainly by GC-induced effects on DCs and macrophages leading to a diminished IL-12 secretion, which is further promoted by their enhanced IL-10 secretion (Blotta et al., 1997, Matyszak et al., 2000, Franchimont, 2004). Consequently, less IFNy and more IL-4 is production by Th1 and Th2 cells, respectively. These effects are further strengthened by the autocrine feedback loop of these cytokines (Elenkov, 2004, Arya et al., 1984). However, GCs can also directly act on T cells as IL-4 mRNA expression is induced upon GC stimulation in naïve $T$ cells and they become unable to respond to IL-12, the former effect being restricted to physiological GC concentrations (Ramirez et al., 1996, Fahey et al., 2006). Furthermore, Th1 development is inhibited at the transcriptional level by interfering with the Th1 transcription factor T-bet. It is worth mentioning that pharmacological GC concentrations suppress Th2 cytokines by regulating the transcription factor GATA-3 (Liberman et al., 2009), although it is the common understanding that GCs ultimately favor a Th2 phenotype (Ashwell et al., 2000). Besides controlling mature $\mathrm{T}$ cells, thymocytes are particularly sensitive to GC-induced apoptosis, even at physiological concentrations (Gruber et al., 1994, Cohen and Duke, 1984). This can be overcome by interactions of the co-stimulatory molecules CD28 and CTLA-4 with B7-1 or B7-2, independent of TCR ligation (Wagner et al., 1996) and also cytokines, such as IL-2 and IL-4 (Zubiaga et al., 1992). One mechanism which explains the different GC-sensitivities within $T$ cell subpopulations is the protective effect of the anti-apoptotic protein $\mathrm{Bcl}-2$ present in $\mathrm{CD}^{+}$and $\mathrm{CD}^{+}$, but not in double-positive (DP) thymocytes (Hockenbery et al., 1991). In addition, through GC regulation of Bcl-2 at the post-transcriptional level, by for example micro RNAs, Th2 and Th17 cells are more resistant to GC-induced apoptosis than Th1 cells (Banuelos et al., 2016). Tregs express high levels of Bcl-2 and upon GC treatment, also higher levels of CTLA-4 and are therefore less susceptible to GC-induced cell death (Chen et al., 2004, Chen et al., 2018). There is even one report claiming that GCs induce Tregs 
with immune regulatory functions (Karagiannidis et al., 2004). The mechanisms of how GCs induce immunosuppressive functions, as mentioned here, are not yet completely understood, but they explain why GCs are such a powerful drug in regard to the treatment of aGvHD.

\subsubsection{GC-induced side-effects}

GCs have potent immunosuppressive activities, but they also have pleiotropic functions in regulating essential biochemical and physiological processes within the body (Oray et al., 2016). Hence, successful GC therapy is limited by inducing a wide range of side-effects. The reason for this is the ubiquitous expression of the GR acting in a context-specific pattern. Statistically, about $0.5-1 \%$ of the human population is treated with GCs and the limitations of GC therapy thus represent a major problem. Side-effects can range from cosmetic issues to more severe life-threatening forms. The development of side-effects and the therapeutic efficacy are often interdependent. Both criteria are dependent on multiple factors including drug type, dosage, duration, timing and route of application, individual susceptibility as well as the history of the patient (Petta et al., 2019). Nevertheless, the side-effects need to be considered individually in regard to the risk factors, but it is overall accepted that long-term administration represents the highest risk factor, followed by high dose application (Schacke et al., 2002).

One important side-effect is myopathy. It is characterized by a reduction in muscle fibers due to a decreased rate of protein synthesis and an increased rate of protein breakdown. The underlying mechanisms are complex, ranging from reduced amino acid transport, negative intervention with the protein synthesis machinery to the augmented activity of the proteolytic system (Schakman et al., 2008, Schakman et al., 2013, Klein, 2015). Muscle fiber types show different sensitivities towards GCs. Hence, predominantly fast-twitch, particularly type IIx and IIb muscle fibers are affected, making glycolytic muscles e.g. the musculus gastrocnemius (M. gastrocnemius) more vulnerable than oxidative muscles e.g. the M. soleus (Fournier et al., 2003, Dekhuijzen et al., 1995). Nevertheless, as GCs trigger peripheral and respiratory muscle 
weakness, this side-effect strongly reduces the quality of life of the patients (Schakman et al., 2013).

Another meaningful side-effect is GC-induced osteoporosis (GIO), which is the most common form of secondary osteoporosis. About $30-50 \%$ of these patients will experience a fracture, occasionally asymptomatic fractures (Canalis et al., 2007). Pathogenic hallmarks of GIO are a reduced bone formation rate and an increase in bone resorption as a consequence of the altered gene expression. This can be explained by the observation that GCs impair osteoblast function, differentiation and proliferation, induce apoptosis in osteocytes, and that they lead to an intensified osteoclastogenesis combined with a prolonged osteoclasts life-span (Delany et al., 1995, Jia et al., 2006, O'Brien et al., 2004, Canalis, 2005). Noteworthy, experiments conducted by Rauch et al. demonstrated the importance of the GR in osteoblasts rather than in osteoclasts in regard to bone loss (Rauch et al., 2010). Besides that, all three cell types have distinct functions, which are tightly coordinated and orchestrated by cytokines, growth factors and hormones. GC application can alter these signals in the bone microenvironment, both by direct and indirect mechanisms, thereby contributing to the disruption of the physiological bone metabolism (Moutsatsou et al., 2012).

One more frequent and severe GC-induced side-effect is type II diabetes, which is the consequence of an impaired glucose homeostasis. About $40 \%$ of organ transplanted patients, receiving GCs, develop the so called post-transplant diabetes mellitus (Onwubalili and Obineche, 1992). The crucial role of GCs in this disease can be concluded from the fact that patients show an improvement upon GC withdrawal (Everson et al., 1999). GCs increase the synthesis of glucose, mainly mediated via the transactivation of enzymes involved in gluconeogenesis. Upon enhanced glucose synthesis, glycogen synthase is activated by GCs which is then stored in the liver. Insulin and GCs are opponents. Insulin prevents gluconeogenesis and triggers the uptake of glucose in insulin-sensitive tissue such as liver, skeletal muscle and adipose tissue, thereby reducing the blood glucose level. However, excess of exogenous GC 
causes pancreatic $\beta$-cell dysfunction and alters the insulin-sensitivity in the respective tissue leading to glucose and insulin intolerance. Thus, hyperglycemia and hyperinsulinemia are the consequence of this destructed feedback loop (Pasieka and Rafacho, 2016).

\subsection{Targeted therapy of GCs}

GCs have been used in the clinics, to treat inflammatory diseases already before their mode of action was explored in more detail. About 7 decades of intensive research improved our knowledge and revealed the complexity of GC actions. As mentioned earlier, it operates in a cell type specific manner and is influenced by physiological processes within the body. Hence, it is not surprising that systemic long-term and high-dose applications of synthesized GCs, with its unspecific distribution within the organism has major drawbacks, namely the induction of life-threatening side-effects and GC resistances (Vandewalle et al., 2018). One possibility to overcome these hurdles is to increase the specificity of GCs by packaging them into carrier systems. Ideally, they fulfill the needs of being biocompatible, biodegradable, having prolonged biological life-times and are released at restricted sites and in cells of interests. These goals can be potentially achieved by using liposomes or nanoparticles (Luhder and Reichardt, 2017). Liposomes (LP) are phospholipid bilayer vesicles typically with a size of about $100 \mathrm{~nm}$ that can encapsulate hydrophobic and hydrophilic structures. Additionally they are often modified by a "shield" of polyethylene glycerol (PEG) preventing the opsonization of plasma proteins and consequently its phagocytic elimination (Alavi et al., 2017). Prednisolone phosphate loaded PEG-LPs were proven to be highly successful in an experimental rat model of arthritis when provided by a single i.v. injection and resulted in a complete remission of inflammatory symptoms due to the preferential delivery to the inflamed joints (Metselaar et al., 2003). Moreover, prednisolone loaded PEG-LPs improved the course of EAE (experimental autoimmune encephalitis), a well-established rodent model for multiple sclerosis (MS), and was superior to a 5-fold higher dose of free methylprednisolone most likely also due to specific drug targeting (Schmidt et al., 2003). Further support of enhanced efficiencies of GC-loaded PEG-LPs derives from EAE studies 
carried out in chronic demyelination models (Linker et al., 2008). This is in line with the study by Schweingruber et al., suggesting that GC-loaded LPs are not simply accumulating at the site of interests, but that they also show an altered mode of action compared to free GCs that mainly act on $T$ cells during $E A E$ therapy. In contrast, LPs are taken up by phagocytes, such as macrophages, thereby inducing an M2-like phenotype. Nevertheless, the GR in macrophages and $\mathrm{T}$ cells was required for a successful therapy with GC-loaded LPS, suggesting that this new delivery vehicle was not entirely cell type specific (Schweingruber et al., 2011). Taken together, these examples show the great potential of GC-loaded LPs in the treatment of inflammatory diseases. A number of LP-based drug formulations are available on the market, but none of them loaded with GCs (Bulbake et al., 2017). One complication of a therapy with LPs is that they are able to trigger the activation of the complement system leading to a "pseudoallergy" and upon reencounter to its rapid clearance (Sercombe et al., 2015, Luhder and Reichardt, 2017).

Nanoparticles (NPs) as a carrier system are another possibility for targeted therapies. Most organic nanoparticle formulations have the advantage to be approved by the FDA due to the use of biodegradable reagents. One example is the widely used polymer poly(lactic-co-glycolic acid) PLGA, which is processed by the body, therefore avoiding the risk associated with bioaccumulation. To increase its target specificity even antibodies can be linked to it (Castillo et al., 2018). In terms of GC-targeted therapy, betamethasone sodium phosphate (BSP) encapsulated in PLGAs has been demonstrated to be highly effective in an animal model for arthritis also due its slow release and target delivery but still, also no GC-loaded PLGA formulations are on the market so far (Higaki et al., 2005). Inorganic nanoparticles are another option though only biocompatible agents, suitable for magnetic resonance images (MRI) are FDA approved. Furthermore, inorganic drug carriers are often associated with low drug loads (Luhder and Reichardt, 2017, Castillo et al., 2018). To overcome this issue, Heck et al. developed a novel material concept of inorganic-organic hybrid nanoparticles (IOH-NP). In brief, they are composed of an inorganic cation, for instance zirconium oxide $\left[\mathrm{ZrO}^{2+}\right]$ and an equimolar amounts of 
functional organic anions, functionalized with a phosphate group, for example betamethasone phosphate (BMP). Different organic anions can be fused, by this combining different properties, such as drug release, fluorescence e.g. flavinmononucleotide (FMN) or serving as a contrast agent, the former being suitable for flow cytometry and the later for MRI studies. The inorganic cation enables a synthesis in aqueous solutions while it converts the NPs into an insoluble compound. IOH-NPs have a hydrodynamic diameter of $30-40 \mathrm{~nm}$, an optimal size for active uptake, and an enormous drug load of up to $90 \mathrm{wt} \%$ (Heck et al., 2015, Shang et al., 2014). Former studies did not provide any indications for cytotoxic effects of IOH-NPs and demonstrated a cell-type specificity towards macrophages, most likely due to their size. Furthermore, $\mathrm{IOH}-\mathrm{NPs}$ loaded with BMP led to a reduction of pro-inflammatory cytokine secretion in vitro and an improvement of EAE symptoms while being as potent as free dexamethasone in vivo (Montes-Cobos et al., 2017, Heck et al., 2015). Findings reported by Nishiwaki et al. let assume that GC-targeted therapy towards macrophages is attractive in the setting of aGvHD, as they administered macrophage engulfing dexamethasone palmitate (DP), a liposteroid in an aGvHD mouse model thereby attenuating disease progression and mortality (Nishiwaki et al., 2014). In conclusion, IOH-NPs might represent a promising targeted therapeutic strategy in order to treat aGvHD while being more tolerable in comparison to systemic applied GCs.

\subsection{Objectives}

Acute GvHD is a severe life-threatening complication, which compromises the success of HSCT. Administration of GCs is the golden standard and first-line therapy owing to their anti-inflammatory and immunosuppressive actions. However, they often trigger severe unwanted side-effects and GC resistances, which might develop upon long-time and/ or at high-dose administration. This is explained by the fact that systemically applied GCs act in an unspecific manner as they can bind to the ubiquitously expressed GR. In order to overcome this hurdle the targeted delivery of GCs to specific organs and cells types of interest would be a possible solution. Analyses of pathophysiological mechanisms of aGvHD, have helped us to identify the major cellular actors. It turned out that 
not only T cells, but also other cells such as DCs or macrophages, with their broad spectrum of phenotypes, play a major role in the course of the disease. Previous results further indicate a high cell-type specificity of $\mathrm{IOH}-\mathrm{NPs}$ towards macrophages. This thesis therefore aimed to define the role of the $\mathrm{GR}$ in recipient myeloid cells and to clarify whether $\mathrm{IOH}-\mathrm{NP}$ therapy is beneficial in the context of aGvHD. To address these issues the thesis is subdivided into five parts.

- The first part investigated effects of endogenous GCs and their relevance in radioresistant recipient myeloid cells in the context of aGvHD by using mice lacking the GR in this particular cell type.

- The second part intended to gain a better understanding of the cell-type specificity, toxicity, cellular uptake mechanism and intracellular fate of $\mathrm{IOH}-\mathrm{NPs}$ being a possible carrier system for the targeted delivery of GCs in aGvHD therapy.

- The third part focused on the organ distribution of $1 \mathrm{OH}-\mathrm{NPs}$ after intraperitoneal (i.p.) injection into mice as a basis for their possible therapeutic application in aGvHD.

○ The fourth part addressed the therapeutic efficiency of $1 \mathrm{OH}-\mathrm{NPs}$ loaded with betamethasone in the treatment of aGvHD in wild type mice in comparison to free GC. Furthermore, the cell type specificity of this therapy was investigated using again mice, lacking the GR in myeloid cells.

- The fifth part was dedicated to the question of whether GC-induced side-effects could be circumvented by the application of $\mathrm{IOH}-\mathrm{NPs}$ loaded with betamethasone. 


\section{Material \& Methods}

\section{$2.1 \quad$ Material}

\subsubsection{Instruments}

If not otherwise declared, the supplier is located within Germany.

Table 1: Instruments

\section{Equipment}

Akku-jet ${ }^{\Theta}$ pro pipette controller

Animal Respirator Advanced

\section{Supplier}

Brand $\mathrm{GmbH}$, Wertheim

TSE, Technical \& Scientific Equipment

GmbH, Bad Homburg

Axio Scope A1

Zeiss, Jena

Axio Scope Aplus

Zeiss, Jena

Balance MC1 RC 210P-OD1

Sartorius, Göttingen

BD FACS Canto II

BD Biosciences, Heidelberg

BioTek ${ }^{\circledR}$ Power Wave 340 plate reader BioTek Instruments, Wetzlar

Centrifuge 2-5

Sigma Laborzentrifugen, Osterode

Centrifuge 5417R

Eppendorf, Hamburg

Centrifuge 5804-R

Eppendorf, Hamburg

Confocal Laser scanning microscope

Leica, Wetzlar

TCS SP2

CONTOUR ${ }^{\mathrm{TM}}$ Next, Ascencia Blood

Bayer Healthcare AG, Leverkusen

Glucose Monitoring System

CONTOUR $^{\mathrm{TM}}$, Ascencia Blood

Bayer Healthcare AG, Leverkusen

Glucose Meter

\section{EasyPet 3}

EasySep ${ }^{\mathrm{TM}}$ Magnet

Eppendorf, Hamburg

STEMCELL Technologies, SARL, Cologne

Electrophoresis power supply 301

Freezer Hera freeze $-80^{\circ} \mathrm{C}$

Amersham Biosciences, Freiburg

Freezer Liebherr Comfort $-20^{\circ} \mathrm{C}$
Heraeus, Hanau

Liebherr-International Deutschland

$\mathrm{GmbH}$, Biberach an der Riss 


\begin{tabular}{|c|c|}
\hline Freezer VIP plus $-150^{\circ} \mathrm{C}$ & $\begin{array}{l}\text { SANYO Electric Co., Ltd., Moriguchi, } \\
\text { Osaka, Japan }\end{array}$ \\
\hline $\begin{array}{l}\text { ImageStream }{ }^{\Theta} \text { X Mark II Imaging Flow } \\
\text { Cytometry }\end{array}$ & Merck KGaA, Darmstadt \\
\hline Incubator, HERACell 240 & Heraeus, Hanau \\
\hline Infrared lamp Balance 100W & Philips, Amsterdam, Netherlands \\
\hline Laminar airflow cabinet, HERASafe & Heraeus, Hanau \\
\hline Microscope Primo Star & Zeiss, Jena \\
\hline Microscope Telaval 31 & Zeiss, Jena \\
\hline Microtom SM2000R & Leica Biosystems, Wetzlar \\
\hline Microwave R-212 & Sharp, Osaka, Japan \\
\hline Multichannel pipette S-12, 20-200 $\mu \mathrm{l}$ & Brandt, Wertheim \\
\hline Neubauer improved haemocytometer & $\begin{array}{l}\text { Henneberg-Sander GmbH, Giessen- } \\
\text { Lützellinden }\end{array}$ \\
\hline Nunc $^{T M}$ Immuno Wash 12 & $\begin{array}{l}\text { Thermo Fisher Scientific, Wilmington, } \\
\text { DE, USA }\end{array}$ \\
\hline pH-Meter 766 Calimatic & $\begin{array}{l}\text { Knick Elektronische Messgeräte } \\
\text { GmbH \& Co. KG, Berlin }\end{array}$ \\
\hline Photometer Nanodrop 2000 & Peqlab Biotechnology, Erlangen \\
\hline $\begin{array}{l}\text { Pipettes Eppendorf Research plus } \\
2.5 \mu \mathrm{l}, 20 \mu \mathrm{l}, 200 \mu \mathrm{l}, 1000 \mu \mathrm{l}\end{array}$ & Eppendorf, Hamburg \\
\hline Real-Time PCR System 7500 & $\begin{array}{l}\text { Applied Biosystems, Foster City, CA, } \\
\text { USA }\end{array}$ \\
\hline Rectal Probe, BIO-BRET-3 & Bioseb, Vitrolles, France \\
\hline Rodent thermometer BIO-TK8851 & Bioseb, Vitrolles, France \\
\hline Rotilabo ${ }^{(}$-mini-centrifuge & Carl Roth GmbH \& Co.KG, Karlsruhe \\
\hline RS 225 X-Ray Research System & $\begin{array}{l}\text { Gulmay Medical Systems, Camberley, } \\
\text { Surrey, UK }\end{array}$ \\
\hline Scale Acculab ALC-3100.2 & Sartorius, Göttingen \\
\hline Scale TE313S & Sartorius, Göttingen \\
\hline Shaker GFL 3006/ 3005 & $\begin{array}{l}\text { Gesellschaft für Labortechnik, } \\
\text { Burgwedel }\end{array}$ \\
\hline
\end{tabular}


Thermocycler Mastercycler EP Eppendorf, Hamburg

Gradient

Thermomixer Comfort Eppendorf, Hamburg

Tissue Homogenizer Ultra Turrax T18 IKA, Staufen

Basic

Tissue Processor Excelsior ES Thermo Fisher Scientific, Wilmingon, DE, USA

Tissue Tek Prisma Slide Stainer Sakura Finetek. Staufen

UV System with camera and gel INTAS, Science Imaging Instruments imager (Chemostar) GmbH, Göttingen

VARIOMAG ${ }^{\circledR}$ Power direct magnetic stirrer Thermo Fisher Scientific, Waltham,

Vortex Genie-2 USA

\begin{tabular}{ll} 
& Scientific Industries, Bohemia, New \\
Water bath W12 & Labortechnik Medingen, Dresden \\
Water Purification System Arium Pro & Sartorius, Göttingen \\
\hline
\end{tabular}

\subsubsection{Consumables}

Table 2: Consumables

\section{Consumable}

6-well, 12-well, 24-well Suspension

Culture Plates Cellstar

BD Falcon ${ }^{\mathrm{TM}} 5 \mathrm{ml}$ Polystrene Round-

Bottom Tube with Cell-Strainer Cap

BD Micro-Fine ${ }^{\mathrm{TM}}+$ Demi U-100 Insulin

Syringes $(0.3 \mathrm{ml}, 30 \mathrm{G})$

BD Microlance ${ }^{\mathrm{TM}} 3$ (20G 1.5“)

BD Microtainer ${ }^{(} \mathrm{SST}^{\mathrm{TM}}$ tubes

CELLSTAR Culture Flasks $75 \mathrm{~cm}^{2}$, $175 \mathrm{~cm}^{2}$

CELLSTAR PS $100 \times 20 \mathrm{~mm}$ Cell Culture Dishes

\section{Supplier}

Greiner bio-one $\mathrm{GmbH}$, Frickenhausen

BD Biosciences, Heidelberg

BD Biosciences, Heidelberg

BD Biosciences, Heidelberg BD Biosciences, Heidelberg

Greiner bio-one $\mathrm{GmbH}$, Frickenhausen Greiner bio-one $\mathrm{GmbH}$, Frickenhausen 
CELLSTAR $^{\circledR}$ serological pipettes

$5 \mathrm{ml}, 10 \mathrm{ml}, 25 \mathrm{ml}$

CONTOUR NEXT ${ }^{\circledR}$ Test stripes

CONTOUR $^{\circledR}$ Test stripes

Cover glas bottom 1.0 Imaging dishes

CryoTube ${ }^{\mathrm{TM}}$ Vials

EASYstrainer $^{\mathrm{TM}}(40 \mu \mathrm{m})$

Falcon 5 ml Polystrene Round-Bottom

Tube, non-sterile

Falcon tubes $15 \mathrm{ml}, 50 \mathrm{ml}$

Filter paper 66 × $24 \mathrm{~mm}$

Glas pipettes $10 \mathrm{ml}, 25 \mathrm{ml}$

Hypodermic needle Sterican ${ }^{\circledR}$

$26 G \times 0.5 “, 24 G \times 1 “$

Labsolute ${ }^{\circledR}$ Pasteur pipettes $3 \mathrm{ml}$

Microscope Cover Slips, 24 × 60 mm

Microscope Slides SuperFrost Plus

Nitril $\left.{ }^{(}\right)$Next Gen $\left.{ }^{(}\right)$single-use gloves

Nunc-Immuno ${ }^{\mathrm{TM}}$ MicroWell $^{\mathrm{TM}} 96$ well

solid plates, flat bottom

Optical Adhesive Covers

Parafilm

PCR reaction tube Multiply ${ }^{(}-\mu$ Strip

Pro 8-Strip

Pipette tips, $2.5 \mu \mathrm{l}, 200 \mu \mathrm{l}, 1000 \mu \mathrm{l}$

PP Tube sterile $14 \mathrm{ml}$

Reaction tubes, $1.5 \mathrm{ml}, 2 \mathrm{ml}$

Saphire Microplate, 96 well, natural for Greiner bio-one $\mathrm{GmbH}$, Frickenhausen PCR

Syringe BD Discardit $^{\mathrm{TM}} \mathrm{II}, 2 \mathrm{ml}, 5 \mathrm{ml}$

Tissue Cassettes MacrOflow
Greiner bio-one $\mathrm{GmbH}$, Frickenhausen

Bayer Vital GmbH, Leverkusen

Bayer Vital GmbH, Leverkusen

Zell-Kontakt, Nörten-Hardenberg

Nunc, Roskilde, Denmark

Greiner bio-one $\mathrm{GmbH}$, Frickenhausen

Th. Geyer GmbH \& Co. KG,

Renningen

Greiner bio-one $\mathrm{GmbH}$, Frickenhausen

DiaTec, Bamberg

Brand $\mathrm{GmbH}$, Wertheim

B Braun, Melsungen

Th. Geyer GmbH \& Co. KG,

Renningen

Menzel-Gläser, Braunschweig

Menzel-Gläser, Braunschweig

Meditrade ${ }^{\circledR}$, Kiefersfelden

eBioScience, San Diego, USA

Applied Biosystems, Foster City, USA

Sarstedt, Nümbrecht

Greiner bio-one $\mathrm{GmbH}$, Frickenhausen

Greiner bio-one $\mathrm{GmbH}$, Frickenhausen

Greiner bio-one $\mathrm{GmbH}$, Frickenhausen

BD Biosciences, Heidelberg

Th. Geyer GmbH \& Co. KG,

Renningen
Bemis, Neeth, WI, USA 


\subsubsection{Chemicals and Reagents}

Table 3: Chemicals and Reagents

\begin{tabular}{|c|c|}
\hline Chemical/ Reagent & Supplier \\
\hline 3, 3', 5, 5'-Tetramethylbenzidin & $\begin{array}{l}\text { Sigma-Aldrich Chemie } \mathrm{GmbH} \text {, } \\
\text { Taufkirchen }\end{array}$ \\
\hline Acetic acid Rotipuran $100 \%$ p.a. & Carl Roth GmbH \& Co.KG, Karlsruhe \\
\hline Ammonium chloride & Merck KGaA, Darmstadt \\
\hline BD FACS Clean Solution & BD Biosciences, Heidelberg \\
\hline BD FACS Flow Sheath Fluid & BD Biosciences, Heidelberg \\
\hline BD FACS Shutdown Solution & BD Biosciences, Heidelberg \\
\hline $\begin{array}{l}\text { Betamethasone phosphate } \\
\text { nanoparticles }\end{array}$ & $\begin{array}{l}\text { Prof. Dr. Klaus Feldmann, Institute for } \\
\text { anorganic chemistry KIT, Karlsruhe }\end{array}$ \\
\hline Bovine serum albumin & Carl Roth GmbH \& Co.KG, Karlsruhe \\
\hline Celestan soluble $4 \mathrm{mg} / \mathrm{ml}$ & MSD Sharp \& Dohme GmbH, Haar \\
\hline Chloroform & $\begin{array}{l}\text { Sigma-Aldrich Chemie } \mathrm{GmbH} \text {, } \\
\text { Taufkirchen }\end{array}$ \\
\hline Citric acid & Carl Roth GmbH \& Co.KG, Karlsruhe \\
\hline Dimethylsulfoxid 99.8 \% Rotipuran p.a. & Carl Roth GmbH \& Co.KG, Karlsruhe \\
\hline Disodium hydrogen phosphate & Carl Roth GmbH \& Co.KG, Karlsruhe \\
\hline Dithiothreitol & $\begin{array}{l}\text { Sigma-Aldrich Chemie } \mathrm{GmbH} \text {, } \\
\text { Taufkirchen }\end{array}$ \\
\hline Empty nanoparticles & $\begin{array}{l}\text { Prof. Dr. Klaus Feldmann, Institute for } \\
\text { anorganic chemistry KIT, Karlsruhe }\end{array}$ \\
\hline Ethanol Rotipuran 99.8 \% p.a. & $\begin{array}{l}\text { Carl Roth GmbH \& Co.KG, Karlsruhe, } \\
\text { Chemsolute }^{\circledR} \text { Th. Geyer GmbH \& Co. } \\
\text { KG, Renningen }\end{array}$ \\
\hline Ethidiumbromide solution $1 \%$ in $\mathrm{H}_{2} \mathrm{O}$ & Carl Roth GmbH \& Co.KG, Karlsruhe \\
\hline Ethylendiaminetetraacedic acid & $\begin{array}{l}\text { Sigma-Aldrich Chemie GmbH, } \\
\text { Taufkirchen }\end{array}$ \\
\hline $\begin{array}{l}\text { F-518 Phusion }{ }^{\circledR} \text { HF buffer with } 7.5 \text { mM } \\
\text { magnesiumchlorid }\end{array}$ & $\begin{array}{l}\text { Thermo Fischer Scientific, Waltham, } \\
\text { USA }\end{array}$ \\
\hline Fetal calf serum & Abbvie, Ludwigshafen \\
\hline
\end{tabular}




\begin{tabular}{|c|c|}
\hline $\begin{array}{l}\text { Gadolinium Adenosinmonophosphate } \\
\text { nanoparticles }\end{array}$ & $\begin{array}{l}\text { Prof. Dr. Klaus Feldmann, Institute for } \\
\text { anorganic chemistry KIT, Karlsruhe }\end{array}$ \\
\hline Gene Ruler 1kb, DNA ladder & $\begin{array}{l}\text { Thermo Fischer Scientific, Waltham, } \\
\text { USA }\end{array}$ \\
\hline Gibco $^{\circledR} 0.25 \%$ Trypsin - EDTA (1x) & $\begin{array}{l}\text { Thermo Fischer Scientific, Waltham, } \\
\text { USA }\end{array}$ \\
\hline Gibco ${ }^{\circledR}$ 2-Mercaptoethanol & $\begin{array}{l}\text { Thermo Fischer Scientific, Waltham, } \\
\text { USA }\end{array}$ \\
\hline Glycerol & Carl Roth GmbH \& Co.KG, Karlsruhe \\
\hline Hydrogen Peroxide $30 \%$ Rotipuran & Carl Roth GmbH \& Co.KG, Karlsruhe \\
\hline Neomycin trisulfate salt hydrate & $\begin{array}{l}\text { Sigma-Aldrich Chemie GmbH, } \\
\text { Taufkirchen }\end{array}$ \\
\hline Nucleoside triphosphate & Genaxxon bioscience, Ulm \\
\hline Orange G sodium salt & $\begin{array}{l}\text { Sigma-Aldrich Chemie GmbH, } \\
\text { Taufkirchen }\end{array}$ \\
\hline Paraffin wax & $\begin{array}{l}\text { Sigma-Aldrich Chemie GmbH, } \\
\text { Taufkirchen }\end{array}$ \\
\hline pegGOLD Universal Agarose & $\begin{array}{l}\text { Peqlab Biotechnology } \mathrm{GmbH} \text {, } \\
\text { Erlangen }\end{array}$ \\
\hline Penicillin/ Streptomycin $(10.000 \mathrm{U} / \mathrm{ml})$ & Invitrogen, Carlsbad, CA, USA \\
\hline Potassium chloride & Merck KGaA, Darmstadt \\
\hline Potassium dihydrogen phosphate & Merck KGaA, Darmstadt \\
\hline Power SYBR ${ }^{\circledR}$ Green Master Mix & Applied Biosystems, Foster City, USA \\
\hline QIAzol $^{\mathrm{TM}}$ Lysis Buffer & Qiagen, Hilden \\
\hline $\begin{array}{l}\text { Roti Histofix } 4 \% \text { pH } 7 \text { (4 \% } \\
\text { Paraformaldehyde) }\end{array}$ & Carl Roth GmbH \& Co.KG, Karlsruhe \\
\hline Sodium carbonate & Merck KGaA, Darmstadt \\
\hline Sodium chloride, $99.5 \%$ p.a. & Carl Roth GmbH \& Co.KG, Karlsruhe \\
\hline Sodium hydrogen carbonate & Merck KGaA, Darmstadt \\
\hline Sulfuric acid, 95 - $98 \%$ & Merck KGaA, Darmstadt \\
\hline Tween $^{(} 20 \%$ & Carl Roth GmbH \& Co.KG, Karlsruhe \\
\hline
\end{tabular}




\subsubsection{Commercial kits}

Table 4: Commercial kits

\begin{tabular}{|c|c|}
\hline Commercial kit & Supplier \\
\hline $\begin{array}{l}\text { CellTiter } 96^{\Theta} \mathrm{AQ} \text { eous One Solution Cell } \\
\text { Proliferation Assay Kit }\end{array}$ & Promega, Madison, WI, USA \\
\hline Dynabeads $^{\mathrm{TM}}$ mRNA Purification Kit & $\begin{array}{l}\text { ThermoFischer Scientific, Waltham, } \\
\text { USA }\end{array}$ \\
\hline $\begin{array}{l}\text { EasySep }^{\mathrm{TM}} \text { negative selection mouse } \\
\mathrm{T} \text { cell isolation Kit }\end{array}$ & $\begin{array}{l}\text { STEMCELL Technologies SARL, } \\
\text { Cologne }\end{array}$ \\
\hline $\begin{array}{l}\text { EasySep }{ }^{\mathrm{TM}} \text { positive selection mouse } \\
\text { CD90.2 Kit II }\end{array}$ & $\begin{array}{l}\text { STEMCELL Technologies SARL, } \\
\text { Cologne }\end{array}$ \\
\hline $\begin{array}{l}\text { ELISA MAX }{ }^{\mathrm{TM}} \text { Standard Set Mouse } \\
\text { IL } 2\end{array}$ & BioLegend, San Diego, USA \\
\hline $\begin{array}{l}\text { ELISA MAX }{ }^{\mathrm{TM}} \text { Standard Set Mouse } \\
\text { IL } 6\end{array}$ & BioLegend, San Diego, USA \\
\hline $\begin{array}{l}\text { ELISA MAX }{ }^{\mathrm{TM}} \text { Standard Set Mouse } \\
\text { IFNY }\end{array}$ & BioLegend, San Diego, USA \\
\hline $\begin{array}{l}\text { ELISA MAX }{ }^{\mathrm{TM}} \text { Standard Set Mouse } \\
\text { TNFa }\end{array}$ & BioLegend, San Diego, USA \\
\hline $\begin{array}{l}\text { ELISA READY-SET-Go! Mouse CCL-2 } \\
\text { (MCP-1) }\end{array}$ & $\begin{array}{l}\text { Affymetrix eBioscience, Frankfurt on } \\
\text { the Main }\end{array}$ \\
\hline iScript $^{\mathrm{TM}}$ cDNA Synthesis Kit & Bio-Rad Laboratories GmbH, Munich \\
\hline $\begin{array}{l}\text { Qiagen RNeasy Plus Universal Mini } \\
\text { Kit }\end{array}$ & Qiagen, Hilden \\
\hline
\end{tabular}

\subsubsection{Enzymes}

Table 5: Enzymes

\begin{tabular}{ll}
\hline Enzyme & Supplier \\
\hline Collagenase type 1-A $(25 \mathrm{mg} / \mathrm{ml})$ & Sigma-Aldrich Chemie GmbH, \\
& Taufkirchen \\
Collagenase type II $(25 \mathrm{mg} / \mathrm{ml})$ & Sigma-Aldrich Chemie GmbH, \\
& Taufkirchen
\end{tabular}


DNase I recombinant, RNase-free

(10.000 U/ml)

PfuS polymerase
Merck KGaA, Darmstadt

kindly provided by Steffen Frey, Max-

Planck-Institute for Biophysical

Chemistry, Göttingen

\subsubsection{Antibodies}

Table 6: Antibodies

\begin{tabular}{|c|c|c|c|c|c|}
\hline Specificity & Antigen & $\begin{array}{l}\text { Fluores- } \\
\text { cent dye }\end{array}$ & Clone & $\begin{array}{l}\text { Di- } \\
\text { lution }\end{array}$ & Supplier \\
\hline$\alpha$-mouse & $\begin{array}{l}\text { CD45R/ } \\
\text { B220 }\end{array}$ & $\mathrm{PE}$ & $\begin{array}{l}\text { RA3- } \\
6 B 2\end{array}$ & $1: 400$ & $\begin{array}{l}\text { BD Biosciences, } \\
\text { Franklin Lakes, USA }\end{array}$ \\
\hline a-mouse & $\begin{array}{l}\text { CD45R/ } \\
\text { B220 }\end{array}$ & APC & $\begin{array}{l}\text { RA3- } \\
\text { 6B2 }\end{array}$ & $1: 500$ & BD Biosciences \\
\hline a-mouse & CD3 & PerCp 5.5 & $17 A 2$ & $1: 500$ & BD Biosciences \\
\hline a-mouse & $\begin{array}{l}\text { TCR- } \beta \\
\text { chain }\end{array}$ & FITCs & $\begin{array}{l}\mathrm{H} 57- \\
597\end{array}$ & $1: 400$ & BD Biosciences \\
\hline a-mouse & CD3 & - & $M-20$ & $1: 2.000$ & $\begin{array}{l}\text { Santa Cruz, } \\
\text { Biotechnology }\end{array}$ \\
\hline a-mouse & CD68 & - & $\mathrm{FA}-11$ & $1: 200$ & $\begin{array}{l}\text { Abcam, Cambridge, UK/ } \\
\text { Biolegend, San Diego, } \\
\text { USA }\end{array}$ \\
\hline a-mouse & Ly6C & APC Cy 7 & HK1.4 & $1: 2.000$ & BioLegend \\
\hline$\alpha$-mouse & Ly6G & APC & $1 \mathrm{~A} 8$ & $1: 500$ & BioLegend \\
\hline a-mouse & CD3 & APC & $17 A 2$ & $1: 1.000$ & BioLegend \\
\hline$\alpha$-mouse & CD8 & PE Cy7 & $53-6.7$ & $1: 1.000$ & BioLegend \\
\hline a-mouse & CD4 & APC Cy7 & RM4-5 & $1: 1.000$ & BioLegend \\
\hline$\alpha$-mouse & CD11b & PE Cy7 & $\mathrm{M} 1 / 70$ & $1: 1.000$ & BD Biosciences \\
\hline a-mouse & CD86 & PE & GL-1 & $1: 1.000$ & BioLegend \\
\hline a-mouse & $\begin{array}{l}\mathrm{MHCll} \\
\mathrm{H} 2^{\mathrm{d}}\end{array}$ & PE & $\begin{array}{l}\text { AMS- } \\
32.1\end{array}$ & $1: 200$ & BD Pharmingen \\
\hline
\end{tabular}




\begin{tabular}{llllll}
\hline a-mouse & CD16/ & - & 93 & $1: 2.000$ & BioLegend \\
& 32 & & & & \\
a-rat CD68 & - & (HRP) & - & - & mmPRESS HRP \\
a-goat CD3 & & & & & Polymer Detection Kit; \\
& & & & Vector Laboratories, \\
& & & & Burlingame, USA \\
\hline
\end{tabular}

\subsubsection{Fluorescent dyes}

Table 7: Fluorescent dyes

\begin{tabular}{|c|c|c|c|c|}
\hline Dye & $\begin{array}{l}\text { Speci- } \\
\text { ficity }\end{array}$ & $\begin{array}{l}\text { Fluorescent } \\
\text { dye properties }\end{array}$ & Dilution & Supplier \\
\hline $\begin{array}{l}\text { Lysotracker }^{\Theta} \\
\text { deep red } \\
\text { (L12492) }\end{array}$ & $\begin{array}{l}\text { Acidic } \\
\text { organelles }\end{array}$ & $\begin{array}{l}\text { Exc.: } 647 \mathrm{~nm}, \\
\text { Em.: } 668 \mathrm{~nm}\end{array}$ & $1: 10.000$ & $\begin{array}{l}\text { Thermo Fischer } \\
\text { Scientific, Waltham, } \\
\text { USA }\end{array}$ \\
\hline $\begin{array}{l}\text { Mitotracker }^{\circledR} \\
\text { Deep Red FM }\end{array}$ & $\begin{array}{l}\text { Mito- } \\
\text { chondrien }\end{array}$ & $\begin{array}{l}\text { Exc.: } 644 \mathrm{~nm} \text {, } \\
\text { Em.: } 665 \mathrm{~nm}\end{array}$ & $1: 10.000$ & $\begin{array}{l}\text { Cell Signaling } \\
\text { Technologies, } \\
\text { Cambridge, UK }\end{array}$ \\
\hline
\end{tabular}

\subsubsection{Inhibitors}

Table 8: Inhibitors

\begin{tabular}{llll}
\hline Inhibitor & $\begin{array}{l}\text { Concen- } \\
\text { tration }\end{array}$ & Pathway & Supplier \\
\hline $\begin{array}{l}\text { Amiloride } \\
\text { hydrochloride }\end{array}$ & $1 \mathrm{mM}$ & $\begin{array}{l}\text { Phago/ Macro- } \\
\text { pinocytosis }\end{array}$ & $\begin{array}{l}\text { Sigma-Aldrich Chemie } \\
\text { GmbH, Taufkirchen }\end{array}$ \\
$\begin{array}{l}\text { hydrate } \\
\text { Cytochalasin }\end{array}$ & $1 \mu \mathrm{g} / \mathrm{ml}$ & $\begin{array}{l}\text { Phago/ Macro- } \\
\text { pinocytosis } \\
\text { D }\end{array}$ & $\begin{array}{l}\text { Sigma-Aldrich Chemie } \\
\text { GmbH, Taufkirchen }\end{array}$ \\
$\begin{array}{l}\text { Monodansyl- } \\
\text { cadaverine }\end{array}$ & $100 \mu \mathrm{M}$ & $\begin{array}{l}\text { Clathediated } \\
\text { endocytosis }\end{array}$ & $\begin{array}{l}\text { Sigma-Aldrich Chemie } \\
\text { GmbH, Taufkirchen }\end{array}$ \\
\hline
\end{tabular}




\subsubsection{Oligonucleotides}

Table 9: Oligonucleotides

\begin{tabular}{ll}
\hline Gene & Sequence 5' - 3' \\
\hline Chemokine (C-C & Fwd.: AGC TGT AGT TTT TGT CAC CAA GC \\
motif) ligand 2 & Rev.: GAC CTT AGG GCA GAT GCA GT \\
(Ccl2) & \\
Collagen, type I, & Fwd.: GTG TTC CCT ACT CAG CCG TC \\
alpha 1 (Col1a1) & Rev.: ACT CGA ACG GGA ATC CAT CG \\
FK506-binding & Fwd.: GAA CCT GGC CAT GTG CTA CCT \\
protein 51 (Fkbp51) & Rev.: GTC CAG TCC AAG GGC CTT GT \\
Forkhead box O1 & Fwd.: GTT GCC CAA CCA AAG CTT CC \\
(Foxo1) & Rev.: ATG TAG CCT GCT CAC TAA CTC TT \\
Heterochromatin & Fwd.: GCC CAA GAT GGA CGC AAT C \\
protein 1 (Hp1) & Rev.: CCG AGG CGC CAG TCT TC \\
Hypoxanthine & Fwd.: GTC CTG TGG CCA TCT GCC TA \\
guanine & Rev.: GGG ACG CAG CAA CTG ACA TT \\
phosphoribosyl & \\
transferase (Hprt) & \\
Interferon gamma & Fwd.: ACT GGC AAA AGG ATG GTG AC \\
(Ifng) & Rev.: TGA GCT CAT TGA ATG CTT GG \\
Interleukin 1 beta & Fwd.: CTC ATC TGG GAT CCT CTC CA \\
(II1b) & Rev.: AAG CAG CCC TTC ATC TTT TG \\
Interleukin 10 (II10) & Fwd.: AGG CAG AGA AGC ATG GCC CAG \\
Interleukin 2 (II2) & Fwd.: ACT TGC CCA AGC AGG CCA CA \\
Interleukin 6 (II6) & Fwd.: AGT TGC CTT CTT GGG ACT GA \\
Metallothionein 2 & Fwd.: ATA GAC CAT GTA GAA GCC TAG CCT TT \\
(Mt2) & Rev.: GGC TTT TAT TGT CAG TTA CAT GCT TTA TAG \\
Phosphoenolpyruva & Fwd.: AAA GCA TTC AAC GCC AGG TT \\
te carboxykinase & Rev.: TGC TGA ATG GGA TGA CAT ACA TG \\
(Pepck) & \\
\hline
\end{tabular}



Tumor necrosis
Fwd.: ATG GCC TCC CTC TCA TCA GT
factor alpha (Tnfa)
Rev.: CTT GGT GGT TTG CTA CGA CG
Tyrosine
Fwd.: CCT CTG GAA GCT AAG GAT GTC ATT
aminotransferase
Rev.: AAC ACG GCT AGA CAC AGC TCA A

\subsubsection{Cell lines}

All cell lines originate from the species Mus musculus.

Table 10: Cell lines

\begin{tabular}{|c|c|c|c|c|}
\hline $\begin{array}{l}\text { Cell } \\
\text { line }\end{array}$ & Origin & Strain & $\begin{array}{l}\text { Culture } \\
\text { medium }\end{array}$ & Supplier \\
\hline $\mathrm{C} 2 \mathrm{C} 12$ & Myoblasts & $\mathrm{C} 3 \mathrm{H}$ & DMEM++ & ATCC \\
\hline L929 & $\begin{array}{l}\text { Fibroblasts } \\
\text { from } \\
\text { connective } \\
\text { tissue }\end{array}$ & $\mathrm{C} 3 \mathrm{H} / \mathrm{An}$ & DMEM++ & $\begin{array}{l}\text { Kindly provided by Prof. Dr. } \\
\text { Jan Tuckermann, Institute } \\
\text { for Comparative Molecular } \\
\text { Endocrinology, Ulm }\end{array}$ \\
\hline LA-4 & $\begin{array}{l}\text { Alveolar } \\
\text { epithelial } \\
\text { cells type II }\end{array}$ & $\mathrm{A} / \mathrm{He}$ & NutMix++ & $\begin{array}{l}\text { Sigma-Aldrich Chemie } \\
\text { GmbH, Taufkirchen }\end{array}$ \\
\hline MH-S & $\begin{array}{l}\text { Alveolar } \\
\text { macrophages }\end{array}$ & BALB/c & $\mathrm{RPMI}_{+++}$ & $\begin{array}{l}\text { Kindly provided by Prof. Dr. } \\
\text { Frauke Alves, Max-Planck } \\
\text { Institute for Experimental } \\
\text { Medicine, Göttingen }\end{array}$ \\
\hline $\begin{array}{l}\text { WEHI } \\
231\end{array}$ & $\begin{array}{l}\text { Immature B } \\
\text { lymphocyte }\end{array}$ & $\begin{array}{l}\mathrm{BALB} / \mathrm{c} / \\
\mathrm{NZB}\end{array}$ & DMEM++ & $\begin{array}{l}\text { Kindly provided by Assoc. } \\
\text { Prof. Marco Herold, Institute } \\
\text { for Medical Research, } \\
\text { Melbourne AUS }\end{array}$ \\
\hline $\begin{array}{l}\text { WEHI } \\
7.1\end{array}$ & $\begin{array}{l}\text { T lymphocyte } \\
\text { (thymus) }\end{array}$ & BALB/c & DMEM++ & ATCC \\
\hline
\end{tabular}




\subsubsection{Media}

Table 11: Media

\begin{tabular}{ll}
\hline Medium & Supplier \\
\hline $1 \times$ LCCM & $\begin{array}{l}\text { Kindly provided by Dr. Katharina Jörß } \\
\text { (AG Reichardt) }\end{array}$ \\
$\begin{array}{l}\text { Gibco }{ }^{\Theta} \text { DMEM + GlutaMAX }{ }^{\mathrm{TM}} 1 \mathrm{x} / \\
\text { phenol-free }\end{array}$ & $\begin{array}{l}\text { ThermoFischer Scientific, Waltham, } \\
\text { USA }\end{array}$ \\
Gibco $^{\Theta}$ F-12 NutMix & ThermoFischer Scientific, Waltham, \\
& USA \\
Gibco $^{\Theta}$ RPMl1640 + GlutaMAX & ThermoFischer Scientific, Waltham, \\
& USA \\
\hline
\end{tabular}

Table 12: Supplemented media

\begin{tabular}{ll}
\hline Supplemented medium & Component \\
\hline DMEM++ and RPMI++ & DMEM/ RPMI1640, \\
& $10 \%$ FCS, \\
& $1 \%$ Penicillin/ Streptomycin \\
RPMl+++ & RPMl1640, \\
& $10 \%$ FCS, \\
& $1 \%$ Penicillin/ Streptomycin, \\
& 0.05 mM 2-Mercaptoethanol \\
F-12 NutMix++ & F-12 NutMix, \\
& $15 \%$ FCS, \\
& $1 \%$ Penicillin/ Streptomycin \\
\hline
\end{tabular}

\subsubsection{Buffers}

Table 13: Buffers

\begin{tabular}{ll}
\hline Buffer & Component \\
\hline EasySep $^{\mathrm{IM}}$ Recommended medium & $2 \%$ BSA \\
& $1 \mathrm{mM}$ EDTA \\
& in PBS \\
ELISA Assay Diluent & $10 \%$ FCS in PBS \\
\hline
\end{tabular}




\begin{tabular}{|c|c|}
\hline ELISA Coating buffer & $1000 \mathrm{ml} \mathrm{ddH} \mathrm{H}_{2} \mathrm{O}$ \\
\hline \multirow[t]{3}{*}{ (0.1 M Sodium carbonate) } & $8.4 \mathrm{~g} \mathrm{NaHCO}_{3}$ \\
\hline & $3.56 \mathrm{~g} \mathrm{Na}_{2} \mathrm{CO}_{3}$ \\
\hline & pH 9.5 \\
\hline \multirow[t]{3}{*}{ ELISA Substrate buffer } & $0.1 \mathrm{M}$ Citric acid \\
\hline & $0.2 \mathrm{M} \mathrm{Na}_{2} \mathrm{HPO}_{4}$ \\
\hline & in $\mathrm{ddH}_{2} \mathrm{O}$ \\
\hline \multirow[t]{3}{*}{ ELISA Developing solution } & ELISA Substrate buffer \\
\hline & $1 \% \mathrm{TMB}$ in DMSO \\
\hline & $0.2 \% \mathrm{H}_{2} \mathrm{O}_{2}$ \\
\hline \multirow[t]{5}{*}{ Phosphate saline buffer pH 7.2} & $137 \mathrm{mM} \mathrm{NaCl}$ \\
\hline & $2.7 \mathrm{mM} \mathrm{KCl}$ \\
\hline & $10 \mu \mathrm{M} \mathrm{Na}{ }_{2} \mathrm{HPO}_{4}$ \\
\hline & $2 \mathrm{mM} \mathrm{KH}_{2} \mathrm{PO}_{4}$ \\
\hline & in $\mathrm{ddH}_{2} \mathrm{O}$ \\
\hline ELISA Washing buffer & $0.05 \%$ Tween $\AA 20 \%$ in PBS \\
\hline \multirow[t]{4}{*}{ TAE buffer } & $40 \mathrm{mM}$ Tris \\
\hline & $20 \mathrm{mM}$ Acetic acid \\
\hline & $1 \mathrm{mM}$ EDTA \\
\hline & in $\mathrm{ddH}_{2} \mathrm{O}$ \\
\hline \multirow[t]{3}{*}{ FACS buffer } & $0.1 \% \mathrm{BSA}$ \\
\hline & $0.01 \%$ Sodium azide \\
\hline & in PBS pH 7.2 \\
\hline \multirow[t]{3}{*}{ Orange G Loading Dye } & $100 \mathrm{ml} \mathrm{dd} \mathrm{H}_{2} \mathrm{O}$ \\
\hline & 100 mg Orange G sodium salt \\
\hline & $30 \%$ Glycerol \\
\hline PBS/ BSA & $0.1 \%$ BSA in PBS \\
\hline ELISA Stop solution & $1 \mathrm{M} \mathrm{H}_{2} \mathrm{SO}_{4}$ in dd $\mathrm{H}_{2} \mathrm{O}$ \\
\hline \multirow[t]{3}{*}{ TAC buffer } & $20 \mathrm{mM}$ Tris \\
\hline & $155 \mathrm{mM} \mathrm{NH}_{4} \mathrm{Cl}$ \\
\hline & in $\mathrm{ddH}_{2} \mathrm{O}$ \\
\hline
\end{tabular}




\subsubsection{Software}

Table 14: Software

\begin{tabular}{|c|c|}
\hline Software & Supplier \\
\hline $\begin{array}{l}\text { 7500 System SDS Software version } \\
\text { 1.4.0.25 }\end{array}$ & $\begin{array}{l}\text { Applied Biosystems, Foster City, CA, } \\
\text { USA }\end{array}$ \\
\hline Adobe Photoshop version 9.0 & Adobe Systems, San Jose, CA, USA \\
\hline $\begin{array}{l}\text { BD FACS Diva }{ }^{\mathrm{TM}} \text { Software version } \\
6.1 .2\end{array}$ & BD Biosciences, Heidelberg \\
\hline BioTek $^{\circledR}$ Gen 5 version 1.09.8 & BioTek Instruments, Bad Friedrichshall \\
\hline EndNoteX9 & Clarivate analytics, Philadelphia, USA \\
\hline FlowJo version 7.6 .5 & Tree Star, Inc., Ashland, OR, USA \\
\hline GraphPad Prism 5 & $\begin{array}{l}\text { GraphPad Software, La Jolla, CA, } \\
\text { USA }\end{array}$ \\
\hline IDEAS Application version 6.2187 .2 & $\begin{array}{l}\text { Amnis part of MilliporeSigma, Seattle, } \\
\text { WA, USA }\end{array}$ \\
\hline ImageJ $1.51 \mathrm{j} 8$ & $\begin{array}{l}\text { National Institute of Health, USA, open } \\
\text { source, http://imagej.nih.gov/ij }\end{array}$ \\
\hline Leica Confocal software & Leica, Wetzlar \\
\hline Microsoft Office 2010 & Microsoft, Redmond, WA, USA \\
\hline Nanodrop 2000 Software & $\begin{array}{l}\text { Thermo Scientific, Wilmington, WA, } \\
\text { USA }\end{array}$ \\
\hline Zeiss ZEN lite (2012) & Zeiss, Jena \\
\hline
\end{tabular}




\section{$2.2 \quad$ Methods}

\subsubsection{Animal experimentation}

C57BL/6 wild type (wt) mice were purchased from the commercial breeder Charles River in Sulzfeld or Janvier Labs in St. Berthevin in France. All other mice were bred and kept at our own animal facility at the University Medical Center in Göttingen. They were housed under specific-pathogen-free conditions (SPF) in individually ventilated cages (IVC) in a 12 hour light/ dark cycle. Food and water was supplied ad libitum. Mice were used at an age of 8 to 12 weeks.

Our aGvHD experiments are based on a total MHC haplotype mismatch bone marrow transplantation (BMT) model employing two different inbred mouse strains. C57BL/6 wt mice have the haplotype $\mathrm{H}^{\mathrm{b}}$ and served as donor, whereas $B A L B / c$ wt mice with the haplotype $H 2^{d}$ served as recipients. Beside recipient $B A L B / c$ wt mice, $N r 3 c 1^{\text {tm2Gsc }} \operatorname{Lyz} 2^{\text {tm1(cre)lfo }}$ mice $\left(G R^{\text {lysM }}\right)$, which carry a knockout of the GR that is restricted to the myeloid linage have been used as recipients. In these $\mathrm{GR}^{\mathrm{lysM}}$ mice the cre recombinase is expressed under the control of the lysosome $\mathrm{M}$ promotor, which leads to a tissue specific deletion of the GR in about 83 - $98 \%$ of all mature macrophages, nearly $100 \%$ of all granulocytes and $16 \%$ of all dendritic cells. Nr3c1 ${ }^{\text {tm2Gsc }}$ BALB/c mice $\left(G^{\text {flox }}\right)$ do not express the cre recombinase and have been used as control mice (Tuckermann et al., 2007). All experiments were conducted according to national and international guidelines and were approved by the responsible authority of Lower Saxony (Niedersächsisches Landesamt für Verbraucherschutz und Lebensmittelsicherheit).

\subsubsection{Acute GvHD mouse model: disease induction}

\subsubsection{Experimental setup}

Female wt, $\mathrm{GR}^{\text {flox }}$ or $\mathrm{GR}^{\mathrm{lysM}}$ mice on a BALB/c background were used as recipients. Two days before BMT (day -2), the drinking water of recipient mice was supplemented with $25 \mu \mathrm{g} / \mathrm{ml}$ neomycin as an antibiosis and renewed every second day for up to three weeks. One day before BMT (day -1 ), recipient mice were transferred to a perspex box and subjected a total body irradiation (TBI) 
with a dose of $8.5 \mathrm{~Gy}$ (1 Gy/min) using an X-Ray source, which operated at $200 \mathrm{kV}, 15 \mathrm{~mA}$ and $0.5 \mathrm{~mm} \mathrm{Cu}$ filtration. At day 0 , the day of BMT, $1 \times 10^{7}$ T cell depleted bone marrow (BM) cells and $2 \times 10^{6}$ purified splenic T cells were resuspended in $200 \mu \mathrm{PBS}$ and injected intravenously (i.v.) with a $30 \mathrm{G}$ syringe into the tail vein of recipient mice to induce aGvHD. BM mice served as controls and received only $1 \times 10^{7}$ BM cells resuspended in $200 \mu$ I PBS (Figure 4).

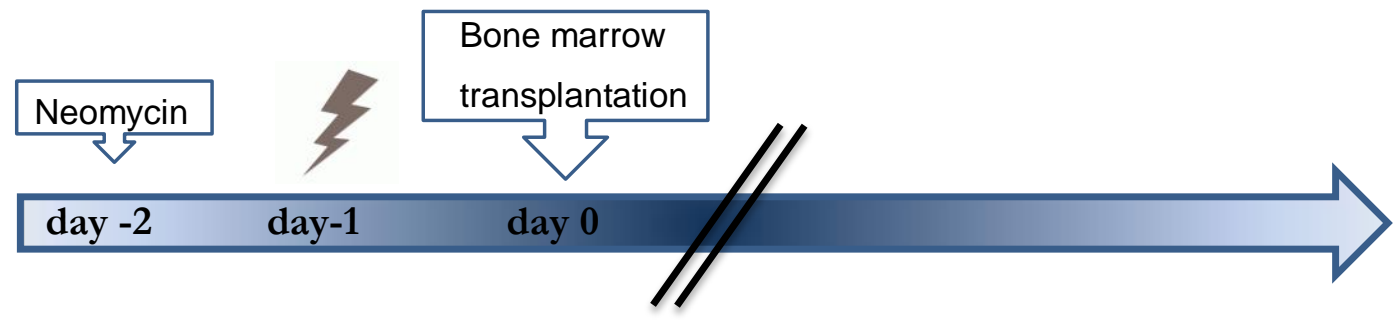

Figure 4: Scheme of aGvHD mouse model induction.

\subsubsection{Preparation of T cell depleted bone marrow cells}

C57BL/6 wt mice were used as donor mice and sacrificed by $\mathrm{CO}_{2}$ inhalation at day 0 , the day of BMT. From these mice tibiae, femora and humeri were collected and placed in ice cold PBS. Under sterile conditions, the bones were opened at both sides and the BM was flushed out with ice cold PBS/ $0.1 \%$ BSA by using a 24G needle, which was attached to a $5 \mathrm{ml}$ syringe. The BM was passed through a $40 \mu \mathrm{m}$ EASY cell strainer into a $50 \mathrm{ml}$ falcon tube and centrifuged at $300 \times \mathrm{g}$ for 7 minutes at $4{ }^{\circ} \mathrm{C}$. The cells were counted with the help of a Neubauer haemocytometer and adjusted to a concentration of $1 \times 10^{8}$ cell $/ \mathrm{ml}$ by adding the respective amount of EasySep ${ }^{\mathrm{TM}}$ recommended medium. In the following, $\mathrm{T}$ cells were depleted by using the EasySep ${ }^{\mathrm{TM}}$ positive selection mouse CD90.2 Kit II according to the manufacturer's instructions. In brief, a selection cocktail was mixed with the ratio of $1: 1$ and left for 5 minutes at room temperature (RT). $50 \mu \mathrm{l} / \mathrm{ml}$ was added to the sample and incubated for 3 minutes at RT. $40 \mu \mathrm{l} / \mathrm{ml}$ of streptavidin RapidSpheres was added and left for 3 minutes at RT. Cell suspension was adjusted to a total volume of $2.5 \mathrm{ml}$ by adding the respective amount of EasySep ${ }^{\mathrm{TM}}$ recommended medium. Afterwards, the tube was placed into the EasySep ${ }^{\mathrm{TM}}$ magnet for 3 minutes at RT and subsequently CD90.2 cells were poured into another tube. The cells were centrifuged, counted and adjusted to a concentration of $1 \times 10^{8}$ cells $/ \mathrm{ml}$ with 
PBS. $100 \mu \mathrm{l}$, which corresponds to $1 \times 10^{7} \mathrm{BM}$ cells, was added to a tube for each mouse.

\subsubsection{Preparation of splenic T cells}

Spleens were isolated from donor mice after sacrificing them with $\mathrm{CO}_{2}$. The freshly isolated organs were placed in ice cold PBS and passed through a $40 \mu \mathrm{m}$ EASY cell strainer under sterile conditions. Subsequently, the cells were centrifuged at $300 \times \mathrm{g}$ for 7 minutes at $4{ }^{\circ} \mathrm{C}$ and $\mathrm{T}$ cells were purified by using the EasySep ${ }^{\mathrm{TM}}$ negative selection mouse $\mathrm{T}$ cell isolation Kit according to manufacturer's instructions. In brief, the cells were counted and adjusted to a concentration of $1 \times 10^{8}$ cells $/ \mathrm{ml}$ by adding the respective volume of PBS/ $0.1 \%$ BSA. $50 \mu \mathrm{l} / \mathrm{ml}$ of normal rat serum and $50 \mu \mathrm{l} / \mathrm{ml}$ of mouse $\mathrm{T}$ cell isolation cocktail was added to the sample and incubated for 10 minutes at RT. $75 \mu \mathrm{l} / \mathrm{ml}$ of streptavidin RapidSpheres were added and incubated for 2.5 minutes at RT. The cell suspension was brought up to a total volume of $2.5 \mathrm{ml}$ by adding the respective volume of PBS/ $0.1 \%$ BSA. The tube was placed in the EasySep ${ }^{\mathrm{TM}}$ magnet for 3 minutes at RT and the T cells were poured into another tube. The cells were centrifuged, counted and adjusted to a final concentration of $2 \times 10^{7}$ cells/ml with PBS. $100 \mu \mathrm{l}$, corresponding to $2 \times 10^{6} \mathrm{~T}$ cells, were added to a tube for each mouse. For BM mice, which did not receive T cells, $100 \mu$ l PBS was added instead.

\subsubsection{Purity control of cell preparation}

The purity of $\mathrm{T}$ cells and $\mathrm{T}$ cell depleted bone marrow cells was analyzed by flow cytometry (see 2.2.9.1). The gating strategy is depicted in Figure 5. 


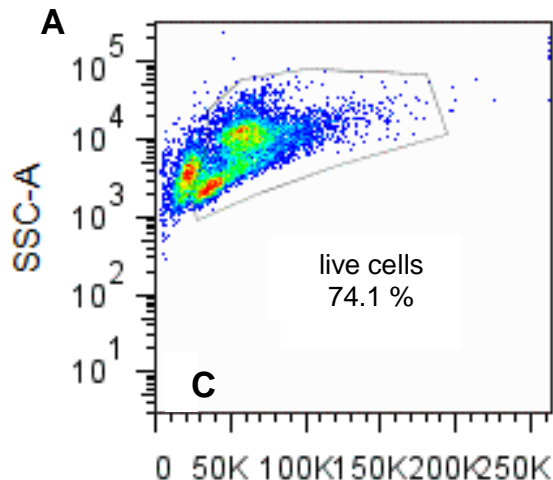

o $50 \mathrm{~K} 100 \mathrm{~K} 150 \mathrm{~K} 200 \mathrm{~K} 250 \mathrm{~K}$

FCS-A

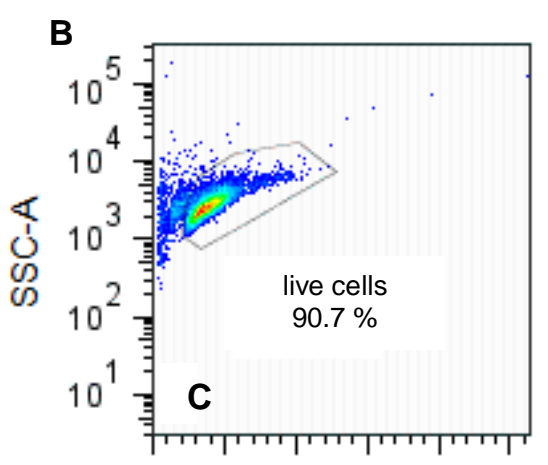

0 50K 100K150K2001250K

FCS-A

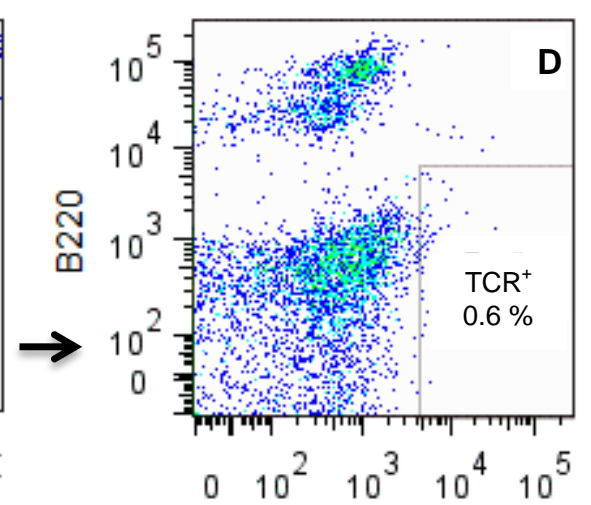

TCR- $\beta$ chain

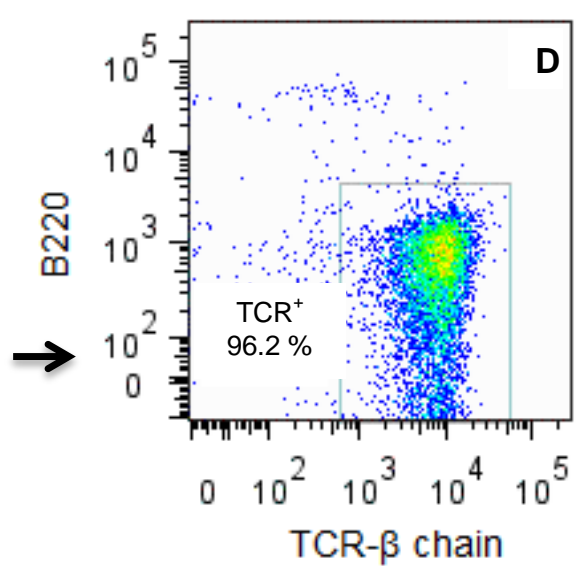

Figure 5: Gating strategy of flow cytometric analyses of $T$ cell depleted bone marrow cells and purified $\mathrm{T}$ cells. $\mathrm{T}$ cell depleted bone marrow cells (A) and purified $T$ cells (B) were first gated for living cells (C) based on forward scatter (FSC) and side scatter (SSC), then on singlets (not depicted) and lastly on TCR- $\beta$ chain ${ }^{+}$cells (D).

\subsubsection{Acute GvHD mouse model: disease progression}

\subsubsection{Monitoring of clinical symptoms}

The vital state and aGvHD progression of recipient mice was monitored from day 2 after BMT onwards based on an established aGvHD clinical scoring system (Cooke et al., 1996, Theiss-Suennemann et al., 2015). This system includes five parameters: posture, activity, fur texture, diarrhea and weight loss. According to the severity of the symptoms the mice received a clinical score between 0 (no symptoms) and 2 (severe symptoms) for each parameter, which resulted in a total score of 0 to 10 . Mice with a clinical score of 7 or higher and mice with a reduction in body weight of more than $20 \%$ at two consecutive days were sacrificed for ethical reasons. Mice, which died or had to be sacrificed assigned a clinical score of 10 (Table 15). 
Table 15: aGvHD clinical grading system

\begin{tabular}{llll}
\hline Parameter & $\mathbf{0}$ & $\mathbf{1}$ & $\mathbf{2}$ \\
\hline Posture & Normal & Hunching & Impaired movement \\
Activity & Normal & Resting & Stationary unless stimulated \\
Fur texture & Normal & Ruffling & Absent grooming, greasy fur \\
Diarrhea & None & Mild & Severe (bloody) \\
Body weight loss & $0 \%-10 \%$ & $10 \%-20 \%$ & More than $20 \%$ \\
\hline
\end{tabular}

\subsubsection{Long-term and short-term acute GvHD experiments}

Acute GvHD studies were either performed as long-term or short-term experiments. In the long-term experiments, the survival of mice was monitored for 50 days. In short-term experiments, aGvHD mice were sacrificed at the first peak of the disease at day 6 after BMT, but partially also in addition at day 4 and 8 after BMT and aGvHD hallmarks were analyzed (Figure 6).

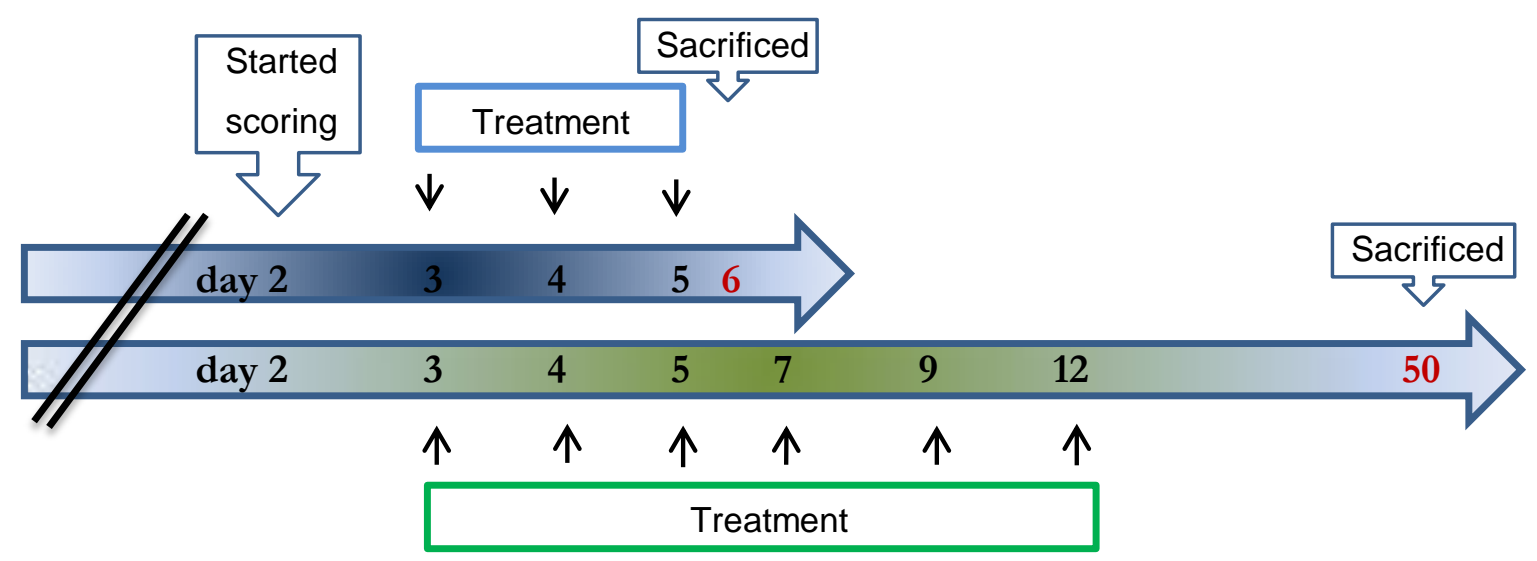

Figure 6: Scheme of GC treatment of aGvHD long-term and short-term experiments.

\subsubsection{Treatment regimens}

Three days after BMT, aGvHD mice developed mild symptoms of the disease. Therefore, the mice in the short-term experiments were treated at day 3, 4 and 5 after BMT intraperitoneally (i.p.) either with $10 \mathrm{mg} / \mathrm{kg}$ free betamethasone (BMX) (Celestan) or BMP-NPs (IOH-NPs, that contain betamethasone phosphate). As a control for potential side-effects of the nanoparticles themselves, the mice were treated with the same volume of EP-NPs (empty $\mathrm{IOH}-\mathrm{NPs}$, which served as vehicle control) or PBS. Mice within the long-term experiments were additionally treated at day 7, 9 and 12 after BMT (Figure 6). 


\subsubsection{In vivo and ex vivo analyses of mice}

\subsubsection{Body temperature}

The body temperature of recipient mice from aGvHD short-term experiments was measured by using a rodent thermometer BIO-TK8851, which was equipped with a BIO-BRET-3 rectal probe.

\subsubsection{Blood glucose level}

Blood glucose level was measured with Ascencia CONTOUR and CONTOUR NEXT test stripes and the corresponding Ascencia CONTOUR blood glucose monitoring system. The tail vein of mice was punctured with a needle and a blood drop was analyzed with the automated device.

\subsubsection{Serum collection}

Mice were sacrificed by placing them in a cage, which was filled with $\mathrm{CO}_{2}$. Afterwards, blood was harvested by cardiac heart puncture using a 24G needle and transferred to a BD Microtainer SST tube. It was left for coagulation for 30 minutes at RT and centrifuged at $14.000 \times \mathrm{g}$ for 2 minutes to separate the blood and obtain the serum. The serum was collected and stored at $-20^{\circ} \mathrm{C}$ for further analysis.

\subsubsection{Tissue culture of jejunum biopsies for the analysis of cytokine secretion by infiltrated immune cells}

In short-term aGvHD experiments recipient mice were sacrificed at the first peak of the disease at day 6 . The jejunum of the animals was removed, four pieces from different sites of $5 \mathrm{~mm}$ length were harvested and flushed with ice cold PBS. The pieces were placed in individual wells in a 24-well plate and incubated with $500 \mu \mathrm{l}$ of $\mathrm{RPMl}++$ at $37^{\circ} \mathrm{C}$ in $5 \% \mathrm{CO}_{2}$ atmosphere for 24 hours. The jejunum pieces were weighted to correct for differences in size and the supernatant was removed and stored at $-20^{\circ} \mathrm{C}$ for further analysis. 


\subsubsection{Flow cytometric characterization of the cellular composition of immune cells in the lamina propria}

Recipient mice from short-term aGvHD experiments were sacrificed at day 6, the jejunum was removed and the size used was standardized. The tissue was removed $4 \mathrm{~cm}$ after the stomach and before the caecum, was flushed with ice cold PBS, the payer patches were removed and the jejunum was opened longitudinally before placing it in individual wells of a 6 -well plate filled with PBS/ $60 \mathrm{mM}$ EDTA/ $3 \mathrm{mM}$ DTT for 45 minutes on ice. The samples were transferred into $50 \mathrm{ml}$ falcon tubes containing $20 \mathrm{ml}$ PBS, were shaken manually for 1 minute and the supernatant was discarded. This step was repeated twice with $20 \mathrm{ml}$ PBS and once with $5 \mathrm{ml}$ RPMI++ to remove epithelial cells and traces of EDTA. Meanwhile, the digestion solution was prepared in $50 \mathrm{ml}$ falcons, for each mouse using $5 \mathrm{ml} \mathrm{RPMl++}$ supplemented with $4 \mathrm{mg}$ collagenase type II, $4 \mathrm{mg}$ collagenase type 1-A and recombinant $500 \mathrm{U}$ DNase I, which resulted in the release of cells from the tissue. Jejunum samples were cut into $3 \mathrm{~cm}$ pieces, transferred to the digestion solution and incubated for 30 minutes at $37^{\circ} \mathrm{C}$. Every 10 minutes, the samples were vortexed and finally passed through a $40 \mu \mathrm{m}$ EASY cell strainer. $30 \mathrm{ml}$ of RPMI++ was added to the cells, centrifuged at $300 \mathrm{xg}$ for 10 minutes and the supernatant was discarded. The cells were resuspended with $400 \mu \mathrm{I}$ PBS and counted. $1 \times 10^{6}$ cells/ sample were transferred into individual FACS tubes and incubated with anti-mouse CD16/32 for 20 minutes in the dark at $4{ }^{\circ} \mathrm{C}$ to prevent unspecific binding to Fc-receptors. Characterization of the cellular composition of the lamina propria in the jejunum was analyzed via FACS (see 2.2.9.1). The gating strategy is depicted in Figure 7. 


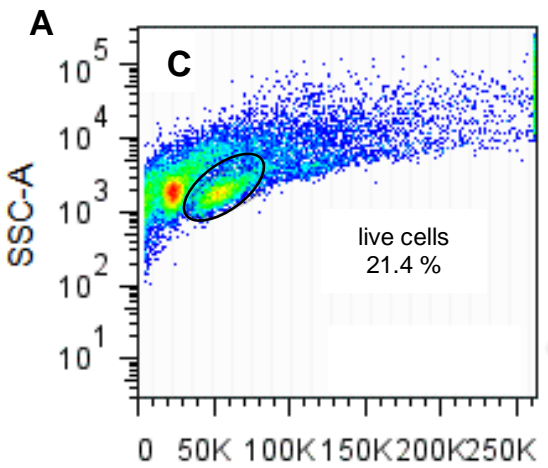

FSC-A
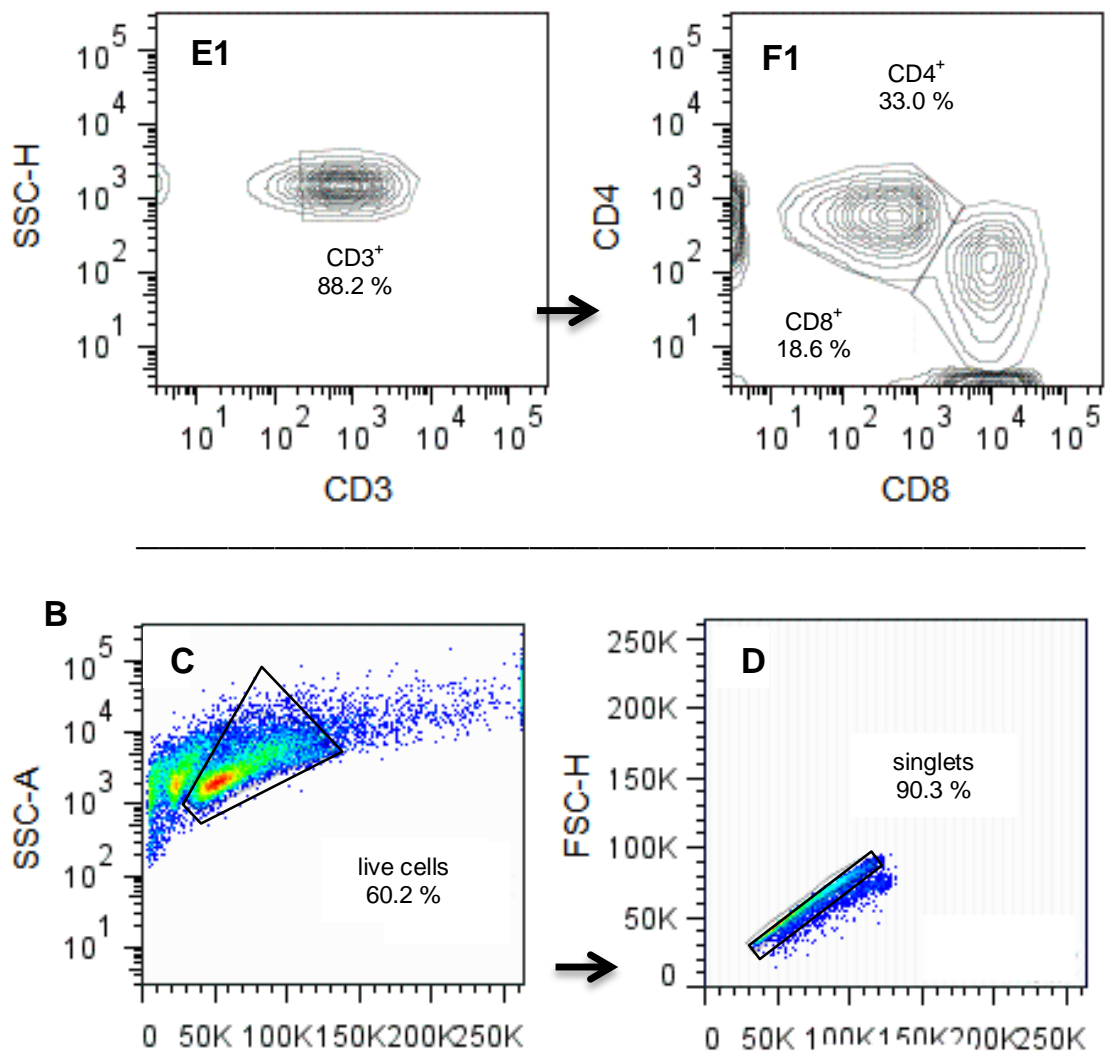

FSC-A

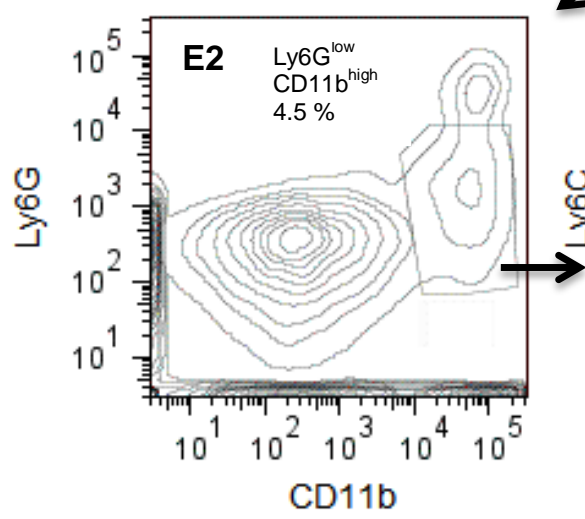

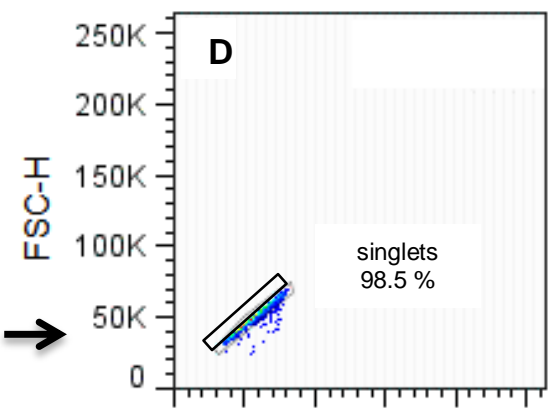

0 50K 100K150K200K250K

FSC-A

Figure 7: Gating strategy of flow cytometric analyses for the characterization of lamina propria cells. Lymphocytes (A) and myeloid cells (B) were first gated for living cells (C) based on forward scatter (FSC) and side scatter (SSC). Next, singlets (D) were gated based on forward scatter area (FSC-A) and forward scatter height (FSC-H). Lymphocytes (A) were gated for $\mathrm{CD}^{+} \mathrm{T}$ cells (E1) and then separated into $\mathrm{CD}^{+}$and $\mathrm{CD}^{+}$ $\mathrm{T}$ cells (F1). Myeloid cells (B) were gated for Ly6G ${ }^{\text {low }}$ CD11 ${ }^{\text {high }}$ cells (E2) and then separated into Ly6C ${ }^{\text {high }}$ CD $11 b^{\text {high }}$ and Ly6C $\mathrm{C}^{\text {low }} \mathrm{Cd} 11 \mathrm{~b}^{\text {high }}$ cells (F2). 


\subsubsection{Inductively Coupled Plasma-Mass Spectrometry}

Inductively Coupled Plasma-Mass Spectrometry (ICP-MS) was performed to determine the tissue distribution of zirconium ( $\mathrm{Zr}$ ) after BMP-NP administration. $500 \mu \mathrm{l} \mathrm{BMP-NPs}$, which contained $0.2 \mathrm{mg} \mathrm{Zr}$, were injected i.p. and 5 and 24 hours later the mice were sacrificed by $\mathrm{CO}_{2}$ inhalation. The lung, left kidney, a central piece of $20 \mathrm{~cm}$ length of the jejunum, left and caudate liver lobe and stomach were dissected, washed with PBS, weighted and stored at $-80^{\circ} \mathrm{C}$. The samples were sent for analysis to the commercial microanalytical laboratory Pascher (Remagen, Germany).

\subsubsection{Experimental setup for the analysis of glucocorticoid associated side-effects in mice}

\subsubsection{Hyperglycemia}

C57BL/6 wt mice were treated with either $10 \mathrm{mg} / \mathrm{kg} \mathrm{BMX}$ or BMP-NPs or with equal amounts of either PBS or EP-NPs i.p. for 14 consecutive days in the morning. Food was removed at 6 p.m. at day 13, the day before analysis. Two hours after the last treatment, at day 14, blood glucose levels were measured (see 2.2.4.2), subsequently the mice were sacrificed and liver biopsies were shock frozen at $-80{ }^{\circ} \mathrm{C}$. The expression of gluconeogenetic enzymes was analyzed via qRT-PCR (see 2.2.7.6).

\subsubsection{Myopathy}

C57BL/6 wt mice were treated as in 2.2.5.1 and the bodyweight was determined at day 14. Two hours after the last treatment, at day 14, mice were sacrificed and the $M$. gastrocnemius of the right leg was removed, weighted and shock frozen at $-80^{\circ} \mathrm{C}$. The expression of myopathy related genes was analyzed via qRT-PCR (see 2.2.7.6).

\subsubsection{Osteoporosis}

10 weeks old female BALB/c wt mice were treated as in 2.2.5.1. Mice were sacrificed at the end of the experiment and serum was collected for the analysis of bone resorption markers (see 2.2.4.3). Sera samples were analyzed by 
ELISA at the Institute of Comparative Molecular Endocrinology at the University of Ulm by Yasmine Hachemi.

\subsubsection{In vitro analysis of IOH-NPs in cell culture}

\subsubsection{Cellular uptake of IOH-NPs into primary immune cells}

Splenocytes were isolated from wt mice as described earlier (see 2.2.2.3). Erythrocytes were lysed by incubation with $4 \mathrm{ml} \mathrm{TAC} \mathrm{buffer} / \mathrm{ml}$ of cell suspension for 12 minutes at RT. The volume was adjusted to $20 \mathrm{ml}$ with PBS and the cells were centrifuged at $300 \times \mathrm{g}$ at $4{ }^{\circ} \mathrm{C}$ for 5 minutes. The supernatant was discarded, the pellet was resuspendend in a total volume of $1 \mathrm{ml}$ with $\mathrm{RPMI}_{++}$medium and the cells were counted with the help of a Neubauer haemocytometer. To this end, $1 \times 10^{6}$ cells $/ \mathrm{ml}$ were cultured in $\mathrm{RPMl}++$ medium in 24-well plates without or with ascending concentrations of EP-NPs $(2.5,12.5$, $25,50 \mu \mathrm{g} / \mathrm{ml}$ ) for 24 hours at $37^{\circ} \mathrm{C}$ and $5 \% \mathrm{CO}_{2}$. Cells were harvested and EP-NP uptake into $\mathrm{CD}^{+}, \mathrm{B}_{2} 2 \mathrm{O}^{+}$and $\mathrm{CD} 11 \mathrm{~b}^{+}$cells was analyzed by flow cytometry (see 2.2.9.1).

\subsubsection{Cellular uptake of IOH-NPs into different cell lines}

$\mathrm{IOH}-\mathrm{NP}$ uptake was analyzed in 6 different cell lines (see Table 10). In one setup, $1 \times 10^{5}$ cells $/ \mathrm{ml}$ cells were seeded in $3 \mathrm{ml}$ of the respective culture medium (see Table 10) and cultured in 6-well plates at $37{ }^{\circ} \mathrm{C}$ and $5 \% \mathrm{CO}_{2}$ atmosphere for 48 hours. Subsequently, $2.5 \mu \mathrm{g} / \mathrm{ml}$ EP-NPs were added to the samples for 0.5 to 6 hours. Alternatively, the cells were first cultured for 24 hours and then $2.5 \mu \mathrm{g} / \mathrm{ml} \mathrm{BMP-NPs}$ or $2.5 \mu \mathrm{g} / \mathrm{ml}$ EP-NPs were added for another 24 hours. In another setup, MH-S cells were cultured for 48 hours and $50 \mu \mathrm{g} / \mathrm{ml} \mathrm{BMP-NPs}$ were added for 6 hours or alternatively, MH-S cells were cultured for 24 hours and thereafter $50 \mu \mathrm{g} / \mathrm{ml}$ BMP-NPs were added for another 24 hours. As a control, cells were cultured in the absence of IOH-NPs. In the end, IOH-NP uptake was analyzed via flow cytometry (see 2.2.9.1). MH-S, L929, C2C12 and LA-4 cells were detached from the bottom of the wells by sucking of the medium and adding $0.25 \%$ trypsin-EDTA $(1 \mathrm{x})$ for 5 minutes. This was not necessary for WEHI7.1 and WEHI231 cells. 


\subsubsection{Viability test of cell lines}

The viability of the cell lines was analyzed after incubation with IOH-NPs and/ or and pharmacological inhibitors. Therefore, $1 \times 10^{6} \mathrm{cells} / \mathrm{ml}$ were seeded and $100 \mu \mathrm{l}$ were cultured in 96-well plates in the presence or absence of $2.5 \mu \mathrm{g} / \mathrm{ml}$ EP-NPs or BMP-NPs for 6 hours. For comparison, $10 \%$ DMSO was added to the culture medium for 3 hours as negative control. Alternatively, $\mathrm{MH}-\mathrm{S}$ cells were incubated in the presence of $6 \mu \mathrm{g} / \mathrm{ml} \mathrm{BMP-NPs}$, with or without $1 \mu \mathrm{g} / \mathrm{ml}$ CytoD (cytochalasin D), $0.5 \mathrm{mM} / 1 \mathrm{mM} / 2 \mathrm{mM}$ Amiloride (amiloride hydrochloride hydrate) or $100 \mu \mathrm{M} / 150 \mu \mathrm{M}$ MDC (monodansyl-cadaverine) for 24 hours. For comparison, $10 \%$ DMSO was added to the culture medium as negative control. In addition, MH-S cells were incubated with $6 \mu \mathrm{g} / \mathrm{ml}$ BMP-NPs together with the inhibitors for 3 to 6 hours as well as 24 hours. For comparison, $10 \%$ DMSO was added to the culture medium as negative control. In all conditions, the cell viability was assessed by using a MTS cell proliferation assay (CellTiter $96{ }^{\circledR} \mathrm{AQ}$ eous One Solution Cell Proliferation Assay Kit) according to manufacturer's instructions. In brief, $20 \mu$ of MTS tetrazolium compound was added to the cells, which gets bioreduced by metabolically active cells into a colored formazan product that is soluble in the culture medium. The absorbance of the colored formazan was recorded at $490 \mathrm{~nm}$ by spectrophotometry.

\subsubsection{Characterization of BMP-NP uptake into MH-S cells}

To study the endocytic pathway via which $\mathrm{IOH}-\mathrm{NPs}$ are taken up, MH-S cells were seeded at a concentration of $5 \times 10^{5}$ cells $/ \mathrm{ml}$ in a volume of $1 \mathrm{ml}$ in 24-well plates and cultured for 48 hours. Subsequently, $50 \mu \mathrm{g} / \mathrm{ml}$ BMP-NPs were added for up or 6 hours in addition to $1 \mu \mathrm{g} / \mathrm{ml}$ CytoD or $1 \mathrm{mM}$ Amiloride or $100 \mu \mathrm{M}$ MDC. For comparison, MH-S cells were cultured in the presence of BMP-NPs, but in the absence of pharmacological inhibitors. Alternatively, $\mathrm{MH}$-S cells were first cultured for 24 hours and subsequently, increasing concentrations of BMP-NPs $(2.5,12.5,25$ or $50 \mu \mathrm{g} / \mathrm{ml})$ in addition to $1 \mu \mathrm{g} / \mathrm{ml}$ CytoD or $1 \mathrm{mM}$ Amiloride or $100 \mu \mathrm{M}$ MDC were added for 24 hours. For comparison, MH-S cells were cultured in the presence of BMP-NPs, but in the absence of inhibitors. BMP-NP uptake was analyzed via flow cytometry (see 2.2.9.1). 


\subsubsection{Bone marrow derived macrophages}

In order to obtain bone marrow derived macrophages (BMDMs), bone marrow from mouse tibia and femora was cultured in the presence of macrophage colony-stimulating factor (M-CSF) present in LCCM (L929 cell conditioned medium) medium. In brief, bone marrow was harvested as described earlier (see 2.2.2.2). Cells were resuspended in pre-warmed DMEM++, adjusted to a concentration of $1 \times 10^{6} \mathrm{cells} / \mathrm{ml}$ and cultured for 24 hours. Whereas fibroblasts and stromal cells adhered to the surface of the culture dish, non-adherent cells representing myeloid progenitor cells could be harvested from the supernatant on the next day. Cells were washed and $2 \times 10^{6}$ cells were plated in $10 \mathrm{~cm}^{2}$ petri dishes with LCCM medium. At day 4, LCCM medium was added to boost the maturation process of these cells. At day 7 to 9 , the myeloid progenitor cells fully matured to BMDMs and were harvested by adding PBS/ 2 mM EDTA for 30 minutes at $37{ }^{\circ} \mathrm{C}$ in $5 \% \mathrm{CO}_{2}$ atmosphere. Cells were washed and resuspended in DMEM++ medium and used for further flow cytometric analysis (see 2.2.9.1).

\subsubsection{Flow cytometric analysis of BMDMs}

The expression of extracellular surface antigens after treatment with IOH-NPs was analyzed in BMDMs. Therefore, $1 \times 10^{6} \mathrm{cell} / \mathrm{s} / \mathrm{ml}$ of differentiated BMDMs from BALB/c wt mice were seeded and cultured in a volume of $1 \mathrm{ml}$ in 24-well plates. Either EP-NPs or BMP-NPs in increasing concentrations $(25,250 \mathrm{ng} / \mathrm{ml}$, 2.5, 25, $50 \mu \mathrm{g} / \mathrm{ml}$ ) or, as a control, no IOH-NPs were added to the cells and incubated for 24 hours. Subsequently, the cells were harvested and analyzed via flow cytometry (see 2.2.9.1).

\subsubsection{Molecular analyses}

\subsubsection{Enzyme Linked Immunosorbant Assay}

Cytokine and chemokine concentrations were analyzed in serum samples and the supernatant of tissue cultures of jejunum biopsies by using different Enzyme Linked Immunosorbant Assay (ELISA) Kits (Table 4) according to manufacturer's instructions. In brief, Nunc-Immuno ${ }^{\mathrm{TM}}$ MicroWell $^{\mathrm{TM}}$ 96-well 
plates were coated with $100 \mu \mathrm{l}$ of the respective capture antibody, which was diluted in coating buffer and incubated at $4{ }^{\circ} \mathrm{C}$ overnight $(\mathrm{O} / \mathrm{N})$ in the dark. Next day, the plates were washed four times. Afterwards $200 \mu$ ELISA assay diluent were added to each well and incubated for 1 hour on the shaker at RT to prevent non-specific binding. Washing was repeated and samples were diluted in ELISA assay diluent and incubated in duplicates for 2 hours at RT as well as the standard, which was incubated in triplicates. After another washing step, the respective detection antibody was diluted in ELISA assay diluent and $100 \mu \mathrm{l}$ were added for 1 hour at RT. The plates were washed and $100 \mu$ of ELISA Horse Radish Peroxidase (HRP) were added to the wells for 30 minutes at RT. Afterwards the plates were intensively washed five times by leaving the washing solution within the wells for 30 seconds before sucking it off after each washing step. Finally, $100 \mu$ l of ELISA Developing solution were added and left for 15 to 20 minutes in the dark to allow peroxidase activity to proceed. The reaction was stopped by adding $50 \mu \mathrm{l}$ of ELISA Stop solution to each well and the color change was measured by spectrophotometry at $450 \mathrm{~nm}$ and $570 \mathrm{~nm}$.

\subsubsection{RNA isolation}

RNA was isolated using the Qiagen RNeasy Plus Universal Mini Kit according to manufacturer's instructions. In brief, frozen tissue biopsies were transferred into sterile $14 \mathrm{ml}$ tubes. $900 \mu \mathrm{l}$ of QIAzol ${ }^{\mathrm{TM}}$ Lysis Buffer was added. The tissue was homogenized using the Tissue Homogenizer Ultra Turrax T18 Basic, transferred into a tube and placed on ice. $100 \mu \mathrm{l}$ of gDNA eliminator solution were added and vortexed for 15 seconds. $180 \mu$ l of chloroform were added and vortexed for 15 seconds. The samples were placed on ice for 3 minutes afterwards they were centrifuged for 15 minutes at $20.817 \times \mathrm{g}$ at $4{ }^{\circ} \mathrm{C} .600 \mu \mathrm{l}$ of the upper phase were harvested and transferred into another tube subsequently mixed with $600 \mu \mathrm{l}$ of $70 \%$ ethanol. $600 \mu \mathrm{l}$ of the sample were transferred into an RNeasy-Mini column and centrifuged at $20.817 \times \mathrm{g}$ for 20 seconds at RT. The flow-through was discarded and this step was repeated. $700 \mu$ of RWT buffer were added and vortexed for 20 seconds at $10.621 \times \mathrm{g}$. The flow-through was discarded and $500 \mu \mathrm{l}$ of RPE buffer were added. The samples were vortexed for 2 minutes at $10.621 \times \mathrm{g}$ and the flow-through was discarded. The RNeasy-Mini 
columns, which contained the samples bound to the membrane, were dried by centrifugation at $10.621 \mathrm{xg}$ for 1 minute. Finally, the RNA was eluted by adding, in two steps, $70 \mu \mathrm{l}$ (35 $\mu \mathrm{l}$ each) RNase free $\mathrm{H}_{2} \mathrm{O}$ followed by centrifugation at $10.621 \mathrm{xg}$ for 1 minute. The samples were frozen at $-20^{\circ} \mathrm{C} /-80^{\circ} \mathrm{C}$. By using a Nanodrop device, the RNA concentration was determined based on the $260 \mathrm{~nm}$ absorption. Protein contamination was measured at $280 \mathrm{~nm}$ and organic compound contamination at $230 \mathrm{~nm}$. RNA quality control was based on the characteristic bands of $18 \mathrm{~S}$ and $28 \mathrm{~S}$ rRNA in a ratio of 1:2 after visualizing it on a $1 \%$ TAE agarose gel. Therefore $1 \mu \mathrm{g}$ RNA, $5 \mu$ Orange $\mathrm{G}$ and $\mathrm{ddH}_{2} \mathrm{O}$ ,adjusted to a volume of $20 \mu$, was loaded on the gel.

\subsubsection{3 mRNA isolation}

mRNA was harvested from total RNA preparations by using the Dynabeads ${ }^{\mathrm{TM}}$ mRNA Purification Kit accordingly to manufacturer's instructions. In brief, $50 \mu \mathrm{l}$ of RNA was heated to $65^{\circ} \mathrm{C}$ for 2 minutes and then immediately placed on ice. Meanwhile $100 \mu \mathrm{l}$ of Dynabeads per sample were transferred to a tube and placed in a magnet for 30 seconds. The beads attached to the wall and the supernatant was discarded. $50 \mu \mathrm{l}$ of binding buffer was added to the tubes outside of the magnet and thereafter placed in the magnet again. The supernatant was discarded and $50 \mu \mathrm{l}$ of binding buffer were added outside of the magnet. RNA and Dynabeads were mixed in a ratio of $1: 1$ and incubated on a shaker at RT for 5 minutes. The samples were placed in the magnet again and the supernatant was removed. Outside of the magnet $100 \mu \mathrm{l}$ of buffer $\mathrm{A}$ was added and the tubes were placed in the magnet. The supernatant was discarded and this washing step was repeated twice with $100 \mu \mathrm{l}$ of buffer $\mathrm{B}$. Finally, mRNA was eluted by adding $15 \mu$ of $10 \mathrm{mM}$ Tris- $\mathrm{HCl}, \mathrm{pH} 7.5$ and heated at $80{ }^{\circ} \mathrm{C}$ for 2 minutes. The samples were immediately placed in the magnet and mRNA was transferred to another tube.

\subsubsection{4 cDNA synthesis}

cDNA was synthesized from total RNA or mRNA samples by using the iScript ${ }^{\mathrm{TM}}$ cDNA Synthesis Kit according to manufacturer's instructions. In brief, $1 \mu \mathrm{g}$ total RNA or $5 \mu \mathrm{l}$ of the mRNA preparations (see 2.2.7.3), $4 \mu \mathrm{l} 5 \mathrm{x}$ iScript Reaction 
Mix, $0.25 \mu \mathrm{l}$ iScript Reverse Transcriptase and nuclease-free $\mathrm{H}_{2} \mathrm{O}$ adjusted to a volume of $20 \mu \mathrm{l}$ were mixed in a tube and placed on ice. cDNA synthesis was then conducted by using the following reaction protocol in a thermocycler: Priming (5 minutes at $\left.25^{\circ} \mathrm{C}\right)$; Reverse Transcriptase (30 minutes at $42{ }^{\circ} \mathrm{C}$ ); Inactivation $\left(5 \min\right.$ at $\left.85^{\circ} \mathrm{C}\right)$.

\subsubsection{Polymerase Chain Reaction}

To verify whether cDNA synthesis has been successful, a Polymerase Chain Reaction (PCR) was performed. Therefore, the expression of the housekeeping gene hypoxanthine guanine phosphoribosyl transferase $(H p r t)$ or heterochromatin protein 1 (Hp1) was analyzed. The PCR reaction mix for each sample contained the following components:

Table 16: PCR reaction mix

\begin{tabular}{ll}
\hline Volume $[\mu l]$ & Reagent \\
\hline 12.7 & dd $\mathrm{H}_{2} \mathrm{O}$ \\
4 & Phusion Reaction Buffer HF \\
0.5 & Hprt or Hp1 Primer forward $[10 \mathrm{pmol} / \mu \mathrm{l}]$ \\
0.5 & Hprt or $\mathrm{Hp} 1$ Primer reverse $[10 \mathrm{pmol} / \mu \mathrm{l}]$ \\
1 & dNTPs $[5 \mathrm{mM}]$ \\
1 & cDNA template \\
0.3 & PhuS (DNA polymerase) \\
\hline
\end{tabular}

The PCR reaction was conducted in a Thermocycler Mastercycler EP Gradient by applying the following program:

Table 17: PCR reaction program

\begin{tabular}{llll}
\hline Step & Time & Temperature $\left[{ }^{\circ} \mathbf{C}\right]$ & Cycle \\
\hline Denaturation I & 2 minutes & 98.5 & 1 \\
Denaturation II & 20 seconds & 98.5 & \\
Annealing & 15 seconds & 64 & 30 \\
Elongation I & 20 seconds & 72 & \multicolumn{1}{|c}{1} \\
Elongation II & 2 minutes & 72 & \\
\hline
\end{tabular}


$5 \mu \mathrm{l}$ of Orange $\mathrm{G}$ was added to the final PCR products and loaded on a $1 \%$ TAE agarose gel.

\subsubsection{Quantitative Reverse Transcription-PCR}

Quantitative Reverse Transcription-PCR (qRT-PCR) was used to analyze the gene expression of target genes. The qRT-PCR reaction mix for each sample contained $12.5 \mu$ I SYBR green reaction mix, $11 \mu \mathrm{lddH_{2 }} \mathrm{O}, 1 \mu$ l template (cDNA), $0.25 \mu \mathrm{H}$ Hprt or Hp1 forward primer and $0.25 \mu \mathrm{l}$ Hprt or Hp1 reverse primer (10 pmol/ $\mu \mathrm{l})$. The components were mixed on ice in 96-well Saphire Microplates and then sealed with Optical Adhesive Covers. The plates were centrifuged and subsequently placed in the Real-Time PCR System 7500 for cDNA amplification. Afterwards, the expression level of target genes was calculated in relation to the housekeeping genes $H p r t$ or $H p 1$ by using the $\Delta \Delta \mathrm{C}_{\mathrm{T}}$ method.

\subsubsection{Histology}

\subsubsection{Preparation of tissue sections}

At the peak of the disease, at day 6, and partially before and after the peak, namely at day 4 and 8 , a $3 \mathrm{~cm}$ central piece of the jejunum was removed and flushed with $4 \%$ paraformaldehyde (PFA) using a 24 G needle. Subsequently the pieces were placed in individual wells of a 24 -well plate filled with $4 \%$ PFA and left for 48 hours at RT. The pieces were cut in three $1 \mathrm{~cm}$ pieces, enwrapped in filter papers in which they have been transferred into histology cassettes. Dehydration and paraffin embedding was performed with the Tissue Processor Excelsior ES, an automatic system installed at the Institute of Pathology of the University Medical Center (UMG) in Göttingen (Dr. med. Hanibal Bohnenberger).

In the following, the samples were placed upside down in metal forms, which were filled with hot paraffin and left for cooling. $2 \mu \mathrm{m}$ sections of the paraffin embedded tissue samples were cut by using a microtome. 
All stainings of the tissue sections were performed at the Institute of Pathology of the UMG by Jennifer Appelhans from the group of Dr. med. Hanibal Bohnenberger using the automatic system Tissue Tek Prisma Slide Stainer.

\subsubsection{Evaluation of histological stainings}

All histological evaluations of stained tissue sections were done in a blinded manner. Histopathological scores were determined based on H\&E stainings. Four criteria were assessed in ten fields per section. (1) Villous blunting/ flattening ( 0 = none, 1 = yes; $20 \times$ magnification), (2) number of apoptotic cells (40 $\times$ magnification), (3) grade of inflammation $(0=$ none, $1=$ mild, $2=$ moderate without abscess, 3 = presence of abscess, erosions or ulcer; $20 \mathrm{x}$ magnification, (4) edema ( 0 = none, 1 = yes; $20 \times$ magnification). The sum of all four criteria of each individual was calculated to obtain the total histological score.

The number of goblet cells was determined based on PAS stainings. $\mathrm{PAS}^{+}$cells were counted per villus in a total of 10 villi in a $40 \times$ magnification and the average was calculated.

The number of $\mathrm{T}$ cells $\left(\mathrm{CD}^{+}\right.$cells) and macrophages $\left(\mathrm{CD}^{+} 8^{+}\right.$cells) was determined based on immunohistochemical stainings. $\mathrm{CD}^{+}$cells were individually counted by photomicrographs, which were acquired with a Zeiss Axio Scope A1 microscope in a 20 x magnification. The average of cells within ten pictures was calculated. For macrophages, the photomicrographs at $20 \mathrm{x}$ magnification were additionally processed with ImageJ and the stained area was measured. The average of the stained area of ten pictures was calculated.

\subsubsection{Optical methods}

\subsubsection{Flow Cytometry}

Flow Cytometry was used to determine the cellular composition, IOH-NP uptake or extracellular antigen expression within samples. To this end, $1 \times 10^{6}$ cells were harvested and primary antibodie(s) were added to the samples and 
incubated for 20 minutes at $4{ }^{\circ} \mathrm{C}$ in the dark. Cells were washed with $3 \mathrm{ml} \mathrm{FACS}$ Buffer and centrifuged for 5 minutes at $300 \times \mathrm{g}$. The supernatant was discarded and the pellet was resuspended in the reflux. Of note, IOH-NP uptake was determined based on the emission of green fluorescence originating from the dye FMN. Analyses were performed with the device FACS Canto II by using the software BD FACS Diva ${ }^{\text {TM }}$. 30.000 to 50.000 cells/ sample were recorded and data were processed with the software FlowJo.

\subsubsection{Imaging Flow Cytometry}

Imaging Flow Cytometry was used to visualize IOH-NPs within different cellular compartments in MH-S cells. In brief, $5 \times 10^{6} \mathrm{MH}-\mathrm{S}$ cells were cultured in $30 \mathrm{ml}$ in $175 \mathrm{~cm}^{2}$ flasks in the presence of $6 \mu \mathrm{g} / \mathrm{ml}$ BMP-NPs for 24 hours. Medium was removed, cells were washed with pre-warmed PBS and fresh pre-warmed medium was added together with either $100 \mathrm{nM}$ Lysotracker ${ }^{\circledR}$ Deep Red (DR) or $100 \mathrm{nM}$ Mitotracker ${ }^{\circledR}$ DR FM for 30 minutes. Alternatively, MH-S cells were cultured for 24 hours and subsequently $6 \mu \mathrm{g} / \mathrm{ml}$ BMP-NPs were added for 6 hours. The medium was removed, cells were washed with pre-warmed PBS and fresh medium was added together with either $100 \mathrm{nM}$ Lysotracker ${ }^{\circledR} \mathrm{DR}$ or 100 nM Mitotracker ${ }^{\circledR}$ DR FM for 30 minutes. The samples were harvested, centrifuged at $300 \mathrm{xg}$ for 5 minutes at $4{ }^{\circ} \mathrm{C}$ and the supernatant was discarded. The pellet was resuspended in $500 \mu \mathrm{l}$ FACS Buffer and passed through the nylon mesh within the cap of a $5 \mathrm{ml}$ falcon tube. $100 \mu \mathrm{l}$ of this cell suspension was used for Imaging Flow Cytometry analysis and 1.000 to 2.000 focused cells were recorded by using the device ImageStream ${ }^{\circledR} X$ Mark II Imaging Flow Cytometry. Data were processed with the software IDEAS and the co-localization wizard was applied. To this end, focused cells were gated on R2, double positive events $\left(\mathrm{FMN}^{+}\right.$and $\left.\mathrm{DR}^{+}\right)$and the Bright Detail Similarity were assessed, which identifies the small punctate stainings in imaged pairs and measures the correlation of these dots.

\subsubsection{Confocal laser scanning microscopy}

Confocal laser scanning microscopy was used to visualize IOH-NPs in MH-S cells. To this end, $1 \times 10^{6} \mathrm{cells} / \mathrm{ml}$ were seeded and $100 \mu \mathrm{l}$ were cultured in 
cover glas bottom 1.0 Imaging dishes for 24 hours in the presence of $6 \mu \mathrm{g} / \mathrm{ml}$ BMP-NPs. Afterwards the cells were washed with PBS, $100 \mu \mathrm{l}$ of phenol-free RPMl++ were added to the cells and the uptake of BMP-NPs was visualized with the help of a Leica TCS SP2 confocal laser scanning microscope installed at the Institute of Medical Microbiology (Prof. Dr. Carsten Lüder) in Göttingen.

\subsubsection{Magnetic Resonance Imaging}

Magnetic Resonance Imaging (MRI) was used to visualize the distribution of $\mathrm{IOH}-\mathrm{NPs}$ in living BALB/c mice in vivo. The experiments were conducted in collaboration with Prof. Dr. Susann Boretius at the German Primate Center (DPZ) in Göttingen. In brief, mice were anaesthetized subcutaneously (s.c.) with $0.6 \mathrm{ml} / \mathrm{kg}$ ketamine and $0.4 \mathrm{ml} / \mathrm{kg}$ medetomidine. Subsequently, they were intubated and ventilated with a mixture of $\mathrm{O}_{2}$, ambient air and, if anesthesia was necessary, with 0.5 to $1 \%$ isoflurane anesthesia with a constant respiratory frequency of 85 breaths/min (Animal Respirator Advanced) during the entire analysis. Thereafter, mice received $500 \mu \mathrm{l}$ GAP-NP $\left(\mathrm{Gd}^{3+} 2[\mathrm{AMP}]^{2-3} \mathrm{IOH}-\mathrm{NPs}\right)$ containing $0.1 \mathrm{mg}$ gadolinium (Gd) i.p. and MRI scans of the abdominal region were performed with the Bruker BioSpec 94/30 MRI scanner prior the i.p. injection and continuously thereafter up to 6 hours at regular intervals. The data were analyzed and processed by our collaboration group. 


\section{RESULTS}

\subsection{Role of the GR in myeloid cells in aGvHD}

Acute GvHD is a life-threatening complication that often occurs after allogeneic HSCT. It is a strong inflammatory disease with a complex pathophysiology that involves various innate and adaptive immune cells. GCs are the only proven first-line aGvHD therapy due to their strong immunosuppressive effects. Of note, studies conducted by our group demonstrated the importance of the GR in transplanted $\mathrm{T}$ cells using a fully MHC-mismatch aGvHD mouse model. In particular, when $\mathrm{CD}^{+} \mathrm{T}$ cells were GR-deficient, clinical symptoms and histological features were aggravated and survival times were reduced (TheissSuennemann et al., 2015). Although, it is believed that GC therapy mainly targets $T$ cells, radioresistant recipient myeloid cells are also important player in aGvHD pathophysiology, where they participate in the initiation phase of the disease and induce tissue damage by the release of mediators, including reactive oxygen species (ROS) or reactive nitrogen species (RNS). GCs can further polarize macrophages towards an anti-inflammatory phenotype and hereby participate in wound healing and the resolution of inflammation. The importance of the GR in myeloid cells in keeping inflammatory processes at bay, has been shown, for example, in sepsis and acute lung injury (Vettorazzi et al., 2015, Kleiman et al., 2012). Previous data from our group taking advantage of the $\mathrm{GR}^{\mathrm{lyM} M}$ mouse model further showed that the resistance of radioresistant myeloid cells to endogenous GCs induces early mortality in aGvHD (Baake et al., 2018). The first part of this thesis will therefore focus on the role of myeloid cells and their regulation by endogenous GCs in aGvHD and shed light on the pathogenic mechanisms leading to the reduced survival in $\mathrm{GR}^{\mathrm{lysM}}$ mice compared to $\mathrm{GR}^{\text {flox }}$ mice in this disease model.

\subsubsection{Deletion of the GR in recipient myeloid cells exacerbated aGvHD}

In order to compare the early phase of aGvHD in a fully MHC-mismatch mouse model, $G^{\text {flox }}$ and $\mathrm{GR}^{\text {lysM }}$ mice were analyzed at different time points after disease induction. BALB/c recipient mice were irradiated and on the following 
day, they were transplanted with BM cells and purified T cells from wild type C57BL/6. Mice receiving only T cell depleted BM served as control. According to an established scoring system, their health status was monitored for 4,6 or 8 days. In addition the body weight and the body temperature was determined (Figure $8 \mathrm{~A}-\mathrm{C}$ ). At the first time point analyzed, namely day 4 , there were no differences in the clinical symptoms detectable between both genotypes and the scores were similar to the ones of control BM mice (Figure 8A). BM mice showed the lowest clinical score, as expected, since they were only exposed to irradiation, but did not suffer from aGvHD. At day 6 and $8, G^{\text {lysM }}$ mice developed significantly higher clinical scores in comparison to $\mathrm{GR}^{\text {flox }}$ control mice (Figure 8A). Furthermore, the mice increasingly lost body weight while the disease proceeded, although there was no significant difference between both genotypes (Figure 8B). The body temperature of $\mathrm{GR}^{\text {lysM }}$ mice was already reduced on day 4 in comparison to $\mathrm{GR}^{\text {flox }}$ mice. At day 6 , it further dropped and was significantly lower in $\mathrm{GR}^{\mathrm{lysM}}$ mice at day 8 (Figure $8 \mathrm{C}$ ). Taken together, GR deletion in radioresistant myeloid cells leads to an aggravated disease course, which is in line with the increasing mortality of these mice after aGvHD induction (Baake et al., 2018). 

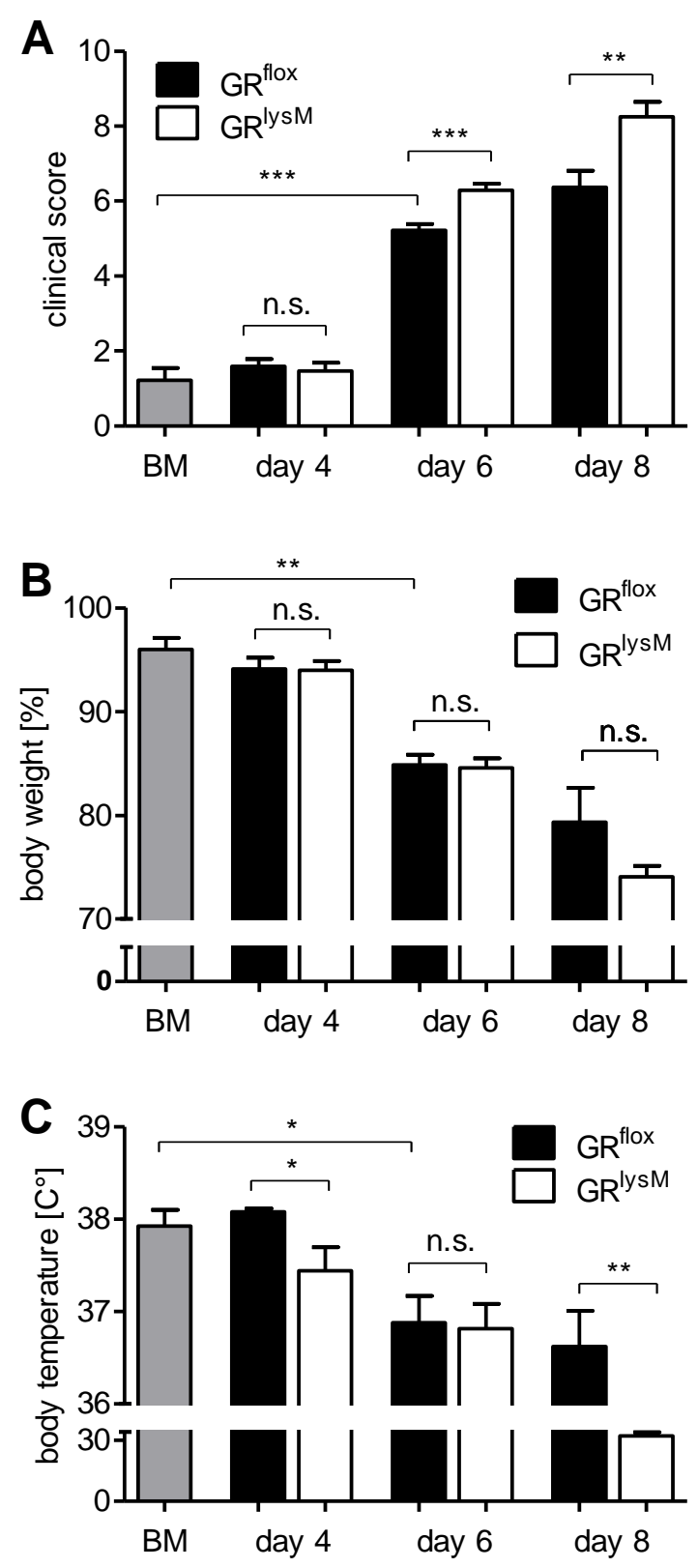

Figure 8: Clinical features of aGvHD in the GR $^{\text {lysM }}$ mouse model. Lethally irradiated BALB/C $\mathrm{GR}^{\text {flox }}$ and $\mathrm{GR}^{\text {lysM }}$ recipient mice were transplanted with $\mathrm{BM}$ and purified $\mathrm{T}$ cells from donor C57BL/6 wt mice. BM controls received T cell depleted BM only. (A) Clinical scores were monitored for 4,6 or 8 days after aGvHD induction (dead mice were documented with a score of 10); analysis of BM controls was conducted on day $6 . N=9(\mathrm{BM}), \quad N=31 / 31\left(\mathrm{GR}^{\mathrm{flox}} / \mathrm{GR}^{\text {lysM }}\right.$; day 4$), N=39 / 40$ ( $\mathrm{GR}^{\text {flox }} / \mathrm{GR}^{\text {lysM }}$; day 6$), N=19 / 20$ (GR ${ }^{\text {flox }} / \mathrm{GR}^{\text {lysM }}$; day 8$)$; data pooled from multiple experiments, including data from Katarina Jörß and Laura Roßmann. (B) Body weights were monitored for 4,6 or 8 days after aGvHD induction; analysis of BM controls was conducted on day $6 . N=4(\mathrm{BM}), N=5 / 5\left(\mathrm{GR}^{\mathrm{flox}} / \mathrm{GR}^{\text {lysM }}\right.$; day 4$), N=14 / 15\left(\mathrm{GR}^{\mathrm{flox}} / \mathrm{GR}^{\text {lysM }}\right.$; day 6$)$, $N=6 / 8\left(\mathrm{GR}^{\text {flox}} / \mathrm{GR}^{\text {lysM}}\right.$; day 8$)$; data pooled from multiple experiments. (C) Body temperatures were monitored for 4,6 or 8 days after aGvHD induction; analysis of BM controls was conducted on day 6. $N=8(\mathrm{BM}), N=5 / 5\left(\mathrm{GR}^{\mathrm{flox}} / \mathrm{GR}^{\text {lysM }}\right.$; day 4$), N=20 / 22\left(\mathrm{GR}^{\text {flox }} / \mathrm{GR}^{\text {lysM }}\right.$; day 6$)$, $N=5 / 7\left(\mathrm{GR}^{\text {flox}} / \mathrm{GR}^{\mathrm{lysM}}\right.$; day 8$)$; data pooled from multiple experiments, including data from Katarina Jörß and Laura Roßmann. All values are depicted as mean \pm SEM. Statistical analyses were performed by Mann-Whitney $U$ test $\left({ }^{*} p<0.05 ;{ }^{* *} p<0.01 ;{ }^{* *} p<0.001\right.$; n.s.: nonsignificant) (Baake et al., 2018). 


\subsubsection{The disease course of aGvHD in GR $^{\text {lysM }}$ mice cannot be explained by target tissue damage in the jejunum}

Searching for an explanation for the exacerbated disease progression in $\mathrm{GR}^{\text {lysM }}$ mice we performed a histological analysis in one of the aGvHD target tissues, the jejunum. Histological alterations were identified by $H \& E$ staining and examined based on an established scoring system (Theiss-Suennemann et al., 2015). The analysis revealed a strong and significant increase in tissue damage, intensifying from day 4 to 8 in both genotypes, which was characterized by more extensive villus blunting, inflammatory infiltration, edema formation and higher numbers of apoptotic cells (Figure 9A, B). Furthermore, the number of goblet cells per villus declined from day 4 to 8 in both genotypes (Figure 9A, C). Importantly, there were no differences in the histological score or the number of goblet cells between $\mathrm{GR}^{\text {flox }}$ and $\mathrm{GR}^{\text {lysM }}$ mice at any time point. Consequently, the tissue damage caused by aGvHD is not responsible for the exacerbated disease course in $\mathrm{GR}^{\mathrm{lysM}}$ mice. 

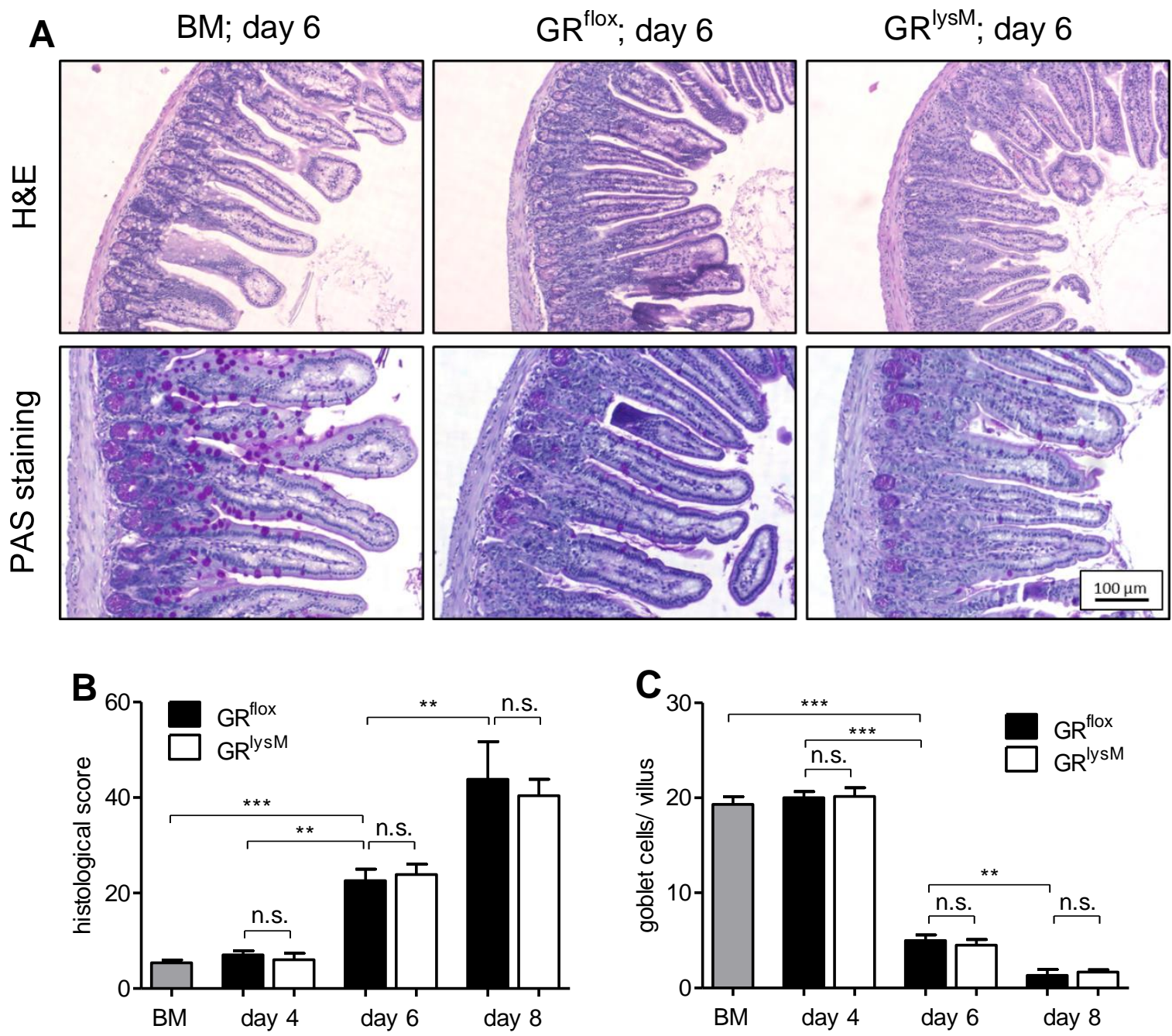

Figure 9: Histological analysis of the aGvHD target tissue jejunum in the $\mathrm{GR}^{\mathrm{lysM}}$ mouse model. Lethally irradiated $B A L B / c R^{f l o x}$ and $G^{\text {lysM }}$ recipient mice were transplanted with $B M$ and purified T cells from donor C57BL/6 wt mice. BM controls received T cell depleted BM only. Mice were sacrificed and analyzed on day 4, 6 and 8 after BMT; analysis of BM controls was conducted on day 6 . (A) Representative microphotographs of sections of the jejunum on day 6 from BM, GR ${ }^{\text {flox }}$ and GR $\mathrm{R}^{\text {lyM }}$ mice stained by H\&E and PAS reaction. Scale bar: $100 \mu \mathrm{m}$. (B) Histological scores imply villus blunting, inflammatory infiltrates, edema and apoptotic cells. It was analyzed by $\mathrm{H} \& \mathrm{E}$ stained jejunum sections from $B M, \mathrm{GR}^{\text {flox }}$ and $\mathrm{GR}^{\text {lysM }}$ mice. $N=7$ (BM), $N$ $=5 / 5\left(\mathrm{GR}^{\text {flox }} / \mathrm{GR}^{\text {lysM }} ;\right.$ day 4$), N=20 / 21\left(\mathrm{GR}^{\text {flox }} / \mathrm{GR}^{\text {lysM }} ;\right.$ day 6$), N=6 / 7\left(\mathrm{GR}^{\text {flox }} / \mathrm{GR}^{\text {lysM }} ;\right.$ day 8$) ;$ data pooled from multiple experiments, including data from Katarina Jörß and Laura Roßmann. (C) Goblet cell number per villus analyzed by PAS reaction jejunum sections from BM, GR ${ }^{\text {flox }}$ and $\mathrm{GR}^{\text {lysM }}$ mice. $N=6(\mathrm{BM}), N=5 / 5\left(\mathrm{GR}^{\text {flox }} / \mathrm{GR}^{\text {lysM }}\right.$; day 4$), N=18 / 21\left(\mathrm{GR}^{\text {flox }} / \mathrm{GR}^{\text {lysM }} ;\right.$ day 6$), N=5 / 8$ $\left(\mathrm{GR}^{\text {flox}} / \mathrm{GR}^{\text {lysM }}\right.$; day 8$)$; data pooled from multiple experiments, including data from Katarina Jörß and Laura Roßmann. All values are depicted as mean \pm SEM. Statistical analyses were performed by Mann-Whitney $U$ test $\left({ }^{*} p<0.05 ;{ }^{* *} p<0.01 ;{ }^{* * *} p<0.001\right.$; n.s.: non-significant) (Baake et al., 2018). 


\subsubsection{The disease course of aGvHD in GR $^{\text {lysM }}$ mice cannot be explained by different infiltration of immune cells into the jejunum}

Since differences in tissue damage and goblet cell numbers per villus were not responsible for the exacerbated disease course in $\mathrm{GR}^{\text {lysM }}$ mice, we examined the number of $\mathrm{CD}^{+} \mathrm{T}$ cells and $\mathrm{CD}^{+} 8^{+}$myeloid cells in sections of the jejunum by immunohistochemical stainings. These analyses revealed an increase of $\mathrm{CD}^{+} \mathrm{T}$ cells numbers from day 4 to 6 , which remained at the same level at day 8 in both genotypes (Figure 10A, B). The number of $\mathrm{CD}^{+} 8^{+}$myeloid cells increased from day 4 to 6 , too, but then decreased at day 8 in both genotypes (Figure 10A, C). The decrease of myeloid cells at day 8 might mirror the extensive destruction of the villi at this advantaged stage of aGvHD. It is noteworthy, that there were no differences in the number of infiltrating immune cells at any of the analyzed time point in the early phase of aGvHD between both genotypes, which indicates that this pathophysiological feature cannot account for the exacerbated disease progression in $\mathrm{GR}^{\mathrm{lysM}}$ mice. 
A BM; day 6
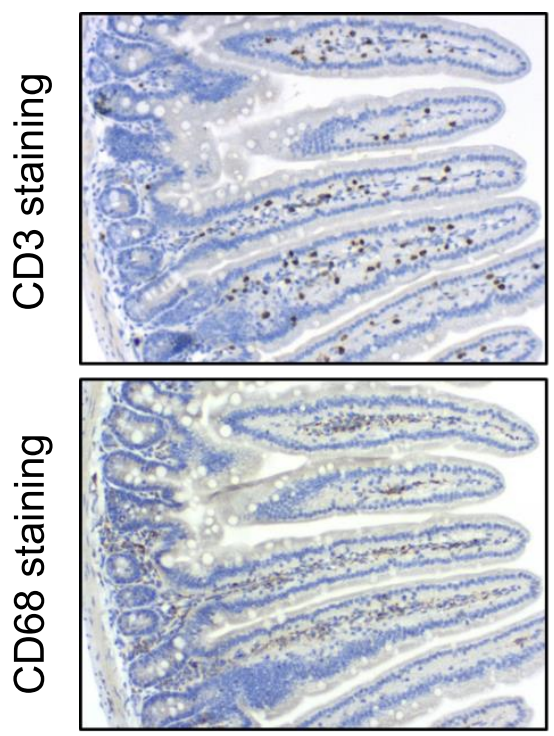

$\mathrm{GR}^{\text {tlox}} ;$ day 6
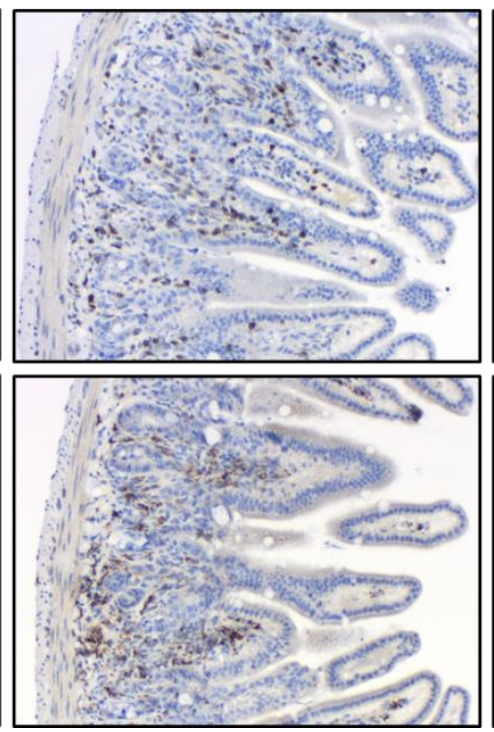

GR $^{\mathrm{lysM}}$; day 6
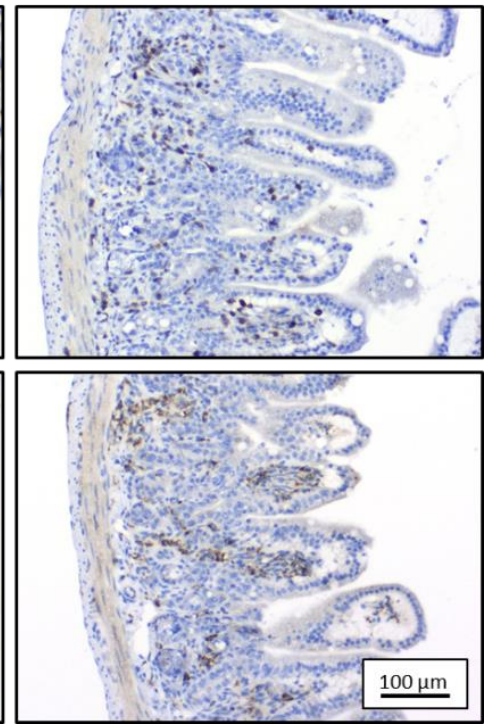

B

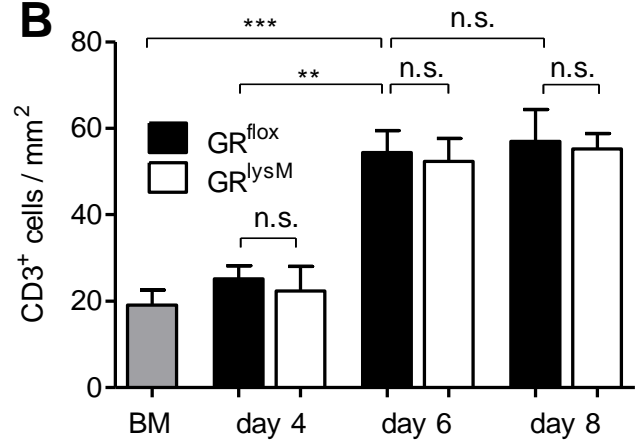

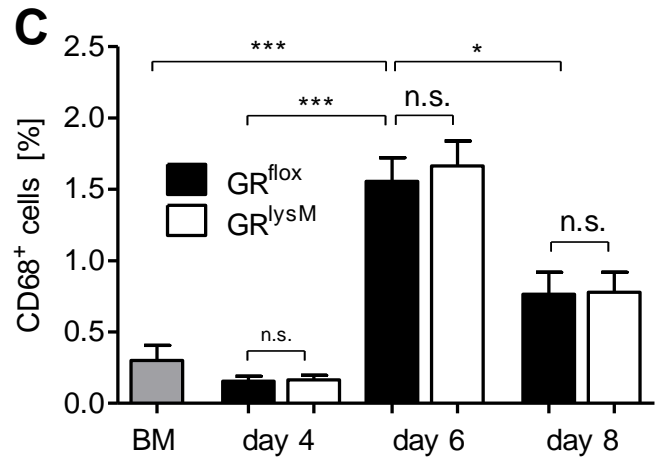

Figure 10: Immunohistochemical analysis of the jejunum in aGvHD in the $\mathrm{GR}^{\text {lysM }}$ mouse model. Lethally irradiated $B A L B / C R^{f l o x}$ and $G R^{l y s M}$ recipient mice were transplanted with $B M$ and purified T cells from donor C57BL/6 wt mice. BM controls received T cell depleted BM only. Mice were sacrificed and analyzed on day 4, 6 and 8 after BMT; analysis of BM controls was conducted on day 6. (A) Representative microphotographs of sections of the jejunum at day 6 from BM, GR ${ }^{\text {flox }}$ and $\mathrm{GR}^{\mathrm{lysM}}$ mice stained with antibodies recognizing CD3 (upper panel) or CD68 (lower panel). Scale bar: $100 \mu \mathrm{m}$. (B) Number of CD3 ${ }^{+} \mathrm{T}$ cells per $\mathrm{mm}^{2}$ were examined by computer-aided counting of stained cells in jejunum sections from BM, $\mathrm{GR}^{\text {flox }}$ and $\mathrm{GR}^{\text {lysM }}$ mice using Zeiss ZEN lite software. $N=7(B M), N=5 / 5$ (GR ${ }^{\text {flox }} / \mathrm{GR}^{\text {lysM }}$; day 4$), N=20 / 21$ (GR ${ }^{\text {flox }} / \mathrm{GR}^{\text {lysm; }}$; day 6$), N=6 / 7\left(\mathrm{GR}^{\text {flox }} / \mathrm{GR}^{\text {lysM }}\right.$; day 8); data pooled from multiple experiments, including data from Katarina Jörß and Laura Roßmann. (C) CD68 ${ }^{+}$myeloid cells were examined in jejunum sections from $B M, \mathrm{GR}^{\text {flox }}$ and $\mathrm{GR}^{\text {lysM }}$ mice by measuring the percentage of stained area using ImageJ software. $N=6(\mathrm{BM}), N=5 / 5\left(\mathrm{GR}^{\text {flox }} / \mathrm{GR}^{\text {lysM }}\right.$; day 4$), N=20 / 20\left(\mathrm{GR}^{\text {flox }} / \mathrm{GR}^{\text {lysM }}\right.$; day 6$), N=6 / 7\left(\mathrm{GR}^{\text {flox}} / \mathrm{GR}^{\mathrm{lysM}}\right.$; day 8$)$; data pooled from multiple experiments, including data from Katarina Jörß and Laura Roßmann. All values are depicted as mean \pm SEM. Statistical analyses were performed by Mann-Whitney $U$ test $\left({ }^{*} p<0.05 ;{ }^{* *} p<0.01 ;{ }^{* * *} p<0.001\right.$; n.s.: nonsignificant) (Baake et al., 2018). 


\subsection{4 $\mathrm{GR}^{\mathrm{lysM}}$ mice show almost no differences in the cytokine expression in the target organ jejunum in comparison to $G^{\text {flox }}$ mice}

Since our analyses so far did not unveil the reason for the exacerbated disease course in $\mathrm{GR}^{\mathrm{lysM}}$ mice, we analyzed another important pathophysiological feature of aGvHD, namely cytokine gene expression in the jejunum. Therefore, mice were sacrificed at day 4, 6 and 8 and RNA from the jejunum was isolated and analyzed by quantitative RT-PCR. The cytokine expression pattern of $/ 16$, Tnfa and Ifng was similar in both genotypes, it increased strongly from day 4 to 6 and decreased again at day 8 (Figure 11A). There were no significant differences between both experimental groups except for day 4, at which Ifng was slightly reduced in $\mathrm{GR}^{\mathrm{lysM}}$ mice in comparison to the control $\mathrm{GR}^{\text {flox }}$ mice. Additional cytokines, including the anti-inflammatory cytokine $/ 110$, were analyzed only at day 6 , which is the peak of the disease during the early phase of aGvHD. With the exception of $/ / 1 b$, the mRNA levels of Ccl2, I/2 and $/ / 10$ significantly increased at day 6 in comparison to control BM mice (Figure 11B). However, we detected no differences between both genotypes at that time point. In conclusion, there are basically no differences in the expression profiles of the predominantly pro-inflammatory cytokines in the aGvHD target organ jejunum, for which reason an explanation for the exacerbated disease course in $\mathrm{GR}^{\text {lysM }}$ mice is still missing. 

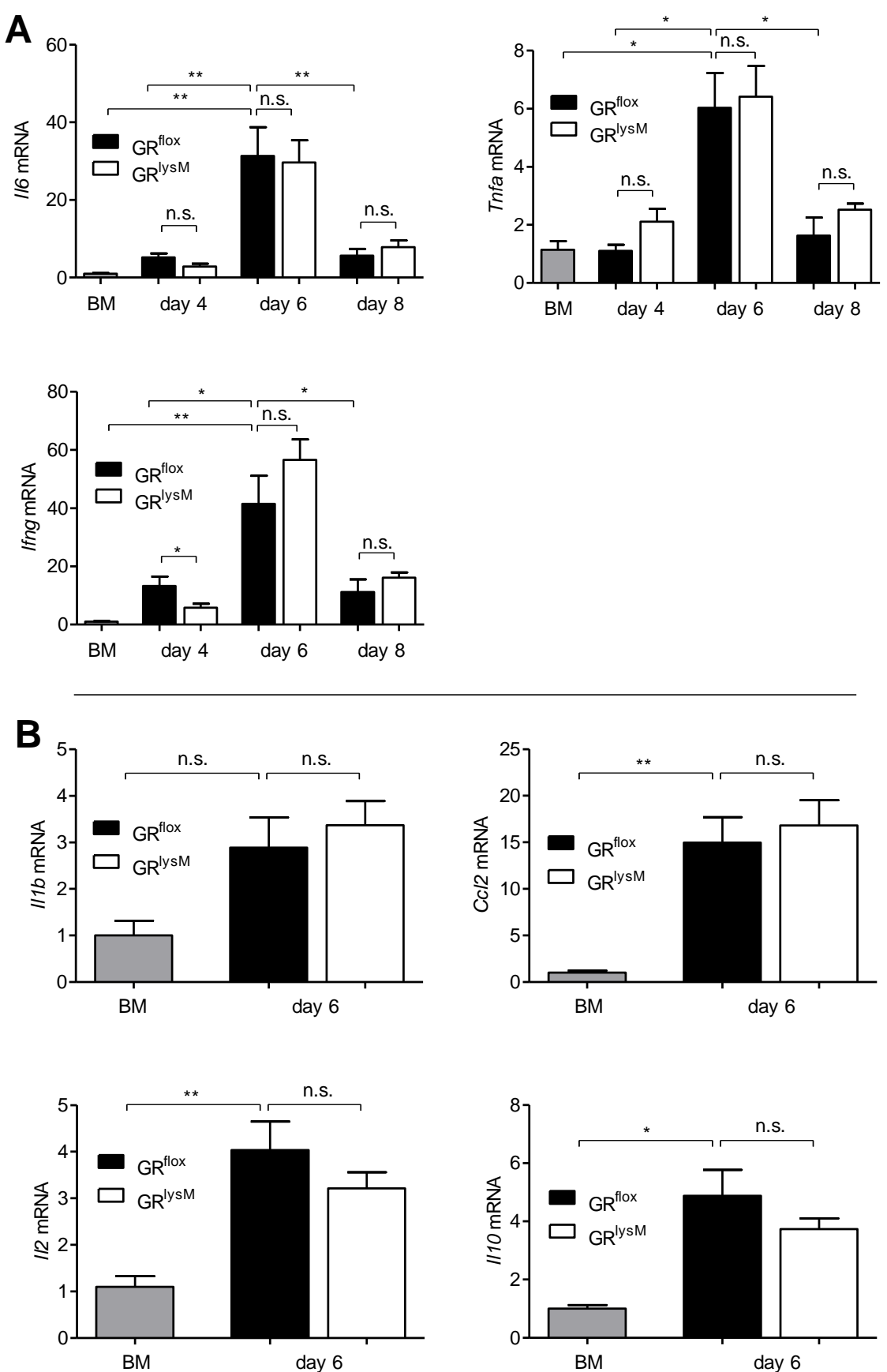

Figure 11: Cytokine expression in the jejunum of aGvHD in the $G^{\text {lysM }}$ mouse model. Lethally irradiated BALB/C $G^{\text {flox }}$ and $G^{\text {lysiM }}$ recipient mice were transplanted with $B M$ and purified T cells from donor C57BL/6 wt mice. BM controls received T cell depleted BM only. (A) Relative mRNA levels of II6, Tnfa, lfng in jejunum biopsies were analyzed on day 4, 6 and 8 after BMT by quantitative RT-PCR using hypoxanthin-phosphoribosyl-transferase (Hprt) for normalization; gene expression analysis of BM controls was conducted on day 6 and arbitrarily set to $1 . N=4(\mathrm{BM}), N=5 / 5\left(\mathrm{GR}^{\text {flox }} / \mathrm{GR}^{\text {lysM }}\right.$; day 4$), N=12 / 15\left(\mathrm{GR}^{\text {flox }} / \mathrm{GR}^{\text {lysM }}\right.$; day 6$), N=5 / 7$ $\left(\mathrm{GR}^{\text {flox }} / \mathrm{GR}^{\text {lysM }}\right.$; day 8$)$; data pooled from multiple experiments. (B) Relative mRNA levels of $/ 11 \mathrm{~b}$, Ccl2, II2 and I/10 in jejunum biopsies were analyzed on day 6 after BMT by quantitative RT-PCR using Hprt for normalization; gene expression analysis of BM controls was arbitrarily set to 1. $N=4(\mathrm{BM}), N=14 / 15\left(\mathrm{GR}^{\mathrm{flox}} / \mathrm{GR}^{\text {lysM }}\right.$; day 6$)$; data pooled from multiple experiments. All values are depicted as mean \pm SEM. Statistical analyses were performed by Mann-Whitney $U$ test $\left({ }^{*} p<0.05 ;{ }^{* *} p<0.01 ;{ }^{* *} p<0.001 ; n . s .:\right.$ non-significant) (Baake et al., 2018). 


\subsection{5 $\mathrm{GR}^{\text {lysM }}$ mice show only minor differences in the cytokine expression in the target organ liver in comparison to $\mathrm{GR}^{\text {flox }}$ mice}

Since differences in the gene expression profile in the jejunum are unlikely to be responsible for the exacerbated disease course of $\mathrm{GR}^{\mathrm{lysM}}$ mice, we investigated the gene expression profile in the liver, another major aGvHD target organ. Therefore, mice were sacrificed at day 4, 6 and 8 and RNA from the liver was isolated and analyzed by quantitative RT-PCR. The cytokine expression pattern of lfng in the liver matched with the cytokine pattern in the jejunum (Figure 12A). In fact, the increase from day 4 to 6 and the decrease from day 6 to 8 were even more pronounced. However, the expression levels in both genotypes were similar at all examined time points. The expression pattern of Tnfa and 116 differed between the jejunum and the liver. Tnfa expression was almost unchanged in the liver of $G R^{\text {flox }}$ mice, but significantly elevated in $\mathrm{GR}^{\mathrm{lysM}}$ mice at day 6. $1 / 6$ increased from day 4 to 8 in $\mathrm{GR}^{\text {flox }}$ mice, whereas in $\mathrm{GR}^{\text {lysM }}$ mice $/ 16$ increased only from day 6 to 8 . At day 6 , 116 was significantly reduced in GR ${ }^{\text {lysM }}$ mice compared to $\mathrm{GR}^{\text {flox }}$ mice. In addition, the pro-inflammatory cytokines $/ / 1 \mathrm{~b}$, Ccl2, II2 and the anti-inflammatory cytokine $/ 110$ were analyzed only at day 6 . The expression of these cytokines was unaltered when comparing $\mathrm{GR}^{\text {flox }}$ mice with control BM mice, with the exception of an increased expression level of I/10 in $\mathrm{GR}^{\text {flox }}$ mice (Figure 12B). This was in contrast to the expression pattern of II10 in the jejunum. The expression levels in the liver of Cc/2 and II2 were similar in both genotypes in contrast to $/ 11 b$, which was significantly increased in $\mathrm{GR}^{\mathrm{lysM}}$ mice, and $/ / 10$, which was significantly decreased in $\mathrm{GR}^{\mathrm{lysM}}$ mice. This was also in contrast to the expression pattern in the jejunum where no differences between both genotypes were detectable at day 6. Collectively, minor differences in the expression pattern between the jejunum and the liver, as well as minor differences in the expression pattern in the liver between both genotypes are hardly suitable to explain the exacerbated disease course in $\mathrm{GR}^{\mathrm{lysM}}$ mice. 

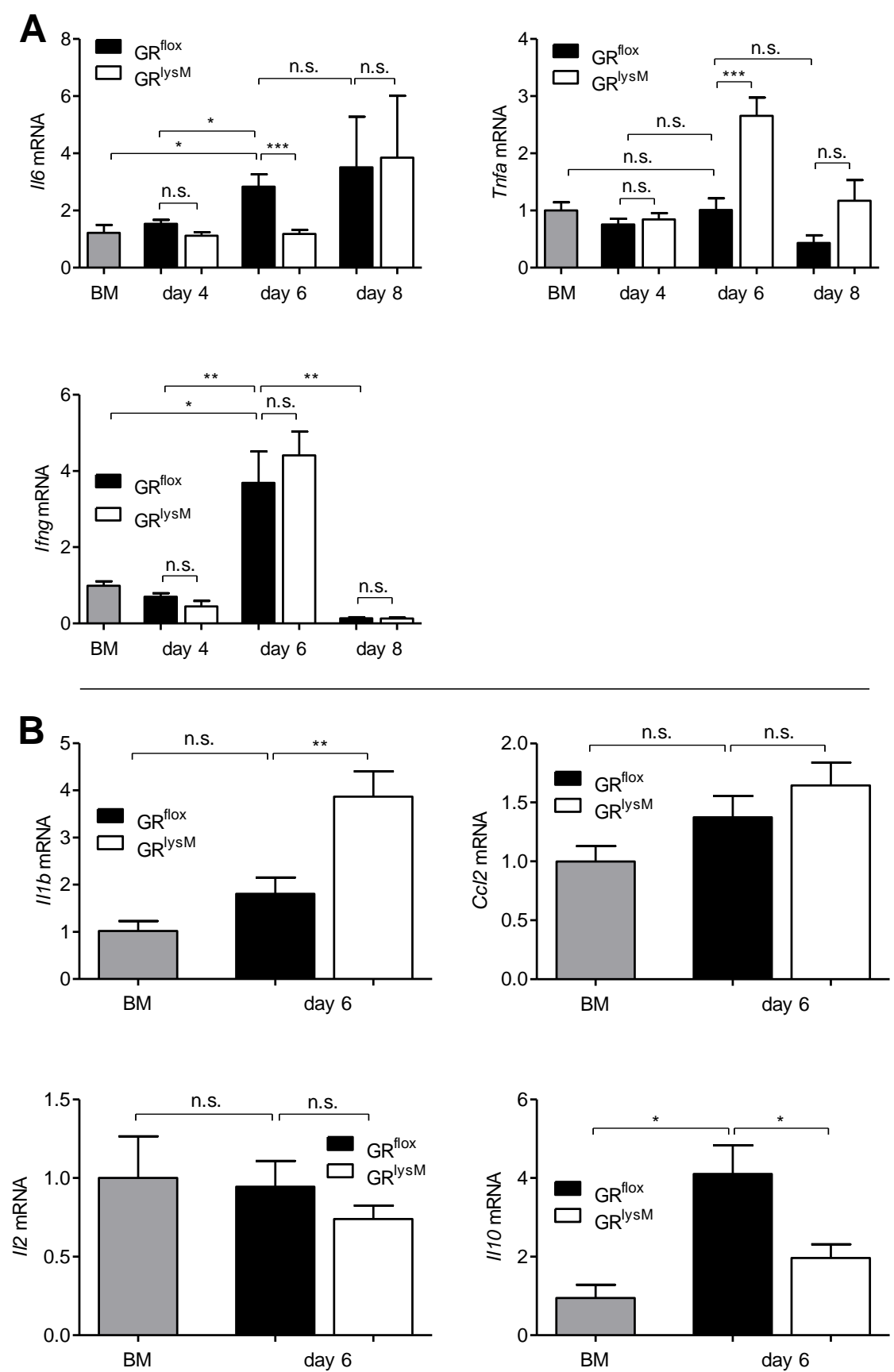

Figure 12: Cytokine expression in the liver of aGvHD in the $\mathrm{GR}^{\mathrm{IysM}}$ mouse model. Lethally irradiated $B A L B / c R^{f l o x}$ and $\mathrm{GR}^{\text {lySM }}$ recipient mice were transplanted with $B M$ and purified $T$ cells from donor C57BL/6 wt mice. BM controls received T cell depleted BM only. (A) Relative mRNA levels of 116 , Tnfa, Ifng in liver biopsies were analyzed on day 4, 6 and 8 after BMT by quantitative RT-PCR using Hprt for normalization; gene expression analysis of BM controls was conducted on day 6 and arbitrarily set to $1 . N=4(\mathrm{BM}), N=5 / 5$ (GR ${ }^{\text {flox }} / \mathrm{GR}^{\text {lysM }}$; day 4$), N=12 / 15$ (GR ${ }^{\text {flox }} / \mathrm{GR}^{\text {lysM }}$; day 6$), N=5 / 7$ (GR ${ }^{\text {flox }} / \mathrm{GR}^{\text {lysM }}$; day 8$)$; data pooled from multiple experiments. (B) Relative mRNA levels of $I / 1 \mathrm{~b}, \mathrm{Cc} / 2, I / 2$ and $/ 110$ in liver biopsies were analyzed on day 6 after BMT by quantitative RT-PCR using Hprt for normalization; gene expression analysis of BM controls was arbitrarily set to $1 . N=4(\mathrm{BM}), N=14 / 15\left(\mathrm{GR}^{\text {flox }} / \mathrm{GR}^{\text {lysM}}\right.$; day 6$)$; data pooled from multiple experiments. All values are depicted as mean \pm SEM. Statistical analyses were performed by Mann-Whitney $U$ test $\left({ }^{*} p<0.05 ;{ }^{* *} p<0.01 ;{ }^{* \star *} p<0.001 ; n . s\right.$.: non-significant). 


\subsubsection{Local cytokine secretion in the target organ jejunum in GR $^{\text {lysM }}$ mice shows only minor differences compared to $\mathrm{GR}^{\text {flox }}$ mice}

Next, we analyzed the local release of pro-inflammatory cytokines in the aGvHD target organ jejunum. To this end, jejunum biopsies were cultured for 24 hours in $\mathrm{RPMI}_{++}$medium and subsequently the cytokine levels in the supernatant were measured by using ELISA. Generally, the secretion of IL-6, TNFa and IFNy showed mild to no fluctuations and matched only partially with the pattern of the RNA expression in the jejunum and liver (Figure 13). There were no differences in the secretion of IL- 6 and TNFa between both genotypes at any time point analyzed (Figure 13). In contrast, the release of IFNy was slightly diminished in $\mathrm{GR}^{\mathrm{lysM}}$ mice at day 4, increased at day 6 and was similar between both groups at day 8 . In conclusion, also the very minor differences in the local cytokine production in the aGvHD target organ jejunum between both genotypes in the early phase of aGvHD cannot explain the exacerbated disease course in $\mathrm{GR}^{\text {lysM }}$ mice. 

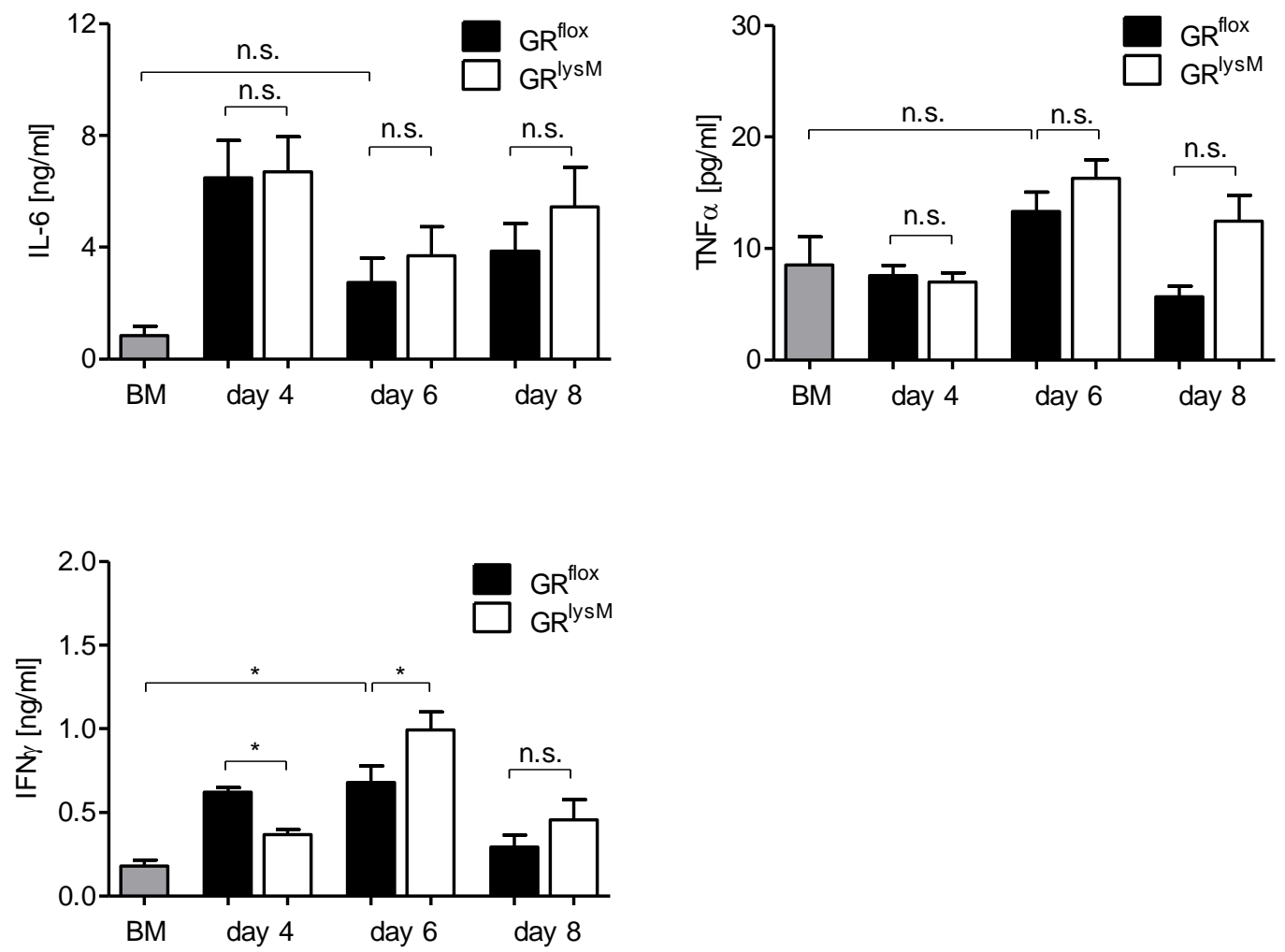

Figure 13: Local cytokine secretion in the jejunum of aGvHD in the GR ${ }^{\text {lysM }}$ mouse model. Lethally irradiated $B A L B / c R^{\text {flox }}$ and $G^{\text {lysi }}$ recipient mice were transplanted with $B M$ and purified T cells from donor C57BL/6 wt mice. BM controls received T cell depleted BM only. Mice were sacrificed and analyzed on day 4, 6 and 8 after BMT; analysis of BM controls was conducted on day 6 . Jejunum biopsies were cultured for 24 hours in RPMI++ medium and the local cytokine production of IL-6, TNFa and IFNy was measured in the supernatant by using ELISA. $N=4$ (BM), $N=5 / 5\left(\mathrm{GR}^{\text {flox }} / \mathrm{GR}^{\text {lysM }}\right.$; day 4$), N=14 / 15\left(\mathrm{GR}^{\text {flox }} / \mathrm{GR}^{\text {lysM }}\right.$; day 6$), N=6 / 8$ $\left(\mathrm{GR}^{\text {flox}} / \mathrm{GR}^{\mathrm{lys} \mathrm{s}}\right.$; day 8$)$; data pooled from multiple experiments. All values are depicted as mean \pm SEM. Statistical analyses were performed by Mann-Whitney $U$ test $\left({ }^{*} p<0.05 ;{ }^{* *} p<0.01 ;{ }^{* * *} p<\right.$ 0.001; n.s.: non-significant) (Baake et al., 2018).

\subsubsection{Systemic cytokine secretion in $\mathrm{GR}^{\mathrm{lysM}}$ mice is strongly elevated compared to $\mathrm{GR}^{\text {flox }}$ mice}

Ultimately, the systemic cytokine secretion was analyzed in an effort to find the reason for the fulminant disease course in $\mathrm{GR}^{\mathrm{lysM}}$ mutant mice. Already at day 4 the serum levels of IL-6, TNFa and IFNy were strongly increased in both genotypes and remained high throughout the experiment in comparison to control BM mice (Figure 14). IL-6 and TNFa levels were similar in both genotypes at day 4 and modestly increased at day 6 in GR ${ }^{\text {lysM }}$ mice. However, the IL- 6 serum levels at day 8 were eightfold higher in GR ${ }^{\text {lysM }}$ mice compared to $\mathrm{GR}^{\text {flox }}$ mice and the TNFa serum levels were also sixfold higher. In contrast, the serum levels of IFNy strongly increased at day 4 but declined again at day 6 
and 8. They did not show significant differences between both genotypes at any time point analyzed. Taken together, the deletion of the GR in radioresistant recipient myeloid cells causes a fulminant disease course in $\mathrm{GR}^{\mathrm{lysM}}$ mice, which is presumably due to the uncontrolled systemic cytokine release, in particular of IL-6 and TNFa, leading to an early mortality of the mutant mice (Baake et al., 2018). These results highlight the beneficial role of GCs acting in a GR-dependent manner on myeloid cells in aGvHD. It is against this background that a targeted delivery of GCs to macrophages appears particularly attractive to treat aGvHD.
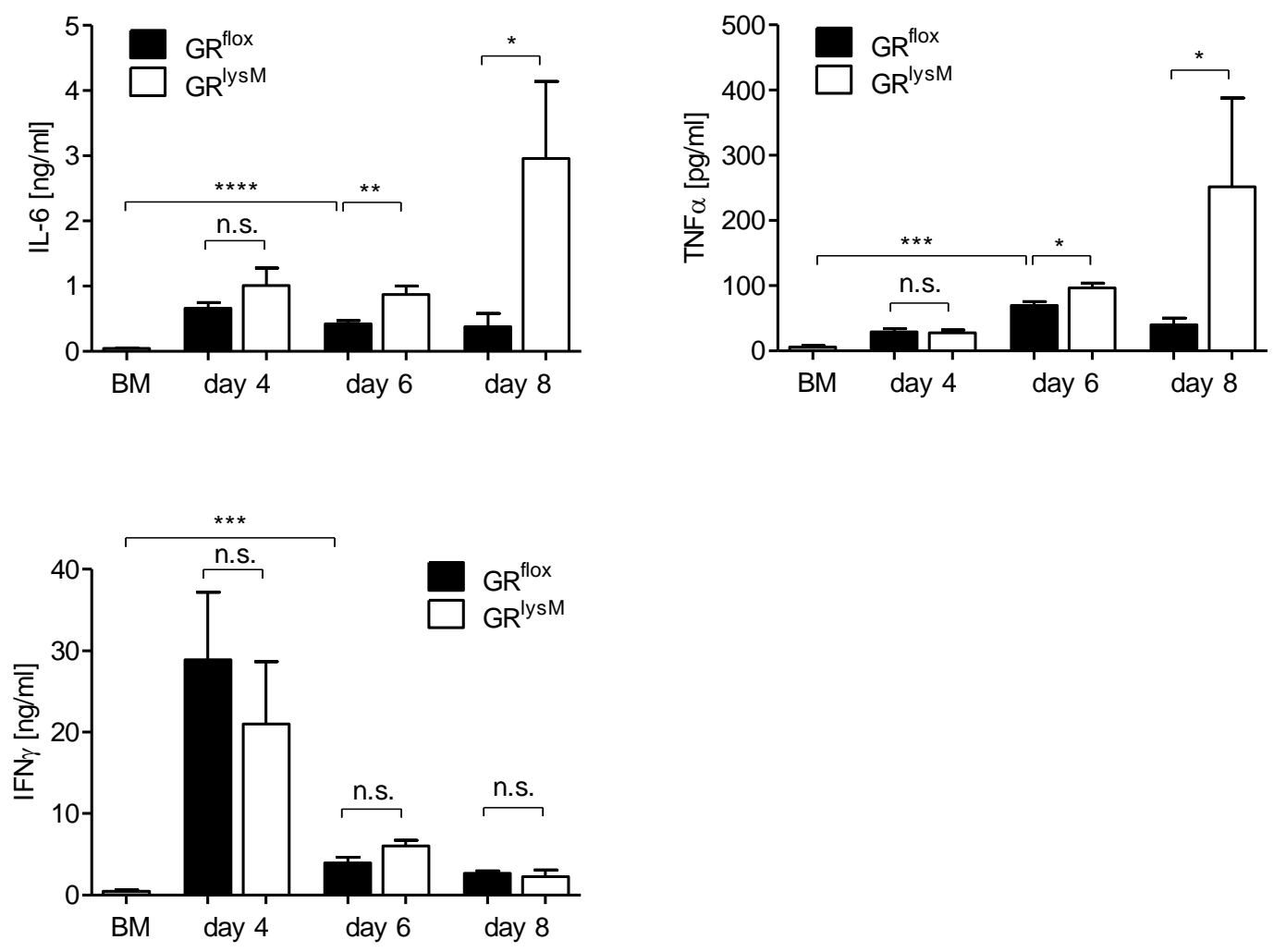

Figure 14: Systemic cytokine levels in aGvHD in the $G^{\text {lysM }}$ mouse model. Lethally irradiated $\mathrm{BALB} / \mathrm{C} \mathrm{GR}^{\text {flox }}$ and $\mathrm{GR}^{\mathrm{lysM}}$ recipient mice were transplanted with $\mathrm{BM}$ and purified $\mathrm{T}$ cells from donor $\mathrm{C} 57 \mathrm{BL} / 6$ wt mice. BM controls received T cell depleted BM only. Mice were sacrificed and analyzed on day 4, 6 and 8 after BMT; analysis of BM controls was conducted on day 6. Serum levels of IL-6, TNF $\alpha$ and IFNy were determined by using ELISA. $N=12$ (BM), $N=$ $5 / 5$ (GR ${ }^{\text {flox }} / \mathrm{GR}^{\text {lysM }}$; day 4$), N=27 / 28\left(\mathrm{GR}^{\text {flox }} / \mathrm{GR}^{\text {lysM }}\right.$; day 6$), N=6 / 7\left(\mathrm{GR}^{\text {flox }} / \mathrm{GR}^{\text {lysM }}\right.$; day 8$) ;$ data pooled from multiple experiments, including data from Katarina Jörß and Laura Roßmann. All values are depicted as mean \pm SEM. Statistical analyses were performed by Mann-Whitney $U$ test $\left({ }^{*} p<0.05 ;{ }^{* *} p<0.01 ;{ }^{* *} p<0.001 ;\right.$ n.s.: non-significant) (Baake et al., 2018). 


\subsection{Cell type specificity of IOH-NPs}

GCs are a powerful therapeutic drug and doubtlessly profitable in the treatment of aGvHD. Notwithstanding, especially when given at high-dose and/ or for longer durations, side-effects might occur ranging from sorely cosmetic issues to even life-threatening complications, which are the consequence of their broad activity profile. To make things even worse, GC resistance develops in many patients limiting the therapeutic success. A chance to overcome these drawbacks is the targeted delivery of GCs to specific cell types. In this therapy form, a reduced dose of GCs could be applied while the drug load would still be increased in areas of interest, causing less side-effects, and in the end a better benefit-to-risk profile for the patient. In fact, within the last years, targeted therapy has attracted the attention of many researchers dealing with the development of carrier systems, for example nanoparticles, being biocompatible and improving the kinetics of the pharmacological agent. Initial work from our group characterized the features of another type of delivery vehicle, namely $\mathrm{IOH}-\mathrm{NP}$ loaded with betamethasone in vitro as well as in vivo in the context of $E A E$, a mouse model for the neuroinflammatory disease multiple sclerosis (Montes-Cobos et al., 2017). These data indicated that IOH-NPs act indeed in a cell-type specific manner. Namely, they are preferentially taken up by macrophages and only to a minor extent by $T$ and B cells. Furthermore, GCs delivered by $\mathrm{IOH}-\mathrm{NPs}$ exerted anti-inflammatory effects in myeloid cells in a GR-dependent manner. Since my previous data, shown in the first part of this thesis, demonstrated beneficial immuno-modulatory properties of GCs in radioresistant myeloid cells in the context of aGvHD, IOH-NPs might be useful to selectively deliver GCs to macrophages in this disease. Using this strategy might allow to diminish disease symptoms and tissue destruction, while keeping inflammatory responses at bay. Most importantly, such a therapy may also provoke less side-effects in comparison to systemically applied GCs. The second part of this work focuses on characterizing the features of $1 O H-N P s$, such as their cell-type specificity, toxicity, their cellular uptake mechanism and their intracellular fate in vitro. 


\subsubsection{Characterization of the cellular uptake of IOH-NPs in primary immune cells and the macrophage cell line $\mathrm{MH}-\mathrm{S}$}

Initial work by our group indicated the preferential uptake of $10 \mathrm{H}-\mathrm{NPs}$ by macrophages. To confirm these results, IOH-NPs were used that contained the fluorescence dye FMN, but no pharmacologically active drug (designated EP-NPs). Splenocytes were cultured and incubated with these EP-NPs at ascending concentrations for 24 hours and the percentage of $\mathrm{FMN}^{+}$cells amongst $\mathrm{T}$ and $\mathrm{B}$ lymphocytes as well as in macrophages was analyzed via FACS. The uptake of EP-NPs was most efficient in CD $11 \mathrm{~b}^{+}$macrophages, $\mathrm{B}^{2} 20^{+} \mathrm{B}$ cells showed only a moderate uptake while hardly any internalization was visible in $\mathrm{CD}^{+} \mathrm{T}$ cells. All subpopulations incorporated EP-NPs in a dose-dependent manner, although with highly different efficiencies (Figure 15A). Furthermore, IOH-NP uptake was exemplarily demonstrated and visualized in the alveolar macrophage cell line $\mathrm{MH}-\mathrm{S}$. In this experiment, $\mathrm{IOH}-\mathrm{NPs}$, which contain the GC betamethasone in addition to FMN, were used (designated BMP-NPs). The MH-S cells were incubated with BMP-NPs for 24 hours and analyzed by confocal microscopy for fluorescence emitted by FMN. The signals were predominantly located in spots within the cytosol but sparing the nucleus (Figure 15B). In addition, MH-S cells were incubated with BMP-NPs for 6 and 24 hours and analyzed by FACS. This study revealed an increased incorporation of BMP-NPs into the cells over time (Figure 15C). Taken together, the incorporation of a fluorescent dye in IOH-NPs allows to study their uptake by using imaging techniques such as confocal microscopy and FACS in cell culture studies in vitro. 


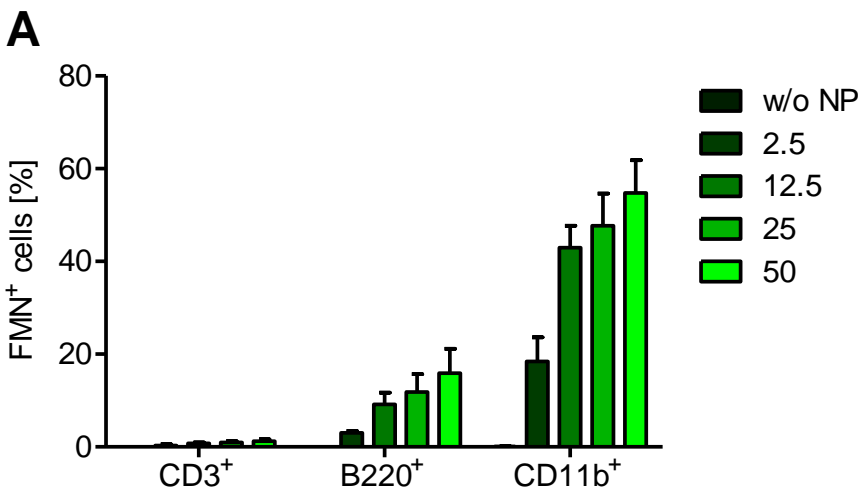

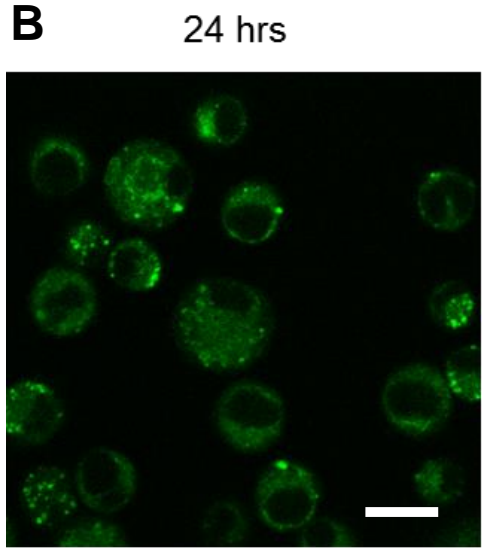

$6 \mu \mathrm{g} / \mathrm{ml}$ confocal microscopy
C

$6 \mathrm{hrs}$

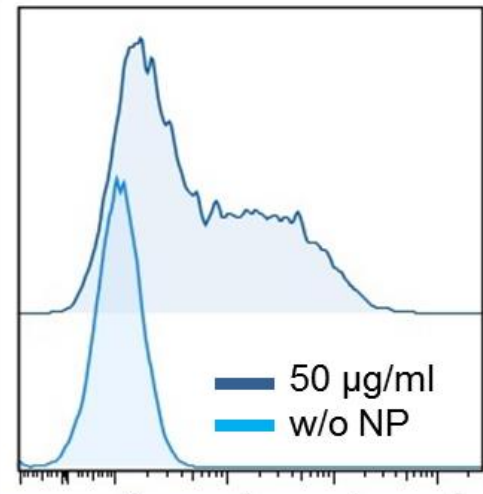

$24 \mathrm{hrs}$

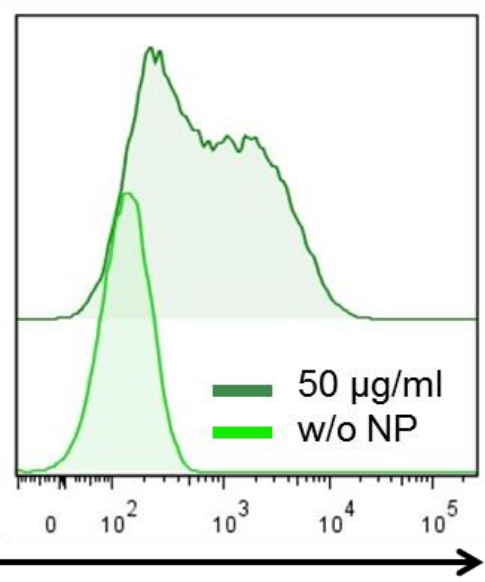

FMN

Figure 15: Characterization of IOH-NPs in cultures and MH-S cells. (A) Splenocytes were incubated with ascending concentrations of EP-NPs (w/o NP, 2.5, 12.5, 25 and $50 \mu \mathrm{g} / \mathrm{ml}$ ) for 24 hours in 24-well plates and the FMN signal within $\mathrm{CD}^{+}, \mathrm{B}^{2} 20^{+}$and $\mathrm{CD} 11 \mathrm{~b}^{+}$cells was analyzed via FACS. All values are depicted as mean \pm SEM $(N=3)(B) M H-S$ cells were incubated with 6 $\mu \mathrm{g} / \mathrm{ml}$ BMP-NPs for 24 hours on cover glas bottom imaging dishes and NP incorporation was visualized by confocal microscopy. Scale bar: $15 \mu \mathrm{m}$. (C) MH-S cells were incubated without (w/o NP) or with $50 \mu \mathrm{g} / \mathrm{ml} \mathrm{BMP-NP}$ for 6 or 24 hours in 24-well plates and the FMN signal within the cells was analyzed via FACS. Exemplary histograms are depicted for both time points blotting the FMN signal on the $x$-axis $(N=3)$ (Kaiser et al., submitted).

\subsubsection{Cell type specific uptake of IOH-NPs}

Cell types vary in their capacity to engulf substances via endocytic pathways and thus this feature can be used to specifically target individual cell types with nanoformulations. To further analyze the potential cell type specificity of $\mathrm{IOH}-\mathrm{NPs}$, the kinetics and incorporation of $\mathrm{IOH}-\mathrm{NPs}$ in six representative cell lines was studied. Three of them are derived from immune cells as MH-S resemble macrophages, and WEHI7.1 (Wang et al., 2006) and WEHI231 are T and B lymphocytes, respectively. The three other cell lines are from solid 
tissues. Specifically L929, LA-4 and $\mathrm{C} 2 \mathrm{C} 12$ are derived from fibroblasts, epithelial cells and myoblasts, respectively. In the first step, we incubated the cell lines with $2.5 \mu \mathrm{g} / \mathrm{ml}$ EP-NPs for up to 6 hours and measured the FMN signal within the cells over time via FACS (Figure 16A). MH-S cells were most efficient in taking up EP-NPs whereas hardly any incorporation was detectable in WEHI7.1 and WEHI231 cells. L929 cells were almost as efficiently incorporating EP-NPs as MH-S cells, whereas LA-4 and $\mathrm{C} 2 \mathrm{C} 12$ showed only a moderate uptake. Next, we incubated the cell lines with $2.5 \mu \mathrm{g} / \mathrm{ml}$ EP-NPs or BMP-NPs for 24 hours and measured the percentages of $\mathrm{FMN}^{+}$cells via FACS (Figure 16B). Longer incubation times with the $\mathrm{IOH}-\mathrm{NPs}$ increased the percentages of $\mathrm{FMN}^{+}$ cells in all cell types. However, the pattern of uptake efficiency in all cell types was similar to the patterns observed for the shorter EP-NP incubation times, even though $\mathrm{MH}-\mathrm{S}$ cells were here clearly most efficient in incorporating $\mathrm{IOH}-\mathrm{NPs}$. Taken together, these studies show clear differences in the ability to engulf $\mathrm{IOH}-\mathrm{NPs}$ between representative cell types. $\mathrm{MH}-\mathrm{S}$ cells are most efficient in doing so, but also other cell lines engulfed IOH-NPs. 

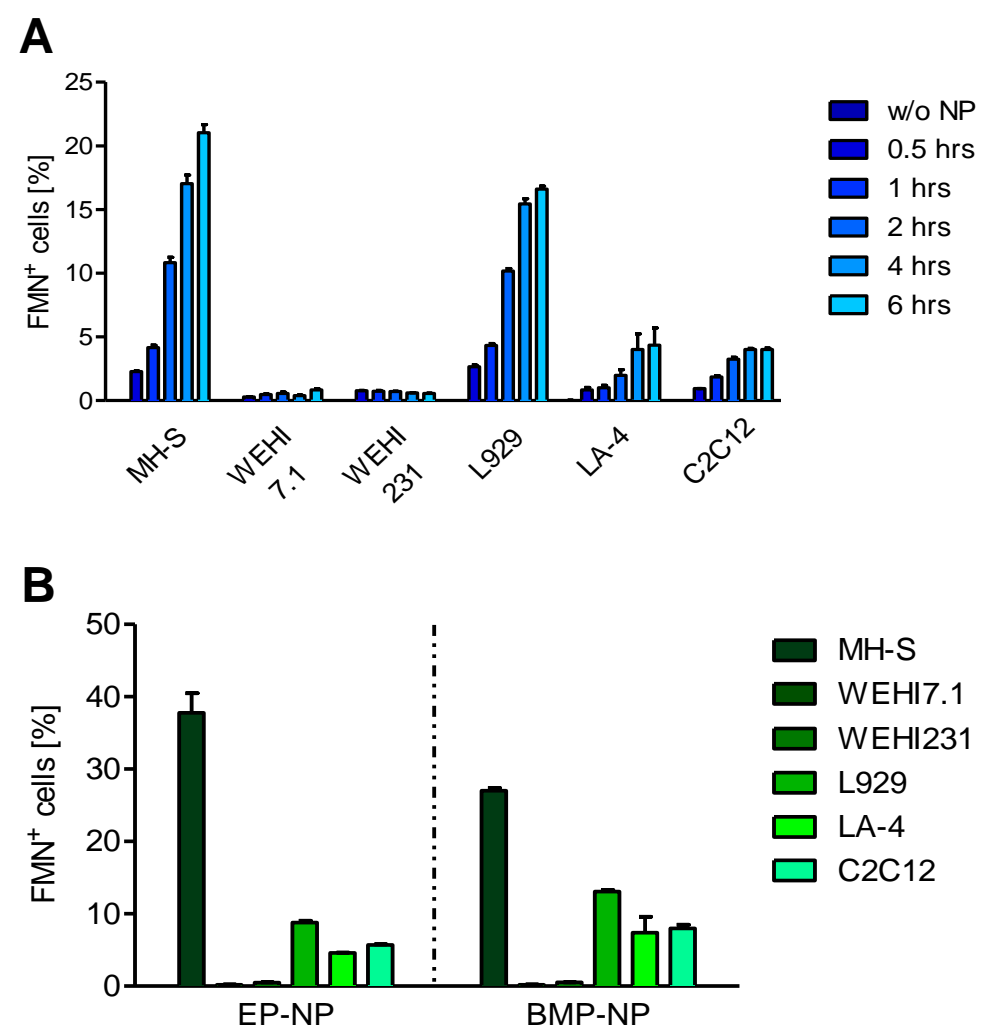

Figure 16: Cell type specific IOH-NP uptake in vitro. (A) Six different cell lines were incubated without (w/o NP) or with $2.5 \mu \mathrm{g} / \mathrm{ml}$ EP-NPs in 6-well plates for up to 6 hours and the FMN signal was analyzed within the cells via FACS $(N=3)$. (B) Six different cell lines were incubated without (w/o NP) or with $2.5 \mu \mathrm{g} / \mathrm{ml}$ EP-NPs or BMP-NPs for 24 hours and the FMN signal was analyzed within the cells via FACS. All values are depicted as mean \pm SEM $(N=3)$ (Kaiser et al., submitted).

\subsubsection{Cell viability in different cell lines upon IOH-NP treatment}

In order to exclude toxic effects of IOH-NPs in the previously described cell lines, we studied their metabolic activity upon treatment with the IOH-NPs, which is an indicator for cell viability. The cell lines were incubated with $2.5 \mu \mathrm{g} / \mathrm{ml}$ EP-NPs or BMP-NPs for 6 hours and the metabolic activity was analyzed based on an MTS test (Figure 17). The metabolic activity was neither affected upon the treatment with EP-NPs nor with BMP-NPs in any of the six cell lines, but it was clearly reduced in the control group that was treated with a toxic dose of $10 \%$ DMSO for 3 hours. These results support the use of $\mathrm{IOH}-\mathrm{NPs}$ as a potential harmless carrier system for targeting selective cell types. 


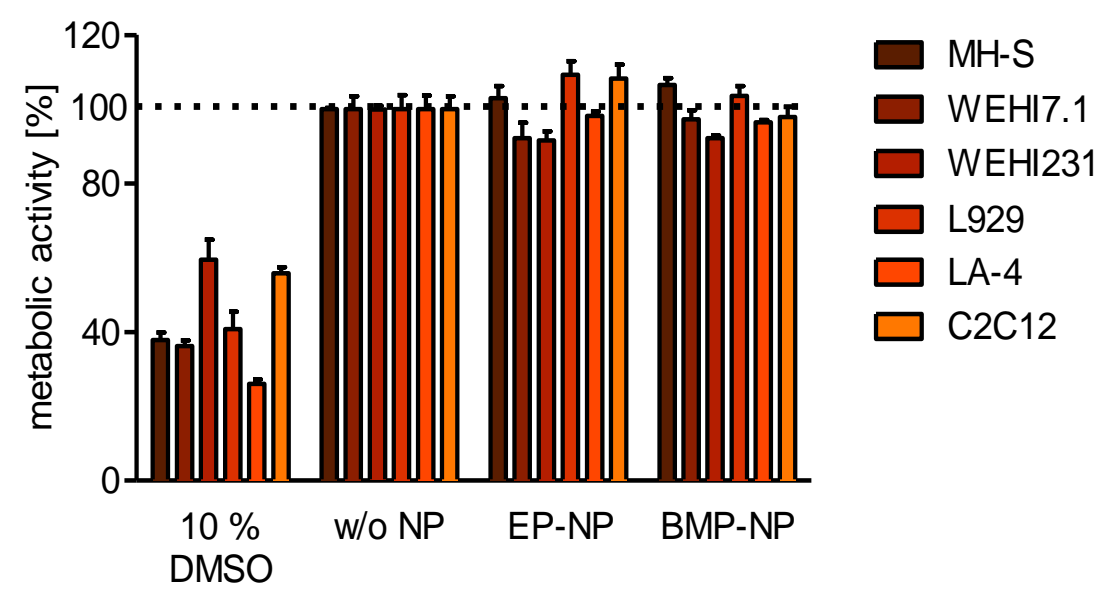

Figure 17: Cell viability upon IOH-NP treatment in different cell lines in vitro. Six different cell lines were incubated without (w/o NP) or with $2.5 \mu \mathrm{g} / \mathrm{ml}$ EP-NP or BMP-NP in 96-well plates for 6 hours or for 3 hours with $10 \%$ DMSO. Subsequently, a MTS assay was performed analyzing the metabolic activity as an indicator for cell viability. For each cell line, the metabolic activity was set to $100 \%$ when cultured in the absence of $\mathrm{IOH}-\mathrm{NPs}$. All values are depicted as mean $\pm \operatorname{SEM}(N=4)$ (Kaiser et al., submitted).

\subsubsection{Characterization of the endocytic IOH-NP uptake pathway in MH-S cells}

Eukaryotic cells constantly form and internalize membrane vesicles allowing bidirectional fluxes of extracellular fluids, membrane lipids or integral proteins from the in- and outside of the cell surface by a process called endo- and exocytosis, respectively. Depending on the characteristics of the cargo and the cell type, different endocytic pathways are used for internalization (Doherty and McMahon, 2009, Kou et al., 2013, Conner and Schmid, 2003). Since our pervious results highlighted that $\mathrm{MH}-\mathrm{S}$ cells were most efficient in taking up $\mathrm{IOH}-\mathrm{NPs}$, we investigated in the following experiments the endocytic pathway of $\mathrm{IOH}-\mathrm{NPs}$ in these cells by applying three pharmacological inhibitors in vitro. In brief, CytoD (cytochalasin $\mathrm{D}$ ) blocks actin polymerization thereby preventing the formation of macropinosomes and phagosomes, which consist of F-actin-coated vesicles. Amiloride (amiloride hydrochloride hydrate) acts as a sodium-proton exchange inhibitor and hereby predominantly prevents the formation of macropinosomes. Finally, MDC (monodansyl-cadaverine) is an inhibitor of clathrin-mediated endocytosis, because it interferes with transglutaminase, which is necessary for the protein-crosslinking that enables the clustering and internalization of clathrin (Guo et al., 2015, Ivanov, 2008, Dutta and Donaldson, 
2012). In order to employ the optimal concentration of the inhibitors that results in minimal toxicity, we treated the cells with different concentrations of the before mentioned inhibitors for 24 hours and analyzed the metabolic activity with the help of an MTS test (Figure 18A). The metabolic activity was clearly reduced in the control group, when treated with a toxic concentration of $10 \%$ DMSO. In contrast, the viability of the cells was not affected when they were incubated with $1 \mu \mathrm{g} / \mathrm{ml}$ CytoD whereas the cells showed a reduced metabolic activity with increasing concentrations of Amiloride $(0.5,1$ and $2 \mathrm{mM})$ and MDC $(100 \mu \mathrm{M}$ and $150 \mu \mathrm{M})$. Consequently, we decided to use $1 \mu \mathrm{g} / \mathrm{ml}$ CytoD, $0.5 \mathrm{mM}$ Amiloride and $100 \mu \mathrm{M}$ MDC in the following experiments. Next, we incubated $\mathrm{MH}-\mathrm{S}$ cells with $50 \mu \mathrm{g} / \mathrm{ml}$ BMP-NPs together with either CytoD, Amiloride or MDC for up to 6 hours and analyzed the FMN signal in the cells via FACS (Figure 18B). IOH-NP uptake increased with longer incubation times, but $\mathrm{IOH}-\mathrm{NP}$ internalization was partially inhibited by CytoD and Amiloride, but not with MDC, suggesting that $\mathrm{IOH}-\mathrm{NP}$ uptake was mediated via the endocytic pathway macropinocytosis. Furthermore, we analyzed the $\mathrm{IOH}-\mathrm{NP}$ uptake in $\mathrm{MH}-\mathrm{S}$ cells when treated for 24 hours with increasing concentrations of BMP-NPs and either CytoD, Amiloride or $\mathrm{MDC}$. $\mathrm{FMN}^{+}$cells were again identified via FACS (Figure 18C). BMP-NP uptake increased in a dose-dependent manner in all four conditions and was partially inhibited by CytoD and Amiloride, but not MDC, providing additional evidence for macropinocytosis being the preferential IOH-NP uptake pathway. Finally, we analyzed potentially toxic effects of all three inhibitors for $\mathrm{MH}-\mathrm{S}$ cells when treated for 3 to 6 hours and 24 hours by applying the MTS test (Figure 18D). In general, all inhibitors were well tolerated with the exception of Amiloride, which reduced the cell viability to some extent. 

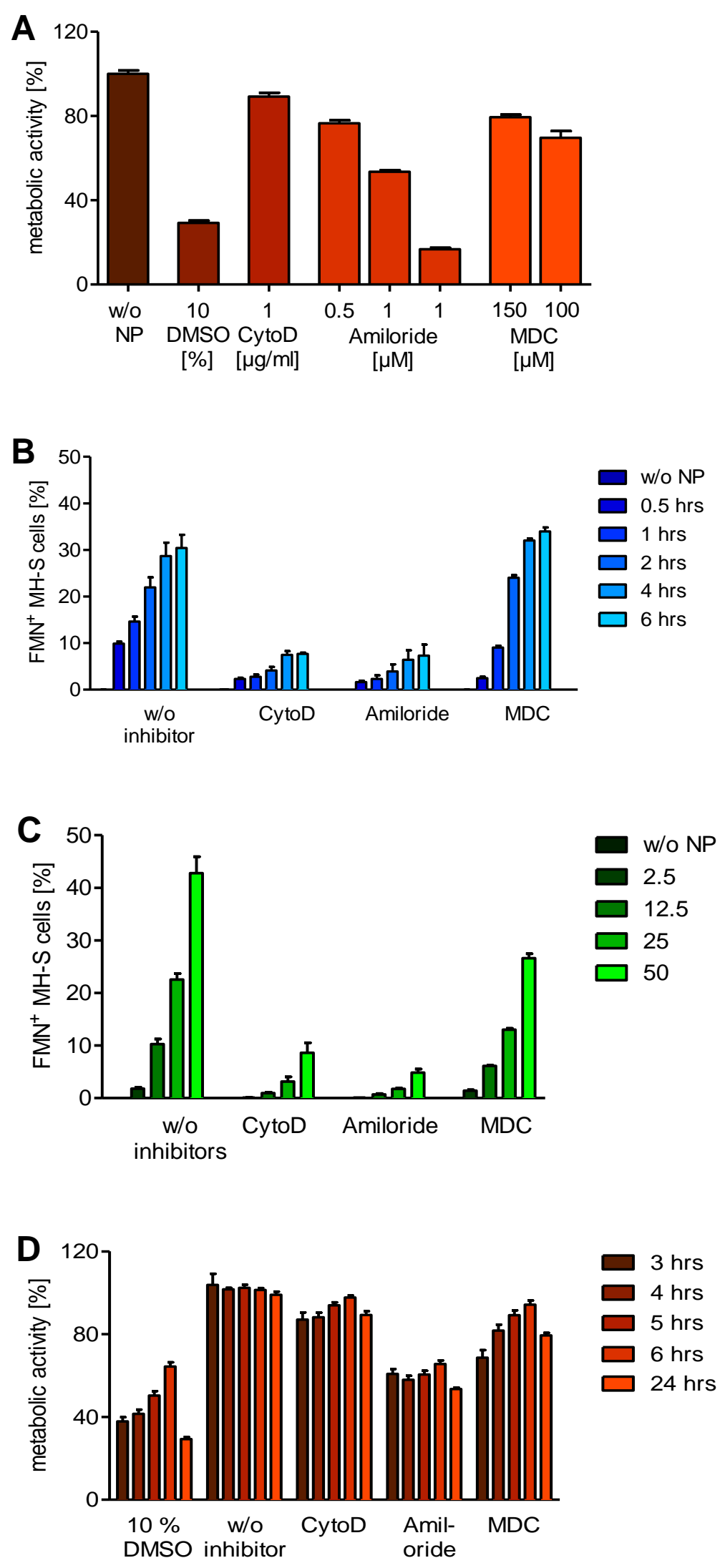

Figure 18: Endocytotic IOH-NP internalization pathway in MH-S cells in vitro. (A) Cells were cultured with $6 \mu \mathrm{g} / \mathrm{ml}$ BMPNPs and without (w/o inhibitor) or with either $1 \mu \mathrm{g} /$ $\mathrm{ml}$ Cytochalasin D (CytoD), $0.5,1$ or $2 \mathrm{mM}$ Amiloride hydrochloride hydrate (Amiloride), $100 \mu \mathrm{M}$ or 150 $\mu \mathrm{M}$ Monodansyl-cadaverine (MDC) or $10 \%$ DMSO in 96-well plates for 24 hours. Subsequently, a MTS assay was performed analyzing the metabolic activity as an indicator for cell viability. For each cell line, the metabolic activity was set to $100 \%$ when cultured in the absence of inhibitors ( $N=$ 4). (B) Cells were cultured with $50 \mu \mathrm{g} / \mathrm{ml} \mathrm{BMP-NPs}$ and without or with $1 \mu \mathrm{g} / \mathrm{ml}$ CytoD, $1 \mathrm{mM}$ Amiloride or $100 \mu \mathrm{M}$ MDC for up to 6 hours in 24-well plates. The FMN signal within the cells was measured via FACS ( $N$ $=3$ ). (C) Cells were cultured with BMP-NPs in increasing concentrations (w/o, 2.5, $12.5,25$ or $50 \mu \mathrm{g} / \mathrm{ml}$ ) and with or without either 1 $\mu \mathrm{g} / \mathrm{ml}$ CytoD, $1 \mathrm{mM}$ Amiloride or $100 \mu \mathrm{M}$ MDC in 24-well plates for 24 hours. The FMN signal within the cells was measured via FACS $(N=4)$. (D) Cells were cultured with $6 \mu \mathrm{g} / \mathrm{ml}$ BMP-NPs and with or without either $1 \mu \mathrm{g} / \mathrm{ml}$ CytoD, $1 \mathrm{mM}$ Amiloride or $100 \mu \mathrm{M}$ MDC or $10 \%$ DMSO in 24-well plates for 3 to 6 hours or 24 hours. Subsequently, a MTS assay was performed analyzing the metabolic activity as an indicator for cell viability. For each cell line, the metabolic activity was set to $100 \%$ when cultured in the absence of inhibitors. All values are depicted as mean $\pm \operatorname{SEM}(N=5)$ (Kaiser et al., submitted). 


\subsubsection{Intracellular fate of IOH-NPs upon engulfment}

The pathway by which nanoparticles enter the cell influences their intracellular fate. Vesicles, that carry the cargo can either fuse with lysosomes for degradation, can be carried to the Golgi complex, are released outside from the cell or are delivered to the endoplasmatic reticulum (ER) and afterwards eventually to the cytosol, mitochondria or nucleus. Only cargo, which enters the cell via calveolae-mediated endocytosis does not end up in lysosomes, whereas all other pathways are associated with lysosomes (Kou et al., 2013). While we could show that IOH-NPs enter MH-S cells via macropinocytosis, we additionally investigated whether their intracellular fate was indeed associated with lysosomes. Therefore, we took advantage of imaging flow cytometry that combines two techniques, namely FACS and confocal microscopy, which enabled us to detect IOH-NP within selected cellular organelles. To this end, we incubated MH-S cells with $6 \mu \mathrm{g} / \mathrm{ml}$ BMP-NPs for 6 or 24 hours and stained either the mitochondria or the lysosomes with Mitotracker or Lysotracker, respectively. Both dyes were conjugated to a deep red (DR) fluorescence dye or fluorescence detection (Figure 19). The overlay of both signals, namely FMN and DR, resulted in a strong yellow signal when lysosomes were stained, indicating a corresponding localization of both dyes (Figure 19A). In contrast, isolated green and red dots were visible when mitochondria were labeled. Furthermore, by applying the co-localization wizard tool in the IDEAS software we were able to quantify the co-localization of BMP-NPs with lysosomes or mitochondria within the cells based on the Bright Detail Similarity (BDS, Figure 19B). The BDS identifies the small punctate stainings in imaged pairs and measures the similarity of these dots. Up to $78 \%$ of the cells showed a co-localization of BMP-NPs and lysosomes, when incubated for 6 and 24 hours, whereas the co-localization scores were only around $4 \%$ when the mitochondria were stained (Figure 19C). Collectively, these data indicate that $\mathrm{IOH}-\mathrm{NPs}$ are incorporated in MH-S cells by macropinocytosis and subsequently fuse with lysosomes for degradation. 

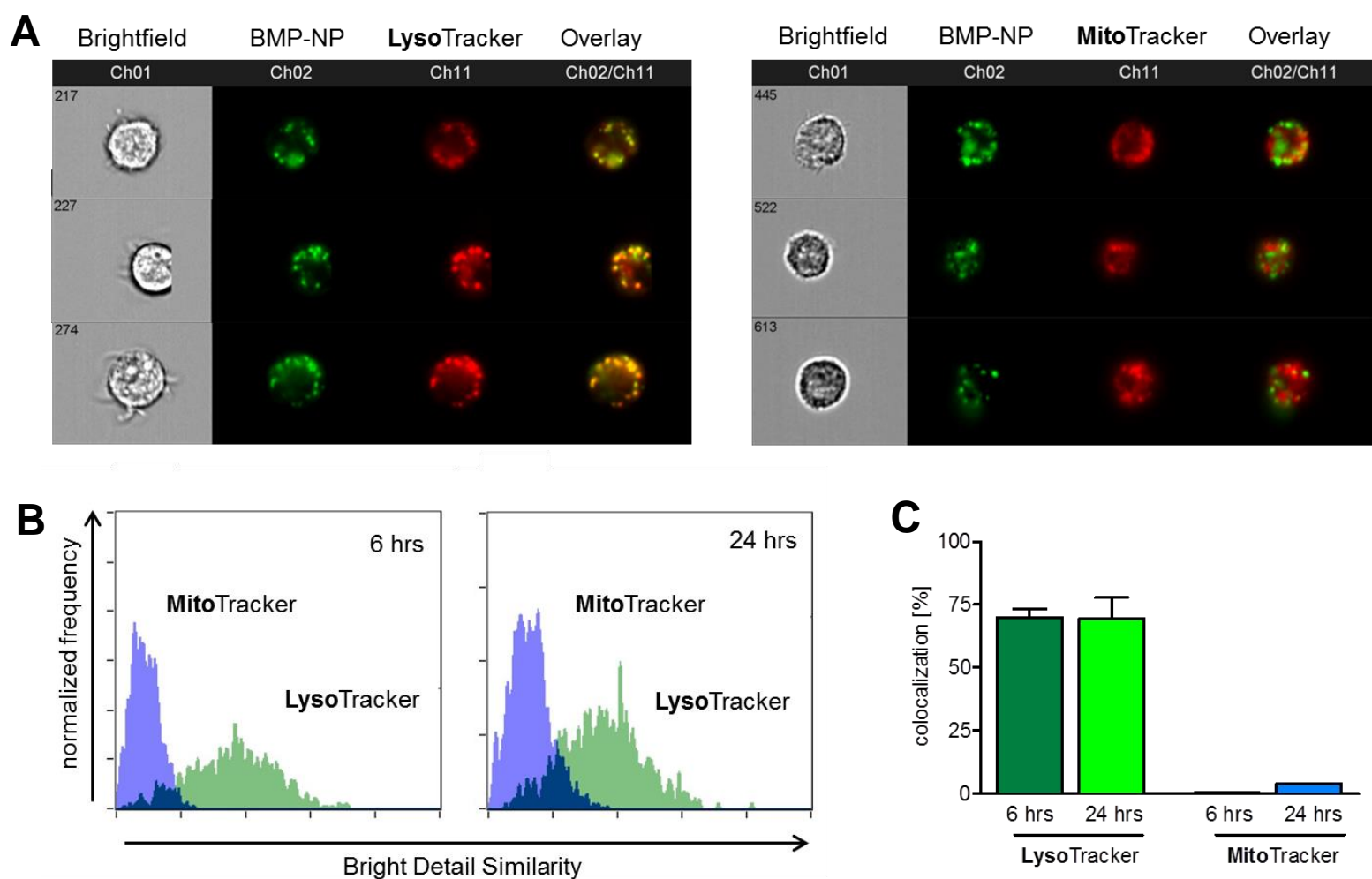

Figure 19: Intracellular fate of IOH-NPs in MH-S cells in vitro. (A) Cells were cultured in the presence of $6 \mu \mathrm{g} / \mathrm{ml}$ BMP-NPs in $175 \mathrm{~cm}^{2}$ flasks for 6 hours and lysosomes or mitochondria were stained for 30 minutes with $100 \mathrm{nM}$ Lysotracker or Mitotracker, respectively. Both tracker were conjugated with a deep red fluorescence dye. The cells were analyzed by imaging flow cytometry. Exemplary figures of brightfield and fluorescence images, including fluorescence overlays are depicted. (B) Cells were cultured in the presence of $6 \mu \mathrm{g} / \mathrm{ml}$ BMP-NPs in $175 \mathrm{~cm}^{2}$ flasks for 6 and 24 hours and lysosomes or mitochondria were stained, as described above. Double-positive cells were analyzed for the co-localization of BMP-NPs and lysosomes or mitochondria based on the bright detail similarity value. Figures depict exemplary both time points of one representative experiment. (C) Quantitative analysis of the co-localization of BMP-NPs and either lysosomes or mitochondria based on the bright detail similarity. Depicted are both time points. All values are depicted as mean \pm SEM. Data derive from three independent experiments (Kaiser et al., submitted).

\subsubsection{Biological effects of IOH-NPs in macrophages}

In order to release the pharmacological drug betamethasone from the phosphate-based IOH-NPs, phosphatases or other enzymes need to hydrolyze the phosphate-ester-bond in the functional anions (Heck et al., 2015). Since lysosomes contain suitable enzymes for this purpose, we investigated the biological effect of BMP-NPs in primary macrophages. To this end, bone marrow derived macrophages (BMDMs) were cultured in the presence of ascending concentrations of BMP-NPs, but also with EP-NPs, as a control group. Subsequently, the expression of surface markers was analyzed via FACS (Figure 20A, B). MHCII and CD86 were chosen because they are known to be downregulated by GCs and additionally play a key role in the initiation 
step of aGvHD. We found that the expression of both surface markers was reduced with ascending concentrations of BMP-NPs. In contrast, the expression of CD86 was unaltered when treated with EP-NPs and MHCII was only reduced to a minor extent by EP-NPs. These data indicate that betamethasone must be released from the BMP-NPs within the lysosomes of the BMDMs, thereby leading to an anti-inflammatory effect, amongst others, by downregulating the surface expression of $\mathrm{MHCI}$ and CD86.
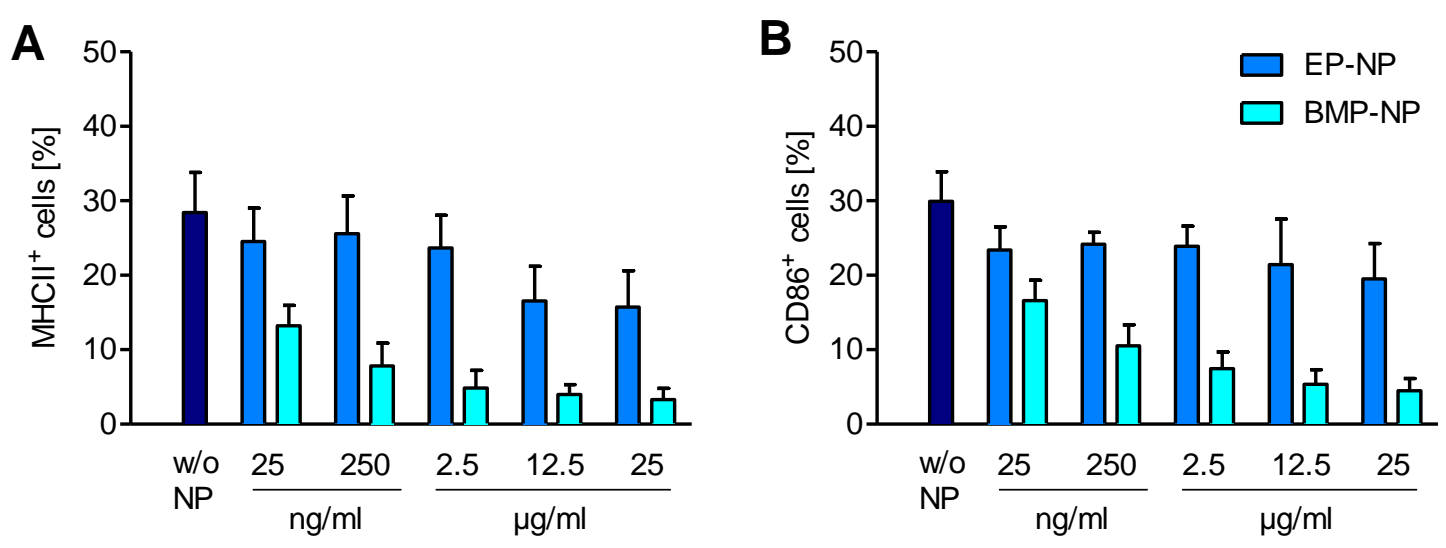

Figure 20: Biological effect of $\mathrm{IOH}-\mathrm{NPs}$ in BMDMs in vitro. Fully matured bone marrow derived macrophages (BMDMs) were cultured in 24-well plates without (w/o NP) or with increasing concentrations of BMP-NPs or EP-NPs for 24 hours. Subsequently, the expression of surface markers, such as MHCII (A) and CD86 (B), was analyzed via FACS. All values are depicted as mean \pm SEM $(N=4 / 5)$ (Kaiser et al., submitted).

\subsection{Organ distribution of IOH-NPs in vivo after intraperitoneal injection into mice}

Conventional pharmacological reagents consist most often of small molecules and thus have the disadvantage of equal systemic distribution. Consequently, higher doses are necessary to increase the concentration of the reagent at target sites, which causes intended and unintended activities, the latter contributing to unwanted side-effects. Theoretically, nanomedicines can circumvent these difficulties by targeting cells, tissues or organs. The pharmacokinetics and organ distribution of NPs relies on various parameters, such as size or surface properties. NPs with a size of $30-100 \mathrm{~nm}$, in which category $\mathrm{IOH}-\mathrm{NPs}$ belong, are known to accumulate in the liver, the spleen, lymph nodes, the bone marrow and vessels. These organs are macrophage-enriched destinations (Weissleder et al., 2014). Since the organ 
distribution of $\mathrm{IOH}-\mathrm{NPs}$ strongly impacts the activity profile of the delivered GCs in vivo, the third part of this thesis focuses on the resorption and organ distribution of $\mathrm{IOH}-\mathrm{NPs}$ after i.p. injection into mice in vivo and ex vivo.

\subsubsection{Resorption and organ distribution of GAP-NPs in vivo}

To address the question of resorption and organ distribution of IOH-NPs in vivo, we took advantage of the magnetic resonance imaging (MRI) technique. Wild type mice were anaesthetized and kept actively ventilated throughout the whole experiment. Cross-sections of the abdominal region were taken every 30 minutes, starting before the i.p. injection of $500 \mu \mathrm{l}$ GAP-NPs containing $0.1 \mathrm{mg}$ Gd until 6.5 hours later when the experiment was terminated (Figure 21A). Regions of interests (ROI) were drawn within the peritoneum and selected organs in order to quantify the accumulation and later the disappearance of GAP-NPs (Figure 21B). Within 30 minutes after the injection, GAP-NPs induced a strong signal in the peritoneal cavity, between the liver lobes, within the intestinal loops, and enwrapped the stomach, the kidneys and the spleen. The signal faded over time and eventually cleared out in some areas, but was still detectable for example within the stomach. The ROI analysis in the peritoneal cavity confirmed the disappearance of GAP-NPs within two hours upon injection. The signal within the liver and small intestine increased slightly over time, whereas the signal in the stomach peaked at 3 hours after injection and stayed at this level until the end of the experiment. In contrast, no signal was visible within the kidney. Taken together, these data demonstrate a slow release of GAP-NPs from the peritoneal cavity and a subsequent accumulation in the liver, stomach and small intestine. 
A $-30 \mathrm{~min}$
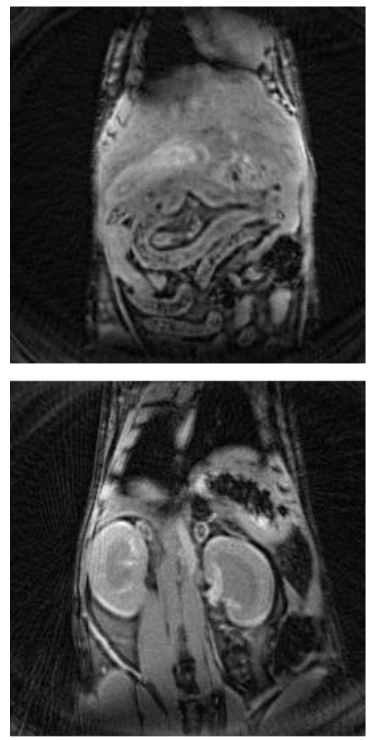

$+30 \mathrm{~min}$
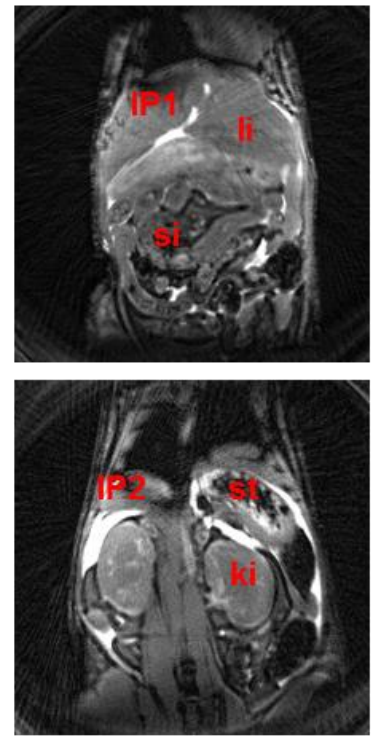

$+3 \mathrm{hrs}$
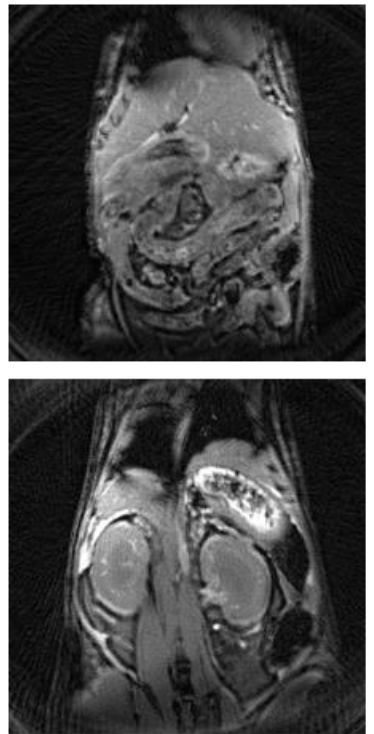

$+5 \mathrm{hrs}$
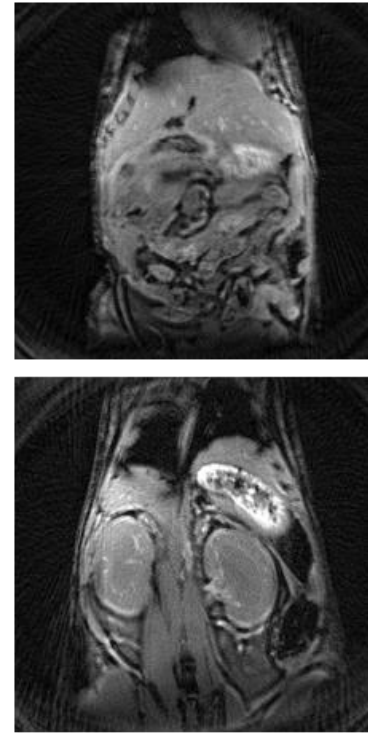

i.p. injection of $\left[\mathrm{Gd}^{3+}\right]_{2}\left[\mathrm{AMP}^{2-}\right]_{3} \mathrm{IOH}-\mathrm{NP}$
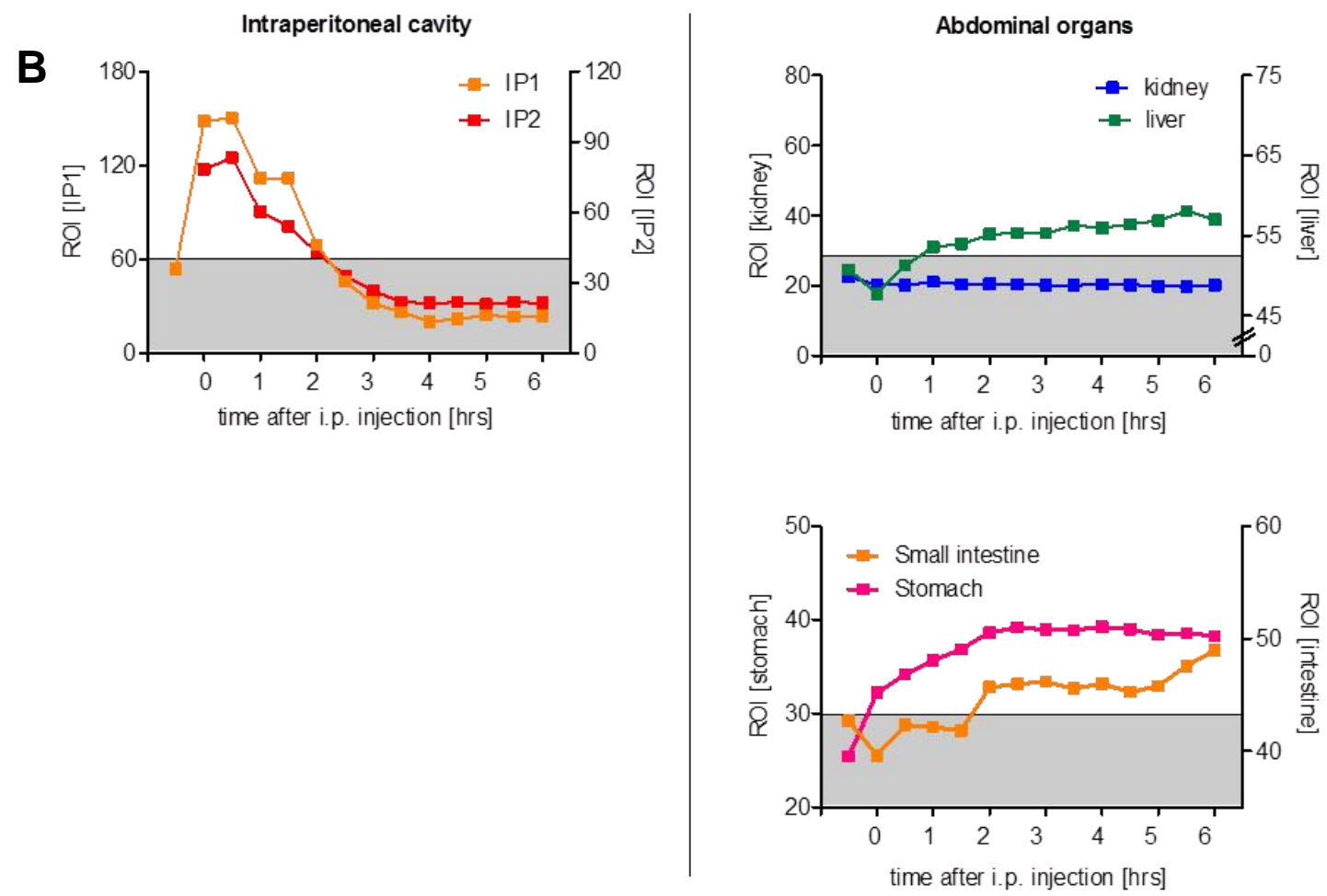

Figure 21: Resorption and organ distribution of GAP-NPs via MRI in vivo. Mice were anaesthetized and actively ventilated throughout the whole experiment. $500 \mu \mathrm{l}$ GAP-NPs were injected i.p. and abdominal cross-sections were obtained 30 minutes before the injection and 6.5 hours onwards with the help of an MRI scanner. (A) Exemplarily are depicted two crosssection levels at the time points $-30 \mathrm{~min},+30 \mathrm{~min}, 3$ and 5 hours upon injection. Region of interests (ROI) are marked for the intraperitoneal cavity $1+2(\mathrm{IP} 1+2)$, liver (li), kidney (ki), small intestine (si) and stomach (st). (B) Quantitative analysis of GAP-NPs distribution within the selected ROI. The grey area indicated the average background signal (Kaiser et al., submitted). 


\subsubsection{Organ distribution of IOH-NPs analyzed ex vivo}

In order to obtain supporting evidence for our previous results with regard to the organ distribution of GAP-NPs in vivo, we determined the zirconium ( $\mathrm{Zr}$ ) concentration within selected organs upon i.p. application of BMP-NPs to mice by Inductive Coupled Plasma-Mass Spectrometry (ICP-MS). Selected organs were dissected and analyzed ex vivo either 5 or 24 hours after the application of $500 \mu \mathrm{l} \mathrm{BMP-NPs}$ containing $0.2 \mathrm{mg} \mathrm{Zr}$. At the early analytical time point, namely 5 hours after the injection, we observed the highest absolute amount of $\mathrm{Zr}$ in the liver, followed by the stomach and jejunum. In contrast, $\mathrm{Zr}$ was hardly detectable in the kidney and lung (Figure 22A). Over time, namely 24 hours after injection, the $\mathrm{Zr}$ content slightly decreased in the liver and was reduced by half in the jejunum (Figure 22B). In summary, these ICP-MS data are indeed in line with our in vivo data acquired from MRI scans and let us assume that $\mathrm{IOH}-\mathrm{NPs}$ are slowly resorbed by the intraperitoneal cavity via lymphatic drainage. Subsequently, IOH-NPs accumulate in the liver, jejunum and stomach, but not in kidney and lung.
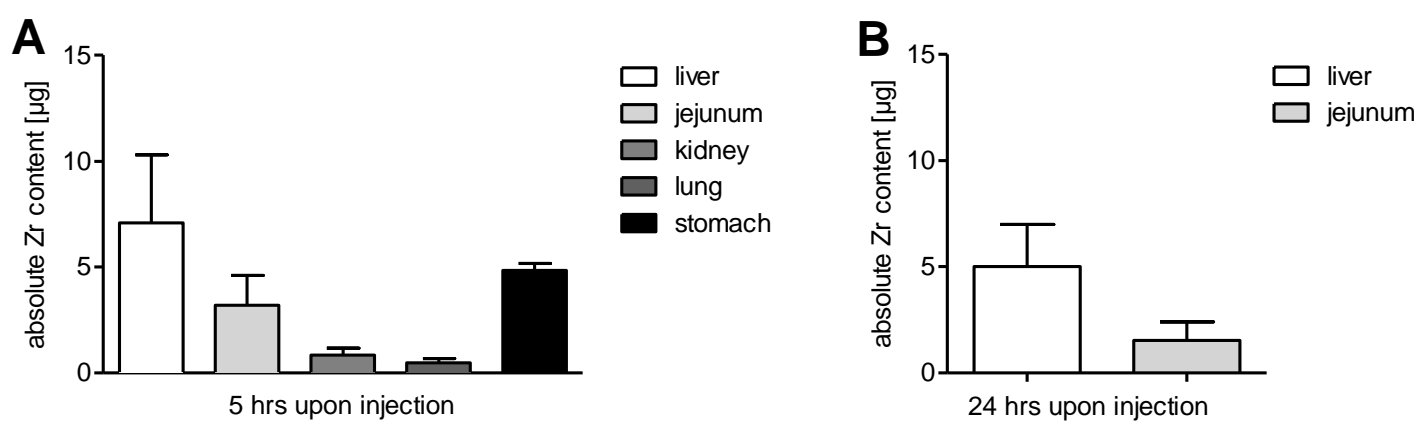

Figure 22: Organic distribution of IOH-NPs analyzed via ICP-MS ex vivo. $500 \mu \mathrm{l}$ BMP-NPs containing $0.2 \mathrm{mg}$ zirkonium $(\mathrm{Zr})$ was injected ip. into mice. Selected organs were dissected either 5 hours or 24 hours upon the injection and the $\mathrm{Zr}$ content within these organs was analyzed. (A) absolute $\mathrm{Zr}$ content in liver, jejunum, kidney, lung and stomach 5 hours upon the injection. (B) absolute $\mathrm{Zr}$ content in liver and jejunum 24 hours upon the injection. All values are depicted as mean \pm SEM. $(N=4)$ (Kaiser et al., submitted). 


\subsection{Application of BMP-NPs as a targeted therapy for aGvHD in mice}

Considering the findings presented in this thesis up to now, BMP-NPs could be a potential powerful carrier system for a targeted GC therapy of aGvHD mice, and eventually also in humans. In brief, we have shown the importance of the GR in recipient myeloid cells in an aGvHD mouse model and found that $\mathrm{IOH}-\mathrm{NPs}$ show a considerable cell-type specificity mainly towards macrophages in the absence of any notable toxic effects in six different cell lines. Moreover, MRI and ICP-MS analyses revealed a favorable organ distribution in healthy mice, including an accumulation in the small intestine and liver being major target organs of aGvHD. Hence, the fourth part of this thesis focuses on the suitability and pathomechanism of BMP-NPs in the treatment of aGvHD in a mouse model in vivo in comparison to free betamethasone (BMX).

\subsubsection{BMP-NP and BMX treatment prolongs the survival in a mouse model of aGvHD mice with similar efficiency}

To explore and compare the treatment efficiencies of BMP-NPs and BMX in the fully MHC-mismatched aGvHD mouse model, which was also used in the first part of this thesis, we monitored the survival of mice from the different treatment groups for 50 days (Figure 23). BALB/c wild type mice served as recipients and C57BL/6 wild type mice were used as donor mice for the BM and T cell graft. The recipients were treatment at day 3, 4, 5, 7, 9 and 12 to mimic a pulse therapy followed by the tapering of the drug. The mice received either $10 \mathrm{mg} / \mathrm{kg}$ BMX or BMP-NPs containing an equal amount of the drug at each time point. Similar volumes of either EP-NPs or PBS were injected as controls. The majority of EP-NP and PBS treated mice succumbed to death before day 10 post-transplantation. No significant differences were noted between both control groups. In comparison to the PBS control group, BMX treated mice died significantly later or had to be sacrificed for ethical reasons, between day 18 and 24 (Figure 23). The majority of BMP-NP treated mice died over a longer time period, namely between day 14 and 31 , which was significantly later than the respective EP-NP control group (Figure 23). In this experiment, BMP-NP was slightly more efficient than BMX in prolonging the survival of the mice (Figure 23). BM mice, which only received T cell depleted BM, all survived until 
the end of the experiment. From this long-term experiment we concluded, that BMX and BMP-NP treatment prolonged the survival in aGvHD mice with largely similar efficiency, although BMP-NP was slightly better.

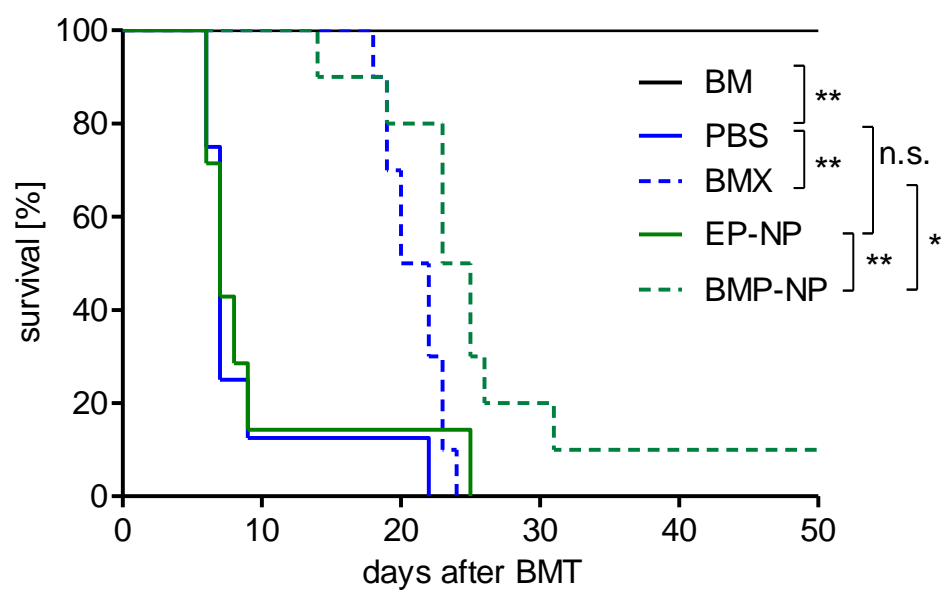

Figure 23: Survival of aGvHD wt mice upon treatment with GCs. Lethally irradiated BALB/C wt recipient mice were transplanted with $\mathrm{BM}$ and purified T cells from donor $\mathrm{C} 57 \mathrm{BL} / 6$ wt mice. BM controls received T cell depleted BM only. Mice received either $10 \mathrm{mg} / \mathrm{kg}$ BMP-NPs or BMX or equal amounts of EP-NPs or PBS at day 3, 4, 5, 7, 9 and 12 i.p.. Survival of mice was recorded for 50 days. $N=4$ (BM), $N=8$ (PBS), $N=10$ (BMX), $N=7$ (EP-NP), $N=9$ (BMP-NP); data pooled from multiple experiments, including data from Laura Roßmann. Survival curves were compared using the Mantel-Cox test $\left({ }^{*} p<0.05\right.$; ${ }^{* *} p<0.01$; ${ }^{* * *} p<0.001$; n.s.: nonsignificant).

\subsubsection{BMP-NP and BMX treatment ameliorates clinical features in the early phase of aGvHD to a similar extent}

In the following, we wanted to explore the mechanisms that may underlay the ameliorating effects of BMP-NPs in the early phase of aGvHD. Thereto, aGvHD was induced in wild type mice followed by treatment with either $10 \mathrm{mg} / \mathrm{kg}$ BMP-NPs or BMX, or equal amounts of EP-NPs or PBS at day 3,4 and 5. Clinical parameters, such as the clinical score and the body weight were monitored for 6 days, which corresponds to the first peak of the disease. Additionally, the body temperature was recorded at day 6 after BMT. Control mice treated with PBS or EP-NPs developed the expected disease course characterized by the progressively increasing clinical scores that were highest at day 6 (Figure 24A, B). In contrast, aGvHD symptoms were attenuated in BMX and BMP-NP treated mice, indicated by significantly lower clinical scores in comparison to PBS and EP-NP treated mice, respectively (Figure 24A, B). 
Furthermore, body weight and body temperature at day 6 were significantly lower in PBS and EP-NP treated mice in comparison to BMX and BMP-NP treated mice, respectively (Figure 24C, D). When we compared all three parameters at day 6 after BMT between PBS and EP-NP treated mice as well as between BMX and BMP-NP treated mice, we did not detect any significant differences. Finally, BM mice did not suffer from aGvHD, which was indicated by the low clinical score, normal body weight and body temperature. Collectively, PBS and EP-NP treated mice suffered strongly from aGvHD characterized by high clinical scores, a low body weight and a low body temperature. In contrast, BMX and BMP-NP treatment ameliorated aGvHD symptoms to a similar extent in the early phase of the disease in these short-term experiments. 

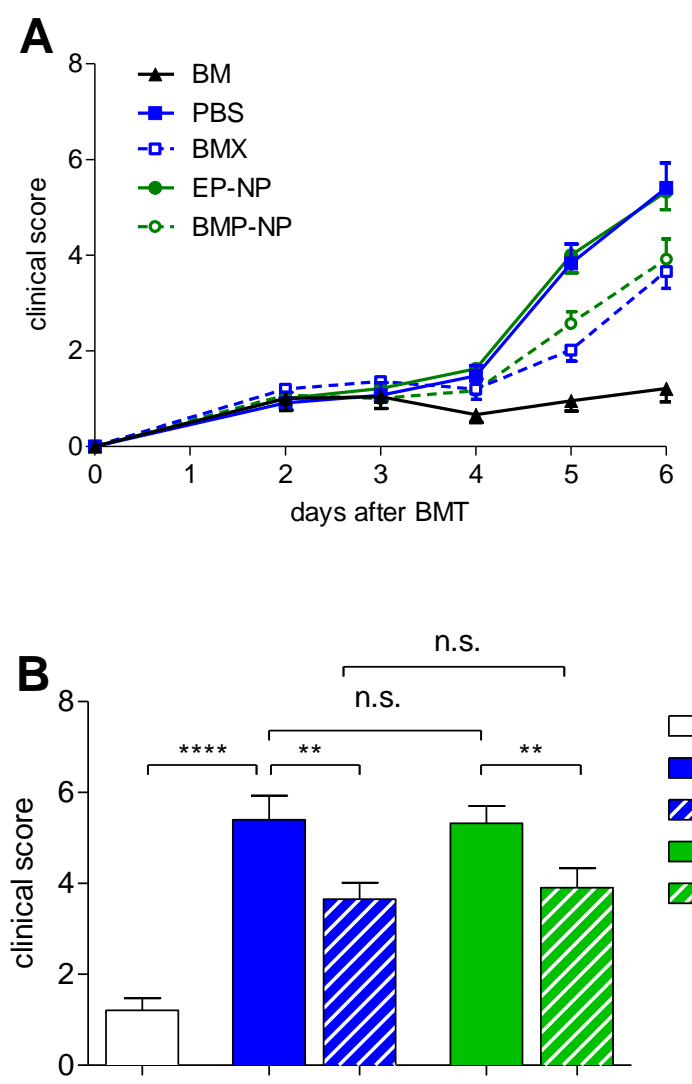

day 6 after BMT

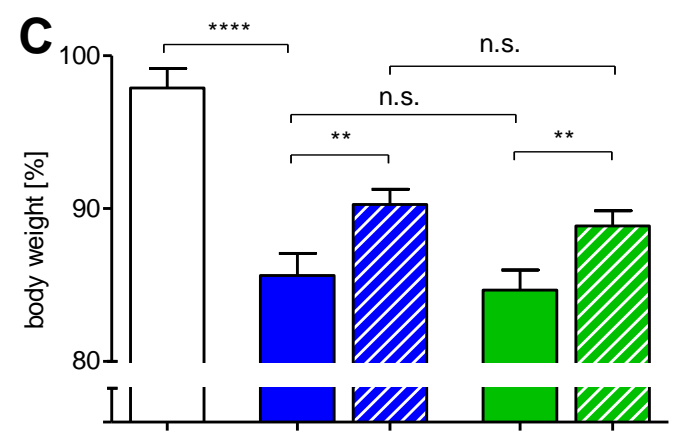

day 6 after BMT

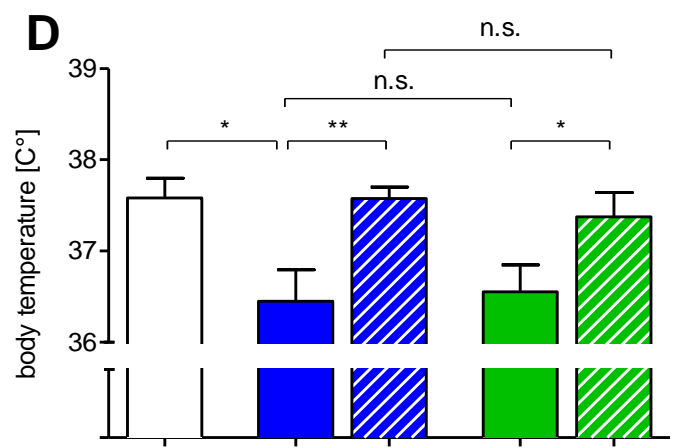

day 6 after BMT
Figure 24: Clinical features of aGvHD in GC-treated wt mice in the early phase. Lethally irradiated BALB/c wt recipient mice were transplanted with BM and purified $T$ cells from donor C57BL/6 wt mice. BM controls received $T$ cell depleted BM only. Mice received either $10 \mathrm{mg} / \mathrm{kg}$ BMP-NPs or BMX or equal amounts of EP-NPs or PBS at day 3, 4, 5 i.p.. (A) Clinical scores were monitored for six days after aGvHD induction (dead mice were listed with a score of 10). (B) Clinical scores at day 6 after BMT. (C) Body weights at day 6 day after BMT; $N=12$ (BM), $N=21$ (PBS), $N=22$ (BMX), $N=23$ (EP-NP), $N=$ 23 (BMP-NP); (D) Body temperature at day 6 after BMT; $N=6$ (BM), $N=10$ (PBS), $N=12$ (BMX), $N=9$ (EP-NP), $N=12$ (BMP-NP). Data pooled from multiple experiments, including data from Laura Roßmann. All values are depicted as the mean \pm SEM. Statistical analyses were performed using the unpaired one-tailed students t-test $\left({ }^{*} \mathrm{p}<0.05 ;{ }^{* *} \mathrm{p}\right.$ $<0.01{ }^{* * *} p<0.001$; n.s.: non-significant). 


\subsubsection{BMP-NP and BMX treatment ameliorates target tissue destruction in the jejunum in the early phase of aGvHD with similar efficiency}

Having demonstrated that BMP-NPs ameliorate aGvHD symptoms in the early phase as efficiently as BMX treatment in mice in vivo, we next wanted to get insights into the beneficial mode of action of BMP-NPs versus BMX in the early phase of aGvHD. Thereto, mice from the short-term experiments (see 3.4.2), including all treatment groups, as well as BM mice were sacrificed at day 6 after BMT and histological analyses of the aGvHD target organ jejunum were performed. The histological score we calculated includes villus blunting, inflammation and the number of apoptotic cells and edemas. Collectively, it is an indicator for the degree of tissue destruction, caused by the disease. Moreover, it is assisted by the number of goblet cells per villus, which is reduced in case of a strong tissue destruction. Both parameters are common aGvHD hallmarks. As expected, PBS and EP-NP treated mice showed significantly higher histopathological scores in comparison to BMX and BMP-NP treated mice (Figure 25A, B). Also the number of goblet cells per villus was significantly reduced in the control groups PBS and EP-NP in contrast to BMX and BMP-NP treated mice, respectively (Figure 25A, C). Based on the before mentioned parameters, BM mice exhibited an intact jejunum, which was not affected by the disease. Taken together, these results suggest, that both ways of GC applications ameliorate the disease by reducing the tissue destruction in the aGvHD target organ jejunum to a similar extent in short-term experiments. 
A
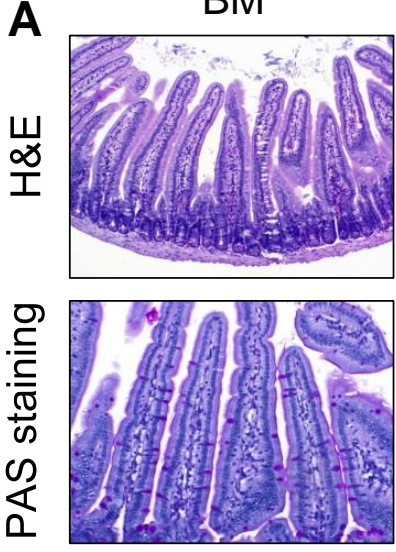

EP-NP
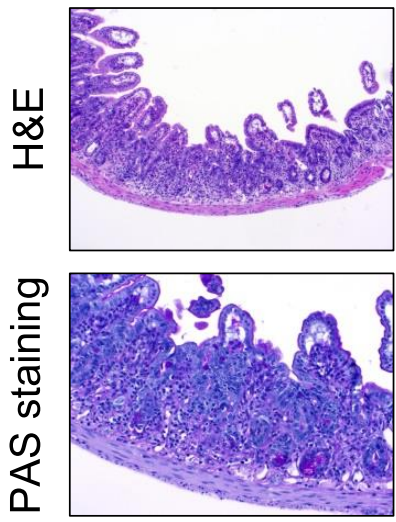

PBS
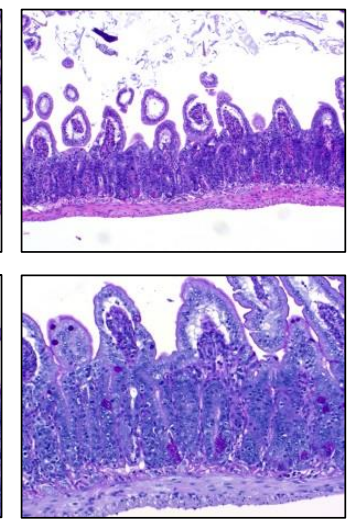

BMP-NP
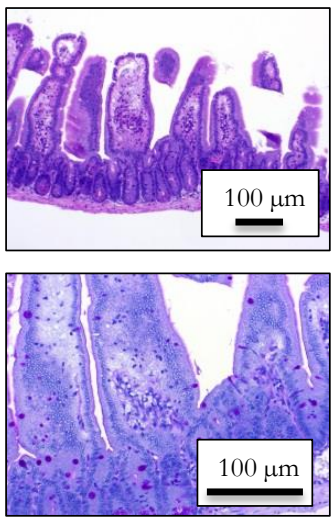

B

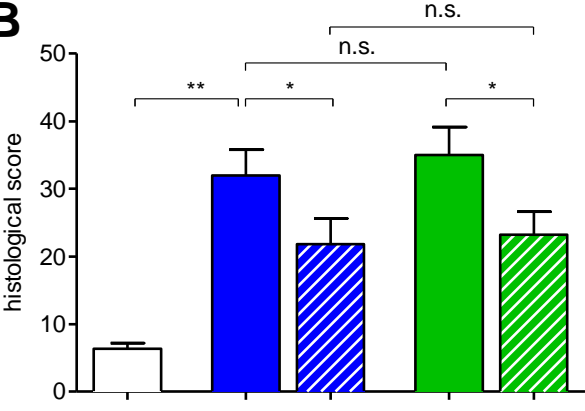

day 6 after BMT
C

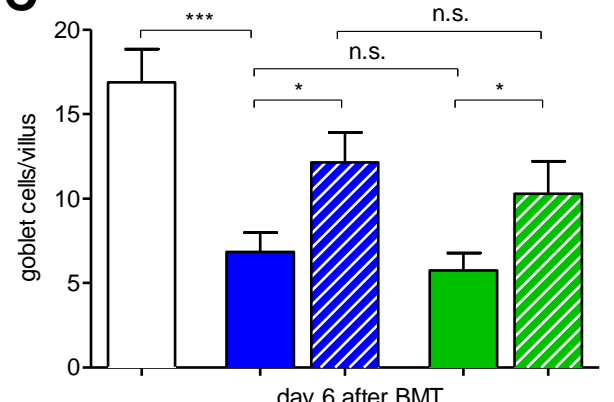

$\square$ BM

II BMX

$\square$ EP-NP

BMP-NP

Figure 25: Histological analysis of the jejunum in the early phase of aGvHD in GC-treated wt mice. Lethally irradiated BALB/c wt recipient mice were transplanted with BM and purified $T$ cells from donor $\mathrm{C} 57 \mathrm{BL} / 6$ wt mice. BM controls received T cell depleted BM only. Mice received either $10 \mathrm{mg} / \mathrm{kg}$ BMP-NPs or BMX or equal amounts of EP-NPs or PBS at day 3, 4, 5 i.p.. Mice were sacrificed at day 6 after BMT and histological analysis of the jejunum was performed. (A) Representative microphotographs of sections of the jejunum stained by H\&E or PAS reaction. Scale bar: $100 \mu \mathrm{m}$. (B) Histological scores imply villus blunting, inflammatory infiltrates, edema and apoptotic cells analyzed by H\&E stained jejunum sections; $N=3$ (BM), $N=10$ (PBS), $N=11$ (BMX), $N=9$ (EP-NP), $N=12$ (BMP-NP); (C) Goblet cell numbers per villus were analyzed by PAS reaction of jejunum sections; $N=3$ (BM), $N=11$ (PBS), $N=11$ (BMX), $N=9$ (EP-NP), $N=11$ (BMP-NP); Data pooled from multiple experiments. All values are depicted as the mean \pm SEM. Statistical analyses were performed using the unpaired one-tailed students $t-$ test $\left({ }^{*} p<0.05 ;{ }^{* *} p<0.01 ;{ }^{* * *} p<0.001 ;\right.$ n.s.: non-significant). 


\subsubsection{BMX, but not BMP-NP treatment reduces infiltration of $\mathrm{CD}^{+}{ }^{+}$and $\mathrm{CD}^{+}$into the jejunum in the early phase of aGvHD}

GC treatment similarly reduced the tissue destruction in the jejunum regardless of the application form. Therefore we were next interested whether this is because they both prevent the infiltration of immune cells into the jejunum or whether they rather locally influence the phenotype of aGvHD relevant immune cells. First, we examined the infiltration of $\mathrm{CD}^{+}$and $\mathrm{CD}^{+} 8^{+}$cells by immunohistochemical stainings of jejunum sections. The numbers of $\mathrm{CD}^{+}$ $\mathrm{T}$ cells and $\mathrm{CD}^{+} 8^{+}$myeloid cells were elevated in PBS treated mice in comparison to BM control mice (Figure 26). Furthermore, the number of both immune cell types was significantly decreased in the BMX treated group in comparison to the PBS group. Surprisingly, the number of both immune cell types was similarly elevated in EP-NP and BMP-NP treated mice in comparison to the BM control group, from which we conclude that BMP-NPs neither reduces the infiltration of $\mathrm{CD}^{+} \mathrm{T}$ cells nor of $\mathrm{CD}^{+} 8^{+}$myeloid cells into the jejunum. 
A

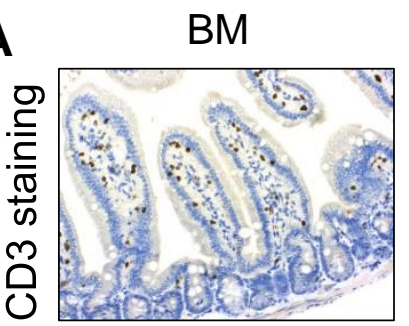

PBS
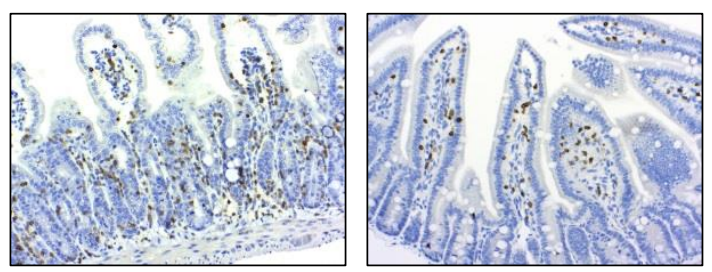

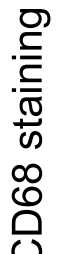
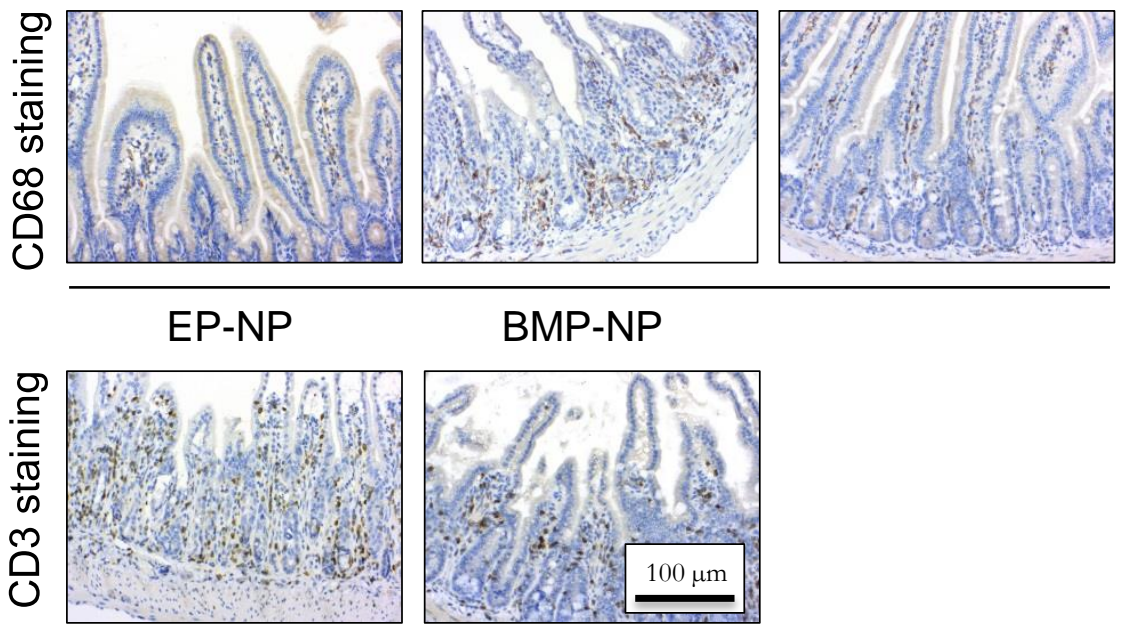

BMP-NP
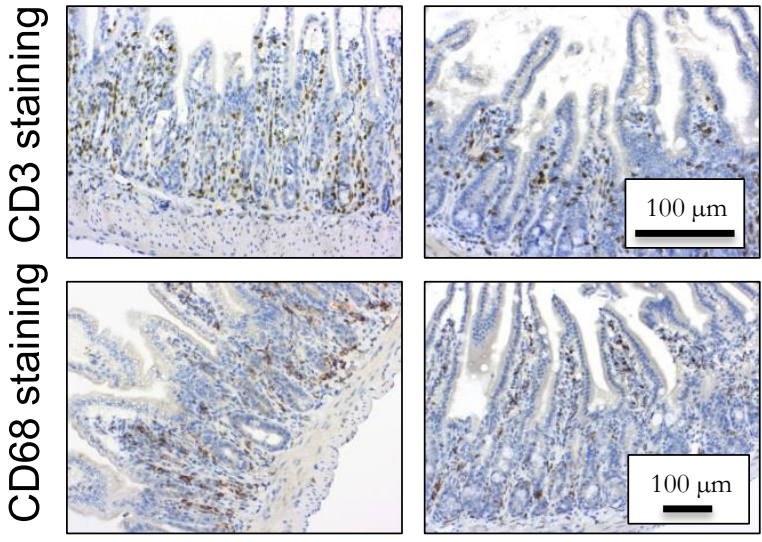

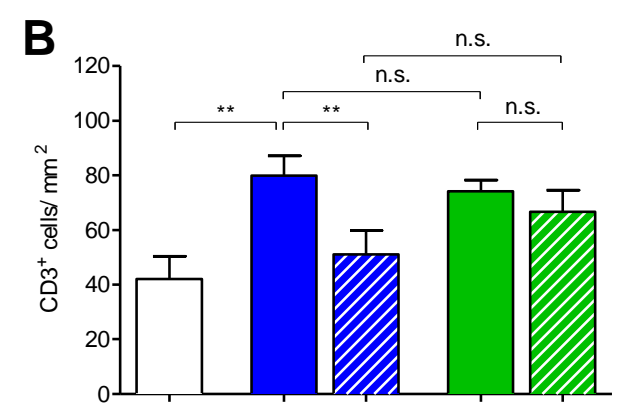

day 6 after BMT

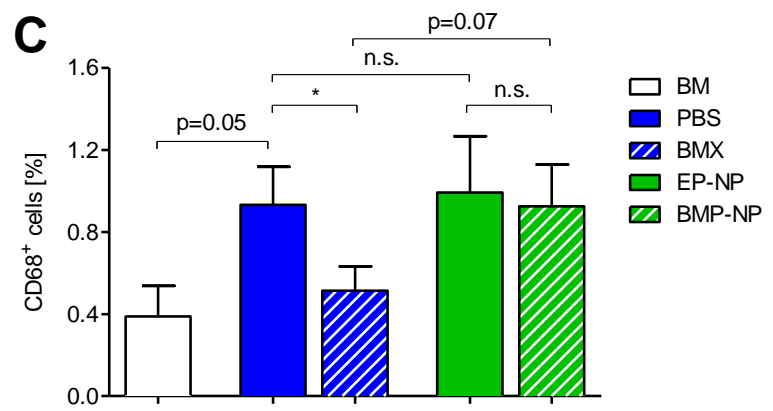

day 6 after BMT

Figure 26: Immunohistochemical analysis of the jejunum in the early phase of aGvHD in GC-treated wt mice. Lethally irradiated BALB/C wt recipient mice were transplanted with BM and purified T cells from donor C57BL/6 wt mice. BM controls received T cell depleted BM only. Mice received either $10 \mathrm{mg} / \mathrm{kg}$ BMP-NPs or BMX or equal amounts of EP-NPs or PBS at day 3, 4, 5 i.p.. Mice were sacrificed at day 6 after BMT and immunohistochemical analysis of the jejunum was performed. (A) Representative microphotographs of sections of the jejunum stained with antibodies recognizing CD3 or CD68. Scale bar: $100 \mu \mathrm{m}$. (B) Number of $\mathrm{CD}^{+} \mathrm{T}$ cells per $\mathrm{mm}^{2}$ were examined by computer-aided counting of stained cells in jejunum sections using the Zeiss Zen lite software; $N=4$ (BM), $N=11$ (PBS), $N=11$ (BMX), $N=9$ (EP-NP), $N=12$ (BMP-NP); (C) CD68 ${ }^{+}$myeloid cells were examined in jejunum sections by measuring the percentage of stained area using the ImageJ software; $N=4$ (BM), $N=11$ (PBS), $N=8$ (BMX), $N=9$ (EP-NP), $N=12$ (BMP-NP). Data pooled from multiple experiments. All values are depicted as the mean \pm SEM. Statistical analyses were performed using the unpaired one-tailed students t-test ( ${ }^{*} p<0.05 ;{ }^{* *} p<0.01 ;{ }^{* *} p<0.001 ; n . s .:$ non-significant). 
To allow a more refined analysis of immune cell subtypes in the infiltrated jejunum of the aGvHD mice, they were isolated from the lamina propria and analyzed via FACS. The percentage of $\mathrm{CD}^{+} \mathrm{CD}^{+} \mathrm{T}$ cells was significantly higher, and of the $\mathrm{CD}^{+} \mathrm{CD}^{+} \mathrm{T}$ cells significantly lower in $\mathrm{BM}$ mice in comparison to PBS treated mice (Figure 27A). Moreover, in BMX treated mice the percentage of $\mathrm{CD} 4^{+} \mathrm{CD} 3^{+} \mathrm{T}$ cells was significantly elevated, and $\mathrm{CD} 8^{+} \mathrm{CD} 3^{+}$ $T$ cells reduced $(p=0.05)$ in comparison to the PBS group. In agreement with the previous immunohistochemical analysis, such differences were not observed between BMP-NP treated mice in comparison to EP-NP treated mice. Next, we examined the abundance of different subpopulations of $\mathrm{CD}_{11 b^{+}}$Ly6G $^{\text {low }}$ myeloid cells, which correspond to different types of macrophages and monocytes. Ly6 $\mathrm{C}^{\text {high }}$ cells, which represent the inflammatory phenotype, were significantly lower in BM mice in comparison to the PBS treated group, whereas Ly6C ${ }^{\text {low }}$ cells, representing the resting non-inflammatory phenotype, were significantly higher (Figure 27B). BMX treatment significantly reduced the percentage of $L y 6 C^{\text {high }}$ myeloid cells and significantly increased the percentage of Ly6C $\mathrm{C}^{\text {low }}$ myeloid cells in comparison to the PBS treatment. Surprisingly, BMP-NP treatment solely caused a weak shift in the same direction in comparison to EP-NP treatment. To summarize these results, BMP-NP treatment, in contrast to the BMX treatment, neither prevents the infiltration of $\mathrm{CD}^{+}$nor $\mathrm{CD}^{+} 8^{+}$cells in the jejunum. Furthermore, BMP-NPs neither impact the percentage of $\mathrm{CD} 4^{+}$and $\mathrm{CD} 8^{+} \mathrm{T}$ cells nor of $\mathrm{Ly} 6 \mathrm{C}^{\text {high }}$ myeloid cells. This let us to conclude, that both GC application forms apply different mechanisms in order to reduce the jejunum's tissue destruction and to ameliorate the disease. 

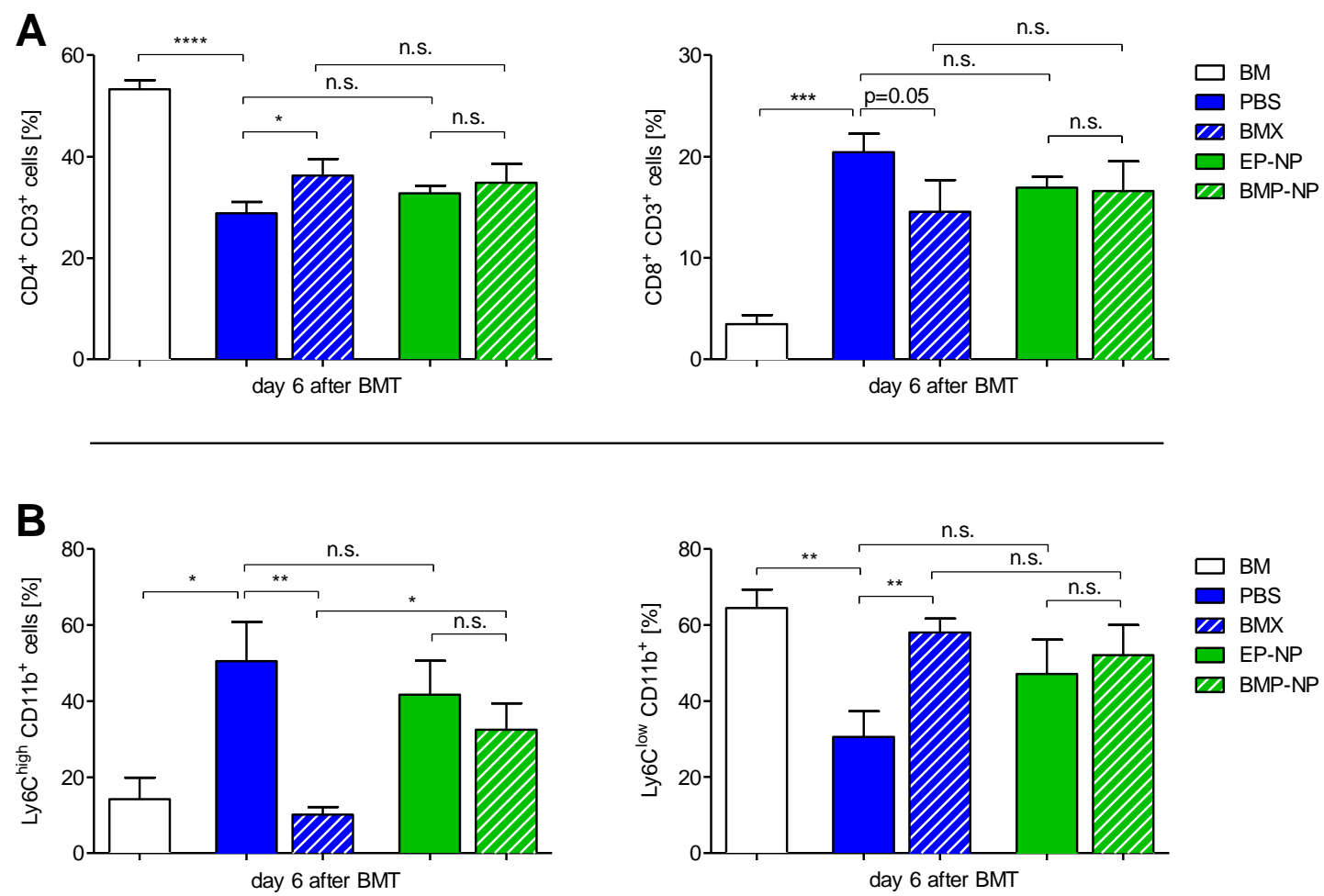

Figure 27: Characterization of the cellular composition of the inflammatory infiltrate in the lamina propria in the jejunum in GC-treated wt mice in the early phase of aGvHD. Lethally irradiated BALB/c wt recipient mice were transplanted with BM and purified T cells from donor C57BL/6 wt mice. BM controls received T cell depleted BM only. Mice received either $10 \mathrm{mg} / \mathrm{kg}$ BMP-NPs or BMX or equal amounts of EP-NPs or PBS at day 3, 4, 5 i.p.. Mice were sacrificed at day 6 after BMT, cells present in the lamina propria were isolated from the jejunum and its cellular composition was characterized via FACS. (A) Percentages of $\mathrm{CD}^{+} \mathrm{CD}^{+}$(left panel) and $\mathrm{CD}^{+} \mathrm{CD}^{+} \mathrm{T}$ cells (right panel) based on the expression of the respective surface markers. $N=3$ (BM), $N=7$ (PBS), $N=4$ (BMX), $N=4$ (EP-NP), $N=5$ (BMP-NP). (B) Percentages of Ly6C high $C D 11 b^{+}$Ly6G ${ }^{\text {low }}$ (left panel) and Ly6C $C^{\text {low }} \mathrm{CD} 11 \mathrm{~b}^{+}$Ly6G ${ }^{\text {low }}$ myeloid cells (right panel) based on the expression of the respective surface markers. $N=3(\mathrm{BM}), N=7$ (PBS), $N=4$ (BMX), $N=4$ (EP-NP), $N=5$ (BMP-NP). Data pooled from multiple experiments. All values are depicted as the mean \pm SEM. Statistical analyses were performed using the unpaired one-tailed students t-test $\left({ }^{*} p<0.05 ;{ }^{* *} p<0.01\right.$; ${ }^{* *} p<0.001$; n.s.: non-significant).

\subsubsection{GR expression in myeloid cells is required for therapeutic efficacy of BMP-NP treatment in the early phase of aGvHD}

Our findings indicated that BMP-NPs and BMX use different mechanisms in order to ameliorate aGvHD. Therefore, we wanted to explore whether GC effects in myeloid cells were indeed essential to ameliorate aGvHD by using $G^{\text {lysM }}$ mice that we had already studied in the first part of this thesis (see 3.1). $G^{\text {lysM }}$ mice carry a deletion of the GR in myeloid cells, which makes them unsusceptible to GCs. $\mathrm{GR}^{\mathrm{lysM}}$ and $\mathrm{GR}^{\text {flox }}$ control mice were treated either with $10 \mathrm{mg} / \mathrm{kg}$ BMP-NPs or equal amounts of EP-NPs at day 3, 4 and 5 . The mice were sacrificed at the peak of the disease, at day 6 , as in previous experiments. 
Clinical parameters were monitored and histological analyses were performed to obtain insights into the health status of the animals. $\mathrm{GR}^{\text {flox }}$ and $\mathrm{GR}^{\mathrm{lysM}}$ mice treated with EP-NPs, not containing any GCs, progressively developed disease symptoms over time. This was indicated by the constantly increasing clinical scores (Figure 28A, B). In contrast, when we treated both mice strains with BMP-NPs, the disease only improved in $\mathrm{GR}^{\text {flox }}$, but not in $\mathrm{GR}^{\mathrm{lysM}}$ mice (Figure 28A). $\mathrm{GR}^{\text {flox }}$ mice treated with BMP-NPs had significantly lower clinical scores and a higher body temperature in comparison to $\mathrm{GR}^{\text {flox }}$ mice treated with EP-NPs (Figure 28B, C), which is in line with the previous results obtained in wild type BALB/c mice (see Figure 24). However, we detected no differences in both parameters between GR $^{\text {lysM }}$ mice treated with either BMP-NPs or EP-NPs (Figure 28B, C). As expected, control BM mice did not suffer from aGvHD symptoms, indicated by a low clinical score and normal temperature. 

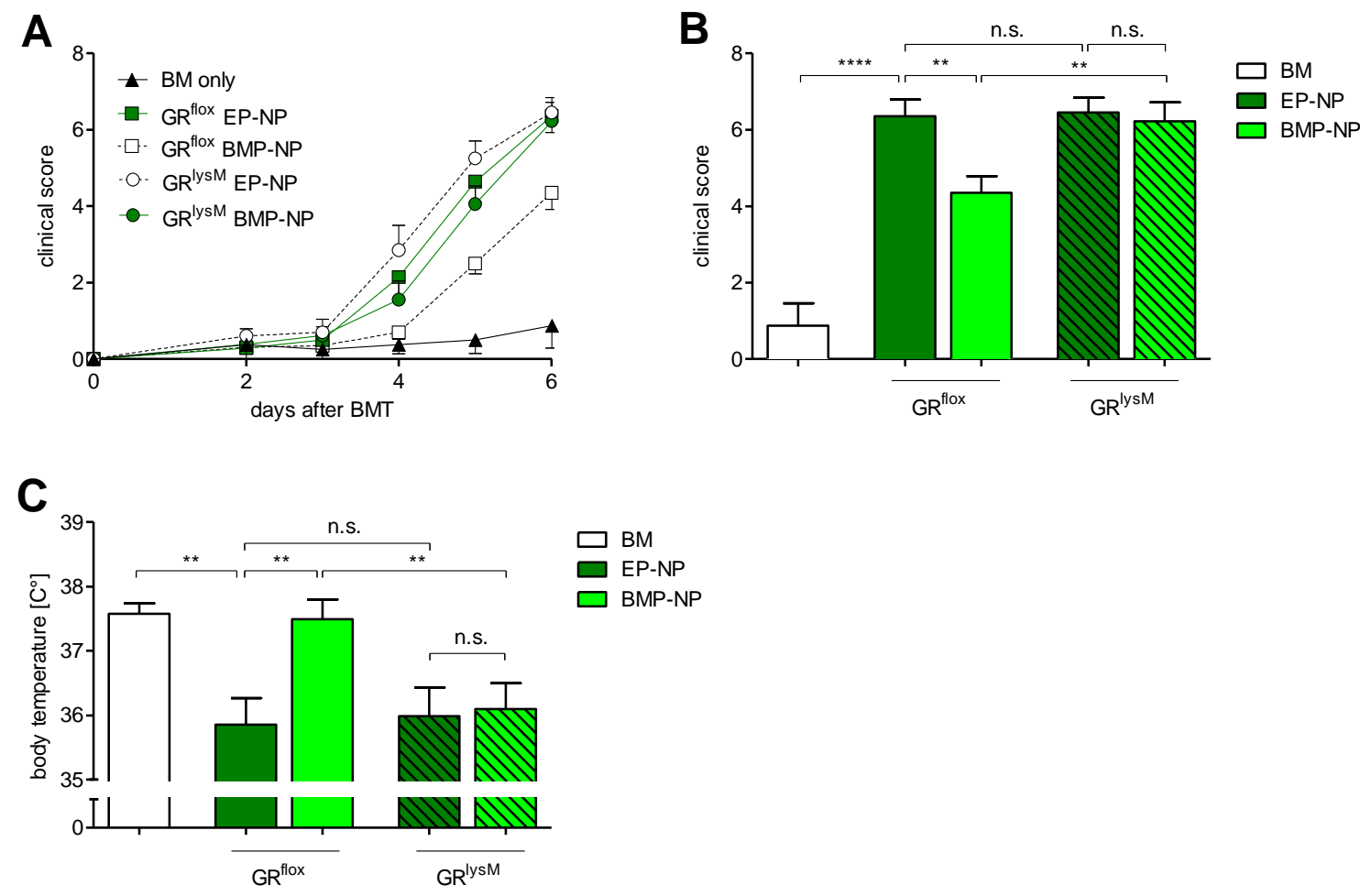

Figure 28: Clinical features in the early phase of aGvHD in the $G R^{\text {lysM }}$ model treated with BMP-NPs. Lethally irradiated BALB/c GR ${ }^{\text {flox }}$ and $\mathrm{GR}^{\text {lysM }}$ recipient mice were transplanted with $\mathrm{BM}$ and purified T cells from donor C57BL/6 wt mice. BM controls received T cell depleted BM only. Mice received either $10 \mathrm{mg} / \mathrm{kg}$ BMP-NPs or equal amounts of EP-NPs at day 3, 4, 5 i.p.. (A) Clinical scores were monitored for six days after aGvHD induction (dead mice were listed with a score of 10). (B) Clinical scores at day 6 after BMT (C) Body temperatures at day 6 after BMT; $N=4$ (BM), $N=7 / 10$ (GR ${ }^{\text {flox }}$; EP-NP/BMP-NP), $N=10 / 9$ (GR ${ }^{\text {lysM }}$; EP-NP/BMP-NP). Data pooled from multiple experiments. All values are depicted as the mean \pm SEM. Statistical analyses were performed using the unpaired one-tailed students t-test $\left({ }^{*} p<0.05\right.$; ${ }^{* *} p<0.01$; ${ }^{* * *} p<0.001$; n.s.: non-significant).

To support our conclusions derived from monitoring the disease course in GR $^{\text {lysM }}$ mice treated with BMP-NPs, we also performed histological analyses similar to our previous study of wild type mice (see Figure 25). The histological score was significantly lower and the number of goblet cells was significantly higher in $\mathrm{GR}^{\text {flox }}$ mice treated with BMP-NPs in comparison to $\mathrm{GR}^{\text {flox }}$ mice treated with EP-NPs (Figure 29A). These results are in agreement with our earlier findings (see Figure 25). In contrast, we detected no differences in both parameters in $\mathrm{GR}^{\mathrm{lysM}}$ mice treated either with BMP-NPs or EP-NPs. BM mice had an intact jejunum based on the histological score and the number of goblet cells per villus. Additionally, immunohistochemical analysis of the jejunum was done to study the infiltration of $\mathrm{CD}^{+} \mathrm{T}$ cells and $\mathrm{CD} 68^{+}$myeloid cells into this organ and showed no differences between BMP-NP and EP-NP treated GR ${ }^{\text {flox }}$ 
mice (Figure 29B) as seen before (see Figure 26). The same observation was made for $\mathrm{GR}^{\mathrm{lysM}}$ mice, as expected. In contrast, BM mice showed low numbers of $\mathrm{CD}^{+} \mathrm{T}$ cells and $\mathrm{CD}^{+} 8^{+}$myeloid cells compared to $\mathrm{GR}^{\text {flox }}$ mice treated with EP-NPs. In conclusion, BMP-NP treatment improves aGvHD symptoms only in

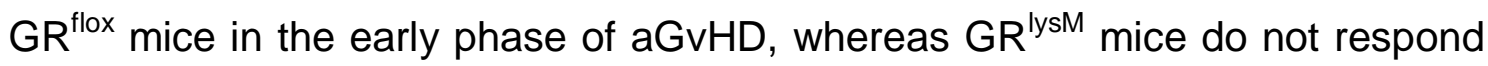
to BMP-NP treatment. This finding proves that BMP-NPs indeed mainly act on myeloid cells such as macrophages in vivo, thereby ameliorating the disease. 
A
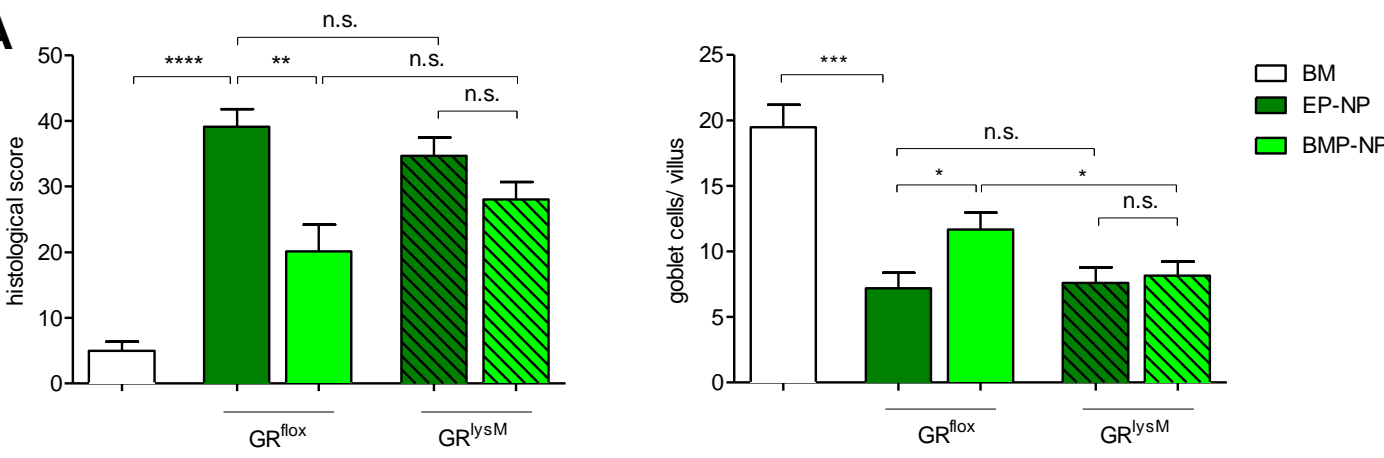

B
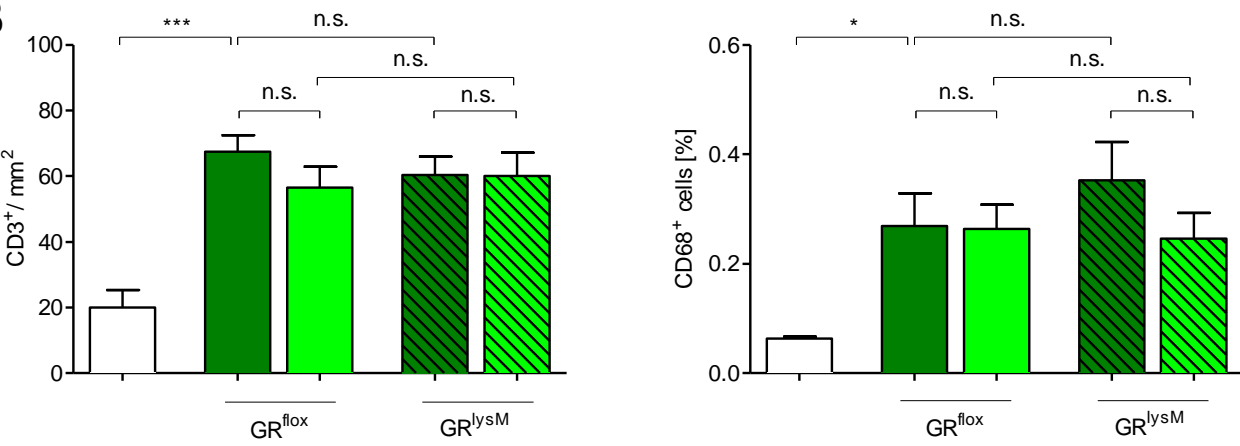

Figure 29: Histological and immunochemical analyses of the jejunum in the early phase of aGvHD in the GR ${ }^{\text {lysM }}$ model treated with BMP-NPs. Lethally irradiated BALB/c GR ${ }^{\text {flox }}$ and $G^{\text {IysM }}$ recipient mice were transplanted with $B M$ and purified T cells from donor C57BL/6 wt mice. BM controls received T cell depleted BM only. Mice received either $10 \mathrm{mg} / \mathrm{kg} \mathrm{BMP-NPs}$ or equal amounts of EP-NPs at day 3, 4, 5 i.p.. Mice were sacrificed at day 6 after BMT and histological and immunohistological analyses of the jejunum were performed. (A) Histological scores (left figure) and goblet cells/ villus (right figure) were determined in sections of the jejunum stained by H\&E or PAS reaction, respectively. Histological scores imply villus blunting, inflammatory infiltrates, edema and apoptotic cells; $N=4$ (BM), $N=7 / 7$ (GR ${ }^{\text {flox; }}$ EP-NP/ BMP-NP), $N=8 / 9$ (GR ${ }^{\text {lysM; }}$; EP-NP/BMP-NP). Goblet cells/ villus; $N=3(\mathrm{BM}), N=7 / 7$ (GR ${ }^{\text {flox}}$; EP-NP/BMP-NP), $N=8 / 8$ (GR ${ }^{\text {lysM }}$; EP-NP/BMP-NP). (B) Number of $\mathrm{CD}^{+} \mathrm{T}$ cells per $\mathrm{mm}^{2}$ (left figure) and $\mathrm{CD} 8^{+}$myeloid cells (right figure) were determined in the jejunum stained with antibodies recognizing CD3 or CD68, respectively. Numbers of $\mathrm{CD}^{+} \mathrm{T}$ cells per $\mathrm{mm}^{2}$ were examined by computer-aided counting of stained cells in jejunum sections using the Zeiss ZEN lite software; $N=4$ (BM), $N=6 / 10$ (GR ${ }^{\text {flox; }}$ EP-NP/BMP-NP), $N=10 / 9$ (GR ${ }^{\text {lysM }}$; EP-NP/ BMP-NP). $\mathrm{CD}^{+} 8^{+}$myeloid cells were examined in jejunum sections by measuring the percentage of stained area using the ImageJ software; $N=4$ (BM), $N=7 / 8$ (GR ${ }^{\text {flox; }}$; EP-NP/BMP-NP), $N=10 / 8$ (GR ${ }^{\text {lysM }}$; EP-NP/BMP-NP). Data pooled from multiple experiments. All values are depicted as the mean \pm SEM. Statistical analyses were performed using the unpaired one-tailed students t-test $\left({ }^{*} p<0.05 ;{ }^{* *} p<0.01 ;{ }^{* * *} p<0.001\right.$; n.s.: non-significant). 


\subsubsection{BMP-NP and BMX treatment does not reduce systemic cytokine secretion in the early phase of aGvHD}

Deletion of the $G R$ in myeloid cells of the $\mathrm{GR}^{\mathrm{lysM}}$ mouse model resulted in a systemic pro-inflammatory cytokine secretion in the early phase of aGvHD, which was responsible for the development of a fulminant disease course with early lethality (Baake et al., 2018). These finding suggest that preventing a cytokine storm is the primary mechanism by which GCs interfere with aGvHD. Hence it is conceivable that treatment with BMX or BMP-NPs uses the same mechanism. In the following, we were therefore interested whether the therapeutic efficacy of BMP-NPs could be explained by a reduction of the systemic secretion of pro-inflammatory cytokines associated with macrophages and indirectly also with T cells. To address this question, aGvHD was induced in wild type mice as previously described, which subsequently received either $10 \mathrm{mg} / \mathrm{kg}$ BMP-NPs or BMX, or equal amounts of EP-NPs or PBS at day 3, 4 and 5. The mice were sacrificed at day 6 after BMT and cytokine levels in the sera were analyzed by ELISA. All inspected cytokines, namely TNFa, IL-6, CCL-2 and IFNy were elevated in PBS treated aGvHD mice in contrast to BM mice (Figure 30). However, the levels of all cytokines were unaltered when comparing PBS and BMX treated mice as well as EP-NP and BMP-NP treated mice. This finding indicates that suppression of systemic cytokine secretion is not the primary mechanism by which BMX and BMP-NPs ameliorate aGvHD. 


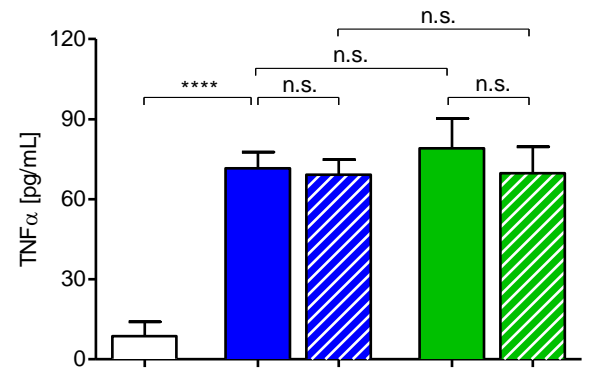

day 6 after BMT

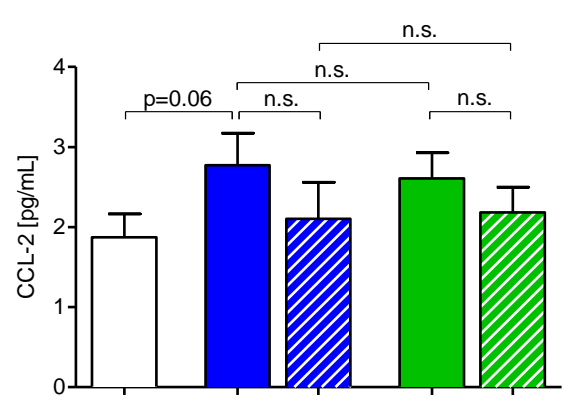

day 6 after BMT

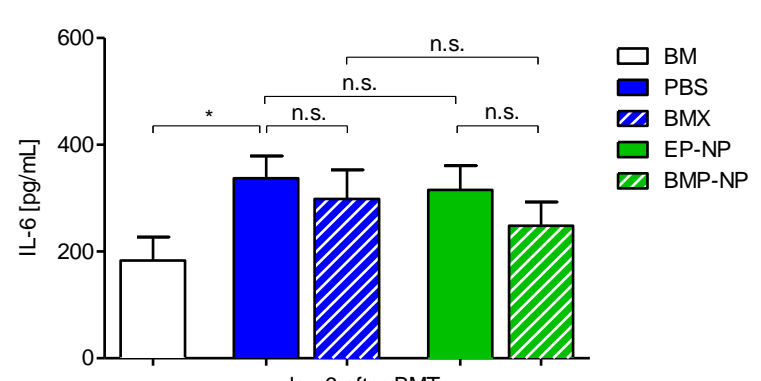

day 6 after BMT

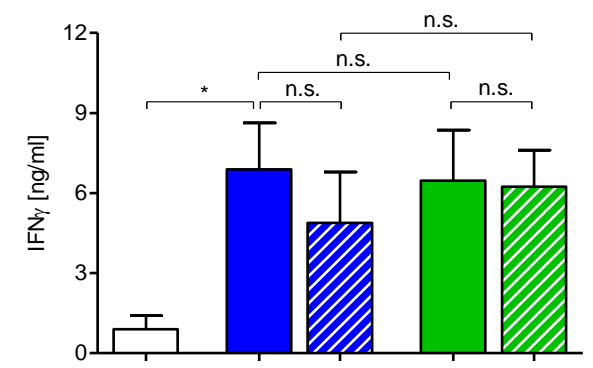

day 6 after BMT

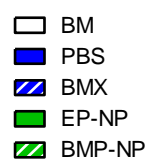

Figure 30: Systemic cytokine levels in the early phase of aGvHD in wt mice treated with GCs. Lethally irradiated BALB/c recipient wt mice were transplanted with BM and purified $T$ cells from donor C57BL/6 wt mice. BM controls received T cell depleted BM only. Mice received either $10 \mathrm{mg} / \mathrm{kg}$ BMP-NPs or BMX or equal amounts of PBS or EP-NPs at day 3, 4, 5 i.p.. Mice were sacrificed at day 6 after BMT. Serum levels of IL-6, TNFa, IFNy and CCL-2 were determined by ELISA. IL6: $N=4$ (BM), $N=11$ (PBS), $N=12$ (BMX), $N=11$ (EP-NP), $N=13$ (BMP-NP). TNFa: $N=4$ (BM), $N=9$ (PBS), $N=5$ (BMX), $N=8$ (EP-NP), $N=8$ (BMP-NP). CCL-2: $N=7$ (BM), CCL-2: $N=11$ (PBS), $N=13$ (BMX), $N=11$ (EP-NP), $N=14$ (BMP-NP). IFNy: $N=6$ (BM), $N=10$ (PBS), $N=13$ (BMX), $N=11$ (EP-NP), $N=14$ (BMP-NP). Data pooled from multiple experiments. All values are depicted as mean \pm SEM. Statistical analyses were performed using the unpaired one-tailed students t-test $\left({ }^{*} p<0.05 ;{ }^{* *} p<0.01 ;{ }^{* *} p<0.001\right.$; n.s.: non-significant).

\subsubsection{BMP-NP and BMX treatment reduces the cytokine gene expression in the early phase of aGvHD in the jejunum to a similar extent}

Since we had failed to detect any differences in the systemic cytokine secretion between the four treatment groups, we investigated the local cytokine expression in the aGvHD target organ jejunum. Therefore, RNA was isolated from jejunum biopsies at day 6 after BMT and analyzed by quantitative RT-PCR. Gene expression of all cytokines that we analyzed, namely Tnfa, I/6, Ccl2, I110, II2 and Ifng were significantly increased in PBS treated aGvHD mice compared to BM controls (Figure 31). Conversely, BMX treatment reduced the mRNA levels of all cytokines in comparison to the PBS group, an effect that was significant with the exception of Cc/2. BMP-NP treatment achieved similar 
effects compared to EP-NP treatment, which was again significant, except for Ccl2 and I/6. Taken together, both forms of GCs similarly provoke a local reduction of mainly macrophage and $\mathrm{T}$ cell associated pro-inflammatory cytokines, as well as of the anti-inflammatory cytokine $/ 110$. We conclude that this effect is the common and main mechanism by which BMX and BMP-NPs limit tissue destruction within the jejunum and ameliorate the disease symptoms. 


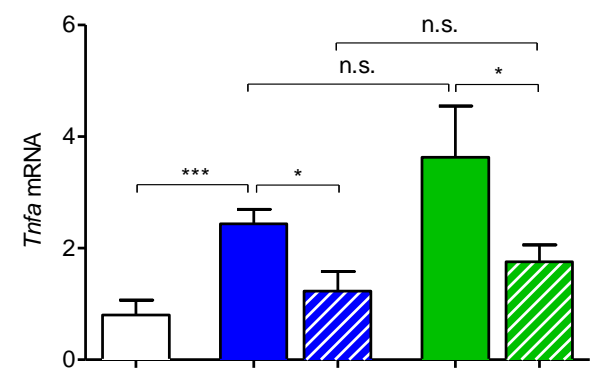

day 6 after BMT
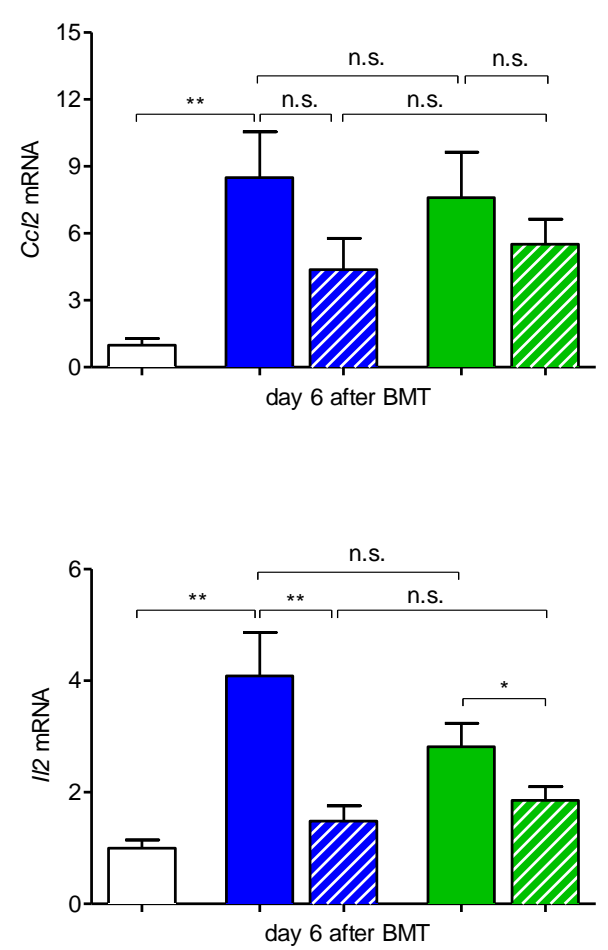

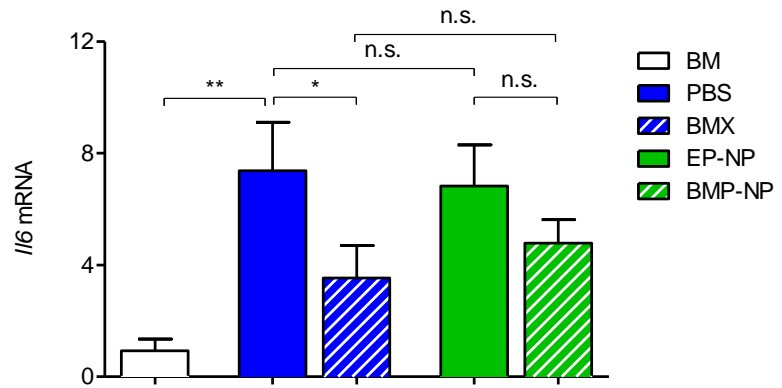

day 6 after BMT

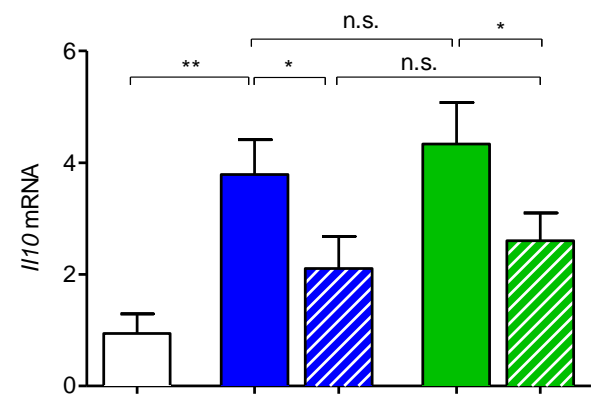

day 6 after BMT

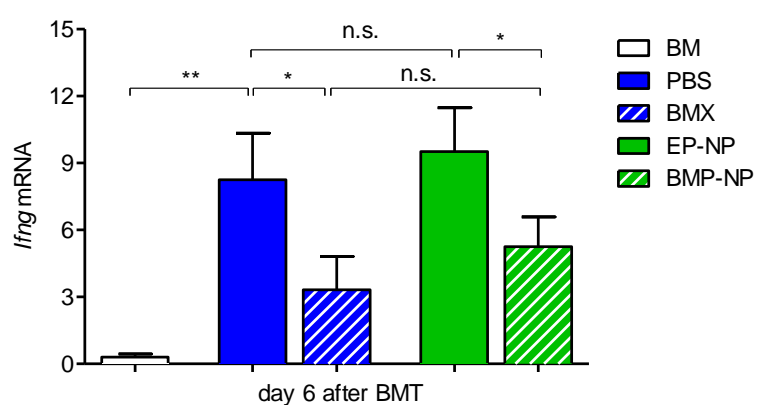

Figure 31: Cytokine expression in the jejunum in the early phase of aGvHD in wt mice treated with GCs. Lethally irradiated $B A L B / c$ recipient wt mice were transplanted with $B M$ and purified T cells from donor C57BL/6 wt mice. BM controls received T cell depleted BM only. Mice received either $10 \mathrm{mg} / \mathrm{kg}$ BMP-NPs or BMX or equal amounts of PBS or EP-NPs at day 3, 4, 5 i.p.. Mice were sacrificed at day 6 after BMT. Relative mRNA levels of Tnfa, II6, Ccl2, II10, II2 and Ifng in jejunum biopsies were analyzed by quantitative RT-PCR using Hprt for normalization; gene expression analysis of BM controls was arbitrarily set to 1. Tnfa: $N=6$ (BM), $N=7$ (PBS), $N=10$ (BMX), $N=9$ (EP-NP), $N=12$ (BMP-NP), II6, Ccl2, II2, Ifng: $N=6$ (BM), $N=8$ (PBS), $N=11$ (BMX), $N=10$ (EP-NP), $N=12$ (BMP-NP), $I 10: N=6$ (BM), $N=8$ (PBS), $N=11$ (BMX), $N=9$ (EP-NP), $N=12$ (BMP-NP). Data pooled from multiple experiments. All values are depicted as mean \pm SEM. Statistical analyses were performed using the unpaired one-tailed students t-test $\left({ }^{*} \mathrm{p}<0.05 ;{ }^{* *} \mathrm{p}<0.01\right.$; ${ }^{* *} \mathrm{p}<0.001$; n.s.: non-significant). 


\subsection{Assessing the side-effect profile of a targeted GC therapy using IOH-NPs}

Synthetic GCs are widely used for the treatment of inflammatory diseases and represent the golden standard for aGvHD first-line therapy due to their immuno-modulatory effects. Nevertheless, the frequent occurrence of severe side-effects considerably complicates their use in clinical practice. Our previous results confirmed that BMP-NPs are highly suitable for the treatment of aGvHD, at least in mouse models, and suggest that they possess a clearly increased cell type specificity, in particular for macrophages. In the last part of this thesis, we therefore investigated whether BMP-NPs were able to circumvent undesirable common GC side-effects as a result of their target mode of action and thus might be a superior drug formulation for the treatment of aGvHD.

\subsubsection{BMP-NP treatment upregulates metabolic liver enzymes similar to BMX}

One common side-effect of GCs concerns the liver as one of the major metabolic organ of our body. Synthetic GCs increase the blood glucose level and the expression of liver enzymes involved in gluconeogenesis. In order to analyze these parameters, C57BL/6 wild type mice were treated with $10 \mathrm{mg} / \mathrm{kg}$ BMP-NPs or BMX or equal amounts of PBS or EP-NPs for 14 consecutive days. Subsequently, the animals were fasted overnight and the blood glucose as well as the mRNA levels of gluconeogenetic enzymes were analyzed two hours after the last injection. The former feature was investigated via tail vein puncture using a standard electronic device and the latter was analyzed via quantitative RT-PCR. The blood glucose level was slightly increased in BMX treated mice compared to PBS treated mice, and also a minor increase was detectable in BMP-NP treated mice compared to the EP-NP group (Figure 32A). However, both effects failed significance. In contrast, all analyzed liver enzymes, namely FK506-binding protein (Fkbp51), tyrosine aminotransferase (Tat) and phosphoenolpyruvate-carboxykinase (Pepck) were significantly upregulated in BMX treated mice compared to PBS treated mice as well as in BMP-NP treated mice compared to EP-NP treated mice (Figure 32B). This let us to conclude that BMP-NPs alter the expression of gluconeogenetic liver 
enzymes as efficiently as BMX treatment. Hence, it is unlikely that $\mathrm{IOH}-\mathrm{NPs}$ allow to circumvent the metabolic side-effects of GCs in the liver.
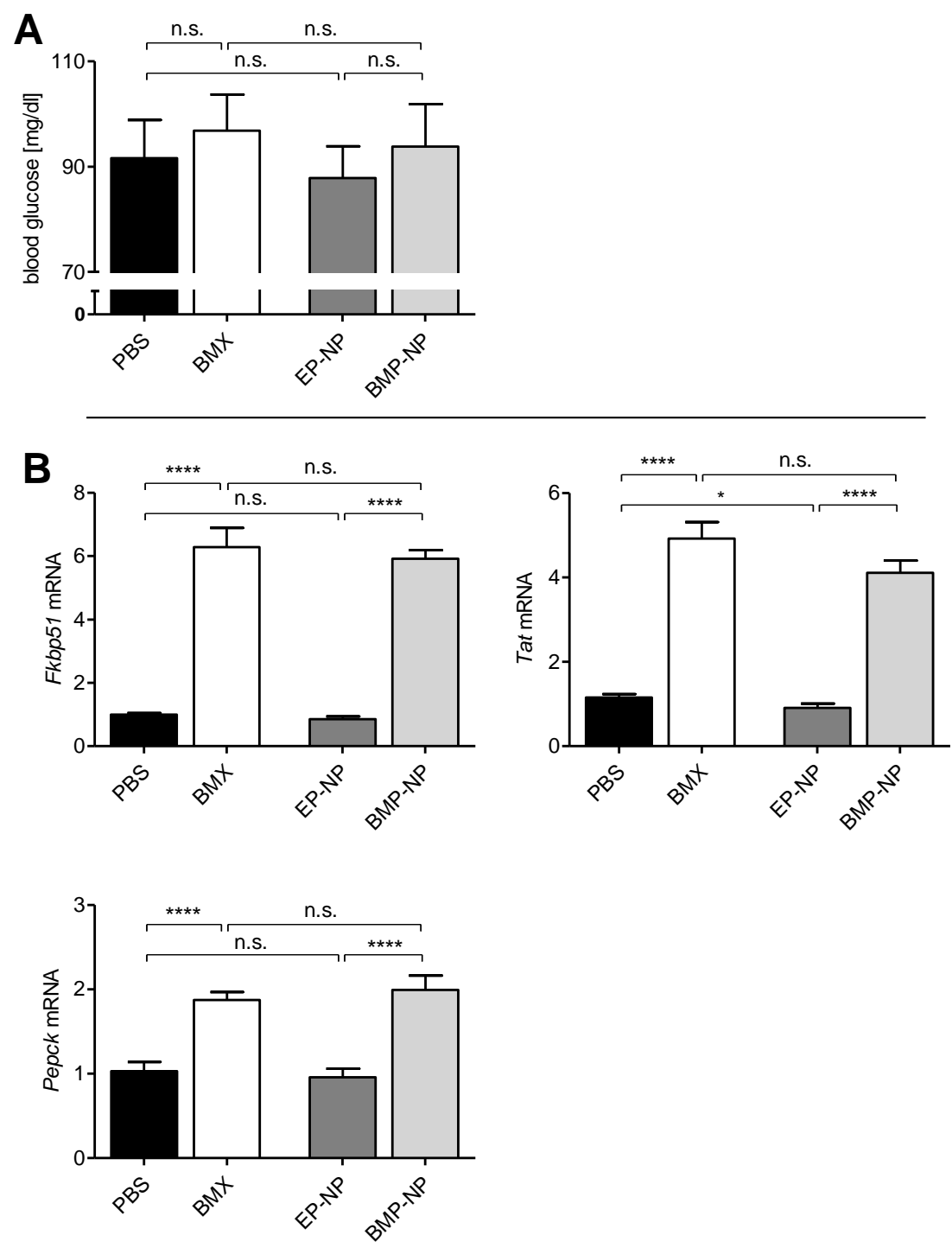

Figure 32: Blood glucose level and metabolic enzyme expression in the liver after GC treatment in wt mice. C57BL/6 wt mice were treated with $10 \mathrm{mg} / \mathrm{kg}$ BMP-NPs or BMX or equal amounts of PBS or EP-NPs i.p. for 14 consecutive days in the morning at 9 a.m.. Food was removed at 6 p.m. at the day before analysis. (A) Blood glucose levels were measured two hours after the last injection via tail vein puncture at day 14 upon fasting $\mathrm{ON}$. $N=13$ (PBS), $N=14$ (BMX), $N=14$ (EP-NP) $N=14$ (BMP-NP); data pooled from multiple experiments, includes data from Elena Montes-Cobos (B) Relative mRNA expression levels of FK506-binding protein (Fkbp51), tyrosine aminotransferase (Tat) and phosphoenolpyruvate-carboxykinase (Pepck) in liver biopsies analyzed by quantitative RT-PCR using heterochromatin protein 1 (Hp1) for normalization. Samples were collected at day 14, two hours after the last i.p. injection. Gene expression in PBS treated mice was arbitrarily set to $1 . N=10$ (PBS), $N=10$ (BMX), $N=10$ (EP-NP), $N=10$ (BMP-NP); data pooled from multiple experiments. All values are depicted as mean \pm SEM. Statistical analyses were performed by using the unpaired one-tailed student's t-test $\left({ }^{*} p<0.05 ;{ }^{* *} p<0.01 ;{ }^{* * *} p<0.001 ;\right.$ n.s.: non-significant). 


\subsubsection{BMP-NP treatment induces myopathy to a similar extent as free BMX treatment}

GCs reduce protein synthesis and increase protein degradation, which leads to a reduction in muscle mass, known as myopathy (Schakman et al., 2008). By setting up the following experiment, we investigated whether BMP-NP treatment was able to circumvent this side-effect. C57BL/6 wild type mice were treated with $10 \mathrm{mg} / \mathrm{kg}$ BMP-NPs or BMX or equal amounts of PBS or EP-NPs for 14 consecutive days. The body weight of mice was measured two hours after the last injection. In addition, the M. gastrocnemius was dissected and weighted. Finally, mRNA levels of myopathy-related genes were analyzed in the muscle by quantitative RT-PCR, in detail collagen type I a 1 (Col1a1), metallothionein 2 (Mt2) and Forkhead box $\mathrm{O1}$ (Foxo1). The expression of Col1a1 is crucial for the preservation of the extracellular matrix of the muscle. MT2 inhibits the Akt pathway, thereby reducing the amino acid synthesis and FoxO1 is a transcription factor that activates E3 ligases, involved in the proteolytic machinery (Summermatter et al., 2017, Watson et al., 2012). We found that the total body weight and the weight of the M. gastrocnemius were both significantly reduced in BMX treated mice in comparison to PBS treated mice (Figure 33A). The same was also observed for the comparison between EP-NP and BMP-NP treated mice. BMP-NPs lost slightly more body weight in comparison to BMX treated mice, even though the muscle mass was similarly reduced by GCs regardless of whether they were applied as free drug or by using IOH-NPs (Figure 33A). Furthermore, BMX and BMP-NP treatment both significantly reduced the expression of Col1a1 compared to the respective control groups receiving PBS or EP-NPs. In contrast, Mt2 and Foxo1 were significantly increased in both GC-treatment groups compared to their respective control groups (Figure 33B). Taken together, the altered expression of myopathy related genes in BMX and BMP-NP treated mice parallels the loss of muscle mass by both treatments, let us to conclude that BMP-NPs provoke this common side-effect as strongly as the freely delivered drug. 

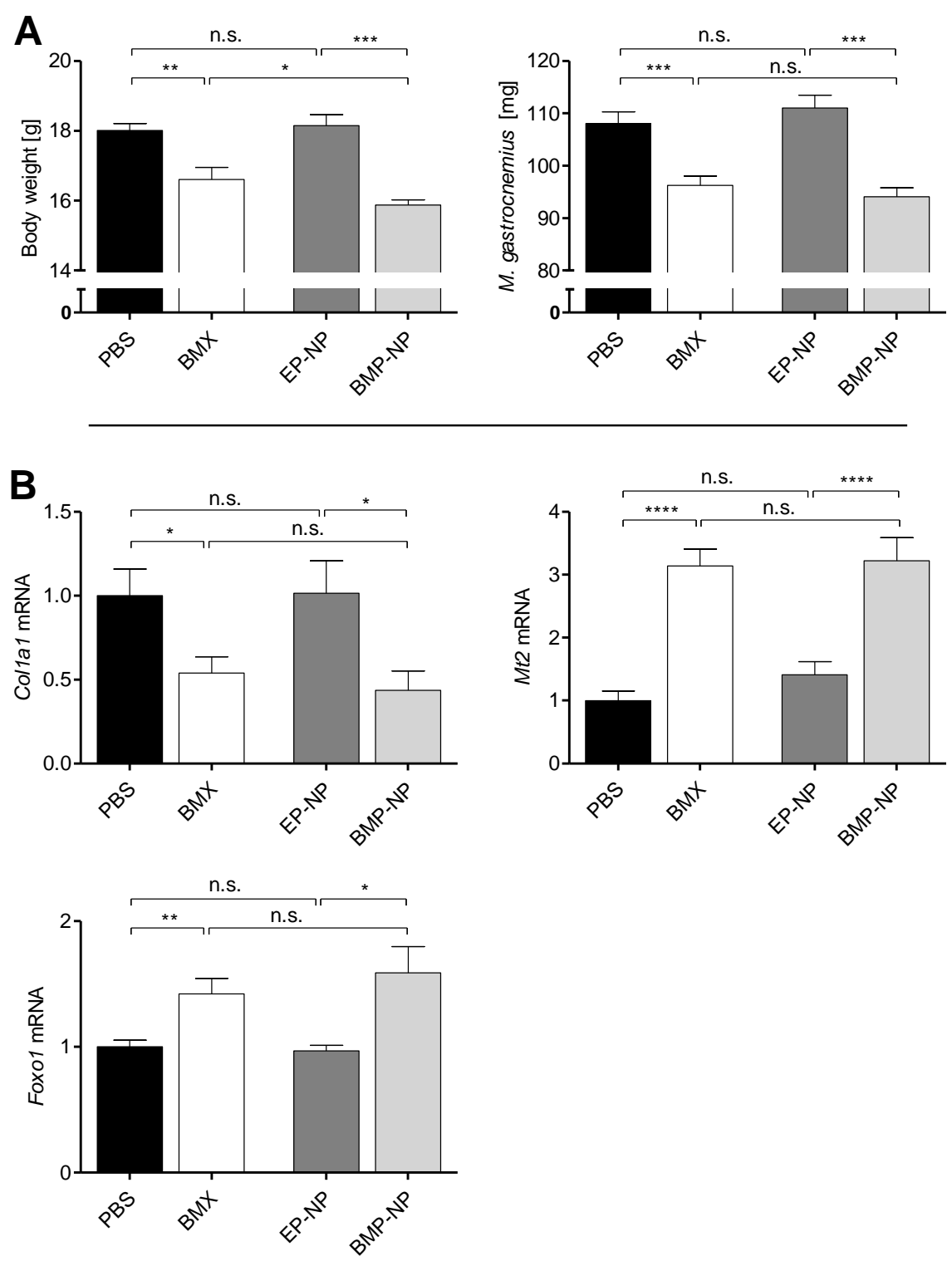

Figure 33: Body weight, muscle weight and gene expression in the $M$. gastrocnemius after GC treatment in wt mice. C57BL/6 wt mice were treated with $10 \mathrm{mg} / \mathrm{kg}$ BMP-NPs or BMX or equal amounts of PBS or EP-NPs i.p. for 14 consecutive days in the morning at 9 a.m.. Body weight was monitored and the M. gastrocnemius was dissected and weighted two hours after the last i.p. injection. (A) Body weight [g] and M. gastrocnemius weight [mg] measured in mice. $N=12$ (PBS), $N=14$ (BMX), $N=10$ (EP-NP) $N=12$ (BMP-NP); data pooled from multiple experiments, includes data from Elena Montes-Cobos (B) Relative mRNA expression levels of collagen type I a 1 (Col1a1), metallothionein 2 (Mt2) and forkhead box 01 (Foxo1) in $M$. gastrocnemius biopsies analyzed by quantitative RT-PCR using Hprt for normalization. Gene expression in PBS treated mice was arbitrarily set to $1 . N=6$ (PBS), $N=7$ (BMX), $N=7$ (EP-NP) $N=7$ (BMP-NP); data pooled from multiple experiments. All values are depicted as mean \pm SEM. Statistical analyses were performed by unpaired one-tailed student's t-test $\left({ }^{*} p<\right.$ $0.05 ;{ }^{* *} \mathrm{p}<0.01 ;{ }^{* * *} \mathrm{p}<0.001$; n.s.: non-significant). 


\subsubsection{BMP-NP treatment reduces the bone turnover similar to BMX application}

Osteoporosis is one more common and very severe side-effect of therapeutic GC administration (Moutsatsou et al., 2012). Markers of bone turnover measured in serum samples are a reliable method to investigate ongoing creeping processes within the bone. Bone formation markers are separated into two categories. On the one hand, there are bone resorption markers, measuring byproducts of osteoclast activity such as the formation of $\mathrm{C}$-terminal telopeptide of type I collagen (CTX-1), a collagen degradation product. On the other hand, there are bone formation markers, measuring products of active osteoblasts, such as pro-collagen type $1 \mathrm{~N}$-terminal peptide (P1NP), a byproduct of collagen synthesis (Shetty et al., 2016). Based on these parameters, we investigated whether BMP-NP treatment was able to circumvent the induction of osteoporosis. BALB/c wild type mice were treated with $10 \mathrm{mg} / \mathrm{kg}$ BMP-NPs or BMX, or equal amounts of PBS or EP-NPs for 14 consecutive days. Subsequently, serum samples were collected via heart puncture two hours after the last injection and bone turnover markers were analyzed via ELISA. The CTX-1 level was slightly elevated by about $15 \%$, although without reaching significance in BMX treated mice compared to PBS treated mice and the same held true for BMP-NP treated mice compared to EP-NP treated mice (Figure 34). In contrast, BMX treatment significantly reduced the P1NP level compared to PBS treatment and the same pattern was observed for BMP-NP treatment compared to EP-NP treatment. These results let us to conclude that BMP-NP treatment negatively affects the bone turnover, mainly via acting on osteoblasts rather than osteoclasts. Hence it is likely that BMP-NPs similarly induce osteoporosis as BMX on the long-run. 

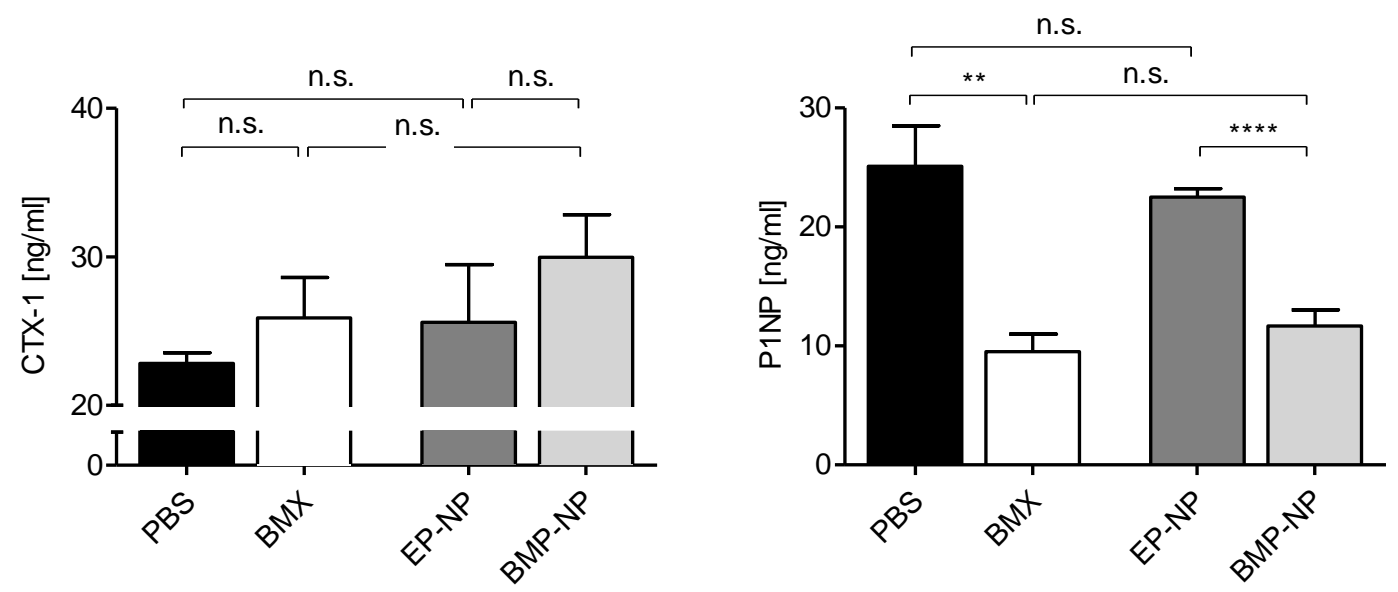

Figure 34: Systemic levels of bone resorption and formation marker in GC-treated wt mice. BALB/c wt mice were treated with $10 \mathrm{mg} / \mathrm{kg}$ BMP-NPs or BMX or equal amounts of PBS or EP-NPs i.p. for 14 consecutive days in the morning at 9 a.m.. Blood was collected by heart puncture two hours after the last injection. CTX-1 and P1NP levels were analyzed by ELISA. $N=4$ (PBS), $N=5$ (BMX), $N=6$ (EP-NP) $N=6$ (BMP-NP); data pooled from multiple experiments. All values are depicted as mean \pm SEM. Statistical analyses were performed by unpaired one-tailed student's t-test $\left({ }^{*} p<0.05 ;{ }^{* \star} p<0.01 ;{ }^{* \star *} p<0.001\right.$; n.s.: non-significant). 


\section{Discussion}

\subsection{Role of the GR in myeloid cells in the context of aGvHD mice}

HSCT is often the only curative therapy for a variety of diseases of malignant or non-malignant origin. However, its success is limited by the frequently occurring life-threatening complication aGvHD (Ferrara et al., 2009, Shlomchik, 2007). Systemic administration of GCs is the standard procedure for initial treatment of aGvHD in the clinics due to their well-described immunosuppressive and anti-inflammatory effects. To ameliorate the disease course, GCs are most often applied at high dosage and over a long period of time leading to unwanted side-effects and GC resistances (Garnett et al., 2013). Gaining a better understanding of GC actions in the context of aGvHD might enable us to develop efficient and more tolerable therapies in the future. GCs exert their functions by binding to the ubiquitously expressed $G R$ and regulating gene expression (Strehl and Buttgereit, 2013). Hence, it is also expressed in macrophages, which play a fundamental role in the pathophysiology of aGvHD (Hashimoto et al., 2011). The role of macrophages in this disease has been neglected for a long time compared to $T$ cells for a long time, which are known as the major inducers of aGvHD. This is also the reason why therapeutic strategies mainly focus on T cells (Ho and Cutler, 2008). In this thesis we now defined an important role of the GR in radioresistant recipient myeloid cells in the context of aGvHD by taking advantage of the $\mathrm{GR}^{\mathrm{lysM}}$ mouse model.

GR deletion in radioresistant recipient myeloid cells of $\mathrm{GR}^{\mathrm{lysM}}$ mice in the early phase of aGvHD leads to an aggravated disease course, which is characterized by higher clinical scores, lower body temperatures and a more pronounced body weight loss compared to $\mathrm{GR}^{\text {flox }}$ control mice. This is in line with previous data from our group revealing an early mortality in the same knock-out mice (Baake et al., 2018). Surprisingly, tissue destruction in one of the major aGvHD target organs, the jejunum, was not altered in comparison to $\mathrm{GR}^{\text {flox }}$ control mice, which contrasts experiments performed in $G R^{\text {lck }}$ mice lacking the $G R$ in $T$ cells (Theiss-Suennemann et al., 2015).The disease in the latter model was strongly aggravated too, but here it was accompanied by severely enhanced tissue 
damage. Already from this finding one can conclude that the mechanisms by which the deletion of the GR in the two cell types impacts disease severity must be different. Furthermore, at least in $\mathrm{GR}^{\mathrm{IysM}}$ mice, the destruction of the jejunum can be excluded as a possible reason for the fulminant disease course. Interestingly, also other hallmarks of aGvHD did not differ between GR $^{\text {lysM }}$ and $\mathrm{GR}^{\text {flox }}$ mice, such as the number of infiltrating $\mathrm{CD} 3^{+} \mathrm{T}$ cells and $\mathrm{CD} 68^{+}$myeloid cells in the jejunum, local cytokine expression and secretion in the jejunum, and cytokine expression in the liver, another important aGvHD target. In contrast, the serum levels of IL-6 and TNFa in GR ${ }^{\text {lysM }}$ mice were strongly increased at day 6 and 8 , which correlates with the time point of death of these animals (Baake et al., 2018). This finding indicates that the GR in radioresistant myeloid cells in the early phase of aGvHD is mainly responsible to keep proinflammatory cytokine secretions at bay rather than to suppress myeloid cells in target organs such as jejunum and liver.

Former animal studies have also noted an important function of the GR in preventing cytokine hypersecretion. These studies have been performed in the $\mathrm{GR}^{\mathrm{dim}}$ mouse model, which is not restricted to myeloid cells in contrast to our studies (Baake et al., 2018). A point mutation within the dimerization region of the GR prevents the receptor from homodimerization in $\mathrm{GR}^{\text {dim }}$ mice (Reichardt et al., 1998). This manipulation affects the DNA-binding capacity of the GR and largely abolishes its gene regulation function (Frijters et al., 2010). Mortality was increased in $\mathrm{GR}^{\mathrm{dim}}$ mice compared to $\mathrm{GR}^{\mathrm{wt}}$ mice after aGvHD induction, and at the peak of the disease, $\mathrm{GR}^{\mathrm{dim}}$ mice had a strongly reduced body temperature. Similar to $\mathrm{GR}^{\mathrm{IysM}}$ mice, the systemic level of the pro-inflammatory cytokine IL-6 was also increased. Treatment of $\mathrm{GR}^{\text {dim }}$ mice with a neutralizing anti-IL-6 antibody reduced the severity of the disease and consequently mortality, indicating that a cytokine storm could indeed also explain the phenotype of $G^{\text {lysM }}$ mice (Baake et al., 2018). The situation encountered in aGvHD is comparable to sepsis, another severe inflammatory disease. Sepsis studies conducted in $\mathrm{GR}^{\mathrm{dim}}$ mice as well as $\mathrm{GR}^{\mathrm{lysM}}$ mice revealed that these animals were unable to diminish systemic pro-inflammatory cytokine secretion in this disease too, leading to their death (Kleiman et al., 2012, Vandevyver et al., 
2012). In aGvHD, as well as in sepsis, myeloid cells seem to be responsible for systemic cytokine secretion of IL-6 and TNFa when their GR is abolished. Of note, the deletion in $\mathrm{GR}^{\text {lysM }}$ mice affects about 83 - $98 \%$ of mature macrophages, nearly $100 \%$ of granulocytes and $16 \%$ of dendritic cells (Tuckermann et al., 2007). Since only resident macrophages and skin DCs survive the conditioning regime, only these cell types are refractory to the repressive effects of endogenous GCs (Haniffa et al., 2009). Especially IL-6, TNFa and IFNy are key pro-inflammatory cytokines in the context of aGvHD and high serum levels of IL-6 and TNFa are associated with aGvHD or even poor outcomes (Symington et al., 1992, Holler et al., 1990). According to this, by applying a neutralizing monoclonal antibody against TNFa in a CD4 ${ }^{+}$ mediated aGvHD mouse model resulted in higher survival rates and moreover prevented the GvL effect (Korngold et al., 2003). In line, treatment with Infliximab, a chimeric antibody directed against the soluble and transmembrane forms of TNFa, was well tolerated by patients and showed an overall response rate of $82 \%$ in steroid-resistant children, which suffered from aGvHD. However, while blocking of TNFa is useful to control aGvHD, its long-term outcome is poor and GvHD often relapses upon interruption of the therapy (Sleight et al., 2007). Furthermore, antibody-mediated blockade of the IL-6 receptor (IL-6R) altered the pro-inflammatory milieu in an aGvHD mouse model and caused a strong reduction in mortality but it prevented also the GvL effect (Tawara et al., 2011). Tocilizumab, a monoclonal antibody against the IL-6R, has been demonstrated to be beneficial in the context of steroid-refractory aGvHD and cGvHD in patients (Drobyski et al., 2018). While the roles of TNFa and IL-6 in aGvHD are well defined, the function of IFNy remains controversial. Studies have shown, on the one hand, that IFNy exacerbates gut GvHD while it acts synergistically with LPS, and on the other hand, that it has a protective role in the gut. Other work suggested that it may not even be required for the development of aGvHD (Wang and Yang, 2014). Our finding that the serum levels of IL-6 and TNFa were strongly increased in GR ${ }^{\text {lysM }}$ mice at the peak of the disease, whereas the serum levels of IFNy, a key cytokine produced by Th1 cells, declined again at this time point, is in line with the previous studies, 
highlighting an important role of IL-6 and TNFa but not IFNY (Beilhack et al., 2005, Chakraverty and Sykes, 2007).

In contrast to systemic cytokine secretion, the gene expression profile of $1 / 6$, Tnfa, Ifng, I/1b, Ccl2, II2 and //10 in the jejunum and/ or the liver was similar in $\mathrm{GR}^{\text {lysM }}$ and $\mathrm{GR}^{\text {flox }}$ mice at all examined time points. Of note, the extent of cytokine regulation was more pronounced in the jejunum as compared to the liver. As a matter of fact, steroid administration seems to impact the expression of inflammatory mediators predominantly in the gastrointestinal tract rather than the liver (Kanojia et al., 1984, Weisdorf et al., 1990). Even though the mice in our experiments received no synthetic steroids, we assume that endogenous GC secretion is very high due to the strong ongoing inflammation, which might explain why the cytokine regulation was more pronounced in the jejunum than in the liver. Furthermore, we observed a "wavelike" gene expression pattern for many of the cytokines we analyzed, namely increasing levels from day 4 to 6 and decreasing again until day 8 . This might reflect the escalating inflammatory reactions within the mice during the first days of the HSCT and the ongoing disease, which is followed by a transient resolution (Beilhack et al., 2005). The pattern of the local cytokine production in the jejunum was similar to the gene expression profile though not that defined, but most importantly we could also barely detect any differences between both groups. As the gene expression pattern in both genotypes in aGvHD target organs was comparable it is not astonishing that the tissue destruction and the cellular infiltration of immune cells into the jejunum revealed no differences. The major conclusion from our data is that the systemic overshooting cytokine secretion of IL-6 and TNFa is responsible for the fulminant disease progression in $\mathrm{GR}^{\mathrm{lysM}}$ mice and that the local cytokine expression and secretion within the target organs jejunums and liver seems to be neglectable. In our view this situation can be explained as following. The majority of host APCs, including precursors are lost during the conditioning regime and their lack is filled by myeloid cells contained in the graft and differentiated ones from progenitor $\mathrm{T}$ cells therein, which eventually creates a chimeric repertoire of APCs within the mice (Haniffa et al., 2009). Wild type monocytes, included in the BMT infusion, are susceptible to the repressive 
effects of endogenous GCs and preferentially migrate into inflamed tissues such as the jejunum and the liver. Hence, inflamed tissues are dominated by wild type monocytes/macrophages whereas radioresistant $\mathrm{GR}^{\text {IysM }}$ macrophages are mostly found in non-inflamed tissues. In turn, this explains why the cytokines are regulated on a systemic level rather than on a local level. Our experiments have impressively demonstrated the role of GC effects mediated by the GR in macrophages in the context of aGvHD. Therefore, targeted delivery of GCs to this cell type appears promising and has already been shown in a variety of other inflammatory diseases, such as EAE or arthritis. There it improved the disease course by a preferential delivery to target sites and/ or cells and had been shown to be superior in its effects compared to free GCs (Luhder and Reichardt, 2017). Targeted delivery of GCs was also successfully applied in an aGvHD mouse model. In this case, dexamethasone palmitates (DP) were engulfed by macrophages which attenuated the disease progression and reduced the mortality (Nishiwaki et al., 2014). This emphasizes the possibility to target macrophages with encapsulated GCs in order to treat aGvHD, which was also tested in this thesis.

\subsection{Interactions of IOH-NPs with selected cell types in vitro}

In the clinics, many inflammatory diseases are handled with GCs, if necessary with high doses and/ or for a long period of time, which often induces severe side-effects and resistance. In theory, targeted delivery of GCs could circumvent these issues (Vandewalle et al., 2018). The type of carrier system, however, is essential for the outcome. For example, PEG-LPs have the disadvantage to provoke an unwanted effect, namely the activation of the complement system (Sercombe et al., 2015). Moreover, the characteristics of NPs, with respect to shape, size or stability influence the interaction with the target cell and needs to be evaluated (Kuhn et al., 2014). Hence, we analyzed the cell type specificity, toxicity, cellular uptake mechanism and intracellular fate of $\mathrm{IOH}-\mathrm{NPs}$, which were available to us in this project.

Due to their hydrophobic structure, GCs can easily pass the cell membrane, where they bind to the cytosolic GR (Strehl and Buttgereit, 2013). GCs 
encapsulated in nanoparticles, like IOH-NPs, need to enter the cell via an active process called endocytosis. The endocytic capacities vary between cell types, thus contributing to the IOH-NPs cell-specificity (Behzadi et al., 2017). To get a good impression of the specificity of IOH-NPs, we selected cell lines representing macrophages, $\mathrm{T}$ and $\mathrm{B}$ lymphocytes, fibroblasts, epithelial cells and myoblasts. Longer incubation times increased the uptake in all cell lines, which indicates an increasing accumulation of $\mathrm{IOH}-\mathrm{NPs}$ within all cells. MH-S cells, resembling macrophages, were most efficient in taking up $1 \mathrm{OH}-\mathrm{NPs}$. Furthermore, L929, resembling fibroblasts were somewhat weaker on the long-run as $\mathrm{MH}-\mathrm{S}$ cells while LA-4 cells and $\mathrm{C} 2 \mathrm{C} 12$ cells, resembling epithelial cell and myoblasts, respectively, took up $\mathrm{IOH}-\mathrm{NPs}$ with only moderate efficiency. In contrast, the cell lines WEHI7.1 and WEHI231, representing T and $B$ lymphocytes hardly took up any IOH-NPs. The latter is in line with previous data from our group that were obtained in experiments in which primary lymphocytes were cultured in the presence of $1 \mathrm{OH}-\mathrm{NPs}$ (Montes-Cobos et al., 2017). Further support comes from in vivo EAE studies where macrophages rather than $\mathrm{T}$ and $\mathrm{B}$ cells were the main target of $\mathrm{IOH}-\mathrm{NPs}$ (Montes-Cobos et al., 2017). Given that cells found in solid tissues such as fibroblasts, and less efficiently epithelial cells and myoblasts engulf IOH-NP too, we assume that $\mathrm{IOH}-\mathrm{NPs}$ are not completely cell type specific for macrophages. This needs to be considered with regard to the efficiency of GC therapy by IOH-NPs in aGvHD and moreover with respect to their ability to induce potential side-effects, such as myopathy or osteoporosis even though $\mathrm{IOH}-\mathrm{NP}$ uptake by osteoblasts has not been tested yet.

Another fundamental aspect of new nanoformulations is that they are being well tolerated, which can be tested for example by tetrazolium-based assays such as MTT (Bahadar et al., 2016). Our results indeed indicate that IOH-NPs, containing $\mathrm{Zr}$ are well tolerated by all cell lines. It is noteworthy that data from a recent study indicates that $\mathrm{Zr}$ activates the TLR 2, 3, 4 and 9 leading to the release of IL- 6 , TNF $\alpha$ and IL-1 $\beta$, which was observed by culturing macrophages in the presence of zirconium particles (Obando-Pereda et al., 2014). Whether 
our $\mathrm{IOH}-\mathrm{NPs}$ provoke the same reaction in the six cell lines needs to be evaluated in the future and should be tested on an mRNA level or via ELISA.

A common way to study the entry route of nanomedicines is the application of pharmacological inhibitors although such a strategy involves disadvantages, for example that they can manipulate other entry routes and are therefore not entirely specific (Kou et al., 2013, Ivanov, 2008). Furthermore, the effects of the inhibitors can be cell line dependent (Vercauteren et al., 2010). However, pharmacological inhibitors are still attractive as their administration results immediately in blocking of individual pathways although it is suggested to obtain corroborating evidence for example from genetic manipulations of crucial proteins or the application of various inhibitors (Dutta and Donaldson, 2012). We applied three commonly used inhibitors in well-tolerated concentrations. CytoD successfully prevented the uptake of $\mathrm{IOH}-\mathrm{NPs}$ in $\mathrm{MH}-\mathrm{S}$ cells. This inhibitor caps actin filaments, thereby preventing their assembly and ultimately leading to actin filament disintegration. Actin polymerization is a crucial process for phagocytosis and macropinocytosis, but probably also for all other endocytic pathways though it plays no obligatory role in the formation of clathrin coated vesicles (Fujimoto et al., 2000). Interestingly, MDC had no effect on the uptake capacities of $\mathrm{IOH}-\mathrm{NPs}$ in $\mathrm{MH}-\mathrm{S}$ cells, which argues against their internalization via clathrin-mediated endocytosis. $M D C$ is a rather specific inhibitor for clathrin-mediated endocytosis, even though some studies have implemented it in inhibiting macropinocytosis and phagocytosis, too, which however would not be compatible with our observation. Amiloride blocks macropinocytosis when applied at millimolar concentrations and we used it even at mircomolar concentrations (Ivanov, 2008). Indeed, Amiloride prevented the uptake of $\mathrm{IOH}-\mathrm{NPs}$ in $\mathrm{MH}-\mathrm{S}$ cells suggesting that internalization occurs mainly via macropinocytosis. Besides that, Amiloride induced cell death to some degree, but it is highly unlikely that the diminished uptake of $\mathrm{IOH}-\mathrm{NPs}$ can be explained only by this fact. Macropinocytosis is an evolutionary conserved, non-selective form of endocytosis. It mediates the uptake of extracellular fluids and in primary immune cells, such as macrophages and dendritic cells, the uptake of soluble antigens derived from pathogens into relatively large macropinosomes 
(>250 nm), a size which is also suitable for IOH-NPs (Canton, 2018, Palm, 2019). Macrophages have a staggering rate of constant macropinocytosis internalizing their surface every 33 minutes (Steinman et al., 1976). However, the process of macropinocytosis itself is not restricted to primary immune cells, because it also occurs in other cell types such as fibroblasts or epithelial cells (Falcone et al., 2006). The fact that phagocytosis is restricted to professional adepts for example monocytes, macrophages, neutrophils and dendritic cells and in addition that it is initiated by the interaction of the respective receptor on the cellular surface of the particle supports our observed entry route of $1 O H-N P s$ (Kuhn et al., 2014). Worth mentioning, our experiments were performed in vitro and nanoparticles can have dynamic entities immediately after administration in vivo, probably unwanted entities, which represent biological obstacles. Generally, solely about $1 \%$ of injected nanoformulations reach the target tissue, which makes it clear why the path towards clinical licensing is remarkable challenging ( $\mathrm{Li}$ and Lane, 2019). The rapid removal of nanoformulations from the circulation can be explained by obstacles such as opsonization by plasma proteins, including complement components or antibodies. Subsequently nanoformulations are recognized by the respective receptors on the surface of phagocytes, which lead to their internalization and finally elimination, but most importantly influencing the entry route (Blanco et al., 2015). Whether IOH-NPs undergo opsonization within the blood circulation in vivo and whether this has any impact on the entry route needs to be studied in the future. So far, we observed $\mathrm{IOH}-\mathrm{NPs}$ are internalized in $\mathrm{MH}-\mathrm{S}$ cells via macropinocytosis, which occurs most likely via the same way in fibroblasts, epithelial cells and myoblasts in vitro.

Macropinocytosis, more precisely the cargo trapped within the macropinosomes, can have two fates, either the cellular surface, where the cargo is released into the extracellular space, or the lysosomes, which contain enzymes for its degradation (Palm, 2019). Our results indicate that IOH-NPs are indeed travelling to lysosomes where the pharmacological agent betamethasone phosphate is released by hydrolysis of the phosphate-ester bond in the functional anions within the $\mathrm{IOH}-\mathrm{NPs}$ and becomes immunologically 
active. GCs promote an anti-inflammatory phenotype in macrophages, which involves the downregulation of surface expression markers such as $\mathrm{MHCll}$ or CD86, both are crucial for $T$ cell activation (Roszer, 2015). This notion is in agreement with our data, which indicate a dose-dependent reduction of both surface markers in BMDMs when cultured in the presence of BMP-NPs. Moreover, these results are supported by earlier data from our group. The mRNA expression levels of pro- and anti-inflammatory genes in BMDMs were altered upon co-culturing them with BMP-NPs. As a consequence, Tnfa and $1 / 1 \mathrm{~b}$ were downregulated, whereas the expression of $C d 163$ and $Y m 1$ was increased (Montes-Cobos et al., 2017). Recent studies by another group also examined effects of BMP-NPs on MH-S cells in vitro. To provoke an immune response, the cells were treated with LPS and cultured with BMP-NPs for 48 hours. Subsequently, IL-6 in the supernatant was reduced in a dose-dependent manner (Napp et al., 2018). Similar results were observed when TNFa secretion was analyzed (Heck et al., 2015). Collectively, betamethasone is efficiently released from $\mathrm{IOH}-\mathrm{NPs}$ within the lysosomes and subsequently exerts immuno-modulatory actions in primary macrophages and $\mathrm{MH}-\mathrm{S}$ cells. The efficiency of BMP-NPs, compared to the reference drug, is described to be similar or even more efficient (Montes-Cobos et al., 2017).

\subsection{Organ distribution of IOH-NPs in mice in vivo}

Intravenous (i.v.), subcutaneous (s.c.) and intramuscular (i.m.) injections are the most common routes for medical treatments in the clinics. The first route is chosen when rapid absorption is required and when the two other routes are not suitable, because the injected substances are too irritable for the tissue (Jin et al., 2015). In contrast, intraperitoneal injection (i.p.) is used in the clinics when regional therapy is needed for example for peritonitis or malignancies within the peritoneal cavity. This application route has the advantage to provide locally a longer half-life of the drug, while it takes longer until the drug reaches the circulation. It is thereby superior to i.v. injections under these circumstances. Nevertheless, i.p. injections are facing various challenges as it can have a negative impact on the target specificity of the drug and/ or the penetration into the target tissue (Bajaj and Yeo, 2010, Pham et al., 2018). However, many 
animal studies involve i.p. injections as it is technically easier when a drug is injected several times daily and/ or for longer periods of time. Furthermore, a study demonstrated that the commercially available anti-fungal drug amphotericin $B$ is better tolerated when given i.p. at high dose rather than when given i.v. (Chang et al., 2010). With regard to the application route of nanoformulations, analysis of $A m B i s o m e \AA$, a liposomal fungal drug formulation revealed major differences in the tissue distribution when administrated i.v. or i.p. as it was noted upon administration of nanoparticles with a size of about $20 \mathrm{~nm}$ (Chang et al., 2010, Gao, 2017). In addition, also differences in the blood concentration were observed in another study depending on the application route when injecting iron-oxide nanoparticles labeled with high density-lipoproteins (Jung et al., 2014). Upon i.v. administration, the concentration of liposomes and iron-oxide NPs in the blood circulation was either highest 30 minutes after injection or had already declined at that time point, and thereafter further decreased due to the uptake into liver, spleen, lung and kidney. The uptake into other tissues such as heart, muscle or femur, however, was neglectable. In contrast after i.p. administration the concentrations within the blood slowly increased and peaked within 2 hours after the injection. This indicates a slow release from the peritoneal cavity into the lymph vessels, for example through the mesentery with its large absorbent surface, and afterwards via the thoracic duct into the blood (Chang et al., 2010, Jung et al., 2014, Gao, 2017). Within 4 hours after injection the level of NPs measured within the peritoneal cavity dropped again to control level. This indicates that the majority of NPs have been distributed within the body, absorbed into the blood stream and the pancreas, the latter by tissue-resident and peritoneal macrophages. NPs become cleared from the systemic circulation through the permeable endothelium and accumulate in liver, spleen, intestine, stomach, lung, kidney and bladder, but not in heart and brain (Pham et al., 2018, Arvizo et al., 2011, Gao, 2017). Collectively, i.v. administration of NPs seems to accumulate quickly and predominantly in liver and spleen. In contrast, i.p. administration leads to the slow accumulation in further organs via the ability to cross the peritoneal barrier, is excreted mainly via the intestine and consequently can be tracked within the feces and also due to a renal excretion 
in the urine. Interestingly, i.p. injection causes a more rapid clearance than i.v. injection (Gao, 2017).

Our own MRI and ICP-MS studies revealed i.p. injected IOH-NPs follow a similar path as described in the literature. We observed a slow release from the peritoneal cavity during the first two hours after injection until the signal here dropped to control levels. Meanwhile, IOH-NPs were detected within one hour after the injection in the liver, where they constantly accumulated over time. $\mathrm{IOH}-\mathrm{NPs}$ have also been found in the stomach two hours after the injection, where the levels increased and remained constant three hours after the injection. Two hours after the injection the IOH-NPs also reached the small intestine and their concentration increased here from now on with fluctuations. Interestingly, IOH-NPs spared the kidney and the lung. 24 hours upon the injection, the signals in the liver and jejunum decreased again, arguing for an intestinal excretion of $\mathrm{IOH}-\mathrm{NPs}$. As we failed to prove the presence of $\mathrm{IOH}-\mathrm{NPs}$ in the urine by MRI (data not shown) and since no IOH-NPs were found in the kidney, it is highly likely that indeed intestinal clearance dominates and might reach it through the stomach. Noteworthy, the IOH-NPs biodistribution after i.v. injection has been characterized before. Here, IOH-NPs were detected in the gall bladder, liver, lung and kidney, but not in the stomach. The studies suggested that i.v. injected $\mathrm{IOH}-\mathrm{NPs}$ are predominantly excreted via the intestinal tract and a small fraction also via the kidney (Poß, 2017). Consequently, the application route strongly determines the fate of IOH-NPs in vivo after injection and results in a different organ distribution. Most importantly, our own results indicate that i.p. injection is favorable as it results in a slower release, a more even distribution between the organs and a lower risk of inducing nephrotoxicity due to its clearance route.

It should be pointed out that our data concerning the biodistribution of IOH-NPs were obtained by using healthy mice. Since we mostly used IOH-NPs in the treatment of mice suffering from aGvHD in this thesis, it would be interesting whether the pharmacokinetics differs under such conditions from the healthy situation. A recent study in a rat arthritis model for instance indicated that a 
single systemic administration of copolymer-dexamethasone conjugate resulted in a higher influx in inflamed joints than healthy joints. This was achieved by the dynamic uptake by synoviocytes, which are a mixture of macrophage-like, fibroblast-like and dendritic cells, and by the enhanced vascular permeability in inflamed joints (Quan et al., 2010). In another study, polystyrene NPs loaded with a fluorescence dye were used for inhalation in a mouse model of allergic airway inflammation (AAI). Here, AAl lungs displayed a significantly stronger fluorescence signal as healthy lungs (Markus et al., 2015). The accumulation of BMP-NPs within inflamed tissue would also be desirable in aGvHD mice.

\subsection{IOH-NPs as a new therapeutic approach for GC therapy of aGvHD}

Each inflammatory disease has its distinct pathophysiology where different immune cell types are involved. Hence, the desired cell type specificity of GCs also differs. For instance, macrophages and neutrophils are the main target cells of GCs in the treatment of contact allergy (Tuckermann et al., 2007). In contrast, airway epithelial cells are crucial targets of GCs in an allergic asthma mouse model (Klassen et al., 2017). In the context of aGvHD, previous studies from our group highlighted a crucial role of GCs in T cells in a total MHC mismatched mouse model where GR deficiency of $\mathrm{CD}^{+}$cells aggravated clinical symptoms, histological features and reduced survival times (TheissSuennemann et al., 2015). Furthermore, results presented in this thesis highlighted a crucial role of GCs also in radioresistant myeloid cells in a total MHC mismatched mouse model (Baake et al., 2018). In the initiation phase of aGvHD myeloid cells, more precisely macrophages, secrete pro-inflammatory cytokines and can induce tissue damage by the release of soluble mediators (Ghimire et al., 2017, Blazar et al., 2012). In contrast, GCs induce an M2 like phenotype in macrophages that contributes to wound healing, resolution of inflammation and suppress inflammatory responses (Desgeorges et al., 2019). Noteworthy, inhibiting the function of macrophages as well as expanding them has both been shown to prevent aGvHD in animal models (Hashimoto et al., 2011, Shlomchik et al., 1999, Everse et al., 2001). However, simply eliminating resident host APCs can have major drawbacks such as infections, which indicates that they should not be underestimated as crucial components of the 
innate immune system (Everse et al., 2001). Interestingly, targeted therapy of GCs can alter the mode of action as demonstrated in an EAE mouse model. Here, $T$ cells were targeted by free GCs while GC-loaded LPs predominantly acted via macrophages. Nevertheless, both application forms improved the disease (Schweingruber et al., 2011). Hence, by modulating the macrophage phenotype by a cell type specific targeting of GCs, for example using IOH-NPs, which are taken up not exclusively, but dominantly by macrophages in vitro, might be a successful strategy to treat aGvHD. The results presented in this thesis provide good evidence that this is indeed the case.

Initially we explored the treatment efficiency of GC-loaded IOH-NPs (BMP-NPs) compared to free GC (BMX) in a long-term experiment. To mimic the situation in the clinics, mice received the drugs when first symptoms appeared. Notably, mice treated with EP-NPs, not containing any drug, were comparable to mice receiving only PBS in most experiments indicating that in this experimental setting $\mathrm{IOH}-\mathrm{NPs}$ are well tolerated, which is in line with our in vitro studies as well as previous in vivo studies conducted in an EAE mouse model (MontesCobos et al., 2017). BMP-NP and BMX treatment extended the survival in aGvHD mice with similar efficiencies, although GC-treated mice still died in the second critical phase of aGvHD at around day 20 to 30 . BMP-NPs were slightly superior to free $B M X$ which might be explained by the better long-term availability of BMP-NPs in contrast to BMX.

In the short-term experiments both $\mathrm{GC}$ formulations were similar in efficiency and resulted in lower clinical scores, higher body weight values and prevented the drop in body temperature at the peak of the disease. Previous reports also showed an improvement of aGvHD in mice by frequently used GCs in free form, such as prednisolone or dexamethasone (Bouazzaoui et al., 2011, TheissSuennemann et al., 2015, Nishiwaki et al., 2014). Noteworthy, the experimental setups partially differ in the drug dose, treatment duration, conditioning regime intensity, mouse strain, number of cells transferred within the graft or grading system used, which is why the disease course may vary between the studies (Schroeder and DiPersio, 2011, Naserian et al., 2018). In one of them, namely 
Nishiwaki et al. applied a dexamethasone palmitate emulsion (DP), a liposteroid, which is engulfed by macrophages via phagocytosis, vs. dexamethasone sodium phosphate (DSP), which is a free GC, in an aGvHD mouse model. Here, DP was slightly more effective than DSP concerning the survival rate (Nishiwaki et al., 2014). Collectively, our data revealed that BMPNP treatment has an overall similar, although not dramatically better efficiency than BMX.

The mode of action of BMP-NPs vs. BMX was studied in the early phase of aGvHD, which is the time when the inflammatory processes start and strongly increase, and when high-dose GCs would have to be applied in the clinics (Ferrara et al., 2009, Svennilson, 2005). Histological analysis revealed that the tissue destruction in the jejunum was similarly reduced in BMP-NP and BMX treated mice. Also the number of goblet cells was increased to the same extent. Surprisingly, $\mathrm{BMX}$ reduced $\mathrm{CD}^{+} \mathrm{T}$ cells and $\mathrm{CD}^{+} 8^{+}$myeloid cells in the gut, whereas BMP-NPs had no such an effect. Recent studies demonstrated the ability of a targeted GC therapy to reduce the number of macrophages. F4/80 cells were strongly reduced in the skin, which is one of the most commonly affected organs in aGvHD (Nishiwaki et al., 2014, Strong Rodrigues et al., 2018). Our pharmacokinetic studies of $\mathrm{IOH}-\mathrm{NPs}$ in healthy mice further let us assume that $\mathrm{IOH}-\mathrm{NPs}$ accumulate in the jejunum and thereby have the potential to influence the phenotype of cells in this aGvHD target organ. However, BMP-NPs neither affected the composition of $T$ cells in the jejunum nor the proportion of inflammatory and resting non-inflammatory macrophages and monocytes, which is fundamentally different from mice treated with BMX. GCs in general are well known to induce apoptosis in T cells, but analyses by our group indicated that $\mathrm{T}$ cell survival was barely effected by BMP-NPs (Tuckermann et al., 2005, Montes-Cobos et al., 2017). These data are in line with our findings that IOH-NPs are hardly taken up by T cells and explain why the number of infiltrating T cells is reduced in the gut of BMX treated mice but not in BMP-NP treated mice. In contrast to our model, BMP-NP treatment reduced the infiltration of monocytes/macrophages into the target region of the disease in an EAE study, namely the central nervous system (CNS) by acting 
specifically on this cell type in vivo (Montes-Cobos et al., 2017). In another EAE study, the application of GC-loaded liposomes reduced the infiltration of macrophages/ monocytes into the CNS too, but not as efficiently as free dexamethasone (Schweingruber et al., 2011). The fact that the number of infiltrating $\mathrm{CD}^{+}$and $\mathrm{CD}^{+} 8^{+}$cells in BMP-NP treated mice was unmodified in the jejunum combined with the observation of a barely effected abundance of different subpopulations of these cells, let us draw the conclusion, that other mechanisms than the repression of immune cell infiltration into the small intestine must be responsible for the ameliorating effect of BMP-NPs in aGvHD.

Our in vitro analysis of the cell type specific uptake of IOH-NPs indicated that myeloid cells were the most important target of this nanoformulation. This conclusion could also be confirmed in vivo for our aGvHD mouse model. The therapeutic effect of BMP-NPs was fully abrogated in GR ${ }^{\text {lysM }}$ mice, lacking the GR in macrophages/ monocytes, suggesting that GC effects in these cells were indeed essential to ameliorate aGvHD. BMP-NP treatment failed to reduce clinical symptoms and to prevent the drop in body temperature. Furthermore, the tissue destruction in the jejunum of $\mathrm{GR}^{\mathrm{lysM}}$ mice and the reduction in goblet cell numbers normally seen after BMX treatment were also abrogated. Hence, GCs delivered with the help of IOH-NPs ameliorate aGvHD by modulating myeloid cell function.

Since our previous work had revealed that $\mathrm{GR}^{\mathrm{lysM}}$ mice succumbed to early death because of a systemic hypersecretion of pro-inflammatory cytokines, we considered it likely that BMP-NPs might act by suppressing systemic cytokine secretion in aGvHD wild type mice, too (Baake et al., 2018). However, systemic levels of IL-6, TNF $\alpha$ and IFNy were elevated in aGvHD mice regardless of their treatment. From this finding we must conclude that therapeutically applied GCs, both free BMX and BMP-NPs do not act by preventing a systemic cytokine release syndrome but rather exert their function locally within the target organs. This notion was supported by our gene expression analyses of relevant cytokines in the jejunum. mRNA levels of Tnfa and 116 , which are primarily expressed in M1 macrophages, as well as crucial Th1 cytokines such as II2 and 
Ifng were reduced in BMX treated mice, which is in agreement with a study conducted in an aGvHD mouse model treated with prednisolone (Bouazzaoui et al., 2011). BMP-NPs reduced the expression of Tnfa, II2, Ifng and II6, too. Both, IFNY and TNFa have been reported to induce direct damage to the Gl tract and thus their reduced expression would be beneficial in aGvHD (Hill et al., 1997, Brown et al., 2003, Burman et al., 2007, Bouazzaoui et al., 2009, Korngold et al., 2003). IL-2 is a key cytokine of T cell dependent immune responses and is primarily produced by activated $\mathrm{CD} 4^{+} \mathrm{T}$ cells (Shin et al., 2011). The humanized monoclonal antibody daclizumab against the IL-2 receptor $\alpha$-chain (CD25) has shown substantial activity in the treatment of aGvHD in patients and proven safety in phase I-III clinical trial studies (Przepiorka et al., 2000). Basiliximab, another IL-2 antibody has also been reported to be effective in a substantial portion of patients with steroid-refractory aGvHD (Massenkeil et al., 2002). On the other hand, IL-2 has immune modulatory functions, as it leads to the expansion of $T$ effector cells (Teffs) and at the same time increases Tregs. Tregs are more resistant to Dex-induced cell death than Teffs due to higher expression of the GR and $\mathrm{Bcl}-2$. Therefore, a combined therapy of IL-2 and dexamethasone was hypothesized to expand selectively Tregs in vivo, which has been tested in an aGvHD MHC mismatched mouse model and EAE. Indeed, both models showed promising results characterized by longer survival times and greater suppression of aGvHD as well as inhibited the development of EAE (Xie et al., 2009, Chen et al., 2006). In contrast, a study testing a combined therapy with corticosteroids and daclizumab in aGvHD patients evoked concerns as serious infections and relapses occurred in the patients contributing to an increased mortality (Lee et al., 2004). Currently it is unknown whether BMP-NP treatment has any effect on Tregs. In our analysis, the expression of the anti-inflammatory cytokine $/ 110$ in the gut was significantly reduced in BMX and BMP-NP treated mice. A significant lower mRNA level of II10 upon dexamethasone treatment in vivo was also noted previously in peritoneal macrophages (Schweingruber et al., 2011). In contrast, II10 mRNA levels of PBMCs from the majority of multiple sclerosis patients increased upon steroid treatment (Gayo et al., 1998). Moreover, ex vivo pre-treatment of human monocytes but not differentiated macrophages or DCs with dexamethasone 
increased I/10 expression indicating a selective mechanism of GCs (Mozo et al., 2004). Generally, IL-10 seems to have a protective role in aGvHD as high frequencies of donor cells, producing this cytokine, coincides with the absence of aGvHD, and vice versa low levels coincide with increased rates of GvHD (Weston et al., 2006, Holler et al., 2000). Of note, endogenous IL-10 is often produced as a reaction to cope with strong inflammation, which might be the case in the control groups in our setting. Nevertheless, high levels of IL-10 can also act as a growth factor for $\mathrm{CD} 4^{+}$and $\mathrm{CD} 8^{+} \mathrm{T}$ cells (Blazar et al., 1998). Ccl2 mRNA levels in the gut were also reduced in both GC-treated groups. An earlier study revealed increased levels of CCL-2 in the intestine of mice suffering from aGvHD similar to our mice (Castor et al., 2011). Another study indicated that high levels of CCL-2 recruiting monocytes and macrophages to the lung, the target organ in idiopathic pneumonia syndrome (IPS), another severe complication of HSCT, resulted in a stronger IPS severity. Interestingly, neutralizing CCL-2 or the infusion of CCL-2 receptor (CCR2) deficient donor cells reduced the cellular infiltration and improved IPS (Hildebrandt et al., 2004). Collectively, our data indicate that BMP-NPs are predominantly incorporated by macrophages in vivo and act on a local level rather than on a systemic one, which let us to conclude that BMP-NPs localize in target organs. Furthermore, BMP-NP treatment is efficient but not superior to BMX. Nevertheless, the apparently different mechanisms by which BMP-NPs ameliorate aGvHD might still be an advantage in the treatment of this disease.

\subsection{GC-induced side-effects after BMP-NP treatment}

A major drawback of GC treatment of inflammatory diseases such as aGvHD is the frequent induction of sometimes even life-threatening side-effects (Petta et al., 2019). For a long time, it was believed that side-effects are induced by dimer-mediated transactivation, while anti-inflammatory effects evoke from monomer-mediated transrepression. The distinction of both effects turned out to be difficult, but several SEGRAs (selective GR antagonists) are still currently tested. Another possible way to overcome side-effects is the targeting of GCs to relevant cell types, which are dependent on the condition (Vandewalle et al., 
2018). Theoretically, this can be realized by the encapsulation of GCs into $\mathrm{IOH}-\mathrm{NPs}$ that we found to target mainly macrophages.

In this thesis we investigated three common metabolic side-effects that frequently occur in patients during chronic application of GCs, namely an impaired liver metabolism, myopathy and osteoporosis. Induction of these side-effects in inbred mouse strains is difficult to achieve, for which reason we treated them for 14 consecutive days although using the same concentration as in our aGvHD experiments. The expression of genes encoding liver proteins and enzymes, known to be controlled by GCs, such as Fkbp51, Tat and Pepck were significantly increased in both GC-treated groups. Not surprisingly, as a consequence, the blood glucose level was also increased, even though lacking significance. All three analyzed genes are regulated on a transcriptional level through GR binding sites within the promotor region (Vander Kooi et al., 2005, Imai et al., 1993, Vermeer et al., 2003, Alexandrova, 1994). Our data are in agreement with other studies showing an upregulation of the analyzed genes in the liver by other GCs such as prednisolone or dexamethasone, even though lower concentrations have been applied there (Frijters et al., 2010, Opherk et al., 2004). Notably, our data on the in vivo biodistribution of IOH-NPs indicated that BMP-NPs accumulate in the liver, which we observed both in MRI and ICP-MS studies. Possibly, they are then taken up by hepatocytes and regulate their function similarly to BMX. Whether IOH-NPs are taken up by Kupffer cells, which are tissue resident macrophages in the liver and constitute their largest reservoir in the body has not yet been tested (Dixon et al., 2013). Interestingly, alternatively activated M2 Kupffer cells can counteract systemic insulin resistance by impacting the lipid metabolism in the liver and theoretically thereby influence the blood glucose level (Odegaard et al., 2008, Odegaard and Chawla, 2011). In fact, insulin intolerance has been tested after the injection of both GC application forms but the results revealed to be inconclusive (data not shown). Taken together, the use of IOH-NPs for GC delivery does not allow to circumvent side-effects related to glucose metabolism in the liver. 
BMP-NP and BMX treatment similarly regulated also key myopathy genes in the M. gastrocnemius on a genetic level that are involved in protein degradation and synthesis. In detail, Mt2 and Foxo1 were significantly elevated in both GC-treated groups. Foxo1 is a transcription factor containing up to eight GREs in the proximal promotor and believed to control in turn a variety of genes involved in myopathy, including E3 ligases (Schakman et al., 2008, Qin et al., 2014, Sato et al., 2017, Waddell et al., 2008). Mt2 contains two GREs within the proximal promotor and is an important zinc buffering protein, which influences signaling pathways involved in protein synthesis, such as mTOR (Kelly et al., 1997). A recent study indicated that the loss of MT2 protects against GC-induced myopathy (Summermatter et al., 2017). Our results are in agreement with another study in which the mRNA levels of both genes were elevated after treatment with dexamethasone, even though the authors analyzed the $M$. triceps surae, which compromises amongst others the M. gastrocnemius (Watson et al., 2012). GCs are also known to induce myopathy by secondary effects, for example by acting on other non-related muscle cells such as fibroblasts, thereby reducing the extracellular matrix as the collagen production is diminished. Indeed, both GC application forms resulted in lower mRNA levels of Col1a1 as associated with dexamethasone treatment which is also shown by other studies (Riso et al., 2008, Watson et al., 2012). Most importantly, the similar regulation of myopathy related genes by both BMP-NPs and BMX also resulted in a similar loss of muscle mass. The weight of the M. gastrocnemius, but also the total body weight, were reduced after 14 days of GC treatment, regardless of whether the free drug was applied or BMP-NPs were used for delivery. Noteworthy, the efficient regulation of genes in the muscle and extracellular matrix, leading to the induction of myopathy by BMP-NPs, is in agreement with our in vitro studies, in which we observed a moderate and even better uptake of $\mathrm{IOH}-\mathrm{NP}$ in myo- and fibroblasts, respectively. Collectively, these data argue that the application of GCs by using $\mathrm{IOH}-\mathrm{NPs}$ will not allow to prevent the induction of myopathy, which is one of the most severe side-effects occurring during GC therapy of aGvHD. 
GC-induced osteoporosis is also a major adverse side-effect observed in the clinics. A previous study in an arthritis mouse model showed equal therapeutic efficiencies of free dexamethasone and a copolymer-dexamethasone-conjugate (P-dex) while P-dex did not induce bone resorption in contrast to free dexamethasone as determined by $\mu \mathrm{CT}$ analysis examining morphometric parameters of the bone (Quan et al., 2016). We used another method to assess the induction of osteoporosis, namely by studying bone resorption markers in serum samples, which is a common practice in the clinics to determine ongoing processes within the bone. C-terminal telopeptide of type I collagen (CTX-1) is a collagen degradation product and a byproduct of osteoclast activity, which serves as bone resorption marker. In contrast, pro-collagen type $1 \mathrm{~N}$-terminal peptide (P1NP) serves as bone formation marker and is a byproduct of collagen synthesis resulting from osteoblast activity (Shetty et al., 2016). CTX-1 was elevated in both GC-treated groups compared to their respective control group although lacking significance, whereas P1NP was significantly reduced in both GC-treated groups. Osteoclasts are differentiated tissue-resident macrophages within the bone, hence, they should theoretically be prone to incorporate IOH-NPs (Desgeorges et al., 2019). Surprisingly, our data indicate that they are rather taken up by osteoblasts than osteoclasts. Notably, Rauch et al. showed that the GR in osteoblasts was more important for the induction of osteoporosis by GCs than in osteoclasts (Rauch et al., 2010). Whether IOH-NPs are indeed taken up by both cell types and with which efficiency their functions are regulated is currently under investigation. In any case, the initial serum analysis of bone markers strongly suggests that also osteoporosis will not be circumvented by using $1 \mathrm{OH}-\mathrm{NPs}$. Collectively, our data indicate that BMP-NPs act on hepatocytes, myoblasts and bone cells with similar efficacy as free BMX, and thereby manipulate the gene expression profiles that can trigger hyperglycemia, myopathy and osteoporosis. It remains unknown whether the induction of these side-effects could be reduced by lowering the dose of $\mathrm{IOH}-\mathrm{NPs}$. However, our results suggest, that the goal to have a GC therapy at hand that lacks major side-effects of traditional GC therapy, can probably not be achieved using the new nanoformulations. 


\subsection{Conclusions and future directions}

Despite the many findings we made concerning the role of macrophages in aGvHD and the mechanisms of $\mathrm{IOH}-\mathrm{NPs}$, many questions remain. For instance, it is unclear to which extent BMP-NPs act on the many different cell types found in vivo in mice and humans. BMP-NP treatment of aGvHD induced in GR ${ }^{\text {lysM }}$ mice suggests that macrophages are efficiently targeted, whereas this is not the case for T cells, being in line with the in vitro experiments. However, the three side-effects tested in this thesis all still occur, arguing that many cell types are capable of taking up the $\mathrm{IOH}-\mathrm{NPs}$, though with different efficiencies. Another issue is that BMP-NPs, when cultured under physiological conditions for 48 hours in vitro, are intact to 90 - 95 \% (Heck et al., 2015). Nevertheless, we observed an aggregation of $\mathrm{IOH}-\mathrm{NPs}$ within the intraperitoneal puncture area upon multiple injections. This raises the questions of how much of the IOH-NPs are indeed taken up by the lymphatic system and whether the amount should be increased. However, it could also mean that the $\mathrm{IOH}-\mathrm{NP}$ form a depot that releases the drug over longer periods of time, which could explain the occurrence of GC-side-effects in mice treated with the nanoformulation. Peritoneal adhesion is a common risk after i.p. injections (Bajaj and Yeo, 2010). Analyzing aGvHD mice via MRI studies that receive multiple injections of GAP-NPs would provide insights into the pharmacokinetic. A crucial question related to the possible future application in humans is, what happens to the remaining $\mathrm{Zr}$ when $\mathrm{IOH}-\mathrm{NPs}$ are hydrolyzed. Is it released via exocytosis and excreted via the GI tract? This could be investigated by analyzing urine samples by using ICP-MS as MRI studies were not sensitive enough for this purpose. Zr-based NPs were previously found to be moderately toxic in a human macrophage and alveolar type II cell line, THP-1 and A549 respectively, and also in the mouse osteoblast cell line 3T3-E1 at high concentrations ( $\mathrm{Ye}$ and Shi, 2018). In addition, $\mathrm{Zr}$ triggers pro-inflammatory cytokine secretion in macrophages (Obando-Pereda et al., 2014). Neither toxicity nor cytokine secretion has been observed in our experimental setups but need to be further examined in the future. 
Taken together, BMP-NPs were successfully applied in the treatment of EAE, AAI and now also aGvHD in mouse models (Montes-Cobos et al., 2017). In all cases the efficiency was comparable to free GCs but not dramatically improved. The advantage is the preferential targeting of macrophages compared to T cells but the hope to circumvent metabolic side-effects did not hold true. Still, it is possible that unwanted activities of GCs on T cells such as the repression of the beneficial GVL effect in HSCT are avoided after application of BMP-NPs. Hence, further work is required to ultimately decide whether there is a benefit from using $\mathrm{IOH}-\mathrm{NPs}$ in treating inflammatory diseases such as aGvHD or not. 


\section{REFERENCES}

ALAVI, M., KARIMI, N. \& SAFAEI, M. 2017. Application of Various Types of Liposomes in Drug Delivery Systems. Adv Pharm Bull, 7, 3-9.

ALEXANDROVA, M. 1994. Stress induced tyrosine aminotransferase activity via glucocorticoid receptor. Horm Metab Res, 26, 97-9.

ALMAWI, W. Y., BEYHUM, H. N., RAHME, A. A. \& RIEDER, M. J. 1996. Regulation of cytokine and cytokine receptor expression by glucocorticoids. J Leukoc Biol, 60, 563-72.

ANDERSON, B. E., MCNIFF, J. M., JAIN, D., BLAZAR, B. R., SHLOMCHIK, W. D. \& SHLOMCHIK, M. J. 2005. Distinct roles for donor- and host-derived antigen-presenting cells and costimulatory molecules in murine chronic graft-versus-host disease: requirements depend on target organ. Blood, 105, 2227-34.

ANTIN, J. H., CHEN, A. R., COURIEL, D. R., HO, V. T., NASH, R. A. \& WEISDORF, D. 2004. Novel approaches to the therapy of steroidresistant acute graft-versus-host disease. Biol Blood Marrow Transplant, 10, 655-68.

ARVIZO, R. R., MIRANDA, O. R., MOYANO, D. F., WALDEN, C. A., GIRI, K., BHATTACHARYA, R., ROBERTSON, J. D., ROTELLO, V. M., REID, J. M. \& MUKHERJEE, P. 2011. Modulating pharmacokinetics, tumor uptake and biodistribution by engineered nanoparticles. PLoS One, 6, e24374.

ARYA, S. K., WONG-STAAL, F. \& GALLO, R. C. 1984. Dexamethasonemediated inhibition of human $T$ cell growth factor and gamma-interferon messenger RNA. J Immunol, 133, 273-6.

ASAVAROENGCHAI, W., WANG, H., WANG, S., WANG, L., BRONSON, R., SYKES, M. \& YANG, Y. G. 2007. An essential role for IFN-gamma in regulation of alloreactive CD8 $T$ cells following allogeneic hematopoietic cell transplantation. Biol Blood Marrow Transplant, 13, 46-55.

ASHWELL, J. D., LU, F. W. \& VACCHIO, M. S. 2000. Glucocorticoids in T cell development and function*. Annu Rev Immunol, 18, 309-45.

AYROLDI, E., CANNARILE, L., MIGLIORATI, G., NOCENTINI, G., DELFINO, D. V. \& RICCARDI, C. 2012. Mechanisms of the anti-inflammatory effects of glucocorticoids: genomic and nongenomic interference with MAPK signaling pathways. FASEB J, 26, 4805-20.

BAAKE, T., JORSS, K., SUENNEMANN, J., ROSSMANN, L., BOHNENBERGER, H., TUCKERMANN, J. P., REICHARDT, H. M., FISCHER, H. J. \& REICHARDT, S. D. 2018. The glucocorticoid receptor in recipient cells keeps cytokine secretion in acute graft-versus-host disease at bay. Oncotarget, 9, 15437-15450.

BAHADAR, H., MAQBOOL, F., NIAZ, K. \& ABDOLLAHI, M. 2016. Toxicity of Nanoparticles and an Overview of Current Experimental Models. Iran Biomed J, 20, 1-11.

BAJAJ, G. \& YEO, Y. 2010. Drug delivery systems for intraperitoneal therapy. Pharm Res, 27, 735-8.

BAKER, K. S., RONCAROLO, M. G., PETERS, C., BIGLER, M., DEFOR, T. \& BLAZAR, B. R. 1999. High spontaneous IL-10 production in unrelated bone marrow transplant recipients is associated with fewer transplant- 
related complications and early deaths. Bone Marrow Transplant, 23, 1123-9.

BALL, L. M., EGELER, R. M. \& PARTY, E. P. W. 2008. Acute GvHD: pathogenesis and classification. Bone Marrow Transplant, 41 Suppl 2, S58-64.

BANUELOS, J., SHIN, S., CAO, Y., BOCHNER, B. S., MORALES-NEBREDA, L., BUDINGER, G. R., ZHOU, L., LI, S., XIN, J., LINGEN, M. W., DONG, C., SCHLEIMER, R. P. \& LU, N. Z. 2016. BCL-2 protects human and mouse Th17 cells from glucocorticoid-induced apoptosis. Allergy, 71, 640-50.

BARCZYK, K., EHRCHEN, J., TENBROCK, K., AHLMANN, M., KNEIDL, J., VIEMANN, D. \& ROTH, J. 2010. Glucocorticoids promote survival of antiinflammatory macrophages via stimulation of adenosine receptor A3. Blood, 116, 446-55.

BARNES, P. J. 2011. Glucocorticosteroids: current and future directions. $\mathrm{Br} J$ Pharmacol, 163, 29-43.

BASCHANT, U. \& TUCKERMANN, J. 2010. The role of the glucocorticoid receptor in inflammation and immunity. J Steroid Biochem Mol Biol, 120, 69-75.

BEHZADI, S., SERPOOSHAN, V., TAO, W., HAMALY, M. A., ALKAWAREEK, M. Y., DREADEN, E. C., BROWN, D., ALKILANY, A. M., FAROKHZAD, O. C. \& MAHMOUDI, M. 2017. Cellular uptake of nanoparticles: journey inside the cell. Chem Soc Rev, 46, 4218-4244.

BEILHACK, A., SCHULZ, S., BAKER, J., BEILHACK, G. F., WIELAND, C. B., HERMAN, E. I., BAKER, E. M., CAO, Y. A., CONTAG, C. H. \& NEGRIN, R. S. 2005. In vivo analyses of early events in acute graft-versus-host disease reveal sequential infiltration of T-cell subsets. Blood, 106, 111322.

BILLINGHAM, R. E. 1958. Studies on the reaction of injected homologous lymphoid tissue cells against the host. Ann N Y Acad Sci, 73, 782-8.

BILLINGHAM, R. E. 1966. The biology of graft-versus-host reactions. Harvey Lect, 62, 21-78.

BLANCO, E., SHEN, H. \& FERRARI, M. 2015. Principles of nanoparticle design for overcoming biological barriers to drug delivery. Nat Biotechnol, 33, 941-51.

BLAZAR, B. R. \& MURPHY, W. J. 2005. Bone marrow transplantation and approaches to avoid graft-versus-host disease (GVHD). Philos Trans $R$ Soc Lond B Biol Sci, 360, 1747-67.

BLAZAR, B. R., MURPHY, W. J. \& ABEDI, M. 2012. Advances in graft-versushost disease biology and therapy. Nat Rev Immunol, 12, 443-58.

BLAZAR, B. R., SHARPE, A. H., TAYLOR, P. A., PANOSKALTSIS-MORTARI, A., GRAY, G. S., KORNGOLD, R. \& VALLERA, D. A. 1996. Infusion of anti-B7.1 (CD80) and anti-B7.2 (CD86) monoclonal antibodies inhibits murine graft-versus-host disease lethality in part via direct effects on CD4+ and CD8+ T cells. J Immunol, 157, 3250-9.

BLAZAR, B. R., TAYLOR, P. A., PANOSKALTSIS-MORTARI, A., NARULA, S. K., SMITH, S. R., RONCAROLO, M. G. \& VALLERA, D. A. 1998. Interleukin-10 dose-dependent regulation of CD4+ and CD8+ $T$ cellmediated graft-versus-host disease. Transplantation, 66, 1220-9. 
BLOTTA, M. H., DEKRUYFF, R. H. \& UMETSU, D. T. 1997. Corticosteroids inhibit IL-12 production in human monocytes and enhance their capacity to induce IL-4 synthesis in CD4+ lymphocytes. J Immunol, 158, 5589-95.

BOIERI, M., SHAH, P., DRESSEL, R. \& INNGJERDINGEN, M. 2016. The Role of Animal Models in the Study of Hematopoietic Stem Cell Transplantation and GvHD: A Historical Overview. Front Immunol, 7, 333.

BOUAZZAOUI, A., SPACENKO, E., MUELLER, G., HUBER, E., SCHUBERT, T., HOLLER, E., ANDREESEN, R. \& HILDEBRANDT, G. C. 2011. Steroid treatment alters adhesion molecule and chemokine expression in experimental acute graft-vs.-host disease of the intestinal tract. Exp Hematol, 39, 238-249 e1.

BOUAZZAOUI, A., SPACENKO, E., MUELLER, G., MIKLOS, S., HUBER, E., HOLLER, E., ANDREESEN, R. \& HILDEBRANDT, G. C. 2009. Chemokine and chemokine receptor expression analysis in target organs of acute graft-versus-host disease. Genes Immun, 10, 687-701.

BRAUN, M. Y., LOWIN, B., FRENCH, L., ACHA-ORBEA, H. \& TSCHOPP, J. 1996. Cytotoxic T cells deficient in both functional fas ligand and perforin show residual cytolytic activity yet lose their capacity to induce lethal acute graft-versus-host disease. J Exp Med, 183, 657-61.

BROWN, G. R., LEE, E. L. \& THIELE, D. L. 2003. TNF enhances CD4+ T cell alloproliferation, IFN-gamma responses, and intestinal graft-versus-host disease by IL-12-independent mechanisms. J Immunol, 170, 5082-8.

BULBAKE, U., DOPPALAPUDI, S., KOMMINENI, N. \& KHAN, W. 2017. Liposomal Formulations in Clinical Use: An Updated Review. Pharmaceutics, 9.

BURMAN, A. C., BANOVIC, T., KUNS, R. D., CLOUSTON, A. D., STANLEY, A. C., MORRIS, E. S., ROWE, V., BOFINGER, H., SKOCZYLAS, R., RAFFELT, N., FAHY, O., MCCOLL, S. R., ENGWERDA, C. R., MCDONALD, K. P. \& HILL, G. R. 2007. IFNgamma differentially controls the development of idiopathic pneumonia syndrome and GVHD of the gastrointestinal tract. Blood, 110, 1064-72.

BUTTGEREIT, F. \& SCHEFFOLD, A. 2002. Rapid glucocorticoid effects on immune cells. Steroids, 67, 529-34.

BUTTS, C. L., SHUKAIR, S. A., DUNCAN, K. M., HARRIS, C. W., BELYAVSKAYA, E. \& STERNBERG, E. M. 2007. Effects of dexamethasone on rat dendritic cell function. Horm Metab Res, 39, 40412.

CAIN, D. W. \& CIDLOWSKI, J. A. 2017. Immune regulation by glucocorticoids. Nat Rev Immunol, 17, 233-247.

CANALIS, E. 2005. Mechanisms of glucocorticoid action in bone. Curr Osteoporos Rep, 3, 98-102.

CANALIS, E., MAZZIOTTI, G., GIUSTINA, A. \& BILEZIKIAN, J. P. 2007. Glucocorticoid-induced osteoporosis: pathophysiology and therapy. Osteoporos Int, 18, 1319-28.

CANTON, J. 2018. Macropinocytosis: New Insights Into Its Underappreciated Role in Innate Immune Cell Surveillance. Front Immunol, 9, 2286.

CAO, Y., BENDER, I. K., KONSTANTINIDIS, A. K., SHIN, S. C., JEWELL, C. M., CIDLOWSKI, J. A., SCHLEIMER, R. P. \& LU, N. Z. 2013. Glucocorticoid receptor translational isoforms underlie maturational 
stage-specific glucocorticoid sensitivities of dendritic cells in mice and humans. Blood, 121, 1553-62.

CARLSON, M. J., WEST, M. L., COGHILL, J. M., PANOSKALTSIS-MORTARI, A., BLAZAR, B. R. \& SERODY, J. S. 2009. In vitro-differentiated TH17 cells mediate lethal acute graft-versus-host disease with severe cutaneous and pulmonary pathologic manifestations. Blood, 113, 136574.

CASTILLO, P. M., JIMENEZ-RUIZ, A., CARNERERO, J. M. \& PRADOGOTOR, R. 2018. Exploring Factors for the Design of Nanoparticles as Drug Delivery Vectors. Chemphyschem, 19, 2810-2828.

CASTOR, M. G., PINHO, V. \& TEIXEIRA, M. M. 2012. The role of chemokines in mediating graft versus host disease: opportunities for novel therapeutics. Front Pharmacol, 3, 23.

CASTOR, M. G., REZENDE, B. M., BERNARDES, P. T., VIEIRA, A. T., VIEIRA, E. L., ARANTES, R. M., SOUZA, D. G., SILVA, T. A., TEIXEIRA, M. M. \& PINHO, V. 2011. PI3Kgamma controls leukocyte recruitment, tissue injury, and lethality in a model of graft-versus-host disease in mice. J Leukoc Biol, 89, 955-64.

CAVET, J., DICKINSON, A. M., NORDEN, J., TAYLOR, P. R., JACKSON, G. H. \& MIDDLETON, P. G. 2001. Interferon-gamma and interleukin-6 gene polymorphisms associate with graft-versus-host disease in HLA-matched sibling bone marrow transplantation. Blood, 98, 1594-600.

CHAKRAVERTY, R. \& SYKES, M. 2007. The role of antigen-presenting cells in triggering graft-versus-host disease and graft-versus-leukemia. Blood, 110, 9-17.

CHANG, T., OLSON, J. A., PROFFITT, R. T. \& ADLER-MOORE, J. P. 2010. Differences in tissue drug concentrations following intravenous versus intraperitoneal treatment with amphotericin B deoxycholate or liposomal amphotericin B. Med Mycol, 48, 430-5.

CHAO, N. J. \& CHEN, B. J. 2006. Prophylaxis and treatment of acute graftversus-host disease. Semin Hematol, 43, 32-41.

CHEN, L., JONDAL, M. \& YAKIMCHUK, K. 2018. Regulatory effects of dexamethasone on NK and T cell immunity. Inflammopharmacology, 26, 1331-1338.

CHEN, X., DAS, R., KOMOROWSKI, R., BERES, A., HESSNER, M. J., MIHARA, M. \& DROBYSKI, W. R. 2009. Blockade of interleukin-6 signaling augments regulatory $\mathrm{T}$-cell reconstitution and attenuates the severity of graft-versus-host disease. Blood, 114, 891-900.

CHEN, X., MURAKAMI, T., OPPENHEIM, J. J. \& HOWARD, O. M. Z. 2004. Differential response of murine CD4+CD25+ and CD4+CD25- T cells to dexamethasone-induced cell death. Eur J Immunol, 34, 859-869.

CHEN, X., OPPENHEIM, J. J., WINKLER-PICKETT, R. T., ORTALDO, J. R. \& HOWARD, O. M. 2006. Glucocorticoid amplifies IL-2-dependent expansion of functional FoxP3(+)CD4(+)CD25(+) T regulatory cells in vivo and enhances their capacity to suppress EAE. Eur J Immunol, 36, 2139-49.

CHEUK, D. K. 2013. Optimal stem cell source for allogeneic stem cell transplantation for hematological malignancies. World J Transplant, 3, 99-112. 
COHEN, J. J. \& DUKE, R. C. 1984. Glucocorticoid activation of a calciumdependent endonuclease in thymocyte nuclei leads to cell death. $J$ Immunol, 132, 38-42.

COHEN, J. L., TRENADO, A., VASEY, D., KLATZMANN, D. \& SALOMON, B. L. 2002. CD4(+)CD25(+) immunoregulatory T Cells: new therapeutics for graft-versus-host disease. J Exp Med, 196, 401-6.

CONNER, S. D. \& SCHMID, S. L. 2003. Regulated portals of entry into the cell. Nature, 422, 37-44.

COOKE, K. R., KOBZIK, L., MARTIN, T. R., BREWER, J., DELMONTE, J., JR., CRAWFORD, J. M. \& FERRARA, J. L. 1996. An experimental model of idiopathic pneumonia syndrome after bone marrow transplantation: I. The roles of minor $\mathrm{H}$ antigens and endotoxin. Blood, 88, 3230-9.

COPELAN, E. A. 2006. Hematopoietic stem-cell transplantation. $N$ Engl J Med, 354, $1813-26$.

CRUZ-TOPETE, D. \& CIDLOWSKI, J. A. 2015. One hormone, two actions: antiand pro-inflammatory effects of glucocorticoids. Neuroimmunomodulation, 22, 20-32.

DEEG, H. J. 2007. How I treat refractory acute GVHD. Blood, 109, 4119-26.

DEKHUIJZEN, P. N., GAYAN-RAMIREZ, G., BISSCHOP, A., DE BOCK, V., DOM, R. \& DECRAMER, M. 1995. Corticosteroid treatment and nutritional deprivation cause a different pattern of atrophy in rat diaphragm. J Appl Physiol (1985), 78, 629-37.

DELANY, A. M., GABBITAS, B. Y. \& CANALIS, E. 1995. Cortisol downregulates osteoblast alpha 1 (I) procollagen mRNA by transcriptional and posttranscriptional mechanisms. J Cell Biochem, 57, 488-94.

DESGEORGES, T., CARATTI, G., MOUNIER, R., TUCKERMANN, J. \& CHAZAUD, B. 2019. Glucocorticoids Shape Macrophage Phenotype for Tissue Repair. Front Immunol, 10, 1591.

DESHMANE, S. L., KREMLEV, S., AMINI, S. \& SAWAYA, B. E. 2009. Monocyte chemoattractant protein-1 (MCP-1): an overview. J Interferon Cytokine Res, 29, 313-26.

DIXON, L. J., BARNES, M., TANG, H., PRITCHARD, M. T. \& NAGY, L. E. 2013. Kupffer cells in the liver. Compr Physiol, 3, 785-97.

DOHERTY, G. J. \& MCMAHON, H. T. 2009. Mechanisms of endocytosis. Annu Rev Biochem, 78, 857-902.

DROBYSKI, W. R., SZABO, A., ZHU, F., KEEVER-TAYLOR, C., HEBERT, K. M., DUNN, R., YIM, S., JOHNSON, B., D'SOUZA, A., EAPEN, M., FENSKE, T. S., HARI, P., HAMADANI, M., HOROWITZ, M. M., RIZZO, J. D., SABER, W., SHAH, N., SHAW, B. \& PASQUINI, M. 2018. Tocilizumab, tacrolimus and methotrexate for the prevention of acute graft-versus-host disease: low incidence of lower gastrointestinal tract disease. Haematologica, 103, 717-727.

DUFFNER, U. A., MAEDA, Y., COOKE, K. R., REDDY, P., ORDEMANN, R., LIU, C., FERRARA, J. L. \& TESHIMA, T. 2004. Host dendritic cells alone are sufficient to initiate acute graft-versus-host disease. J Immunol, 172, 7393-8.

DUMA, D., JEWELL, C. M. \& CIDLOWSKI, J. A. 2006. Multiple glucocorticoid receptor isoforms and mechanisms of post-translational modification. $J$ Steroid Biochem Mol Biol, 102, 11-21. 
DUNN, A. J. 2000. Cytokine activation of the HPA axis. Ann N Y Acad Sci, 917, 608-17.

DUTTA, D. \& DONALDSON, J. G. 2012. Search for inhibitors of endocytosis: Intended specificity and unintended consequences. Cell Logist, 2, 203208.

EGDAHL, R. H., ROLLER, F. R., SWANSON, R. L. \& VARCO, R. L. 1958. Acquired tolerance to homografts and heterografts in the rat. Ann $N Y$ Acad Sci, 73, 842-7.

EHRCHEN, J., STEINMULLER, L., BARCZYK, K., TENBROCK, K., NACKEN, W., EISENACHER, M., NORDHUES, U., SORG, C., SUNDERKOTTER, C. \& ROTH, J. 2007. Glucocorticoids induce differentiation of a specifically activated, anti-inflammatory subtype of human monocytes. Blood, 109, 1265-74.

ELENKOV, I. J. 2004. Glucocorticoids and the Th1/Th2 balance. Ann N Y Acad Sci, 1024, 138-46.

EMMER, P. M., VAN DER VLAG, J., ADEMA, G. J. \& HILBRANDS, L. B. 2006. Dendritic cells activated by lipopolysaccharide after dexamethasone treatment induce donor-specific allograft hyporesponsiveness. Transplantation, 81, 1451-9.

EVERSE, L. A., ANDERSON, L. D., JR., VAN ROOIJEN, N. \& MULLEN, C. A. 2001. Bone marrow transplant conditioning intensified with liposomal clodronate to eliminate residual host antigen presenting cells fails to ameliorate GVHD and increases PERI-BMT mortality. Transplantation, 71, 611-8.

EVERSON, G. T., TROUILLOT, T., WACHS, M., BAK, T., STEINBERG, T., KAM, I., SHRESTHA, R. \& STEGALL, M. 1999. Early steroid withdrawal in liver transplantation is safe and beneficial. Liver Transpl Surg, 5, S4857.

FAHEY, A. J., ROBINS, R. A., KINDLE, K. B., HEERY, D. M. \& CONSTANTINESCU, C. S. 2006. Effects of glucocorticoids on STAT4 activation in human T cells are stimulus-dependent. J Leukoc Biol, 80, $133-44$.

FALCONE, S., COCUCCI, E., PODINI, P., KIRCHHAUSEN, T., CLEMENTI, E. \& MELDOLESI, J. 2006. Macropinocytosis: regulated coordination of endocytic and exocytic membrane traffic events. J Cell Sci, 119, 475869.

FERRARA, J. L. 1993. Cytokine dysregulation as a mechanism of graft versus host disease. Curr Opin Immunol, 5, 794-9.

FERRARA, J. L., LEVINE, J. E., REDDY, P. \& HOLLER, E. 2009. Graft-versushost disease. Lancet, 373, 1550-61.

FINERTY, J. C. 1952. Parabiosis in physiological studies. Physiol Rev, 32, 277302.

FOURNIER, M., HUANG, Z. S., LI, H., DA, X., CERCEK, B. \& LEWIS, M. I. 2003. Insulin-like growth factor I prevents corticosteroid-induced diaphragm muscle atrophy in emphysematous hamsters. Am J Physiol Regul Integr Comp Physiol, 285, R34-43.

FOWLER, D. H., KURASAWA, K., SMITH, R., ECKHAUS, M. A. \& GRESS, R. E. 1994. Donor CD4-enriched cells of Th2 cytokine phenotype regulate graft-versus-host disease without impairing allogeneic engraftment in sublethally irradiated mice. Blood, 84, 3540-9. 
FRANCHIMONT, D. 2004. Overview of the actions of glucocorticoids on the immune response: a good model to characterize new pathways of immunosuppression for new treatment strategies. Ann $N$ Y Acad Sci, 1024, 124-37.

FRANCO, L. M., GADKARI, M., HOWE, K. N., SUN, J., KARDAVA, L., KUMAR, P., KUMARI, S., HU, Z., FRASER, I. D. C., MOIR, S., TSANG, J. S. \& GERMAIN, R. N. 2019. Immune regulation by glucocorticoids can be linked to cell type-dependent transcriptional responses. J Exp Med, 216, 384-406.

FRIJTERS, R., FLEUREN, W., TOONEN, E. J., TUCKERMANN, J. P., REICHARDT, H. M., VAN DER MAADEN, H., VAN ELSAS, A., VAN LIEROP, M. J., DOKTER, W., DE VLIEG, J. \& ALKEMA, W. 2010. Prednisolone-induced differential gene expression in mouse liver carrying wild type or a dimerization-defective glucocorticoid receptor. BMC Genomics, 11, 359.

FUJIMOTO, L. M., ROTH, R., HEUSER, J. E. \& SCHMID, S. L. 2000. Actin assembly plays a variable, but not obligatory role in receptor-mediated endocytosis in mammalian cells. Traffic, 1, 161-71.

GAO, Y. Z., X; ZHANG, Y; CHEN, X; WANG, L; FENG, W; HUANG, C; LI, F, 2017. In vivo biodistribution and passive accumulation of upconversion nanoparticles in colorectal cancer models via intraperitoneal injection. RSC Advances, 7.

GARNETT, C., APPERLEY, J. F. \& PAVLU, J. 2013. Treatment and management of graft-versus-host disease: improving response and survival. Ther Adv Hematol, 4, 366-78.

GAYO, A., MOZO, L., SUAREZ, A., TUNON, A., LAHOZ, C. \& GUTIERREZ, C. 1998. Glucocorticoids increase IL-10 expression in multiple sclerosis patients with acute relapse. J Neuroimmunol, 85, 122-30.

GHIMIRE, S., WEBER, D., MAVIN, E., WANG, X. N., DICKINSON, A. M. \& HOLLER, E. 2017. Pathophysiology of GvHD and Other HSCT-Related Major Complications. Front Immunol, 8, 79.

GILES, K. M., ROSS, K., ROSSI, A. G., HOTCHIN, N. A., HASLETT, C. \& DRANSFIELD, I. 2001. Glucocorticoid augmentation of macrophage capacity for phagocytosis of apoptotic cells is associated with reduced p130Cas expression, loss of paxillin/pyk2 phosphorylation, and high levels of active Rac. J Immunol, 167, 976-86.

GIVON, T., REVEL, M. \& SLAVIN, S. 1994. Potential use of interleukin-6 in bone marrow transplantation: effects of recombinant human interleukin- 6 after syngeneic and semiallogeneic bone marrow transplantation in mice. Blood, 83, 1690-7.

GOKER, H., HAZNEDAROGLU, I. C. \& CHAO, N. J. 2001. Acute graft-vs-host disease: pathobiology and management. Exp Hematol, 29, 259-77.

GRATWOHL, A., BALDOMERO, H., GRATWOHL, M., ALJURF, M., BOUZAS, L. F., HOROWITZ, M., KODERA, Y., LIPTON, J., IIDA, M., PASQUINI, M. C., PASSWEG, J., SZER, J., MADRIGAL, A., FRAUENDORFER, K., NIEDERWIESER, D., WORLDWIDE NETWORK OF, B. \& MARROW, T. 2013. Quantitative and qualitative differences in use and trends of hematopoietic stem cell transplantation: a Global Observational Study. Haematologica, 98, 1282-90. 
GRAUBERT, T. A., DIPERSIO, J. F., RUSSELL, J. H. \& LEY, T. J. 1997. Perforin/granzyme-dependent and independent mechanisms are both important for the development of graft-versus-host disease after murine bone marrow transplantation. J Clin Invest, 100, 904-11.

GRUBER, J., SGONC, R., HU, Y. H., BEUG, H. \& WICK, G. 1994. Thymocyte apoptosis induced by elevated endogenous corticosterone levels. Eur $J$ Immunol, 24, 1115-21.

GUO, S., ZHANG, X., ZHENG, M., ZHANG, X., MIN, C., WANG, Z., CHEON, S. H., OAK, M. H., NAH, S. Y. \& KIM, K. M. 2015. Selectivity of commonly used inhibitors of clathrin-mediated and caveolae-dependent endocytosis of $\mathrm{G}$ protein-coupled receptors. Biochim Biophys Acta, 1848, 2101-10.

HANIFFA, M., GINHOUX, F., WANG, X. N., BIGLEY, V., ABEL, M., DIMMICK, I., BULLOCK, S., GRISOTTO, M., BOOTH, T., TAUB, P., HILKENS, C., MERAD, M. \& COLLIN, M. 2009. Differential rates of replacement of human dermal dendritic cells and macrophages during hematopoietic stem cell transplantation. J Exp Med, 206, 371-85.

HANNON, M., LECHANTEUR, C., LUCAS, S., SOMJA, J., SEIDEL, L., BELLE, L., BRUCK, F., BAUDOUX, E., GIET, O., CHANTILLON, A. M., DELVENNE, P., DRION, P., BEGUIN, Y., HUMBLET-BARON, S. \& BARON, F. 2014. Infusion of clinical-grade enriched regulatory $T$ cells delays experimental xenogeneic graft-versus-host disease. Transfusion, 54, 353-63.

HASHIMOTO, D., CHOW, A., GRETER, M., SAENGER, Y., KWAN, W. H., LEBOEUF, M., GINHOUX, F., OCHANDO, J. C., KUNISAKI, Y., VAN ROOIJEN, N., LIU, C., TESHIMA, T., HEEGER, P. S., STANLEY, E. R., FRENETTE, P. S. \& MERAD, M. 2011. Pretransplant CSF-1 therapy expands recipient macrophages and ameliorates GVHD after allogeneic hematopoietic cell transplantation. J Exp Med, 208, 1069-82.

HECK, J. G., NAPP, J., SIMONATO, S., MOLLMER, J., LANGE, M., REICHARDT, H. M., STAUDT, R., ALVES, F. \& FELDMANN, C. 2015. Multifunctional phosphate-based inorganic-organic hybrid nanoparticles. J Am Chem Soc, 137, 7329-36.

HEIDEVELD, E., HAMPTON-O'NEIL, L. A., CROSS, S. J., VAN ALPHEN, F. P. J., VAN DEN BIGGELAAR, M., TOYE, A. M. \& VAN DEN AKKER, E. 2018. Glucocorticoids induce differentiation of monocytes towards macrophages that share functional and phenotypical aspects with erythroblastic island macrophages. Haematologica, 103, 395-405.

HIGAKI, M., ISHIHARA, T., IZUMO, N., TAKATSU, M. \& MIZUSHIMA, Y. 2005. Treatment of experimental arthritis with poly(D, L-lactic/glycolic acid) nanoparticles encapsulating betamethasone sodium phosphate. Ann Rheum Dis, 64, 1132-6.

HILDEBRANDT, G. C., DUFFNER, U. A., OLKIEWICZ, K. M., CORRION, L. A., WILLMARTH, N. E., WILLIAMS, D. L., CLOUTHIER, S. G., HOGABOAM, C. M., REDDY, P. R., MOORE, B. B., KUZIEL, W. A., LIU, C., YANIK, G. \& COOKE, K. R. 2004. A critical role for CCR2/MCP-1 interactions in the development of idiopathic pneumonia syndrome after allogeneic bone marrow transplantation. Blood, 103, 2417-26.

HILL, G. R., CRAWFORD, J. M., COOKE, K. R., BRINSON, Y. S., PAN, L. \& FERRARA, J. L. 1997. Total body irradiation and acute graft-versus-host 
disease: the role of gastrointestinal damage and inflammatory cytokines. Blood, 90, 3204-13.

HILL, G. R. \& FERRARA, J. L. 2000. The primacy of the gastrointestinal tract as a target organ of acute graft-versus-host disease: rationale for the use of cytokine shields in allogeneic bone marrow transplantation. Blood, 95, 2754-9.

HILLIER, S. G. 2007. Diamonds are forever: the cortisone legacy. J Endocrinol, 195, 1-6.

HO, V. T. \& CUTLER, C. 2008. Current and novel therapies in acute GVHD. Best Pract Res Clin Haematol, 21, 223-37.

HOCKENBERY, D. M., ZUTTER, M., HICKEY, W., NAHM, M. \& KORSMEYER, S. J. 1991. BCL2 protein is topographically restricted in tissues characterized by apoptotic cell death. Proc Natl Acad Sci U $S A$, 88, 6961-5.

HOFER, T., KRICHEVSKY, O. \& ALTAN-BONNET, G. 2012. Competition for IL2 between Regulatory and Effector T Cells to Chisel Immune Responses. Front Immunol, 3, 268.

HOGGER, P., DREIER, J., DROSTE, A., BUCK, F. \& SORG, C. 1998. Identification of the integral membrane protein $R M 3 / 1$ on human monocytes as a glucocorticoid-inducible member of the scavenger receptor cysteine-rich family (CD163). J Immunol, 161, 1883-90.

HOLLER, E., BUTZHAMMER, P., SCHMID, K., HUNDSRUCKER, C., KOESTLER, J., PETER, K., ZHU, W., SPORRER, D., HEHLGANS, T., KREUTZ, M., HOLLER, B., WOLFF, D., EDINGER, M., ANDREESEN, R., LEVINE, J. E., FERRARA, J. L., GESSNER, A., SPANG, R. \& OEFNER, P. J. 2014. Metagenomic analysis of the stool microbiome in patients receiving allogeneic stem cell transplantation: loss of diversity is associated with use of systemic antibiotics and more pronounced in gastrointestinal graft-versus-host disease. Biol Blood Marrow Transplant, 20, 640-5.

HOLLER, E., KOLB, H. J., MOLLER, A., KEMPENI, J., LIESENFELD, S., PECHUMER, H., LEHMACHER, W., RUCKDESCHEL, G., GLEIXNER, B., RIEDNER, C. \& ET AL. 1990. Increased serum levels of tumor necrosis factor alpha precede major complications of bone marrow transplantation. Blood, 75, 1011-6.

HOLLER, E., RONCAROLO, M. G., HINTERMEIER-KNABE, R., EISSNER, G., ERTL, B., SCHULZ, U., KNABE, H., KOLB, H. J., ANDREESEN, R. \& WILMANNS, W. 2000. Prognostic significance of increased IL-10 production in patients prior to allogeneic bone marrow transplantation. Bone Marrow Transplant, 25, 237-41.

HOROWITZ, M. M., GALE, R. P., SONDEL, P. M., GOLDMAN, J. M., KERSEY, J., KOLB, H. J., RIMM, A. A., RINGDEN, O., ROZMAN, C., SPECK, B. \& ET AL. 1990. Graft-versus-leukemia reactions after bone marrow transplantation. Blood, 75, 555-62.

ICLOZAN, C., YU, Y., LIU, C., LIANG, Y., YI, T., ANASETTI, C. \& YU, X. Z. 2010. $T$ helper17 cells are sufficient but not necessary to induce acute graft-versus-host disease. Biol Blood Marrow Transplant, 16, 170-8.

IMAI, E., MINER, J. N., MITCHELL, J. A., YAMAMOTO, K. R. \& GRANNER, D. K. 1993. Glucocorticoid receptor-cAMP response element-binding protein 
interaction and the response of the phosphoenolpyruvate carboxykinase gene to glucocorticoids. J Biol Chem, 268, 5353-6.

IVANOV, A. I. 2008. Pharmacological inhibition of endocytic pathways: is it specific enough to be useful? Methods Mol Biol, 440, 15-33.

JACOBSOHN, D. A. \& VOGELSANG, G. B. 2007. Acute graft versus host disease. Orphanet $J$ Rare Dis, 2, 35.

JAKSCH, M. \& MATTSSON, J. 2005. The pathophysiology of acute graftversus-host disease. Scand J Immunol, 61, 398-409.

JIA, D., O'BRIEN, C. A., STEWART, S. A., MANOLAGAS, S. C. \& WEINSTEIN, R. S. 2006. Glucocorticoids act directly on osteoclasts to increase their life span and reduce bone density. Endocrinology, 147, 5592-9.

JIN, J. F., ZHU, L. L., CHEN, M., XU, H. M., WANG, H. F., FENG, X. Q., ZHU, X. P. \& ZHOU, Q. 2015. The optimal choice of medication administration route regarding intravenous, intramuscular, and subcutaneous injection. Patient Prefer Adherence, 9, 923-42.

JOHNSON, B. D. \& TRUITT, R. L. 1995. Delayed infusion of immunocompetent donor cells after bone marrow transplantation breaks graft-host tolerance allows for persistent antileukemic reactivity without severe graft-versushost disease. Blood, 85, 3302-12.

JUNG, C., KAUL, M. G., BRUNS, O. T., DUCIC, T., FREUND, B., HEINE, M., REIMER, R., MEENTS, A., SALMEN, S. C., WELLER, H., NIELSEN, P., ADAM, G., HEEREN, J. \& ITTRICH, H. 2014. Intraperitoneal injection improves the uptake of nanoparticle-labeled high-density lipoprotein to atherosclerotic plaques compared with intravenous injection: a multimodal imaging study in ApoE knockout mice. Circ Cardiovasc Imaging, 7, 303-11.

KADMIEL, M. \& CIDLOWSKI, J. A. 2013. Glucocorticoid receptor signaling in health and disease. Trends Pharmacol Sci, 34, 518-30.

KANDA, J. 2013. Effect of HLA mismatch on acute graft-versus-host disease. Int $J$ Hematol, 98, 300-8.

KANOJIA, M. D., ANAGNOSTOU, A. A., ZANDER, A. R., VELLEKOOP, L., SPITZER, G., VERMA, D. S., JAGANNATH, S. \& DICKE, K. A. 1984. High-dose methylprednisolone treatment for acute graft-versus-host disease after bone marrow transplantation in adults. Transplantation, 37, 246-9.

KAPPEL, L. W., GOLDBERG, G. L., KING, C. G., SUH, D. Y., SMITH, O. M., LIGH, C., HOLLAND, A. M., GRUBIN, J., MARK, N. M., LIU, C., IWAKURA, Y., HELLER, G. \& VAN DEN BRINK, M. R. 2009. IL-17 contributes to CD4-mediated graft-versus-host disease. Blood, 113, 94552.

KARAGIANNIDIS, C., AKDIS, M., HOLOPAINEN, P., WOOLLEY, N. J., HENSE, G., RUCKERT, B., MANTEL, P. Y., MENZ, G., AKDIS, C. A., BLASER, K. \& SCHMIDT-WEBER, C. B. 2004. Glucocorticoids upregulate FOXP3 expression and regulatory T cells in asthma. J Allergy Clin Immunol, 114, 1425-33.

KELLY, E. J., SANDGREN, E. P., BRINSTER, R. L. \& PALMITER, R. D. 1997. A pair of adjacent glucocorticoid response elements regulate expression of two mouse metallothionein genes. Proc Natl Acad Sci US A, 94, 10045-50. 
KIM, S. W., RHEE, H. J., KO, J., KIM, Y. J., KIM, H. G., YANG, J. M., CHOI, E. C. \& NA, D. S. 2001. Inhibition of cytosolic phospholipase A2 by annexin I. Specific interaction model and mapping of the interaction site. J Biol Chem, 276, 15712-9.

KITAJIMA, T., ARIIZUMI, K., BERGSTRESSER, P. R. \& TAKASHIMA, A. 1996. A novel mechanism of glucocorticoid-induced immune suppression: the inhibiton of $\mathrm{T}$ cell-mediated terminal maturation of a murine dendritic cell line. J Clin Invest, 98, 142-7.

KLASSEN, C., KARABINSKAYA, A., DEJAGER, L., VETTORAZZI, S., VAN MOORLEGHEM, J., LUHDER, F., MEIJSING, S. H., TUCKERMANN, J. P., BOHNENBERGER, H., LIBERT, C. \& REICHARDT, H. M. 2017. Airway Epithelial Cells Are Crucial Targets of Glucocorticoids in a Mouse Model of Allergic Asthma. J Immunol, 199, 48-61.

KLEIMAN, A., HUBNER, S., RODRIGUEZ PARKITNA, J. M., NEUMANN, A., HOFER, S., WEIGAND, M. A., BAUER, M., SCHMID, W., SCHUTZ, G., LIBERT, C., REICHARDT, H. M. \& TUCKERMANN, J. P. 2012. Glucocorticoid receptor dimerization is required for survival in septic shock via suppression of interleukin-1 in macrophages. FASEB J, 26, 722-9.

KLEIN, G. L. 2015. The Effect of Glucocorticoids on Bone and Muscle. Osteoporos Sarcopenia, 1, 39-45.

KORNGOLD, R., MARINI, J. C., DE BACA, M. E., MURPHY, G. F. \& GILESKOMAR, J. 2003. Role of tumor necrosis factor-alpha in graft-versushost disease and graft-versus-leukemia responses. Biol Blood Marrow Transplant, 9, 292-303.

KORNGOLD, R. \& SPRENT, J. 1978. Lethal graft-versus-host disease after bone marrow transplantation across minor histocompatibility barriers in mice. Prevention by removing mature T cells from marrow. $J$ Exp Med, 148, 1687-98.

KORNGOLD, R. \& SPRENT, J. 1987. T cell subsets and graft-versus-host disease. Transplantation, 44, 335-9.

KOU, L., SUN, J., ZHAI, Y. \& HE, Z. 2013. The endocytosis and intracellular fate of nanomedicines: Implication for rational design. Asian Journal of Pharmaceutical Sciences, 8, 1-10.

KUHN, D. A., VANHECKE, D., MICHEN, B., BLANK, F., GEHR, P., PETRIFINK, A. \& ROTHEN-RUTISHAUSER, B. 2014. Different endocytotic uptake mechanisms for nanoparticles in epithelial cells and macrophages. Beilstein J Nanotechnol, 5, 1625-36.

LASKIN, D. L. 2009. Macrophages and inflammatory mediators in chemical toxicity: a battle of forces. Chem Res Toxicol, 22, 1376-85.

LEE, S. J., ZAHRIEH, D., AGURA, E., MACMILLAN, M. L., MAZIARZ, R. T., MCCARTHY, P. L., JR., HO, V. T., CUTLER, C., ALYEA, E. P., ANTIN, J. H. \& SOIFFER, R. J. 2004. Effect of up-front daclizumab when combined with steroids for the treatment of acute graft-versus-host disease: results of a randomized trial. Blood, 104, 1559-64.

LI, B. \& LANE, L. A. 2019. Probing the biological obstacles of nanomedicine with gold nanoparticles. Wiley Interdiscip Rev Nanomed Nanobiotechnol, 11, e1542.

LI, C. C., MUNITIC, I., MITTELSTADT, P. R., CASTRO, E. \& ASHWELL, J. D. 2015. Suppression of Dendritic Cell-Derived IL-12 by Endogenous 
Glucocorticoids Is Protective in LPS-Induced Sepsis. PLoS Biol, 13, e1002269.

LIBERMAN, A. C., DRUKER, J., REFOJO, D., HOLSBOER, F. \& ARZT, E. 2009. Glucocorticoids inhibit GATA-3 phosphorylation and activity in $T$ cells. FASEB J, 23, 1558-71.

LINKER, R. A., WELLER, C., LUHDER, F., MOHR, A., SCHMIDT, J., KNAUTH, M., METSELAAR, J. M. \& GOLD, R. 2008. Liposomal glucocorticosteroids in treatment of chronic autoimmune demyelination: long-term protective effects and enhanced efficacy of methylprednisolone formulations. Exp Neurol, 211, 397-406.

LIU, Y., COUSIN, J. M., HUGHES, J., VAN DAMME, J., SECKL, J. R., HASLETT, C., DRANSFIELD, I., SAVILL, J. \& ROSSI, A. G. 1999. Glucocorticoids promote nonphlogistic phagocytosis of apoptotic leukocytes. J Immunol, 162, 3639-46.

LU, Y. \& WALLER, E. K. 2009. Dichotomous role of interferon-gamma in allogeneic bone marrow transplant. Biol Blood Marrow Transplant, 15, 1347-53.

LUHDER, F. \& REICHARDT, H. M. 2017. Novel Drug Delivery Systems Tailored for Improved Administration of Glucocorticoids. Int J Mol Sci, 18.

MACMILLAN, M. L., WEISDORF, D. J., WAGNER, J. E., DEFOR, T. E., BURNS, L. J., RAMSAY, N. K., DAVIES, S. M. \& BLAZAR, B. R. 2002. Response of 443 patients to steroids as primary therapy for acute graftversus-host disease: comparison of grading systems. Biol Blood Marrow Transplant, 8, 387-94.

MAEDA, Y., LEVY, R. B., REDDY, P., LIU, C., CLOUTHIER, S. G., TESHIMA, T. \& FERRARA, J. L. 2005. Both perforin and Fas ligand are required for the regulation of alloreactive CD8+ $T$ cells during acute graft-versus-host disease. Blood, 105, 2023-7.

MAPARA, M. Y., KIM, Y. M., WANG, S. P., BRONSON, R., SACHS, D. H. \& SYKES, M. 2002. Donor lymphocyte infusions mediate superior graftversus-leukemia effects in mixed compared to fully allogeneic chimeras: a critical role for host antigen-presenting cells. Blood, 100, 1903-9.

MAPARA, M. Y., LENG, C., KIM, Y. M., BRONSON, R., LOKSHIN, A., LUSTER, A. \& SYKES, M. 2006. Expression of chemokines in GVHD target organs is influenced by conditioning and genetic factors and amplified by GVHR. Biol Blood Marrow Transplant, 12, 623-34.

MARKUS, M. A., NAPP, J., BEHNKE, T., MITKOVSKI, M., MONECKE, S., DULLIN, C., KILFEATHER, S., DRESSEL, R., RESCH-GENGER, U. \& ALVES, F. 2015. Tracking of Inhaled Near-Infrared Fluorescent Nanoparticles in Lungs of SKH-1 Mice with Allergic Airway Inflammation. ACS Nano, 9, $11642-57$.

MARQUES, A. H., SILVERMAN, M. N. \& STERNBERG, E. M. 2009. Glucocorticoid dysregulations and their clinical correlates. From receptors to therapeutics. Ann N Y Acad Sci, 1179, 1-18.

MARTINEZ, F. O., SICA, A., MANTOVANI, A. \& LOCATI, M. 2008. Macrophage activation and polarization. Front Biosci, 13, 453-61.

MASSENKEIL, G., RACKWITZ, S., GENVRESSE, I., ROSEN, O., DORKEN, B. \& ARNOLD, R. 2002. Basiliximab is well tolerated and effective in the treatment of steroid-refractory acute graft-versus-host disease after 
allogeneic stem cell transplantation. Bone Marrow Transplant, 30, 899903.

MATTE, C. C., LIU, J., CORMIER, J., ANDERSON, B. E., ATHANASIADIS, I., JAIN, D., MCNIFF, J. \& SHLOMCHIK, W. D. 2004. Donor APCs are required for maximal GVHD but not for GVL. Nat Med, 10, 987-92.

MATYSZAK, M. K., CITTERIO, S., RESCIGNO, M. \& RICCIARDICASTAGNOLI, P. 2000. Differential effects of corticosteroids during different stages of dendritic cell maturation. Eur J Immunol, 30, 1233-42.

METSELAAR, J. M., WAUBEN, M. H., WAGENAAR-HILBERS, J. P., BOERMAN, O. C. \& STORM, G. 2003. Complete remission of experimental arthritis by joint targeting of glucocorticoids with longcirculating liposomes. Arthritis Rheum, 48, 2059-66.

MIN, C. K., LEE, W. Y., MIN, D. J., LEE, D. G., KIM, Y. J., PARK, Y. H., KIM, H. J., LEE, S., KIM, D. W., LEE, J. W., MIN, W. S. \& KIM, C. C. 2001. The kinetics of circulating cytokines including IL-6, TNF-alpha, IL-8 and IL-10 following allogeneic hematopoietic stem cell transplantation. Bone Marrow Transplant, 28, 935-40.

MONTES-COBOS, E., RING, S., FISCHER, H. J., HECK, J., STRAUSS, J., SCHWANINGER, M., REICHARDT, S. D., FELDMANN, C., LUHDER, F. \& REICHARDT, H. M. 2017. Targeted delivery of glucocorticoids to macrophages in a mouse model of multiple sclerosis using inorganicorganic hybrid nanoparticles. J Control Release, 245, 157-169.

MORISHIMA, S., KASHIWASE, K., MATSUO, K., AZUMA, F., YABE, T., SATOOTSUBO, A., OGAWA, S., SHIINA, T., SATAKE, M., SAJI, H., KATO, S., KODERA, Y., SASAZUKI, T., MORISHIMA, Y. \& JAPAN MARROW DONOR, P. 2016. High-risk HLA alleles for severe acute graft-versushost disease and mortality in unrelated donor bone marrow transplantation. Haematologica, 101, 491-8.

MOSER, M., DE SMEDT, T., SORNASSE, T., TIELEMANS, F., CHENTOUFI, A. A., MURAILLE, E., VAN MECHELEN, M., URBAIN, J. \& LEO, O. 1995. Glucocorticoids down-regulate dendritic cell function in vitro and in vivo. Eur J Immunol, 25, 2818-24.

MOUTSATSOU, P., KASSI, E. \& PAPAVASSILIOU, A. G. 2012. Glucocorticoid receptor signaling in bone cells. Trends Mol Med, 18, 348-59.

MOZO, L., SUAREZ, A. \& GUTIERREZ, C. 2004. Glucocorticoids up-regulate constitutive interleukin-10 production by human monocytes. Clin Exp Allergy, 34, 406-12.

MURRAY, P. J., ALLEN, J. E., BISWAS, S. K., FISHER, E. A., GILROY, D. W., GOERDT, S., GORDON, S., HAMILTON, J. A., IVASHKIV, L. B., LAWRENCE, T., LOCATI, M., MANTOVANI, A., MARTINEZ, F. O., MEGE, J. L., MOSSER, D. M., NATOLI, G., SAEIJ, J. P., SCHULTZE, J. L., SHIREY, K. A., SICA, A., SUTTLES, J., UDALOVA, I., VAN GINDERACHTER, J. A., VOGEL, S. N. \& WYNN, T. A. 2014. Macrophage activation and polarization: nomenclature and experimental guidelines. Immunity, 41, 14-20.

NAKIC, B. \& SILOBRCIC, V. 1958. Tolerance of skin homografts related to fatal disease in separated rat parabionts. Nature, 182, 264-5.

NAPP, J., MARKUS, M. A., HECK, J. G., DULLIN, C., MOBIUS, W., GORPAS, D., FELDMANN, C. \& ALVES, F. 2018. Therapeutic Fluorescent Hybrid 
Nanoparticles for Traceable Delivery of Glucocorticoids to Inflammatory Sites. Theranostics, 8, 6367-6383.

NASERIAN, S., LECLERC, M., THIOLAT, A., PILON, C., LE BRET, C., BELKACEMI, Y., MAURY, S., CHARLOTTE, F. \& COHEN, J. L. 2018. Simple, Reproducible, and Efficient Clinical Grading System for Murine Models of Acute Graft-versus-Host Disease. Front Immunol, 9, 10.

NASSEREDDINE, S., RAFEI, H., ELBAHESH, E. \& TABBARA, I. 2017. Acute Graft Versus Host Disease: A Comprehensive Review. Anticancer Res, 37, 1547-1555.

NELSON, T., BEHFAR, A. \& TERZIC, A. 2008. Stem cells: biologics for regeneration. Clin Pharmacol Ther, 84, 620-3.

NESTEL, F. P., PRICE, K. S., SEEMAYER, T. A. \& LAPP, W. S. 1992. Macrophage priming and lipopolysaccharide-triggered release of tumor necrosis factor alpha during graft-versus-host disease. J Exp Med, 175, 405-13.

NIKOLIC, B., LEE, S., BRONSON, R. T., GRUSBY, M. J. \& SYKES, M. 2000. Th1 and Th2 mediate acute graft-versus-host disease, each with distinct end-organ targets. J Clin Invest, 105, 1289-98.

NISHIMOTO, N. \& KISHIMOTO, T. 2006. Interleukin 6: from bench to bedside. Nat Clin Pract Rheumatol, 2, 619-26.

NISHIWAKI, S., NAKAYAMA, T., MURATA, M., NISHIDA, T., TERAKURA, S., SAITO, S., KATO, T., MIZUNO, H., IMAHASHI, N., SETO, A., OZAWA, Y., MIYAMURA, K., ITO, M., TAKESHITA, K., KATO, H., TOYOKUNI, S., NAGAO, K., UEDA, R. \& NAOE, T. 2014. Dexamethasone palmitate ameliorates macrophages-rich graft-versus-host disease by inhibiting macrophage functions. PLoS One, 9, e96252.

O'BRIEN, C. A., JIA, D., PLOTKIN, L. I., BELliDO, T., POWERS, C. C., STEWART, S. A., MANOLAGAS, S. C. \& WEINSTEIN, R. S. 2004. Glucocorticoids act directly on osteoblasts and osteocytes to induce their apoptosis and reduce bone formation and strength. Endocrinology, 145, 1835-41.

OAKLEY, R. H. \& CIDLOWSKI, J. A. 2013. The biology of the glucocorticoid receptor: new signaling mechanisms in health and disease. J Allergy Clin Immunol, 132, 1033-44.

OBANDO-PEREDA, G. A., FISCHER, L. \& STACH-MACHADO, D. R. 2014. Titanium and zirconia particle-induced pro-inflammatory gene expression in cultured macrophages and osteolysis, inflammatory hyperalgesia and edema in vivo. Life Sci, 97, 96-106.

ODEGAARD, J. I. \& CHAWLA, A. 2011. Alternative macrophage activation and metabolism. Annu Rev Pathol, 6, 275-97.

ODEGAARD, J. I., RICARDO-GONZALEZ, R. R., RED EAGLE, A., VATS, D., MOREL, C. R., GOFORTH, M. H., SUBRAMANIAN, V., MUKUNDAN, L., FERRANTE, A. W. \& CHAWLA, A. 2008. Alternative M2 activation of Kupffer cells by PPARdelta ameliorates obesity-induced insulin resistance. Cell Metab, 7, 496-507.

OKAMOTO, S. 2017. Current indication for hematopoietic cell transplantation in adults. Hematol Oncol Stem Cell Ther, 10, 178-183.

ONWUBALILI, J. K. \& OBINECHE, E. N. 1992. High incidence of posttransplant diabetes mellitus in a single-centre study. Nephrol Dial Transplant, 7, 346-9. 
OPHERK, C., TRONCHE, F., KELLENDONK, C., KOHLMULLER, D., SCHULZE, A., SCHMID, W. \& SCHUTZ, G. 2004. Inactivation of the glucocorticoid receptor in hepatocytes leads to fasting hypoglycemia and ameliorates hyperglycemia in streptozotocin-induced diabetes mellitus. Mol Endocrinol, 18, 1346-53.

ORAY, M., ABU SAMRA, K., EBRAHIMIADIB, N., MEESE, H. \& FOSTER, C. S. 2016. Long-term side effects of glucocorticoids. Expert Opin Drug Saf, 15, 457-65.

PACHOT, A., CAZALIS, M. A., VENET, F., TURREL, F., FAUDOT, C., VOIRIN, N., DIASPARRA, J., BOURGOIN, N., POITEVIN, F., MOUGIN, B., LEPAPE, A. \& MONNERET, G. 2008. Decreased expression of the fractalkine receptor CX3CR1 on circulating monocytes as new feature of sepsis-induced immunosuppression. J Immunol, 180, 6421-9.

PALM, W. 2019. Metabolic functions of macropinocytosis. Philos Trans $R$ Soc Lond B Biol Sci, 374, 20180285.

PASIEKA, A. M. \& RAFACHO, A. 2016. Impact of Glucocorticoid Excess on Glucose Tolerance: Clinical and Preclinical Evidence. Metabolites, 6.

PEMBERTON, P. A., STEIN, P. E., PEPYS, M. B., POTTER, J. M. \& CARRELL, R. W. 1988. Hormone binding globulins undergo serpin conformational change in inflammation. Nature, 336, 257-8.

PEMMARI, A., PAUKKERI, E. L., HAMALAINEN, M., LEPPANEN, T., KORHONEN, R. \& MOILANEN, E. 2019. MKP-1 promotes antiinflammatory $M(I L-4 / I L-13)$ macrophage phenotype and mediates the anti-inflammatory effects of glucocorticoids. Basic Clin Pharmacol Toxicol, 124, 404-415.

PEREZ-SIMON, J. A., DIEZ-CAMPELO, M., MARTINO, R., BRUNET, S., URBANO, A., CABALLERO, M. D., DE LEON, A., VALCARCEL, D., CARRERAS, E., DEL CANIZO, M. C., LOPEZ-FIDALGO, J., SIERRA, J. \& SAN MIGUEL, J. F. 2005. Influence of the intensity of the conditioning regimen on the characteristics of acute and chronic graft-versus-host disease after allogeneic transplantation. Br J Haematol, 130, 394-403.

PETTA, I., PEENE, I., ELEWAUT, D., VEREECKE, L. \& DE BOSSCHER, K. 2019. Risks and benefits of corticosteroids in arthritic diseases in the clinic. Biochem Pharmacol.

PHAM, B. T. T., COLVIN, E. K., PHAM, N. T. H., KIM, B. J., FULLER, E. S., MOON, E. A., BARBEY, R., YUEN, S., RICKMAN, B. H., BRYCE, N. S., BICKLEY, S., TANUDJI, M., JONES, S. K., HOWELL, V. M. \& HAWKETT, B. S. 2018. Biodistribution and Clearance of Stable Superparamagnetic Maghemite Iron Oxide Nanoparticles in Mice Following Intraperitoneal Administration. Int J Mol Sci, 19.

PIEMONTI, L., MONTI, P., ALLAVENA, P., LEONE, B. E., CAPUTO, A. \& DI CARLO, V. 1999a. Glucocorticoids increase the endocytic activity of human dendritic cells. Int Immunol, 11, 1519-26.

PIEMONTI, L., MONTI, P., ALLAVENA, P., SIRONI, M., SOLDINI, L., LEONE, B. E., SOCCI, C. \& DI CARLO, V. 1999b. Glucocorticoids affect human dendritic cell differentiation and maturation. J Immunol, 162, 6473-81.

POBER, J. S. 1987. Effects of tumour necrosis factor and related cytokines on vascular endothelial cells. Ciba Found Symp, 131, 170-84.

POß, M. , ; TOWER, R, J; NAPP, J,; APPOLD, L, C,; LAMMERS, T,; ALVES, F,; GLÜER, C,; BORETIUS, S,; FELDMANN, C, 2017. Multimodal 
[GdO]+[ICG]- Nanoparticles for Optical, Photoacousticm and Magnetic Resonance Imaging. Chemistry of Materials, 29, 3547-3554.

PRZEPIORKA, D., KERNAN, N. A., IPPOLITI, C., PAPADOPOULOS, E. B., GIRALT, S., KHOURI, I., LU, J. G., GAJEWSKI, J., DURETT, A., CLEARY, K., CHAMPLIN, R., ANDERSSON, B. S. \& LIGHT, S. 2000. Daclizumab, a humanized anti-interleukin-2 receptor alpha chain antibody, for treatment of acute graft-versus-host disease. Blood, 95, 839.

PRZEPIORKA, D., WEISDORF, D., MARTIN, P., KLINGEMANN, H. G., BEATTY, P., HOWS, J. \& THOMAS, E. D. 1995. 1994 Consensus Conference on Acute GVHD Grading. Bone Marrow Transplant, 15, 8258.

QIN, W., PAN, J., QIN, Y., LEE, D. N., BAUMAN, W. A. \& CARDOZO, C. 2014. Identification of functional glucocorticoid response elements in the mouse FoxO1 promoter. Biochem Biophys Res Commun, 450, 979-83.

QUAN, L., ZHANG, Y., DUSAD, A., REN, K., PURDUE, P. E., GOLDRING, S. R. \& WANG, D. 2016. The Evaluation of the Therapeutic Efficacy and Side Effects of a Macromolecular Dexamethasone Prodrug in the Collagen-Induced Arthritis Mouse Model. Pharm Res, 33, 186-93.

QUAN, L. D., PURDUE, P. E., LIU, X. M., BOSKA, M. D., LELE, S. M., THIELE, G. M., MIKULS, T. R., DOU, H., GOLDRING, S. R. \& WANG, D. 2010. Development of a macromolecular prodrug for the treatment of inflammatory arthritis: mechanisms involved in arthrotropism and sustained therapeutic efficacy. Arthritis Res Ther, 12, R170.

RAMIREZ, F., FOWELL, D. J., PUKLAVEC, M., SIMMONDS, S. \& MASON, D. 1996. Glucocorticoids promote a TH2 cytokine response by CD4+ T cells in vitro. J Immunol, 156, 2406-12.

RATANATHARATHORN, V., AYASH, L., LAZARUS, H. M., FU, J. \& UBERTI, J. P. 2001. Chronic graft-versus-host disease: clinical manifestation and therapy. Bone Marrow Transplant, 28, 121-9.

RAUCH, A., SEITZ, S., BASCHANT, U., SCHILLING, A. F., ILLING, A., STRIDE, B., KIRILOV, M., MANDIC, V., TAKACZ, A., SCHMIDTULLRICH, R., OSTERMAY, S., SCHINKE, T., SPANBROEK, R., ZAISS, M. M., ANGEL, P. E., LERNER, U. H., DAVID, J. P., REICHARDT, H. M., AMLING, M., SCHUTZ, G. \& TUCKERMANN, J. P. 2010. Glucocorticoids suppress bone formation by attenuating osteoblast differentiation via the monomeric glucocorticoid receptor. Cell Metab, 11, 517-31.

REA, D., VAN KOOTEN, C., VAN MEIJGAARDEN, K. E., OTTENHOFF, T. H., MELIEF, C. J. \& OFFRINGA, R. 2000. Glucocorticoids transform CD40triggering of dendritic cells into an alternative activation pathway resulting in antigen-presenting cells that secrete IL-10. Blood, 95, 3162-7.

REICHARDT, H. M., KAESTNER, K. H., TUCKERMANN, J., KRETZ, O., WESSELY, O., BOCK, R., GASS, P., SCHMID, W., HERRLICH, P., ANGEL, P. \& SCHUTZ, G. 1998. DNA binding of the glucocorticoid receptor is not essential for survival. Cell, 93, 531-41.

REICHARDT, H. M. \& SCHUTZ, G. 1998. Glucocorticoid signalling--multiple variations of a common theme. Mol Cell Endocrinol, 146, 1-6. 
RHEN, T. \& CIDLOWSKI, J. A. 2005. Antiinflammatory action of glucocorticoids--new mechanisms for old drugs. N Engl J Med, 353, 1711-23.

RISO, E. M., AHTIKOSKI, A., ALEV, K., KAASIK, P., PEHME, A. \& SEENE, T. 2008. Relationship between extracellular matrix, contractile apparatus, muscle mass and strength in case of glucocorticoid myopathy. J Steroid Biochem Mol Biol, 108, 117-20.

ROSZER, T. 2015. Understanding the Mysterious M2 Macrophage through Activation Markers and Effector Mechanisms. Mediators Inflamm, 2015, 816460.

ROWE, V., BANOVIC, T., MACDONALD, K. P., KUNS, R., DON, A. L., MORRIS, E. S., BURMAN, A. C., BOFINGER, H. M., CLOUSTON, A. D. \& HILL, G. R. 2006. Host B cells produce IL-10 following TBI and attenuate acute GVHD after allogeneic bone marrow transplantation. Blood, 108, 2485-92.

ROZKOVA, D., HORVATH, R., BARTUNKOVA, J. \& SPISEK, R. 2006. Glucocorticoids severely impair differentiation and antigen presenting function of dendritic cells despite upregulation of Toll-like receptors. Clin Immunol, 120, 260-71.

SALOMAO, M., DORRITIE, K., MAPARA, M. Y. \& SEPULVEDA, A. 2016. Histopathology of Graft-vs-Host Disease of Gastrointestinal Tract and Liver: An Update. Am J Clin Pathol, 145, 591-603.

SATO, A. Y., RICHARDSON, D., CREGOR, M., DAVIS, H. M., AU, E. D., MCANDREWS, K., ZIMMERS, T. A., ORGAN, J. M., PEACOCK, M., PLOTKIN, L. I. \& BELLIDO, T. 2017. Glucocorticoids Induce Bone and Muscle Atrophy by Tissue-Specific Mechanisms Upstream of E3 Ubiquitin Ligases. Endocrinology, 158, 664-677.

SCHACKE, H., DOCKE, W. D. \& ASADULLAH, K. 2002. Mechanisms involved in the side effects of glucocorticoids. Pharmacol Ther, 96, 23-43.

SCHAKMAN, O., GILSON, H. \& THISSEN, J. P. 2008. Mechanisms of glucocorticoid-induced myopathy. J Endocrinol, 197, 1-10.

SCHAKMAN, O., KALISTA, S., BARBE, C., LOUMAYE, A. \& THISSEN, J. P. 2013. Glucocorticoid-induced skeletal muscle atrophy. Int J Biochem Cell Biol, 45, 2163-72.

SCHMIDT, J., METSELAAR, J. M., WAUBEN, M. H., TOYKA, K. V., STORM, G. \& GOLD, R. 2003. Drug targeting by long-circulating liposomal glucocorticosteroids increases therapeutic efficacy in a model of multiple sclerosis. Brain, 126, 1895-904.

SCHROEDER, M. A. \& DIPERSIO, J. F. 2011. Mouse models of graft-versushost disease: advances and limitations. Dis Model Mech, 4, 318-33.

SCHWEINGRUBER, N., HAINE, A., TIEDE, K., KARABINSKAYA, A., VAN DEN BRANDT, J., WUST, S., METSELAAR, J. M., GOLD, R., TUCKERMANN, J. P., REICHARDT, H. M. \& LUHDER, F. 2011. Liposomal encapsulation of glucocorticoids alters their mode of action in the treatment of experimental autoimmune encephalomyelitis. $J$ Immunol, 187, 4310-8.

SERCOMBE, L., VEERATI, T., MOHEIMANI, F., WU, S. Y., SOOD, A. K. \& HUA, S. 2015. Advances and Challenges of Liposome Assisted Drug Delivery. Front Pharmacol, 6, 286. 
SHANG, L., NIENHAUS, K. \& NIENHAUS, G. U. 2014. Engineered nanoparticles interacting with cells: size matters. J Nanobiotechnology, $12,5$.

SHETTY, S., KAPOOR, N., BONDU, J. D., THOMAS, N. \& PAUL, T. V. 2016. Bone turnover markers: Emerging tool in the management of osteoporosis. Indian J Endocrinol Metab, 20, 846-852.

SHIN, H. J., BAKER, J., LEVESON-GOWER, D. B., SMITH, A. T., SEGA, E. I. \& NEGRIN, R. S. 2011. Rapamycin and IL-2 reduce lethal acute graftversus-host disease associated with increased expansion of donor type CD4+CD25+Foxp3+ regulatory T cells. Blood, 118, 2342-50.

SHLOMCHIK, W. D. 2007. Graft-versus-host disease. Nat Rev Immunol, 7, 340-52.

SHLOMCHIK, W. D., COUZENS, M. S., TANG, C. B., MCNIFF, J., ROBERT, M. E., LIU, J., SHLOMCHIK, M. J. \& EMERSON, S. G. 1999. Prevention of graft versus host disease by inactivation of host antigen-presenting cells. Science, 285, 412-5.

SIMONSEN, M. 1957. The impact on the developing embryo and newborn animal of adult homologous cells. Acta Pathol Microbiol Scand, 40, 480500.

SLEIGHT, B. S., CHAN, K. W., BRAUN, T. M., SERRANO, A. \& GILMAN, A. L. 2007. Infliximab for GVHD therapy in children. Bone Marrow Transplant, 40, 473-80.

SOCIE, G. \& BLAZAR, B. R. 2009. Acute graft-versus-host disease: from the bench to the bedside. Blood, 114, 4327-36.

SPRENT, J., SCHAEFER, M., GAO, E. K. \& KORNGOLD, R. 1988. Role of T cell subsets in lethal graft-versus-host disease (GVHD) directed to class I versus class II H-2 differences. I. L3T4+ cells can either augment or retard GVHD elicited by Lyt-2+ cells in class I different hosts. J Exp Med, 167, 556-69.

STAHN, C. \& BUTTGEREIT, F. 2008. Genomic and nongenomic effects of glucocorticoids. Nat Clin Pract Rheumatol, 4, 525-33.

STEINMAN, R. M., BRODIE, S. E. \& COHN, Z. A. 1976. Membrane flow during pinocytosis. A stereologic analysis. J Cell Biol, 68, 665-87.

STORB, R., DEEG, H. J., WHITEHEAD, J., APPELBAUM, F., BEATTY, P., BENSINGER, W., BUCKNER, C. D., CLIFT, R., DONEY, K., FAREWELL, V. \& ET AL. 1986. Methotrexate and cyclosporine compared with cyclosporine alone for prophylaxis of acute graft versus host disease after marrow transplantation for leukemia. $N$ Engl $J$ Med, 314, 729-35.

STREHL, C. \& BUTTGEREIT, F. 2013. Optimized glucocorticoid therapy: teaching old drugs new tricks. Mol Cell Endocrinol, 380, 32-40.

STRONG RODRIGUES, K., OLIVEIRA-RIBEIRO, C., DE ABREU FIUZA GOMES, S. \& KNOBLER, R. 2018. Cutaneous Graft-Versus-Host Disease: Diagnosis and Treatment. Am J Clin Dermatol, 19, 33-50.

SUMMERMATTER, S., BOUZAN, A., PIERREL, E., MELLY, S., STAUFFER, D., GUTZWILLER, S., NOLIN, E., DORNELAS, C., FRYER, C., LEIGHTON-DAVIES, J., GLASS, D. J. \& FOURNIER, B. 2017. Blockade of Metallothioneins 1 and 2 Increases Skeletal Muscle Mass and Strength. Mol Cell Biol, 37. 
SURJIT, M., GANTI, K. P., MUKHERJI, A., YE, T., HUA, G., METZGER, D., LI, M. \& CHAMBON, P. 2011. Widespread negative response elements mediate direct repression by agonist-liganded glucocorticoid receptor. Cell, 145, 224-41.

SVENNILSON, J. 2005. Novel approaches in GVHD therapy. Bone Marrow Transplant, 35 Suppl 1, S65-7.

SYMINGTON, F. W., SYMINGTON, B. E., LIU, P. Y., VIGUET, H., SANTHANAM, U. \& SEHGAL, P. B. 1992. The relationship of serum IL-6 levels to acute graft-versus-host disease and hepatorenal disease after human bone marrow transplantation. Transplantation, 54, 457-62.

SZYSKA, M. \& NA, I. K. 2016. Bone Marrow GvHD after Allogeneic Hematopoietic Stem Cell Transplantation. Front Immunol, 7, 118.

TALABER, G., JONDAL, M. \& OKRET, S. 2013. Extra-adrenal glucocorticoid synthesis: immune regulation and aspects on local organ homeostasis. Mol Cell Endocrinol, 380, 89-98.

TAWARA, I., KOYAMA, M., LIU, C., TOUBAI, T., THOMAS, D., EVERS, R., CHOCKLEY, P., NIEVES, E., SUN, Y., LOWLER, K. P., MALTER, C., NISHIMOTO, N., HILL, G. R. \& REDDY, P. 2011. Interleukin-6 modulates graft-versus-host responses after experimental allogeneic bone marrow transplantation. Clin Cancer Res, 17, 77-88.

TERWEY, T. H., KIM, T. D., KOCHMAN, A. A., HUBBARD, V. M., LU, S., ZAKRZEWSKI, J. L., RAMIREZ-MONTAGUT, T., ENG, J. M., MURIGLAN, S. J., HELLER, G., MURPHY, G. F., LIU, C., BUDAKALPDOGAN, T., ALPDOGAN, O. \& VAN DEN BRINK, M. R. 2005. CCR2 is required for CD8-induced graft-versus-host disease. Blood, 106, 3322-30.

TESHIMA, T., ORDEMANN, R., REDDY, P., GAGIN, S., LIU, C., COOKE, K. R. \& FERRARA, J. L. 2002. Acute graft-versus-host disease does not require alloantigen expression on host epithelium. Nat Med, 8, 575-81.

THEISS-SUENNEMANN, J., JORSS, K., MESSMANN, J. J., REICHARDT, S. D., MONTES-COBOS, E., LUHDER, F., TUCKERMANN, J. P., H, A. W., DRESSEL, R., GRONE, H. J., STRAUSS, G. \& REICHARDT, H. M. 2015. Glucocorticoids attenuate acute graft-versus-host disease by suppressing the cytotoxic capacity of CD8(+) T cells. J Pathol, 235, 64655.

TUCKERMANN, J. P., KLEIMAN, A., MCPHERSON, K. G. \& REICHARDT, H. M. 2005. Molecular mechanisms of glucocorticoids in the control of inflammation and lymphocyte apoptosis. Crit Rev Clin Lab Sci, 42, 71104.

TUCKERMANN, J. P., KLEIMAN, A., MORIGGL, R., SPANBROEK, R., NEUMANN, A., ILLING, A., CLAUSEN, B. E., STRIDE, B., FORSTER, I., HABENICHT, A. J., REICHARDT, H. M., TRONCHE, F., SCHMID, W. \& SCHUTZ, G. 2007. Macrophages and neutrophils are the targets for immune suppression by glucocorticoids in contact allergy. J Clin Invest, $117,1381-90$.

UNGER, W. W., LABAN, S., KLEIJWEGT, F. S., VAN DER SLIK, A. R. \& ROEP, B. O. 2009. Induction of Treg by monocyte-derived DC modulated by vitamin D3 or dexamethasone: differential role for PD-L1. Eur J Immunol, 39, 3147-59. 
VAN DIJK, A. M., KESSLER, F. L., STADHOUDERS-KEET, S. A., VERDONCK, L. F., DE GAST, G. C. \& OTTEN, H. G. 1999. Selective depletion of major and minor histocompatibility antigen reactive $\mathrm{T}$ cells: towards prevention of acute graft-versus-host disease. $\mathrm{Br} J$ Haematol, 107, 169-75.

VANDER KOOI, B. T., ONUMA, H., OESER, J. K., SVITEK, C. A., ALLEN, S. R., VANDER KOOI, C. W., CHAZIN, W. J. \& O'BRIEN, R. M. 2005. The glucose-6-phosphatase catalytic subunit gene promoter contains both positive and negative glucocorticoid response elements. Mol Endocrinol, 19, 3001-22.

VANDEVYVER, S., DEJAGER, L., TUCKERMANN, J. \& LIBERT, C. 2013. New insights into the anti-inflammatory mechanisms of glucocorticoids: an emerging role for glucocorticoid-receptor-mediated transactivation. Endocrinology, 154, 993-1007.

VANDEVYVER, S., DEJAGER, L., VAN BOGAERT, T., KLEYMAN, A., LIU, Y., TUCKERMANN, J. \& LIBERT, C. 2012. Glucocorticoid receptor dimerization induces MKP1 to protect against TNF-induced inflammation. J Clin Invest, 122, 2130-40.

VANDEWALLE, J., LUYPAERT, A., DE BOSSCHER, K. \& LIBERT, C. 2018. Therapeutic Mechanisms of Glucocorticoids. Trends Endocrinol Metab, 29, $42-54$.

VERCAUTEREN, D., VANDENBROUCKE, R. E., JONES, A. T., REJMAN, J., DEMEESTER, J., DE SMEDT, S. C., SANDERS, N. N. \& BRAECKMANS, K. 2010. The use of inhibitors to study endocytic pathways of gene carriers: optimization and pitfalls. Mol Ther, 18, 561-9.

VERMEER, H., HENDRIKS-STEGEMAN, B. I., VAN DER BURG, B., VAN BUUL-OFFERS, S. C. \& JANSEN, M. 2003. Glucocorticoid-induced increase in lymphocytic FKBP51 messenger ribonucleic acid expression: a potential marker for glucocorticoid sensitivity, potency, and bioavailability. J Clin Endocrinol Metab, 88, 277-84.

VETTORAZZI, S., BODE, C., DEJAGER, L., FRAPPART, L., SHELEST, E., KLASSEN, C., TASDOGAN, A., REICHARDT, H. M., LIBERT, C., SCHNEIDER, M., WEIH, F., HENRIETTE UHLENHAUT, N., DAVID, J. P., GRALER, M., KLEIMAN, A. \& TUCKERMANN, J. P. 2015. Glucocorticoids limit acute lung inflammation in concert with inflammatory stimuli by induction of SphK1. Nat Commun, 6, 7796.

VIA, C. S. \& FINKELMAN, F. D. 1993. Critical role of interleukin-2 in the development of acute graft-versus-host disease. Int Immunol, 5, 565-72.

VIZZARDELLI, C., PAVELKA, N., LUCHINI, A., ZANONI, I., BENDICKSON, L., PELIZZOLA, M., BERETTA, O., FOTI, M., GRANUCCI, F., NILSENHAMILTON, M. \& RICCIARDI-CASTAGNOLI, P. 2006. Effects of dexamethazone on LPS-induced activationand migration of mouse dendritic cells revealed by a genome-wide transcriptional analysis. Eur $J$ Immunol, 36, 1504-15.

WADDELL, D. S., BAEHR, L. M., VAN DEN BRANDT, J., JOHNSEN, S. A., REICHARDT, H. M., FURLOW, J. D. \& BODINE, S. C. 2008. The glucocorticoid receptor and FOXO1 synergistically activate the skeletal muscle atrophy-associated MuRF1 gene. Am J Physiol Endocrinol Metab, 295, E785-97. 
WAGNER, D. H., JR., HAGMAN, J., LINSLEY, P. S., HODSDON, W., FREED, J. H. \& NEWELL, M. K. 1996. Rescue of thymocytes from glucocorticoidinduced cell death mediated by CD28/CTLA-4 costimulatory interactions with B7-1/B7-2. J Exp Med, 184, 1631-8.

WAGNER, J. E., THOMPSON, J. S., CARTER, S. L., KERNAN, N. A. \& UNRELATED DONOR MARROW TRANSPLANTATION, T. 2005. Effect of graft-versus-host disease prophylaxis on 3-year disease-free survival in recipients of unrelated donor bone marrow (T-cell Depletion Trial): a multi-centre, randomised phase II-III trial. Lancet, 366, 733-41.

WANG, D., MULLER, N., MCPHERSON, K. G. \& REICHARDT, H. M. 2006. Glucocorticoids engage different signal transduction pathways to induce apoptosis in thymocytes and mature T cells. J Immunol, 176, 1695-702.

WANG, H., ASAVAROENGCHAI, W., YEAP, B. Y., WANG, M. G., WANG, S., SYKES, M. \& YANG, Y. G. 2009. Paradoxical effects of IFN-gamma in graft-versus-host disease reflect promotion of lymphohematopoietic graftversus-host reactions and inhibition of epithelial tissue injury. Blood, 113, 3612-9.

WANG, H. \& YANG, Y. G. 2014. The complex and central role of interferongamma in graft-versus-host disease and graft-versus-tumor activity. Immunol Rev, 258, 30-44.

WATSON, M. L., BAEHR, L. M., REICHARDT, H. M., TUCKERMANN, J. P., BODINE, S. C. \& FURLOW, J. D. 2012. A cell-autonomous role for the glucocorticoid receptor in skeletal muscle atrophy induced by systemic glucocorticoid exposure. Am J Physiol Endocrinol Metab, 302, E1210-20.

WEISDORF, D., HAAKE, R., BLAZAR, B., MILLER, W., MCGLAVE, P., RAMSAY, N., KERSEY, J. \& FILIPOVICH, A. 1990. Treatment of moderate/severe acute graft-versus-host disease after allogeneic bone marrow transplantation: an analysis of clinical risk features and outcome. Blood, 75, 1024-30.

WEISSLEDER, R., NAHRENDORF, M. \& PITTET, M. J. 2014. Imaging macrophages with nanoparticles. Nat Mater, 13, 125-38.

WESTON, L. E., GECZY, A. F. \& BRISCOE, H. 2006. Production of IL-10 by alloreactive sibling donor cells and its influence on the development of acute GVHD. Bone Marrow Transplant, 37, 207-12.

WILLIAMSON, E., GARSIDE, P., BRADLEY, J. A., MORE, I. A. \& MOWAT, A. M. 1997. Neutralizing IL-12 during induction of murine acute graft-versushost disease polarizes the cytokine profile toward a Th2-type alloimmune response and confers long term protection from disease. J Immunol, 159, 1208-15.

XIE, Y., WU, M., SONG, R., MA, J., SHI, Y., QIN, W. \& JIN, Y. 2009. A glucocorticoid amplifies IL-2-induced selective expansion of CD4(+)CD25(+)FOXP3(+) regulatory $T$ cells in vivo and suppresses graft-versus-host disease after allogeneic lymphocyte transplantation. Acta Biochim Biophys Sin (Shanghai), 41, 781-91.

YANG, J., ZHANG, L., YU, C., YANG, X. F. \& WANG, H. 2014. Monocyte and macrophage differentiation: circulation inflammatory monocyte as biomarker for inflammatory diseases. Biomark Res, 2, 1.

YANG, Y. G., DEY, B. R., SERGIO, J. J., PEARSON, D. A. \& SYKES, M. 1998. Donor-derived interferon gamma is required for inhibition of acute graftversus-host disease by interleukin 12. J Clin Invest, 102, 2126-35. 
YE, M. \& SHI, B. 2018. Zirconia Nanoparticles-Induced Toxic Effects in Osteoblast-Like 3T3-E1 Cells. Nanoscale Res Lett, 13, 353.

YI, T., ZHAO, D., LIN, C. L., ZHANG, C., CHEN, Y., TODOROV, I., LEBON, T., KANDEEL, F., FORMAN, S. \& ZENG, D. 2008. Absence of donor Th17 leads to augmented Th1 differentiation and exacerbated acute graftversus-host disease. Blood, 112, 2101-10.

YU, Y., WANG, D., LIU, C., KAOSAARD, K., SEMPLE, K., ANASETTI, C. \& YU, X. Z. 2011. Prevention of GVHD while sparing GVL effect by targeting Th1 and Th17 transcription factor T-bet and RORgammat in mice. Blood, 118, 5011-20.

ZEISER, R. \& BLAZAR, B. R. 2016. Preclinical models of acute and chronic graft-versus-host disease: how predictive are they for a successful clinical translation? Blood, 127, 3117-26.

ZEISER, R. \& BLAZAR, B. R. 2017. Acute Graft-versus-Host Disease - Biologic Process, Prevention, and Therapy. N Engl J Med, 377, 2167-2179.

ZEISER, R., SOCIE, G. \& BLAZAR, B. R. 2016. Pathogenesis of acute graftversus-host disease: from intestinal microbiota alterations to donor T cell activation. Br J Haematol, 175, 191-207.

ZHANG, L., YU, J. \& WEI, W. 2018. Advance in Targeted Immunotherapy for Graft-Versus-Host Disease. Front Immunol, 9, 1087.

ZHANG, Y., LOUBOUTIN, J. P., ZHU, J., RIVERA, A. J. \& EMERSON, S. G. 2002a. Preterminal host dendritic cells in irradiated mice prime CD8+ T cell-mediated acute graft-versus-host disease. J Clin Invest, 109, 133544.

ZHANG, Y., SHLOMCHIK, W. D., JOE, G., LOUBOUTIN, J. P., ZHU, J., RIVERA, A., GIANNOLA, D. \& EMERSON, S. G. 2002b. APCs in the liver and spleen recruit activated allogeneic CD8+ $T$ cells to elicit hepatic graft-versus-host disease. J Immunol, 169, 7111-8.

ZUBIAGA, A. M., MUNOZ, E. \& HUBER, B. T. 1992. IL-4 and IL-2 selectively rescue Th cell subsets from glucocorticoid-induced apoptosis. $J$ Immunol, 149, 107-12. 


\section{APPENDIX}

\subsection{Acknowledgements}

At this point of my thesis, I would to give my thanks to many people who distributed to this work in different ways.

At first I sincerely dedicate my thanks to my supervisor Prof. Dr. Holger Reichardt for his everlasting and kind openness for questions and discussions. I appreciated that he gladly shared his outstanding analytical scientific skills with me as well as for providing helpful suggestions throughout the time of my $\mathrm{PhD}$ from all I learned much.

Next, I would like to thank the members of my thesis committee Prof. Dr. Lutz Walter and Prof. Dr. Matthias Dobbelstein for their interest in my project and encouraging discussions during my thesis committee meetings.

Furthermore, I am thankful for the successful, pleasant and honest collaboration with Dr. Hanibal Bohnenberger, Jennifer Appelhans, Prof. Dr. Susann Boretius, Dr. Amir Moussavi, Kristin Kötz, Prof. Dr. Jan Tuckermann, Yasmine Hachemi and Dr. Michael Engelke. I would also like to give my thanks to our collaborators in the Institute for Technology in Karlsruhe for providing us with IOH-NPs, which have been partially modified for our needs.

Moreover, I was very grateful for the enjoyable and helpful atmosphere in our $\mathrm{lab} /$ office created by the cordial current and former lab members of our research group. I would also like to express my special thanks to those who assisted me during the last months of my $\mathrm{PhD}$ as well as various students I supervised with pleasure, especially to those who distributed to this work, in particular Katrin Ciupka, Bhakti Irene Seth and Lara Gentemann.

Finally, I very much thank my family for supporting me in so many ways at any time of my life. 


\subsection{Publications}

BAAKE, T., JORSS, K., SUENNEMANN, J., ROSSMANN, L., BOHNENBERGER, H., TUCKERMANN, J. P., REICHARDT, H. M., FISCHER, H. J. \& REICHARDT, S. D. 2018. The glucocorticoid receptor in recipient cells keeps cytokine secretion in acute graft-versus-host-disease at bay. Oncotarget, 9, 15437-15450.

LI, H., KAISER, T. K., BORSCHIWER, M., BOHNENBERGER, H., LÜHDER, F., WALTER, L., DRESSEL, R., MEIJSING, S. H. \& REICHARDT, H. M. submitted. Glucocorticoid resistance of allogeneic $T$ cells alters the gene expression profile in the inflamed small intestine of mice suffering from acute graft-versus-host disease. J. Steroid Biochem. Mol. Biol.

KAISER, T. K., KHORENKO, M., MOUSSAVI, A., ENGELKE, M., BORETIUS, S., FELDMANN, C. \& REICHARDT, H. M. submitted. Highly selective organ distribution and cellular uptake of inorganic-organic hybrid nanoparticles customized for the targeted delivery of glucocorticoids. Journal of Controlled Release. 